\author{
UNIVERSIDADE DE SÃO PAULO \\ ESCOLA DE ENGENHARIA DE SÃO CARLOS
}

RICARDO POLISAITIS OLIVEIRA

\title{
AnSBBR e AnSBR submetidos a diferentes condições de alimentação de água residuária de indústria de produtos de higiene pessoal
}

São Carlos, SP

2009 

RICARDO POLISAITIS OLIVEIRA

\section{AnSBBR e AnSBR submetidos a diferentes condições de alimentação de água residuária de indústria de produtos de higiene pessoal}

Dissertação apresentada à Escola de Engenharia de São Carlos da Universidade de São Paulo como parte dos requisitos necessários à obtenção do título de Mestre em Engenharia

Área de concentração: Engenharia Hidráulica e Saneamento

Orientador: Prof. Dr. José Alberto Domingues Rodrigues

São Carlos, SP

2009 
(Ficha catalográfica) 
(Folha de aprovação) 

DEDICATÓRIA

A meus pais,

Marco Aurélio e Silvia 



\section{AGRADECIMENTOS}

A todos que contribuíram direta ou indiretamente para a realização deste trabalho;

a USP, a UFSCar e ao IMT, pela estrutura disponibilizada;

e a FAPESP, pelo financiamento do projeto e pela bolsa de estudos. 



\section{RESUMO}

\section{OLIVEIRA, R. P. AnSBBR e AnSBR submetidos a diferentes condições de}

alimentação de água residuária de indústria de produtos de higiene pessoal. 2009. 222 p. Dissertação (Mestrado em Engenharia Hidráulica e Saneamento) Escola de Engenharia de São Carlos, Universidade de São Paulo, São Carlos, 2009.

Este trabalho apresenta a avaliação da estabilidade e da eficiência de dois reatores anaeróbios operados em batelada seqüencial no tratamento de água residuária que simula o efluente de indústria de produtos de higiene pessoal, sendo um com biomassa imobilizada em espuma de poliuretano (AnSBBR) e recirculação da fase líquida, e outro com biomassa granular autoimobilizada (AnSBR) e agitação mecânica. O AnSBBR foi operado em batelada e em batelada alimentada, seguida de batelada, com tempo de ciclo (tc) de $8 \mathrm{~h}$ e carga orgânica volumétrica aplicada (COVA) de 0,9 e 1,5 gDQO/L.d, tratando 2,5 L de meio líquido por ciclo. Os valores de eficiência de remoção de matéria orgânica de amostras filtradas do efluente ficaram abaixo de $71 \%$ nas condições operadas em batelada, e acima de $74 \%$ nas condições operadas em batelada alimentada, seguida de batelada. Por outro lado, o AnSBR foi operado em batelada, com tc de 8,12 e $24 \mathrm{~h}$ e COVA de 0,75, 0,50 e 0,25 gDQO/L.d, tratando 2,0 $\mathrm{L}$ de meio líquido por ciclo. $\mathrm{O}$ aumento de $\mathrm{t}_{\mathrm{C}}$ resultou em ganho de eficiência nas condições de mesma COVA, chegando a $77 \%$ para tc de $24 \mathrm{~h}$, contra $69 \%$ para tc de $8 \mathrm{~h}$. Porém, houve queda de eficiência nas condições em que a COVA foi reduzida em função do aumento de $t_{c}$.

Palavras-chave: AnSBBR; AnSBR; efluente industrial; estratégia de alimentação. 



\begin{abstract}
OLIVEIRA, R. P. AnSBBR and AnSBR submitted to different conditions of wastewater feeding from industry of personal care products. 2009. $222 \mathrm{p}$. Dissertation (Master in Hydraulic and Sanitary Engineering) - School of Engineering of Sao Carlos, University of Sao Paulo, Sao Carlos, 2009.
\end{abstract}

This study presents the evaluation of stability and efficiency of two anaerobic sequencing batch reactors for wastewater treatment simulating the effluent from industry of personal care products, one containing immobilized biomass on polyurethane foam (AnSBBR) and external circulation of the liquid phase, and the other with self-immobilized granulated biomass (AnSBR) and mechanical agitation. The AnSBBR was operated in batch and fed batch/batch modes, with cycle time ( $\left.\mathrm{t}_{\mathrm{c}}\right)$ of $8 \mathrm{~h}$ and applied organic loading rates (COVA) of 0.9 and $1.5 \mathrm{gDQO} / \mathrm{L} . \mathrm{d}$, treating $2.5 \mathrm{~L}$ of liquid medium per cycle. The values of organic matter removal efficiency for filtered samples of effluent were below $71 \%$ in batch operations, and over $74 \%$ in fedbatch/batch operations. On the other hand, the AnSBR was operated in batch, with $t_{C}$ of 8,12 and $24 \mathrm{~h}$ and COVA of $0.75,0.50$ and $0.25 \mathrm{gDQO} / \mathrm{L} . \mathrm{d}$, treating $2.0 \mathrm{~L}$ of liquid medium per cycle. The increase of $t_{c}$ resulted in higher values of efficiency for conditions with the same COVA, reaching $77 \%$ for a 24 -h cycle against $69 \%$ for an 8-h cycle. However, there was an efficiency drop at the conditions in which COVA was reduced due to an increase of $t_{c}$.

Keywords: AnSBBR; AnSBR, industrial effluent, feeding strategy. 



\section{LISTA DE FIGURAS}

Figura 4.1 Esquema do aparato experimental do AnSBBR 50

Figura 4.2 Fotografia do aparato experimental do AnSBBR 51

Figura 4.3 Fotografias: (a) do reator (esquerda), do reservatório (direita) 51 e do tubo graduado (centro), (b) da bomba peristáltica e (c) das bombas de diafragma e dos temporizadores

Figura 4.4 Fotografia dos cubos de espuma de poliuretano 52

Figura 4.5 Esquema do aparato experimental do AnSBR 53

Figura 4.6 Fotografia do aparato experimental do AnSBR 53

Figura 4.7 Fotografias: (a) do reator e vistas (b) inferior e (c) lateral do 54 impelidor

$\begin{array}{lll}\text { Figura } 4.8 & \text { Fotografia do inóculo } & 54\end{array}$

Figura 4.9 Espuma de poliuretano (b) antes e (a) depois da inoculação 77

Figura 5.1 Concentração de matéria orgânica do AnSBBR na condição 90 preliminar

Figura 5.2 Eficiência de remoção de matéria orgânica do AnSBBR na 90 condição preliminar

Figura 5.3 Concentração de matéria orgânica na saída do AnSBBR nas 95 Condições 1 a 4

Figura 5.4 Eficiência de remoção de matéria orgânica do AnSBBR nas 95 Condições 1 a 4

Figura 5.5 Perfil de concentração de matéria orgânica do AnSBBR nas 100 Condições 1 a 4

Figura 5.6 Perfil de concentração de ácidos voláteis totais do AnSBBR 101 nas Condições 1 a 4

Figura 5.7 Perfil de pH do AnSBBR nas Condições 1 a 4

Figura 5.8 Perfil de alcalinidade a bicarbonato do AnSBBR nas 102 Condições 1 a 4

Figura 5.9 Perfil de concentração de metano do AnSBBR nas Condições 103 1 a 4 
Figura 5.10 Perfil de concentração de gás carbônico do AnSBBR nas 103 Condições 1 a 4

Figura 5.11 Perfil de fração molar de metano do AnSBBR nas Condições 104 1 a 4

Figura 5.12 Perfil de fração molar de gás carbônico do AnSBBR nas 104 Condições 1 a 4

Figura 5.13 Perfil de produção de metano do AnSBBR nas Condições 1 a 106 4

Figura 5.14 Perfil de produção específica de metano do AnSBBR nas 107 Condições 1 a 4

Figura 5.15 Concentração de matéria orgânica na saída do AnSBBR nas 108 Condições 5 a 8

Figura 5.16 Eficiência de remoção de matéria orgânica do AnSBBR nas 108 Condições 5 a 8

Figura 5.17 Perfil de concentração de matéria orgânica do AnSBBR nas 113 Condições 5 a 8

Figura 5.18 Perfil de pH do AnSBBR nas Condições 5 a 8

Figura 5.19 Perfil de concentração de ácidos voláteis totais do AnSBBR 114 nas Condições 5 a 8

Figura 5.20 Perfil de alcalinidade a bicarbonato do AnSBBR nas 114 Condições 5 a 8

Figura 5.21 Perfil de concentração de metano do AnSBBR nas Condições 5 a 8

115

Figura 5.22 Perfil de concentração de gás carbônico do AnSBBR nas 116 Condições 5 a 8

Figura 5.23 Perfil de fração molar de metano do AnSBBR nas Condições 5 a 8

Figura 5.24 Perfil de fração molar de gás carbônico do AnSBBR nas 117 Condições 5 a 8

Figura 5.25 Exame microbiológico do inóculo 122

Figura 5.26 Exame microbiológico do inóculo 122

$\begin{array}{lll}\text { Figura 5.27 } & \text { Exame microbiológico do inóculo } & 123\end{array}$

Figura 5.28 Exame microbiológico da biomassa do AnSBBR 124 
Figura 5.29 Exame microbiológico da biomassa do AnSBBR

Figura 5.30 Concentração de matéria orgânica do AnSBR na condição 126 preliminar

Figura 5.31 Eficiência de remoção de matéria orgânica do AnSBR na 126 condição preliminar

Figura 5.32 Concentração de matéria orgânica na saída do AnSBR nas Condições 9,10 e 11

Figura 5.33 Eficiência de remoção de matéria orgânica do AnSBR nas Condições 9,10 e 11

Figura 5.34 Perfil de concentração de matéria orgânica do AnSBR nas Condições 9, 10 e 11

Figura 5.35 Perfil de pH do AnSBR nas Condições 9, 10 e 11

Figura 5.36 Perfil de concentração de ácidos voláteis totais do AnSBR nas Condições 9,10 e 11

134

Figura 5.37 Perfil de alcalinidade a bicarbonato do AnSBR nas Condições 9,10 e 11

Figura 5.38 Perfil de concentração de metano do AnSBR nas Condições 9,10 e 11

Figura 5.39 Perfil de concentração de gás carbônico do AnSBR nas Condições 9, 10 e 11

Figura 5.40 Perfil de fração molar de metano do AnSBR nas Condições 9, 10 e 11

Figura 5.41 Perfil de fração molar de gás carbônico do AnSBR nas Condições 9, 10 e 11

135

136

136

137

137

Figura 5.42 Concentração de matéria orgânica na saída do AnSBR nas Condições 9, 12 e 13

Figura 5.43 Eficiência de remoção de matéria orgânica do AnSBR nas Condições 9,10 e 11

Figura 5.44 Perfil de concentração de matéria orgânica do AnSBR nas Condições 9, 12 e 13

Figura 5.45 Perfil de pH do AnSBR nas Condições 9, 12 e 13

Figura 5.46 Perfil de concentração de ácidos voláteis totais do AnSBR nas 143 Condições 9,12 e 13 
Figura 5.47 Perfil de alcalinidade a bicarbonato do AnSBR nas Condições 144 9,12 e 13

Figura 5.48 Perfil de concentração de metano do AnSBR nas Condições 145 9,12 e 13

Figura 5.49 Perfil de concentração de gás carbônico do AnSBR nas 145 Condições 9, 12 e 13

Figura 5.50 Perfil de fração molar de metano do AnSBR nas Condições 9, 146 12 e 13

Figura 5.51 Perfil de fração molar de gás carbônico do AnSBR nas 146 Condições 9,12 e 13

Figura 5.52 Concentração de matéria orgânica na saída do AnSBR nas 147 Condições 9 e 14

Figura 5.53 Eficiência de remoção de matéria orgânica do AnSBR nas 147 Condições 9 e 14

Figura 5.54 Perfil de concentração de matéria orgânica do AnSBR nas 150 Condições 9 e 14

Figura 5.55 Perfil de pH do AnSBR nas Condições 9 e 14

Figura 5.56 Perfil de concentração de ácidos voláteis totais do AnSBR nas 151 Condições 9 e 14

Figura 5.57 Perfil de alcalinidade a bicarbonato do AnSBR nas Condições 152 9 e 14

Figura 5.58 Perfil de concentração de metano do AnSBR nas Condições 9152 e 14

Figura 5.59 Perfil de concentração de gás carbônico do AnSBR nas 153 Condições 9 e 14

Figura 5.60 Perfil de fração molar de metano do AnSBR nas Condições 9153 e 14

Figura 5.61 Perfil de fração molar de gás carbônico do AnSBR nas 154 Condições 9 e 14

Figura 5.62 Exame microbiológico da biomassa do AnSBR 156

Figura 5.63 Exame microbiológico da biomassa do AnSBR 157

$\begin{array}{lll}\text { Figura 5.64 Exame microbiológico do inóculo } & 157\end{array}$ 


\section{LISTA DE TABELAS}

Tabela 4.1 Formulação de produto de mesma especificação que o xampu usado no preparo da água residuária

56

Tabela 4.2 Composição do meio sintético para uma concentração média de $500 \mathrm{mgDQO} / \mathrm{L}$

Tabela 4.3 Composição da água residuária nas Condições 1 a 8

Tabela 4.4 Composição da água residuária nas Condições 9 a 14

Tabela 4.5 Métodos analíticos do Standard Methods for the Examination 60 of Water and Wastewater (1995)

Tabela 4.6 Composição da água residuária nas Condições S1 a S4

Tabela 4.7 Resumo das Condições S1 a S4 76

Tabela 4.8 Resumo das condições experimentais do AnSBBR 79

Tabela 4.9 Resumo das condições experimentais do AnSBR 84

Tabela 5.1 Variáveis monitoradas das Condições S1 a S4 87

Tabela 5.2 Variáveis monitoradas das Condições S1 a S4 89

Tabela 5.3 Variáveis monitoradas do AnSBBR na condição preliminar 91

Tabela 5.4 Variáveis monitoradas do AnSBBR na Condição 1

Tabela 5.5 Composição da água residuária na Condição 1

Tabela 5.6 Variáveis monitoradas do AnSBBR nas Condições 1 a $4 \quad 96$

Tabela 5.7 Variáveis monitoradas do AnSBBR nas Condições 5 a $8 \quad 109$

Tabela 5.8 Quadro resumo das condições experimentais do AnSBBR 118

Tabela 5.9 Variáveis monitoradas do AnSBR na condição preliminar 127

Tabela 5.10 Variáveis monitoradas do AnSBR nas Condições 9, 10 e $11 \quad 130$

Tabela 5.11 Variáveis monitoradas do AnSBR nas Condições 9, 12 e $13 \quad 139$

Tabela 5.12 Variáveis monitoradas do AnSBR nas Condições 9 e $14 \quad 148$

Tabela 5.13 Quadro resumo das condições experimentais do AnSBR 154 



\section{LISTA DE SIGLAS}

ABES Associação Brasileira de Engenharia Sanitária e Ambiental

ABIHPEC Associação Brasileira da Indústria de Higiene Pessoal, Perfumaria e Cosméticos

ABNT Associação Brasileira de Normas Técnicas

AnSBBR reator anaeróbio operado em batelada seqüencial contendo biomassa imobilizada

AnSBR reator anaeróbio operado em batelada seqüencial

APHA American Public Health Association

AWWA American Water Works Association

DQA Departamento de Engenharia Química e Alimentos

DQO demanda química de oxigênio

ECP polímeros extracelulares

EEM Escola de Engenharia Mauá

EESC Escola de Engenharia de São Carlos

FAPESP Fundação de Amparo à Pesquisa do Estado de São Paulo

IMT Instituto Mauá de Tecnologia

LEB Laboratório de Engenharia Bioquímica

LPB Laboratório de Processos Biológicos

PROSAB Programa de Pesquisas em Saneamento Básico

SHS Departamento de Hidráulica e Saneamento

UASB reator anaeróbio de manta de lodo e fluxo ascendente

UFSCar Universidade Federal de São Carlos

USP Universidade de São Paulo

WEF Water Environment Federation 



\section{LISTA DE SÍMBOLOS}

$A_{R T} \quad$ área interna da secção transversal do reator $\quad \mathrm{cm}^{2}$

A área interna da secção transversal do reservatório $\mathrm{cm}^{2}$

$\mathrm{AB}$ alcalinidade a bicarbonato $\mathrm{mgCaCO}_{3} / \mathrm{L}$

$\mathrm{AB}_{\mathrm{A}} \quad$ alcalinidade a bicarbonato do afluente $\quad \mathrm{mgCaCO}_{3} / \mathrm{L}$

$\mathrm{AB}_{\mathrm{E}} \quad$ alcalinidade a bicarbonato do efluente $\quad \mathrm{mgCaCO}_{3} / \mathrm{L}$

$\mathrm{AB}_{\mathrm{i}} \quad$ alcalinidade a bicarbonato do meio reacional no instante $\quad \mathrm{mgCaCO}_{3} / \mathrm{L}$ $t_{i}$

Al alcalinidade intermediária

$\mathrm{mgCaCO}_{3} / \mathrm{L}$

$\mathrm{Al}_{\mathrm{A}} \quad$ alcalinidade intermediária do afluente $\quad \mathrm{mgCaCO}_{3} / \mathrm{L}$

$\mathrm{Al}_{\mathrm{E}} \quad$ alcalinidade intermediária do efluente $\quad \mathrm{mgCaCO}_{3} / \mathrm{L}$

AP alcalinidade parcial $\quad \mathrm{mgCaCO}_{3} / \mathrm{L}$

$\mathrm{AP}_{\mathrm{A}} \quad$ alcalinidade parcial do afluente $\quad \mathrm{mgCaCO}_{3} / \mathrm{L}$

$\mathrm{AP}_{\mathrm{E}} \quad$ alcalinidade parcial do efluente $\quad \mathrm{mgCaCO}_{3} / \mathrm{L}$

AT alcalinidade total $\quad \mathrm{mgCaCO}_{3} / \mathrm{L}$

$\mathrm{AT}_{\mathrm{A}} \quad$ alcalinidade total do afluente $\quad \mathrm{mgCaCO}_{3} / \mathrm{L}$

$\mathrm{AT}_{\mathrm{E}} \quad$ alcalinidade total do efluente $\quad \mathrm{mgCaCO}_{3} / \mathrm{L}$

AVI concentração de ácidos voláteis intermediários mg/L

$\mathrm{AVI}_{\mathrm{i}} \quad$ concentração de ácidos voláteis intermediários do meio $\mathrm{mg} / \mathrm{L}$ reacional no instante $t_{i}$

AVT concentração de ácidos voláteis totais mgHAc/L

$\mathrm{AVT}_{\mathrm{A}}$ concentração de ácidos voláteis totais do afluente mgHAc/L

$\mathrm{AVT}_{\mathrm{E}} \quad$ concentração de ácidos voláteis totais do efluente $\mathrm{mgHAc} / \mathrm{L}$

$\mathrm{AVT}_{\mathrm{i}} \quad$ concentração de ácidos voláteis totais do meio reacional $\mathrm{mgHAc} / \mathrm{L}$ no instante $t_{i}$

$\mathrm{C}_{\mathrm{A}}$ concentração de matéria orgânica do afluente $\mathrm{mgDQO} / \mathrm{L}$

$\mathrm{C}_{\mathrm{AF}} \quad$ concentração de matéria orgânica de amostras filtradas mgDQO/L do afluente 
$\mathrm{C}_{\mathrm{AT}}$ concentração de matéria orgânica de amostras não filtradas do afluente

$\mathrm{mgDQO} / \mathrm{L}$

$\mathrm{C}_{\mathrm{CH} 4} \quad$ concentração de metano

$\mathrm{mmol} / \mathrm{L}$

$\mathrm{C}_{\mathrm{CH} 4, \mathrm{i}} \quad$ concentração de metano no instante $\mathrm{t}_{\mathrm{i}}$

$\mathrm{mmol} / \mathrm{L}$

$\mathrm{C}_{\mathrm{CO} 2}$ concentração de gás carbônico

$\mathrm{mmol} / \mathrm{L}$

$\mathrm{C}_{\mathrm{CO} 2, \mathrm{i}} \quad$ concentração de gás carbônico no instante $\mathrm{t}_{\mathrm{i}}$

$\mathrm{mmol} / \mathrm{L}$

$C_{E} \quad$ concentração de matéria orgânica do efluente

$\mathrm{mgDQO} / \mathrm{L}$

$\mathrm{C}_{\mathrm{EF}} \quad$ concentração de matéria orgânica de amostras filtradas do efluente

$\mathrm{mgDQO} / \mathrm{L}$

$\mathrm{C}_{\mathrm{ET}}$ concentração de matéria orgânica de amostras não filtradas do efluente

$\mathrm{mgDQO} / \mathrm{L}$

Cop ciclo de operação

Cs concentração de matéria orgânica

$\mathrm{mgDQO} / \mathrm{L}$

$\mathrm{C}_{\mathrm{Sf}} \quad$ concentração de matéria orgânica de amostras filtradas do meio reacional no instante $t_{f}$

$\mathrm{mgDQO} / \mathrm{L}$

C concentração de matéria orgânica de amostras filtradas do meio reacional no instante $t_{0}$

$\mathrm{mgDQO} / \mathrm{L}$

$\mathrm{C}_{\mathrm{S}, \mathrm{i}} \quad$ concentração de matéria orgânica de amostras filtradas do meio reacional no instante $t_{i}$

$\mathrm{mgDQO} / \mathrm{L}$

COEA carga orgânica específica aplicada

mgDQO/gSVT.d

COER carga orgânica específica removida

mgDQO/gSVT.d

COER $_{F}$ carga orgânica específica removida de amostras mgDQO/gSVT.d filtradas do efluente

$\mathrm{COER}_{T}$ carga orgânica específica removida de amostras não mgDQO/gSVT.d filtradas do efluente

COVA carga orgânica volumétrica aplicada

$\mathrm{mgDQO} / \mathrm{L} . \mathrm{d}$

COVR carga orgânica volumétrica removida

$\mathrm{mgDQO} / \mathrm{L} . \mathrm{d}$

COVR $_{F}$ carga orgânica volumétrica removida de amostras filtradas do efluente

$\mathrm{mgDQO} / \mathrm{L} \cdot \mathrm{d}$

$\operatorname{COVR}_{T}$ carga orgânica volumétrica removida de amostras não filtradas do efluente

$\mathrm{mgDQO} / \mathrm{L} . \mathrm{d}$ 


\begin{tabular}{|c|c|c|}
\hline $\mathrm{D}_{\mathrm{RT}}$ & diâmetro externo da secção transversal do reator & $\mathrm{mm}$ \\
\hline $\mathrm{D}_{\mathrm{RS}}$ & diâmetro externo da secção transversal do reservatório & $\mathrm{mm}$ \\
\hline$e_{R T}$ & espessura de parede do reator & $\mathrm{mm}$ \\
\hline $\mathrm{e}_{\mathrm{RS}}$ & espessura de parede do reservatório & $\mathrm{mm}$ \\
\hline$\varepsilon$ & eficiência de remoção de matéria orgânica & $\%$ \\
\hline$\varepsilon_{\mathrm{F}}$ & $\begin{array}{l}\text { eficiência de remoção de matéria orgânica de amostras } \\
\text { filtradas do efluente }\end{array}$ & $\%$ \\
\hline$\varepsilon_{\top}$ & $\begin{array}{l}\text { eficiência de remoção de matéria orgânica de amostras } \\
\text { não filtradas do efluente }\end{array}$ & $\%$ \\
\hline $\mathrm{H}_{\mathrm{RT}}$ & altura do reator & $\mathrm{mm}$ \\
\hline $\mathrm{H}_{\mathrm{RS}}$ & altura do reservatório & $\mathrm{mm}$ \\
\hline$\varphi$ & porosidade do leito & $\%$ \\
\hline M & identificação do meio & \\
\hline$m_{\mathrm{ei}}$ & massa amostral de espuma com biomassa imobilizada & $g$ \\
\hline$M_{\mathrm{ei}}$ & massa total de espuma com biomassa imobilizada & $g$ \\
\hline$m_{\mathrm{el}}$ & massa amostral de espuma limpa & $g$ \\
\hline $\mathrm{Mel}_{\mathrm{el}}$ & massa total de espuma limpa & $g$ \\
\hline $\mathrm{m}_{\mathrm{ST}}$ & massa amostral de sólidos totais & $g$ \\
\hline $\mathrm{M}_{\mathrm{ST}}$ & massa total de sólidos totais & $g$ \\
\hline $\mathrm{m}_{\mathrm{SVT}}$ & massa amostral de sólidos voláteis totais & g \\
\hline MSVT & massa total de sólidos voláteis totais & $g$ \\
\hline $\mathrm{pH}$ & potencial hidrogeniônico & \\
\hline $\mathrm{pH}_{\mathrm{A}}$ & potencial hidrogeniônico do afluente & \\
\hline $\mathrm{pH}_{\mathrm{E}}$ & potencial hidrogeniônico do efluente & \\
\hline $\mathrm{pH}_{\mathrm{i}}$ & potencial hidrogeniônico do meio reacional no instante $t_{i}$ & \\
\hline Q & vazão de recirculação & $\mathrm{L} / \mathrm{h}$ \\
\hline SST & concentração de sólidos em suspensão totais & $\mathrm{mg} /$ \\
\hline
\end{tabular}


SST $_{\mathrm{A}}$ concentração de sólidos em suspensão totais do afluente

$\mathrm{mg} / \mathrm{L}$

$S_{S T} T_{E}$ concentração de sólidos em suspensão totais do efluente

$\mathrm{mg} / \mathrm{L}$

SSV concentração de sólidos em suspensão voláteis

$\mathrm{mg} / \mathrm{L}$

$\mathrm{SSV}_{\mathrm{A}}$ concentração de sólidos em suspensão voláteis do afluente

$\mathrm{mg} / \mathrm{L}$

$S_{S S V}$ concentração de sólidos em suspensão voláteis do efluente

ST concentração de sólidos totais

$\mathrm{mg} / \mathrm{L}$

$\mathrm{ST}_{\mathrm{A}}$ concentração de sólidos totais do afluente $\mathrm{mg} / \mathrm{L}$

$\mathrm{ST}_{\mathrm{E}} \quad$ concentração de sólidos totais do efluente $\mathrm{mg} / \mathrm{L}$

SVT concentração de sólidos voláteis totais $\mathrm{mg} / \mathrm{L}$

$\mathrm{SVT}_{\mathrm{A}} \quad$ concentração de sólidos voláteis totais do afluente $\mathrm{mg} / \mathrm{L}$

$\mathrm{SVT}_{\mathrm{E}} \quad$ concentração de sólidos voláteis totais do efluente $\mathrm{mg} / \mathrm{L}$

$t_{B} \quad$ tempo de enchimento em batelada $\quad \min$

$t_{\mathrm{BA}}$ tempo de enchimento em batelada alimentada $\mathrm{h}$

$t_{C}$ tempo de ciclo $h$

TDH tempo de detenção hidráulica d

$t_{i} \quad$ fração de tempo do ciclo operacional $\quad h$

$t_{F}$ tempo de enchimento $\min$ ou $\mathrm{h}$

$t_{f} \quad$ instante final do ciclo operacional $h$

to instante inicial do ciclo operacional $h$

top tempo de operação d

$\begin{array}{lll}t_{R} & \text { tempo de reação } & \text { min ou } h\end{array}$

$V_{A} \quad$ volume total de afluente alimentado $L$

$V_{B} \quad$ volume de afluente alimentado em batelada $L$

$V_{B A} \quad$ volume de afluente alimentado em batelada alimentada $L$

$\mathrm{V}_{\mathrm{CH} 4} \quad$ volume de metano $\mathrm{mL}^{\text {(CNTP) }}$ 
$\mathrm{V}_{\mathrm{CH} 4, \mathrm{i}} \quad$ volume de metano no instante $\mathrm{t}_{\mathrm{i}}$

$V_{\mathrm{CH} 4} \quad$ volume específico de metano

$\mathrm{mL}^{(\mathrm{CNTP})} / \mathrm{gDQO}$

$V_{\mathrm{CH} 4, \mathrm{i}} \quad$ volume específico de metano no instante $\mathrm{t}_{\mathrm{i}}$

$\mathrm{mL}^{(\mathrm{CNTP})} / \mathrm{gDQO}$

$V_{D} \quad$ volume de efluente descarregado do sistema

$V_{D, R T} \quad$ volume de efluente descarregado do reator

$V_{D, R S} \quad$ volume de efluente descarregado do reservatório

$V_{\mathrm{ei}} \quad$ volume total de espuma com biomassa imobilizada

$V_{\text {Iodo }} \quad$ volume total de lodo anaeróbio

VIodo volume amostral de lodo anaeróbio

$\mathrm{mL}$

$V_{O} \quad$ volume operacional do sistema

$\mathrm{V}_{\mathrm{O}, \mathrm{RT}} \quad$ volume operacional do reator

$\mathrm{V}_{\mathrm{O}, \mathrm{RS}} \quad$ volume operacional do reservatório

vs velocidade superficial ascensional do meio líquido

$\mathrm{cm} / \mathrm{s}$

$\mathrm{V}_{\mathrm{T}} \quad$ volume total do sistema

$\mathrm{V}_{\mathrm{T}, \mathrm{RT}} \quad$ volume total do reator

$\mathrm{V}_{\mathrm{T}, \mathrm{RS}} \quad$ volume total do reservatório

$V_{U} \quad$ volume de meio líquido do sistema

$\mathrm{V}_{\mathrm{U}, \mathrm{RT}} \quad$ volume de meio líquido do reator

$\mathrm{V}_{\mathrm{U}, \mathrm{RS}} \quad$ volume de meio líquido do reservatório

$\mathrm{Y}_{\mathrm{CH} 4}$ fração molar de metano

$\%$

$\mathrm{Y}_{\mathrm{CH} 4, \mathrm{i}}$ fração molar de metano no instante $t_{\mathrm{i}} \quad \%$

$\mathrm{Y}_{\mathrm{CO} 2}$ fração molar de gás carbônico \%

$Y_{C O 2, i}$ fração molar de gás carbônico no instante $t_{i}$ 
$1,5 \mathrm{~B}$

1,5B-RES

$0,9 B$

0,9B-RES

1,5BA/B

1,5BA/B-RES

0,9BA/B

0,9BA/B-RES

0,75B-8

0,75B-12

0,75B-24

0,50B-12

0,25B-24

0,75B-8SPL condição experimental com COVA de 1,5 gDQO/L, modo de operação em batelada, sem volume residual

condição experimental com COVA de $1,5 \mathrm{gDQO} / \mathrm{L}$, modo de operação em batelada, com volume residual

condição experimental com COVA de 0,9 gDQO/L, modo de operação em batelada, sem volume residual

condição experimental com COVA de 0,9 gDQO/L, modo de operação em batelada, com volume residual

condição experimental com COVA de 1,5 gDQO/L, modo de operação em batelada alimentada, seguida de batelada, sem volume residual

condição experimental com COVA de $1,5 \mathrm{gDQO} / \mathrm{L}$, modo de operação em batelada alimentada, seguida de batelada, com volume residual

condição experimental com COVA de 0,9 gDQO/L, modo de operação em batelada alimentada, seguida de batelada, sem volume residual

condição experimental com COVA de 0,9 gDQO/L, modo de operação em batelada alimentada, seguida de batelada, com volume residual

condição experimental com COVA de 0,75 gDQO/L, tc de $8 \mathrm{~h}$ e modo de operação em batelada

condição experimental com COVA de $0,75 \mathrm{gDQO} / \mathrm{L}$, tc de $12 \mathrm{~h}$ e modo de operação em batelada

condição experimental com COVA de 0,75 gDQO/L, tc de $24 \mathrm{~h}$ e modo de operação em batelada

condição experimental com COVA de $0,50 \mathrm{gDQO} / \mathrm{L}$, tc de $12 \mathrm{~h}$ e modo de operação em batelada

condição experimental com COVA de 0,25 gDQO/L, tc de $24 \mathrm{~h}$ e modo de operação em batelada

condição experimental com COVA de 0,75 gDQO/L, tc de $8 \mathrm{~h}$, suplementação de nutrientes e modo de operação em batelada 


\section{SUMÁRIO}

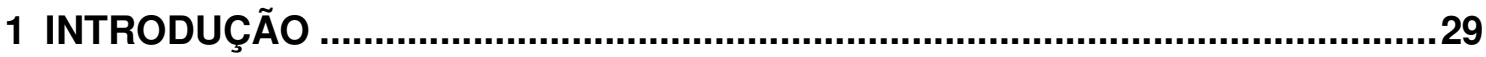

2 OBJETIVOS

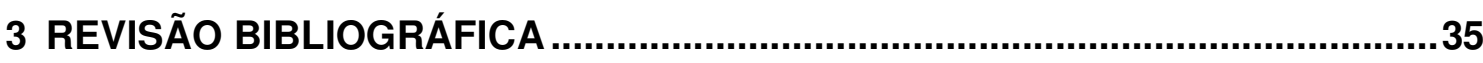

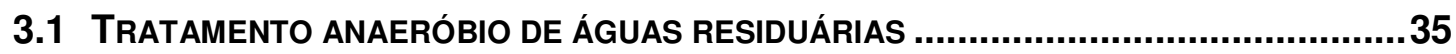

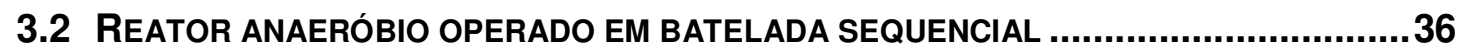

3.3 REATOR ANAERÓBIO EM BATELADA SEQÜENCIAL COM BIOMASSA IMOBILIZADA......40

3.4 ESTRATÉGIA DE ALIMENTAÇÃO E RECIRCULAÇÃO DA FASE LíQUIDA ......................43

3.5 ÁGUA RESIDUÁRIA CONTENDO SURFACTANTES .............................................45

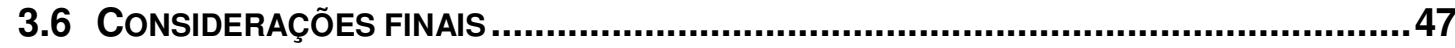

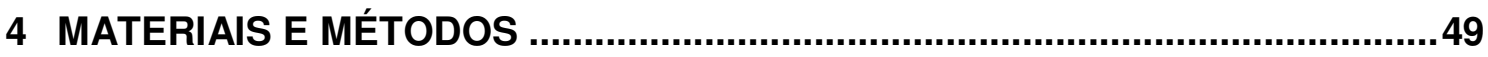

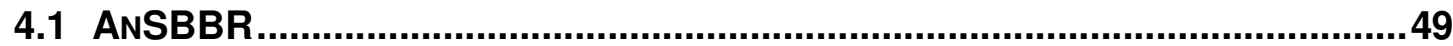

4.1.1 Suporte de imobilização da biomassa .............................................52

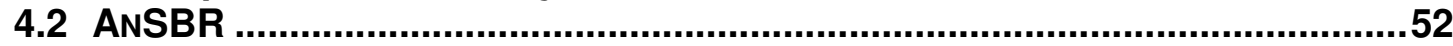

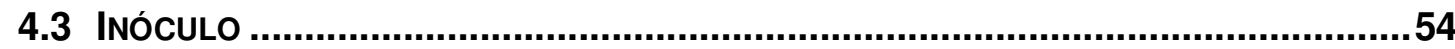

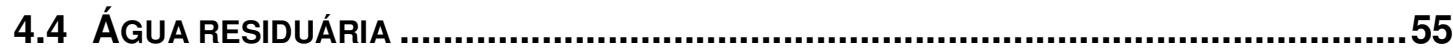

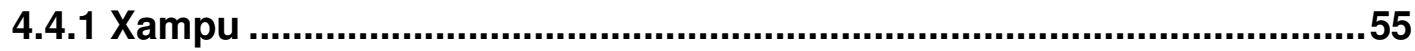

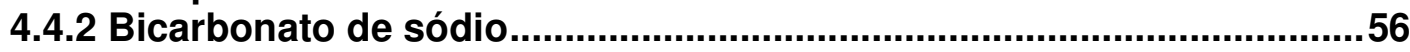

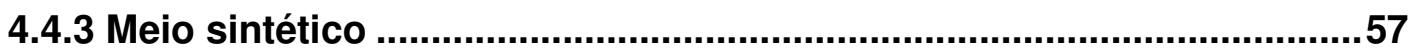

4.4.4 Composição da água residuária ............................................................58

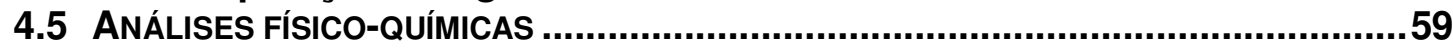

4.6 DeTERMINAÇÃo da CONCENTRAÇão dos ÁCIDOS VOLÁTEIS INTERMEDIÁRIOS ........60

4.7 DETERMINAÇÃo DA COMPOSIÇÃO E DA PRODUÇÃO DE BIOGÁs ...............................61

4.8 DETERMINAÇÃO DA CONCENTRAÇÃO DE BIOMASSA ……...................................61

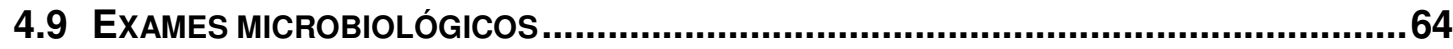

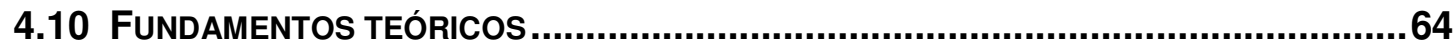

4.10.1 Eficiência de remoção de matéria orgânica.........................................65

4.10.2 Carga orgânica volumétrica aplicada ..................................................65

4.10.3 Carga orgânica volumétrica removida ...............................................66

4.10.4 Carga orgânica específica aplicada.....................................................66

4.10.5 Carga orgânica específica removida ..............................................67

4.10.6 Frações molares de metano e gás carbônico.....................................67

4.10.7 Volume específico de metano ..............................................................68

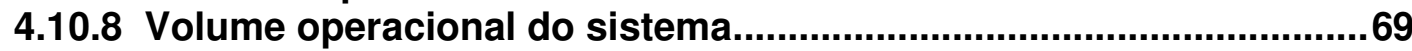

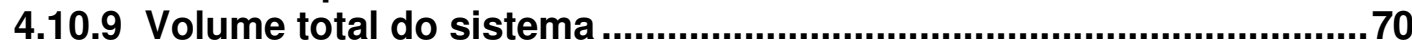

4.10.10 Volume de espuma com biomassa imobilizada ...............................72

4.10.11 Velocidade superficial ascensional do meio líquido .......................72

4.10.12 Tempo de detenção hidráulica ......................................................73

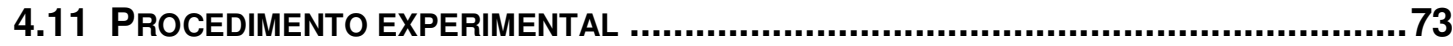

4.11.1 Preparo da água residuária e do meio sintético.................................73

4.11.2 Ensaios de biodegradabilidade....................................................75

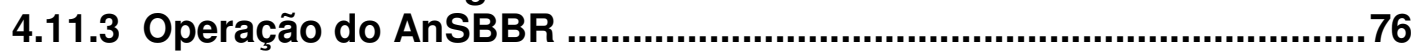

4.11.3.1 IMOBILIZAÇÃO DA BIOMASSA ANAERÓBIA ……………………….......76

4.11.3.2 ANSBBR NA CONDIÇÃO PRELIMINAR …………............................77

4.11.3.3 OTIMIZAÇÃO DA SUPLEMENTAÇÃO DE ALCALINIDADE ………...............78 
4.11.3.4 ANSBBR NAS CONDIÇÕES EXPERIMENTAIS ..................................... 78

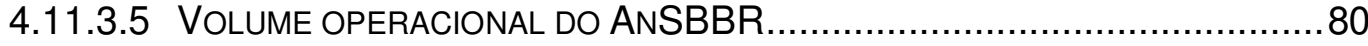

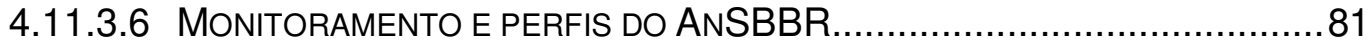

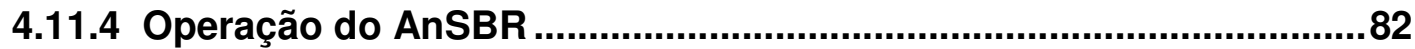

4.11.4.1 ANSBR NA CONDIÇÃO PRELIMINAR ............................................ 82

4.11.4.2 ANSBR NAS CONDIÇÕES EXPERIMENTAIS ........................................ 83

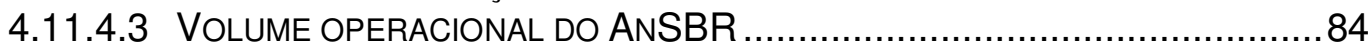

4.11.4.4 MONITORAMENTO E PERFIS DO ANSBR ..................................... 85

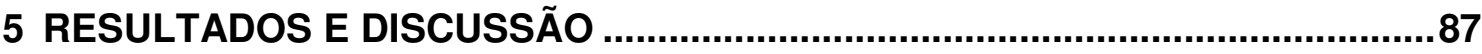

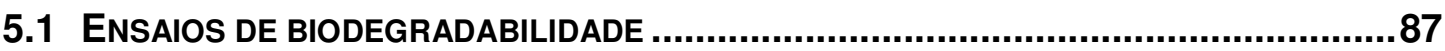

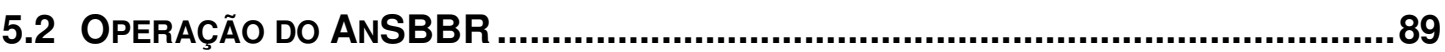

5.2.1 AnSBBR na condição preliminar .......................................................... 89

5.2.2 AnSBBR nas condições experimentais ..............................................92

5.2.2.1 CARACTERIZAÇÃO DO AFLUENTE .................................................. 92

5.2.2.2 OTIMIZAÇÃO DA SUPLEMENTAÇÃO DE ALCALINIDADE .............................92

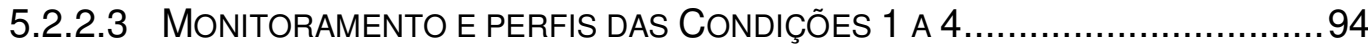

5.2.2.4 MONITORAMENTO E PERFIS DAS CONDIÇÕES 5 A 8 ............................ 107

5.2.2.5 ESTUDO COMPARATIVO DAS CONDIÇÕES EXPERIMENTAIS DO ANSBBR .117

5.2.3 Análise de sólidos do AnSBBR........................................................121

5.2.4 Exames microbiológicos do AnSBBR ..............................................121

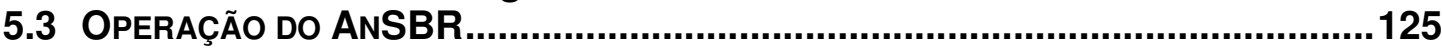

5.3.1 AnŞBR na condição preliminar...........................................................125

5.3.2 AnSBR nas condições experimentais ................................................128

5.3.2.1 CARACTERIZAÇÃO DO AFLUENTE .............................................. 128

5.3.2.2 MONITORAMENTO E PERFIS DAS CONDIÇÕES 9, 10 E $11 \ldots \ldots \ldots \ldots \ldots \ldots \ldots . . . . . . . . . .128$

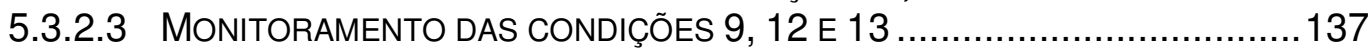

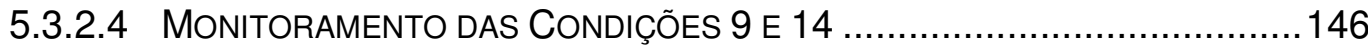

5.3.2.5 ESTUDO COMPARATIVO DAS CONDIÇÕES EXPERIMENTAIS DO ANSBR ....154

5.3.3 Análise de sólidos do AnSBR .............................................................155

5.3.4 Exames microbiológicos do AnSBR ................................................156

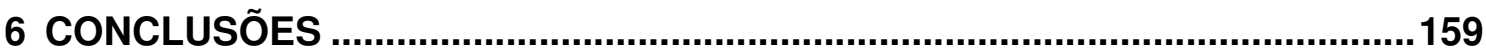

7 REFERÊNCIAS BIBLIOGRÁFICAS ..............................................................163

APÊNDICE A - TABELAS DE MONITORAMENTO ............................................173

APÊNDICE B - TABELAS DOS PERFIS.........................................................214

APÊNDICE C - CARACTERIZAÇÃO DO AFLUENTE ........................................221 


\section{INTRODUÇÃO}

A preocupação com o lançamento de efluentes nos corpos receptores, a liberação de gases para a atmosfera e a disposição de resíduos sólidos em aterros está centrada na conservação do meio ambiente e, principalmente, na saúde dos seres humanos. É por esse motivo que as leis ambientais estão cada vez mais rígidas, educando os cidadãos a evitar o desperdício e direcionando governos e empresas ao desenvolvimento sustentado. De certo, as indústrias químicas, metalúrgicas, farmacêuticas, entre outras consideradas potencialmente poluidoras, são as que mais investem em obras e serviços de adequação à legislação ambiental, pois temem o prejuízo financeiro que teriam com o pagamento de indenizações por liberar qualquer substância tóxica para o meio ambiente sem tratamento prévio; isto sem contar que a maioria dos acidentes ambientais figura como fator de total desprestígio à imagem de uma empresa, podendo até minar suas pretensões de crescimento dentro do mercado.

A construção e a operação de unidades próprias de tratamento de efluentes constituem uma área de investimento muito procurada pelas indústrias de grande porte, não só pela redução de custos a longo prazo, como também pelo ganho de autonomia no processo. Hoje em dia, o sistema de tratamento mais usado nessas unidades é o aeróbio contínuo, mas estudos recentes já apontam boas alternativas, como a aplicação de reatores anaeróbios operados em batelada seqüencial (AnSBR), muito embora o uso pleno desse sistema ainda dependa do esclarecimento de aspectos fundamentais e tecnológicos. Entre os aspectos fundamentais, destacam-se a transferência de massa, a produção de biogás e os modelos cinético e hidrodinâmico do sistema, enquanto que entre os aspectos 
tecnológicos, consideram-se principalmente os parâmetros de operação, como agitação e estratégia de alimentação, além da mudança de escala e da capacidade de tratamento de águas residuárias de diferentes origens e composições.

As configurações do AnSBR são bastante variadas, pois muitas delas tem origem em adaptações de modelos usados em processos anaeróbios contínuos, ou mesmo aeróbios, sem falar nas variações decorrentes do aprimoramento desses reatores em função do entendimento dos aspectos fundamentais e tecnológicos supracitados. Nesse sentido, pode-se dizer que a forma e a disposição da biomassa também contribuem para o aumento das variantes do AnSBR, já que o lodo anaeróbio normalmente é usado tanto na forma granular quanto imobilizado em material inerte. Contudo, as vantagens da imobilização do lodo incluem não somente o aumento da retenção de sólidos no sistema e a eliminação da etapa de sedimentação, como principalmente o aumento da superfície de contato entre a biomassa e o meio líquido, com o conseqüente ganho de flexibilidade para o tratamento de cargas orgânicas mais elevadas. É por isso que a escolha do meio suporte é tão importante e, não à toa, a espuma de poliuretano aparece como uma das melhores opções, o que em parte se deve a seu baixo valor comercial.

Por conta da gama de alternativas, o sistema de agitação é outro que engrossa o número de variantes do AnSBR, sendo que cada modelo se ajusta melhor a uma determinada condição de tratamento. Os agitadores mecânicos, por exemplo, certamente figuram entre os mais usados, mas não são muito indicados para reatores com biomassa imobilizada, visto que a distribuição da fase líquida no leito desses reatores ocorreria de forma irregular se não houvesse um dispositivo de correção de fluxo acoplado, como o draft tube. Nesse caso, em especial, o modelo 
de recirculação da fase líquida parece ser uma alternativa mais interessante, pois garantiria uma boa homogeneidade do meio, com baixo custo de operação. Ademais, é um sistema que permite o tratamento de um volume maior de meio líquido sem necessariamente mexer na configuração do reator, bastando inserir um tanque-pulmão na linha de recirculação.

A flexibilidade de operação do AnSBR é especialmente interessante para o tratamento de águas residuárias industriais, visto que em algumas indústrias a produção de efluentes ocorre de forma intermitente. Mesmo nos casos em que a produção é contínua, o AnSBR ajusta-se bem, pois as características do efluente variam bastante, não só em termos de vazão, como também de concentração; tanto que para amenizar a desestabilização do sistema e não comprometer a eficiência do processo é muito comum encontrar tanques de equalização na entrada das unidades de tratamento das indústrias. A operação do AnSBR em batelada alimentada pode tornar desnecessário o uso desses tanques, além de garantir maior estabilidade ao sistema através do controle da produção de ácidos voláteis. No entanto, a mudança na estratégia de alimentação do reator nem sempre é suficiente para assegurar essa estabilidade, devendo-se averiguar a composição, o pH e a temperatura do efluente gerado pela indústria.

De todas as indústrias, as do setor de higiene pessoal estão entre as que mais cresceram nos últimos treze anos. Segundo a Associação Brasileira da Indústria de Higiene Pessoal, Perfumaria e Cosméticos (ABIHPEC), de 1996 a 2008, o setor apresentou crescimento médio anual de 10,6\%, muito acima da média das indústrias do país, que foi de $2,9 \%$, e hoje o mercado brasileiro já figura entre os três maiores do mundo, atrás apenas de Estados Unidos e Japão. Ao todo são 1694 empresas 
espalhadas pelas cinco regiões do Brasil. Não se sabe ao certo quantas delas dispõem de sistemas de tratamento, muito menos como padronizar o efluente gerado diante de um número interminável de produtos e reagentes, mas alguns pesquisadores já estão em busca de soluções para os problemas ambientais que cercam o dia-a-dia das indústrias desse setor.

Dentro deste contexto, a proposta do presente trabalho foi avaliar o comportamento de dois reatores anaeróbios operados em batelada seqüencial no tratamento de água residuária que simula o efluente de indústria de produtos de higiene pessoal, um contendo biomassa imobilizada em espuma de poliuretano (AnSBBR), e o outro, biomassa granulada (AnSBR). Espera-se com isso aprimorar o conhecimento sobre os fundamentos da digestão anaeróbia e sobre o funcionamento do AnSBBR e do AnSBR e confirmar a flexibilidade de operação de ambos no tratamento de um tipo específico de efluente. O trabalho foi financiado pela Fundação de Amparo à Pesquisa do Estado de São Paulo (FAPESP) por meio do Projeto Temático "Desenvolvimento de Sistemas Combinados de Tratamento de Águas Residuárias Visando à Remoção de Poluentes e à Recuperação de Energia e de Produtos dos Ciclos de Carbono, Nitrogênio e Enxofre" (Processo FAPESP № 2005/51.702-9) e da Reserva Técnica do bolsista (Processo FAPESP № 2006/58.681-0), e desenvolvido no Laboratório de Engenharia Bioquímica (LEB) do Departamento de Engenharia Química e Alimentos (DQA) da Escola de Engenharia Mauá (EEM) do Instituto Mauá de Tecnologia (IMT), em conjunto com o Laboratório de Processos Biológicos (LPB) do Departamento de Hidráulica e Saneamento (SHS) da Escola de Engenharia de São Carlos (EESC) da Universidade de São Paulo (USP). 


\section{OBJETIVOS}

O objetivo principal deste trabalho foi avaliar a aplicação de dois reatores anaeróbios operados em batelada seqüencial, com biomassa imobilizada em espuma de poliuretano (AnSBBR) e na forma granular (AnSBR), no tratamento de água residuária que simula o efluente de indústria de produtos de higiene pessoal, em função da carga orgânica volumétrica aplicada (COVA), variando-se a concentração afluente $\left(C_{A}\right)$, o volume alimentado por ciclo $\left(V_{A}\right)$, o tempo de enchimento $\left(t_{F}\right)$, o tempo de ciclo ( $\mathrm{t}_{\mathrm{c}}$ ) e a composição do volume alimentado. Para tornar mais clara a proposta deste trabalho e facilitar a discussão dos resultados obtidos, destacam-se os seguintes objetivos específicos:

(a) verificação da necessidade de suplementação de alcalinidade à água residuária;

(b) avaliação da estabilidade e da eficiência do AnSBBR, variando-se $C_{A}, V_{A}$ e $t_{F}$, simultaneamente, para COVA de 0,9 e 1,5 gDQO/L.d;

(c) avaliação do uso de volume residual de um ciclo operacional para outro na operação do AnSBBR;

(d) avaliação da estabilidade e da eficiência do AnSBR, variando-se $C_{A}$ e $t_{C}$, simultaneamente, mantendo-se COVA de 0,75 gDQO/L.d;

(e) avaliação da estabilidade e da eficiência do AnSBR, variando-se $t_{C}$, mantendose $C_{A}$ de $500 \mathrm{mgDQO} / \mathrm{L}$, para COVA de 0,25, 0,50 e 0,75 gDQO/L.d;

(f) avaliação da estabilidade e da eficiência do AnSBR, variando-se a composição do afluente, mantendo-se COVA de 0,75 gDQO/L.d; 



\section{REVISÃO BIBLIOGRÁFICA}

Os reatores anaeróbios vêm sendo estudados por muitos pesquisadores que, diante das mais diversas configurações e estratégias de operação, procuram potencializar suas qualidades no tratamento de águas residuárias distintas.

\subsection{TRATAMENTO ANAERóbio de ÁGUAS RESIDUÁrias}

A disposição de esgotos brutos no solo ou em corpos receptores, como lagoas, rios e oceanos, é uma prática que foi e ainda é empregada de forma muito intensa. Dependendo da carga orgânica lançada, os esgotos provocam a deterioração completa do ambiente ou, em outros casos, o ambiente demonstra ter condições de receber e degradar o esgoto a um nível que não cause alterações acentuadas que possam prejudicar o ecossistema local e circunvizinho. Esse fato demonstra que a natureza é capaz de promover o "tratamento" de esgotos, desde que não ocorra sobrecarga e haja condições ambientais que favoreçam a evolução, a reprodução e o crescimento de organismos que decomponham a matéria orgânica. Dessa forma, o objetivo do tratamento biológico de águas residuárias é reproduzir, com auxilio da tecnologia, o processo de depuração que ocorre naturalmente nos corpos receptores, no qual a matéria orgânica presente é convertida em produtos mineralizados (CAMPOS, 1999).

A crise energética da década de 70 abriu espaço para o desenvolvimento de alternativas no tratamento de águas residuárias, como foi o caso dos processos anaeróbios. Suas vantagens amplamente enunciadas incluem baixo consumo de energia, por não requerer aeração do meio, e possibilidade de recuperação e 
utilização de metano como combustível, além de um menor custo operacional decorrente da baixa produção de lodo. Por outro lado, essa reduzida velocidade de crescimento da biomassa, notadamente dos microrganismos metanogênicos, faz com que o controle do processo seja delicado, pois a recuperação do sistema se torna bastante lenta quando o mesmo é exposto a adversidades (CAMPOS, 1999).

A digestão anaeróbia é um processo biológico no qual um consórcio de espécies de microrganismos, na ausência de oxigênio molecular dissolvido, promove a transformação de compostos orgânicos complexos, como carboidratos, proteínas e lipídeos, em produtos mais simples, como metano e gás carbônico. Os microrganismos envolvidos nesse processo são altamente especializados e cada grupo atua em reações específicas, podendo-se distinguir as principais etapas da conversão global de matéria orgânica: hidrólise, acidogênese, acetogênese e metanogênese (HARPER e POHLAND, 1986). Além delas, o processo de digestão anaeróbia conta ainda com uma outra etapa, conhecida como sulfetogênese, que concorre com a etapa de metanogênese, podendo diminuir o grau de conversão de substrato a metano (LENS et al., 1998).

\subsection{REATOR ANAERÓBIO OPERADO EM BATELADA SEQUENCIAL}

O reator anaeróbio operado em batelada seqüencial (AnSBR) apresenta algumas características apontadas como vantagens sobre os reatores contínuos: boa retenção de sólidos, eficiência no controle de operação, eficiência na remoção de substâncias orgânicas, simples operação e baixo custo para tratamento de esgoto industrial e doméstico (CAMPOS, 1999). 
De acordo com Dague, Habben e Pidaparti (1992), a característica básica do AnSBR é a de ser preenchido com água residuária no início e esvaziado ao final do tratamento, repetindo-se a operação com nova batelada. O conteúdo no interior do reator é misturado, permitindo um bom contato substrato/biomassa. O tratamento é efetuado em tanque único, em uma seqüência operacional que compreende basicamente as seguintes fases: (i) enchimento com água residuária, (ii) tratamento propriamente dito, por meio de transformações dos constituintes da água residuária pela ação de microrganismos; (iii) sedimentação do lodo biológico; (iv) esvaziamento do tanque, com a retirada do líquido tratado e clarificado.

Essa configuração de reator possibilita a obtenção de uma baixa razão entre as concentrações de substrato e biomassa, ao mesmo tempo em que consegue processar esgoto com elevadas velocidades de reação (DAGUE, HABBEN e PIDAPARTI, 1992). A concentração de matéria orgânica é máxima logo após a alimentação, diminuindo com o tempo de reação; no entanto, antes da nova fase de alimentação, a concentração geralmente é mais baixa nesse tipo de configuração do que em sistemas contínuos. Dessa forma, em reatores operados em batelada, a formação de grânulos, a biodegradação e a capacidade de sedimentação podem ser mais eficientes que nos sistemas anaeróbios contínuos, como o de contato, por exemplo (BAGLEY e BRODKORB, 1999).

Desde sua criação, o AnSBR vem sendo empregado no tratamento de diferentes águas residuárias. Dague, Habben e Pidaparti (1992), tratando meio sintético a base de leite desnatado em AnSBR de $13 \mathrm{~L}$, a $35^{\circ} \mathrm{C}$, com carga orgânica volumétrica aplicada (COVA) ${ }^{(1)}$ de 0,5 a 5,0 gDQO/L.d e tempos de detenção hidráulica (TDH) de 2,17, 1,08 e 0,54 d, observaram que a eficiência média de remoção de matéria

(1) As definições de COVA, COEA e TDH para reatores descontínuos são apresentadas no item 4.10. 
orgânica ficou em 80\% para COVA até 4,0 gDQO/L.d e TDH de 2,17 e 1,08 d. Para valores de COVA superiores a esse, houve queda rápida de eficiência. Quando o AnSBR foi operado com TDH de 0,54 d e COVA até 2,0 gDQO/L.d, obteve-se $80 \%$ de conversão, enquanto que para COVA superiores a 3,0 gDQO/L.d, com o mesmo TDH, a eficiência obtida não passou de $70 \%$.

Ainda com relação ao tratamento de meio sintético a base de leite desnatado, Sung e Dague (1995) avaliaram o desempenho de quatro AnSBR de $12 \mathrm{~L}$ de diferentes configurações e tempos de agitação. Foram testadas as COVA de 2 a 12 gDQO/L.d, com TDH de 48, 24 e $12 \mathrm{~h}$, a $35^{\circ} \mathrm{C}$, e, em todas as condições, os pesquisadores obtiveram eficiências superiores a 90\%. Dague, Banik e Ellis (1998), usando três AnSBR com volume útil de $6 \mathrm{~L}$, concentração afluente $\left(C_{A}\right)$ de $600 \mathrm{mgDQO} / \mathrm{L}$, e TDH entre 6 e 24 h, também obtiveram valores de remoção de matéria orgânica superiores a $90 \%$, tratando meio sintético semelhante, entre 20 e $25^{\circ} \mathrm{C}$.

Mockaitis et al. (2006) utilizaram um AnSBR no tratamento de soro de queijo, aplicando COVA de 0,6 a 4,8 gDQO/L.d. O reator mostrou estabilidade em todas as condições operacionais, apresentando valores de eficiência sempre acima dos 90\%. Contudo, os pesquisadores relataram problemas com a formação de polímeros extracelulares (ECP) e a flotação da biomassa nas condições experimentais com COVA de 2,5 e 4,8 gDQO/L.d.

Utilizando um AnSBR no tratamento de esterco de porco, Massé et al. (1997) obtiveram valores de eficiência de remoção de matéria orgânica entre 58 e 73\%, para amostras não filtradas, e entre 85 e 96\%, para amostras filtradas do efluente, em condições experimentais com COVA de 0,7 a 1,2 gDQO/L.d. Já a produção de 
metano variou entre 0,30 e 0,66 L/gSSV, mesmo quando a concentração de ácido acético no meio reacional chegou a $5500 \mathrm{mg} / \mathrm{L}$. Ademais, a fração molar de metano no biogás ficou entre 50 e $80 \%$.

Hollopeter e Dague (1994) testaram um AnSBR de $12 \mathrm{~L}$ tratando percolado de aterro sanitário a 35ํㅡ, TDH de 0,5 a 2 d e COVA de 1,6 a 3,5 gDQO/L.d. Como etapa de pós-tratamento foi utilizado um sistema aeróbio de lodos ativados. O AnSBR alcançou de 85 a 90\% de remoção de matéria orgânica solúvel, enquanto que o sistema completo atingiu eficiências de 94 a $99 \%$. Este mesmo substrato foi estudado por Timur e Özturk (1999) em AnSBR, com COVA de 0,4 a 9,4 gDQO/L.d, na mesma temperatura, com TDH de 1,5 a 10 d e $C_{A}$ de 3800 a $15900 \mathrm{mgDQO} / \mathrm{L}$. Os pesquisadores obtiveram valores médios de eficiência entre 64 e 85\%. Já a produção de metano chegou a 1,85 L/L.d, na condição com COVA de 9,4 gDQO/L.d.

Chebel et al. (2006) estudaram o efeito do aumento da COVA sobre o comportamento de um AnSBR com agitação mecânica e tempos de ciclo ( $\left.\mathrm{t}_{\mathrm{c}}\right)$ de 8 e $12 \mathrm{~h}$, tratando esgoto doméstico sintético ${ }^{(2)}$. O volume alimentado era cerca de $2 \mathrm{~L}$, com $\mathrm{C}_{\mathrm{A}}$ entre 550 e $3600 \mathrm{mgDQO} / \mathrm{L}$, o que resultou em COVA de 0,7 a 2,9 gDQO/L.d. O reator atingiu a estabilidade nas condições experimentais em que a COVA era igual e inferior a 2,3 gDQO/L, apresentando valores de eficiência de remoção de matéria orgânica de amostras filtradas do efluente entre 84 e $88 \%$. De acordo com os pesquisadores, tanto $C_{A}$ quanto $t_{C}$ parecem ter desempenhado papéis importantes sobre o comportamento do reator. Por outro lado, Zaiat et al. (2001) sugerem que os principais fatores que afetam a estabilidade e a eficiência de um AnSBR são: agitação, razão inicial entre as concentrações de substrato e biomassa, configuração geométrica do reator e estratégia de alimentação.

(2) O esgoto doméstico sintético usado nos trabalhos desses e de outros pesquisadores corresponde ao meio sintético descrito no item 4.4.3. 
Kennedy et al. (1991) utilizaram um AnSBR no tratamento de água residuária facilmente biodegradável, alterando a relação entre os tempos de enchimento $\left(t_{F}\right)$ e de reação $\left(t_{R}\right)$. As COVA variaram de 2,5 a 18,5 gDQO/L.d, resultando em valores de eficiência entre 35 e 97\%. No entanto, os pesquisadores observaram que valores da razão $t_{F} / t_{R}$ entre 0,2 e 0,5 reduziram significativamente a eficiência do tratamento para COVA acima de 9,0 gDQO/L.d. Com base nos resultados, concluíram que a carga orgânica específica aplicada (COEA), baseada em $t_{F}$, deve ser um parâmetro crítico de projeto.

Angenent e Dague (1995) compararam o desempenho de um AnSBR com o de um reator anaeróbio de manta de lodo e fluxo ascendente (UASB) no tratamento de água residuária sintética a base de sacarose, em reatores de 12 e 13 L, respectivamente, operados a $35^{\circ} \mathrm{C}$. Em ambos, o TDH era de $12 \mathrm{~h}$, com $\mathrm{C}_{\mathrm{A}}$ variando de 3000 a 11500 mgDQO/L no UASB, e de 3000 a 9500 mgDQO/L, no AnSBR. As COVA máximas do UASB e do AnSBR foram 19 e 23 gDQO/L.d, respectivamente. Em termos de estabilização de matéria orgânica, ambos apresentaram valores de eficiência superiores a 90\% para COVA de 19 gDQO/L.d, em menos de três meses de operação. Contudo, o UASB apresentou melhor desempenho que o AnSBR sempre que eram operados com COVA elevadas.

\subsection{REATOR ANAERÓBIO EM BATELADA SEQÜENCIAL COM BIOMASSA IMOBILIZADA}

Uma alternativa que vem sendo estudada para aprimorar a configuração dos AnSBR é a utilização de biomassa imobilizada em suporte inerte, sobre o qual ocorre a formação de biofilme aderido à superfície, com predomínio deste sobre culturas livres em suspensão (VARESCHE et al., 1997; ORTEGA et al., 2001). Dessa forma, 
nota-se a criação de microambientes especiais pela interação entre as espécies, favorecendo o conjunto como um todo e, principalmente, garantindo estabilidade aos microrganismos.

A configuração do AnSBR contendo biomassa imobilizada em cubos de espuma de poliuretano foi proposta por Ratusznei et al. (2000). O reator foi operado a $30^{\circ} \mathrm{C}$, com agitação mecânica, tratando $0,5 \mathrm{~L}$ de esgoto doméstico sintético, com $485 \mathrm{mgDQO} / \mathrm{L}$, em ciclos de 8 h. Em 10 dias de operação, o sistema atingiu a estabilidade, com valores de eficiência de remoção de matéria orgânica de até $86 \%$. A utilização dos cubos de espuma assegurou a retenção da biomassa no reator, permitindo a eliminação da etapa de sedimentação necessária em reatores anaeróbios descontínuos que não utilizam material suporte e, desta forma, otimizando a operação através da redução do tempo total de ciclo.

Siman et al. (2004) investigaram o desempenho de um reator anaeróbio operado em batelada seqüencial contendo biomassa imobilizada (AnSBBR) em cubos de espuma de poliuretano, tratando esgoto doméstico sintético. As COVA variaram entre 1,5 e 6,0 gDQO/L.d, sendo 2,0 L de afluente, com $\mathrm{C}_{\mathrm{A}}$ de 500 a $2000 \mathrm{mgDQO} / \mathrm{L}$ e tc de 8 e 12 h. Nas condições experimentais com COVA até 5,4 gDQO/L.d, as eficiências de remoção de matéria orgânica para amostras filtradas estiveram entre 73 e $88 \%$. Acima disto, o sistema apresentou problemas de acúmulo de ácidos voláteis totais resultando em $55 \%$ de eficiência.

Bezerra Junior et al. (2005) também utilizaram espuma de poliuretano como material suporte para a operação de um AnSBBR, tratando esgoto doméstico sintético com aproximadamente $500 \mathrm{mgDQO} / \mathrm{L}$. Nesse trabalho, a principal característica 
operacional investigada foi a razão do volume de água residuária alimentada por ciclo $\left(\mathrm{V}_{\mathrm{A}}\right)$ pelo volume de meio líquido do sistema $\left(\mathrm{V}_{\mathrm{U}}\right)$, mantendo-se a COVA constante. Os resultados indicaram que o AnSBBR foi capaz de operar com diferentes razões $V_{A} / V_{U}$ sem perda significante da eficiência. Para as condições nas quais $V_{A} / V_{U} \geq 0,50$, a remoção de matéria orgânica para amostras filtradas e não filtradas foi de 84 e 79\%, respectivamente, ao passo que, em condições com maiores diluições do afluente, ou seja, $V_{A} / V_{U} \leq 0,25$, estes valores de eficiência foram menores, em torno de 80 e $74 \%$, respectivamente. Os pesquisadores ainda observaram que, para diluições maiores, foi difícil controlar a variação de volume do reator devido à formação ECP.

Miqueleto et al. (2005) operaram um AnSBBR com agitação mecânica e espuma de poliuretano, em ciclos de $8 \mathrm{~h}$, tratando meio sintético a base de glicose, com 500 , 1000 e $2000 \mathrm{mgDQO} / \mathrm{L}$. Das três condições, apenas a de $500 \mathrm{mgDQO} / \mathrm{L}$ atingiu a estabilidade de operação, chegando a 97\% de eficiência. As outras duas, de maior COVA, apresentaram problemas com a formação de ECP. Para tentar contornar o problema, os pesquisadores resolveram reduzir o $t_{c}$ de 8 para $3 \mathrm{~h}$, supondo que a formação de ECP estivesse relacionada a um longo período de exposição a baixas concentrações de substrato. No entanto, logo perceberam que a explicação vinha do elevado valor de COVA, pois na tentativa com $500 \mathrm{mgDQO} / \mathrm{L}$ já houve formação de grandes quantidades do polímero.

Além da formação de ECP, outro ponto que merece ser mais investigado é a tolerância do AnSBBR a variações abruptas da concentração afluente. Neste sentido, Moreira et al. (2008) estudaram a aplicação de cargas de choque de duas a quatro vezes o valor da concentração afluente, durante um ou dois ciclos 
operacionais, em um AnSBBR alimentado com dois tipos de água residuária sintética, com concentrações de 500, 1000 e $2000 \mathrm{mgDQO} / \mathrm{L}$, a $30^{\circ} \mathrm{C}$ e $500 \mathrm{rpm}$. Os resultados mostraram que o reator recuperou a estabilidade em um curto período de tempo após a perturbação do sistema em todas as condições experimentais estudadas, apresentando valores de eficiência acima de $80 \%$.

Sarti et al. (2007) investigaram a aplicação de um AnSBBR com espuma de poliuretano em escala piloto, operado em ciclos de $8 \mathrm{~h}$, com agitadores tipo turbina a $40 \mathrm{rpm}$, tratando $0,65 \mathrm{~m}^{3}$ de esgoto sanitário por ciclo. Os valores médios de eficiência e concentração residual de matéria orgânica foram respectivamente $66 \%$ e $133 \mathrm{mgDQO} / \mathrm{L}$. Este resultado mostra a necessidade de pós-tratamento do efluente quando se usa reatores anaeróbios no tratamento de esgoto doméstico.

\subsection{ESTRATÉGIA DE ALIMENTAÇÃO E RECIRCULAÇÃo DA FASE LíQUIDA}

Quando existe o interesse em manter a concentração de substrato no reator em valores baixos, seja pela elevada carga orgânica do afluente ou pela presença de alguma substância tóxica, uma alternativa cabível é mudar a estratégia de alimentação do reator para batelada alimentada, de modo que a etapa de alimentação tenha um período maior que aquele convencionalmente adotado. A utilização de uma etapa de alimentação mais longa pode evitar a ocorrência de valores elevados de concentração de ácidos voláteis, favorecendo a estabilidade do reator. Por outro lado, resulta em menores concentrações de matéria orgânica ao longo de um ciclo de operação, o que implica uma velocidade média de reação menor se comparada à obtida em sistemas operados em batelada simples, podendo assim diminuir a eficiência global do processo (ZAIAT et al., 2001). 
Ratusznei et al. (2003) estudaram o comportamento de um AnSBBR operado em batelada e batelada alimentada, a $30^{\circ} \mathrm{C}$ e $200 \mathrm{rpm}$, tratando $0,5 \mathrm{~L}$ de esgoto doméstico sintético com $\mathrm{C}_{\mathrm{A}}$ de $500 \mathrm{mgDQO} / \mathrm{L}$ em ciclos de $3 \mathrm{~h}$. O tempo de alimentação em batelada era de $3 \min$ e, em batelada alimentada, de 30, 60 e 180 min. No sistema operado em batelada, a eficiência de remoção de matéria orgânica para amostras filtradas chegou a $86 \%$. Nos sistemas operados em batelada alimentada, em contrapartida, a estabilidade operacional só foi alcançada no ciclo de 30 min, enquanto nos demais ciclos houve formação de uma quantidade considerável de ECP que impediu o contato eficiente entre substrato e biomassa. A queda da eficiência atentou os pesquisadores para o fato de manter o leito do reator sempre coberto com o afluente para evitar a formação do biopolímero.

Orra et al. (2004) também avaliaram a influência de estratégias distintas de alimentação sobre o desempenho de um AnSBBR, que foi operado em batelada e batelada alimentada, com recirculação externa da fase líquida, tratando $890 \mathrm{~mL}$ de esgoto doméstico sintético em ciclos de $6 \mathrm{~h}$. A eficiência de remoção para amostras filtradas diminuiu de 85 a $81 \%$ com o aumento do $t_{F}$ de 6 para 360 min. Apesar disso, os pesquisadores observaram que a operação em batelada alimentada conferiu estabilidade ao sistema. Ademais, houve formação de ECP durante o período de operação, mas nada que comprometesse a estabilidade.

Borges et al. (2004) variaram a estratégia de alimentação de um AnSBBR tratando 2,5 L de esgoto doméstico sintético com $500 \mathrm{mgDQO} / \mathrm{L}$. O ciclo era de $8 \mathrm{~h}$ e a agitação de 500 rpm. No início de cada ciclo, o reator era alimentado com $60 \%$ do volume total a ser tratado, e os $40 \%$ restantes eram adicionados com $t_{F}$ de 10,120 , 240, 260 e 480 min, o que caracterizava as diferentes estratégias de alimentação. 
Os resultados obtidos mostraram que para a razão $t_{F} / t_{C} \leq 0,5$, a eficiência de remoção de matéria orgânica de amostras filtradas do efluente ficou acima de $75 \%$, enquanto que para razão $t_{F} / t_{C}>0,5$, os valores obtidos foram menores.

Tratando soro de queijo em AnSBBR, Damasceno et al. (2007) avaliaram a influência da COVA e da estratégia de alimentação sobre a estabilidade e a eficiência do sistema. As COVA foram de 2, 4, 8 e 12 gDQO/L.d para as estratégias de alimentação de 10, 120 e 240 min, mantendo-se a suplementação de alcalinidade em $50 \%$ da razão mássica $\mathrm{NaHCO}_{3} / \mathrm{DQO}$. Obtiveram melhores resultados nas condições com COVA de 2 a 4 gDQO/L.d e $t_{F}$ de 120 min e com COVA de 8 e $12 \mathrm{gDQO} / \mathrm{L} . \mathrm{d}$ e $\mathrm{t}_{\mathrm{F}}$ de $240 \mathrm{~min}$.

Com relação à agitação do meio, uma das alternativas é a implementação de um sistema de recirculação da fase líquida. Esse sistema apresenta grande flexibilidade operacional, já que o volume de meio a ser tratado pode aumentar com o uso de um reservatório paralelo. Nesse sentido, Camargo et al. (2002) obtiveram um incremento no desempenho de um AnSBBR através da recirculação, tratando meio sintético a base de glicose com 500 mgDQO/L. A eficiência chegou a 95\%, em conseqüência do melhor contato substrato/biomassa. A mesma justificativa foi usada por Mohan et al. (2007) para explicar o ganho de eficiência no tratamento de água residuária hipersalina no mesmo tipo de reator.

\section{5 ÁGUA RESIDUÁRIA CONTENDO SURFACTANTES}

Estudando a biodegradabilidade e os impactos ambientais de surfactantes aniônicos, Cserháti, Forgács e Oros (2002) concluíram que o papel destes 
compostos no meio ambiente é ambíguo, já que podem causar efeitos tóxicos sobre organismos vivos, como também promover a decomposição de poluentes de natureza orgânica e a oxidação de compostos inorgânicos. De acordo com os autores, a relação entre a estrutura química, as propriedades físico-químicas, a biodegradabilidade e o impacto causado pelos surfactantes ainda não está muito bem esclarecida.

Patel e Madamwar (1998) estudaram o efeito da aplicação de diferentes surfactantes no tratamento de soro de queijo em um reator anaeróbio contínuo de leito fixo e fluxo ascendente. A adição de $200 \mathrm{mg} / \mathrm{L}$ de lauril sulfato de sódio resultou em um aumento de $70 \%$ na produção de biogás, chegando a 5,7L/L. A fração molar de metano no biogás também foi maior, passando de $69 \%$ para $77 \%$, depois que o lauril foi adicionado. Além disso, nesta condição foram encontrados os mais baixos valores de concentração de ácidos voláteis totais, mostrando que o sistema se manteve estável ao longo do período de operação. O reator operou por 60 dias em cada condição experimental, depois de atingir o estado estacionário, com TDH de $2 \mathrm{~d}, \mathrm{a} 37^{\circ} \mathrm{C}$ e $\mathrm{C}_{\mathrm{A}}$ de $30000 \mathrm{mgDQO} / \mathrm{L}$.

Também usando um reator anaeróbio contínuo de leito fixo e fluxo ascendente, Baumann e Müller (1997) estudaram a degradação do lauril sulfato de sódio, sem adição de qualquer outro composto. Os meios eram preparados com $350 \mathrm{mgDQO} / \mathrm{L}$ e sais, e autoclavados a $121^{\circ} \mathrm{C}$. Para o TDH de $1 \mathrm{~h}$, a produção de metano foi de apenas $15 \%$ do que teoricamente poderia ser obtido. A justificativa, de acordo com os pesquisadores, é que o lauril foi parcialmente degradado a dodecanol pelas bactérias redutoras de sulfato; e como consumo seu era mais lento, houve acúmulo no meio reacional, o que pode ter provocado inibição nos microrganismos. 
Além do uso de reatores biológicos, uma outra possibilidade de tratamento para a remoção de surfactantes é através de processos físico-químicos que envolvem floculação e coagulação. Beltrán-Heredia e Sánchez-Martín (2009) obtiveram mais de $80 \%$ de remoção de lauril sulfato de sódio utilizando um agente floculante/ /coagulante natural a base de extrato de Moringa oleifera.

\subsection{CONSIDERAÇÕES FINAIS}

Os estudos desenvolvidos com reatores bioquímicos em escala de bancada ajudam na compreensão das rotas de degradação da matéria orgânica e na avaliação das principais variáveis de projeto, permitindo a identificação e, em alguns casos, a determinação de parâmetros críticos. Esse conhecimento é de extrema importância para aplicação dos mesmos reatores nas escalas piloto e real. Além disso, o tratamento de águas residuárias distintas está em pauta em muitos grupos de pesquisa, pois sua composição interfere diretamente na estabilidade e na eficiência dos reatores, podendo alterar os parâmetros críticos previamente estabelecidos para um tipo específico de efluente, mesmo que as condições operacionais sejam mantidas. Dentro desse contexto, o foco deste trabalho foi avaliar a aplicação de um AnSBBR, com recirculação da fase líquida, e de um AnSBR, com agitação mecânica, no tratamento de água residuária simulando efluente de indústria de produtos de higiene pessoal. 



\section{MATERIAIS E MÉTODOS}

Os reatores usados neste trabalho foram operados em batelada seqüencial e em condições anaeróbias. Um deles continha biomassa imobilizada em espuma de poliuretano (AnSBBR), enquanto o outro apresentava biomassa autoimobilizada na forma de grânulos (AnSBR).

\subsection{ANSBBR}

O AnSBBR consistia em um frasco de acrílico cilíndrico compartimentado de $100 \mathrm{~mm}$ de diâmetro externo e 3,5 mm de espessura de parede. Placas perfuradas de aço inoxidável 314 dividiam o compartimento central de $560 \mathrm{~mm}$ de altura em cinco estágios isométricos com o propósito de minimizar os efeitos de compactação do leito, onde a biomassa encontrava-se acondicionada junto do suporte de imobilização. Na parte inferior, havia um compartimento de $35 \mathrm{~mm}$ de altura que favorecia a distribuição da água residuária e, na parte superior, um outro de $65 \mathrm{~mm}$ que funcionava como câmara coletora de biogás. O reator é apresentado nas Figuras 4.1 e 4.2 e mostrado em detalhes na Figura 4.3.

A mistura do meio reacional foi realizada por um sistema de recirculação da fase líquida, composto por uma bomba peristáltica (Ismatec® MCP Standard) e um reservatório lateral de acrílico cilíndrico com as seguintes dimensões: $320 \mathrm{~mm}$ de altura, $100 \mathrm{~mm}$ de diâmetro externo e $3,5 \mathrm{~mm}$ de espessura de parede. Um tubo graduado de vidro de $100 \mathrm{~mL}$ permaneceu conectado ao sistema para auxiliar o acerto da vazão de recirculação, sempre que necessário. 


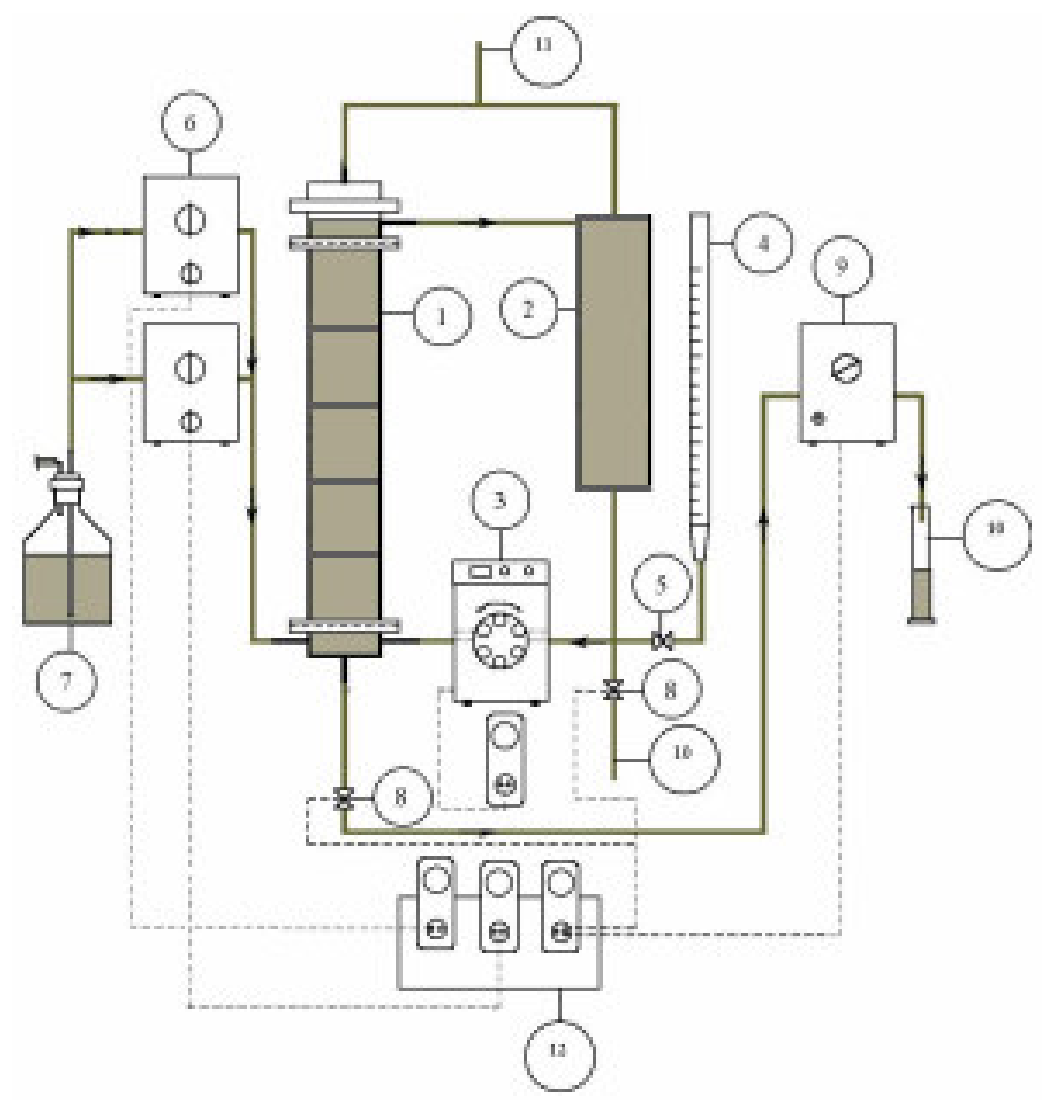

Figura 4.1 - Esquema do aparato experimental do AnSBBR [Notação: 1 - reator com biomassa imobilizada; 2 - reservatório lateral; 3 - bomba de recirculação; 4 - tubo graduado; 5 - válvula de acerto de vazão; 6 - bombas de alimentação; 7 - reservatório de água residuária; 8 - válvulas de descarga; 9 - bomba de descarga; 10 - saída de efluente; 11 - saída de biogás; 12 - unidade de controle; - ligações hidráulicas; --- ligações elétricas]. (adaptado de CAMARGO et al., 2002).

A alimentação do reator foi realizada por bombas de diafragma tanto nas operações em batelada (ProMinent® BT5a_0232) quanto em batelada alimentada (ProMinent ${ }^{\circledR}$ BT4a_1602). A descarga do reator também foi realizada por bomba de diafragma (ProMinent® CONb_0223). As operações de carga e descarga, assim como a recirculação da fase líquida, foram auxiliadas por um sistema automatizado composto por temporizadores (Grässlin® Logica 500 e Coel® RTST/20). O aparato experimental utilizado, apresentado nas Figuras 4.1 e 4.2, era mantido em câmara isotérmica, com controle de temperatura realizado por um sistema constituído de: 
sensor, controlador (Novus® N480), microventilador (Ventisilva® E-11 NYCD) e resistência elétrica cônica de rosca (IIEß 032).

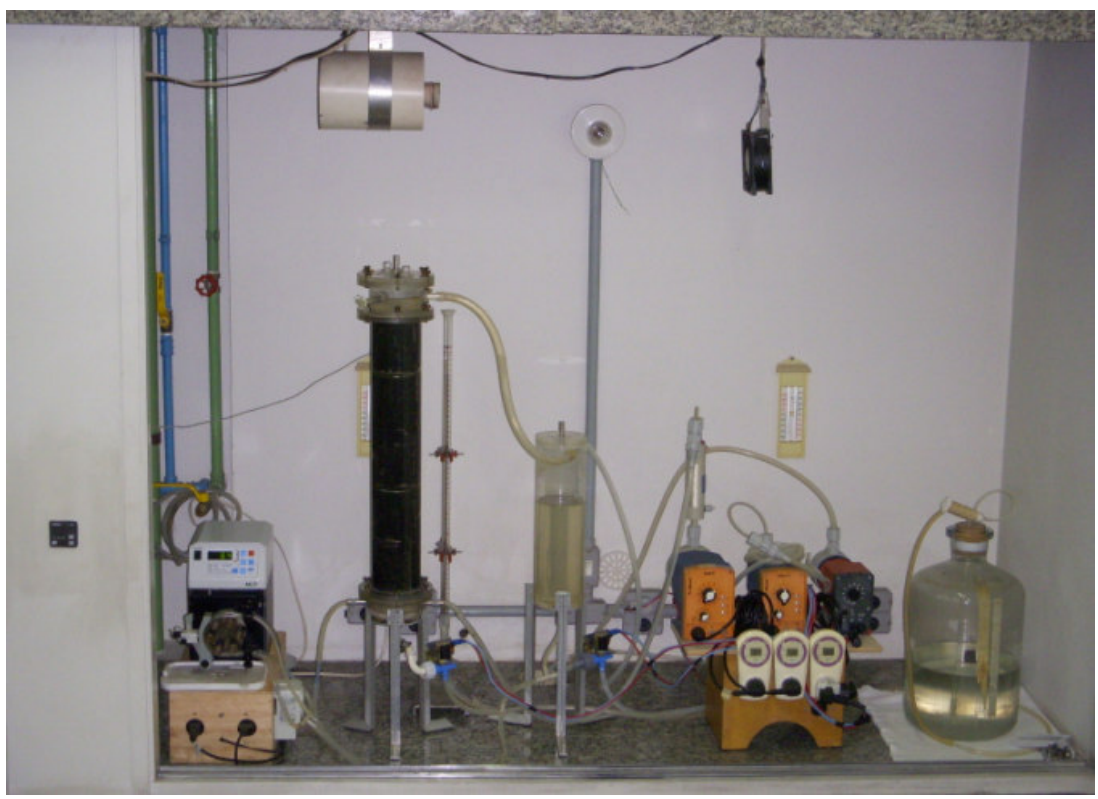

Figura 4.2 - Fotografia do aparato experimental do AnSBBR

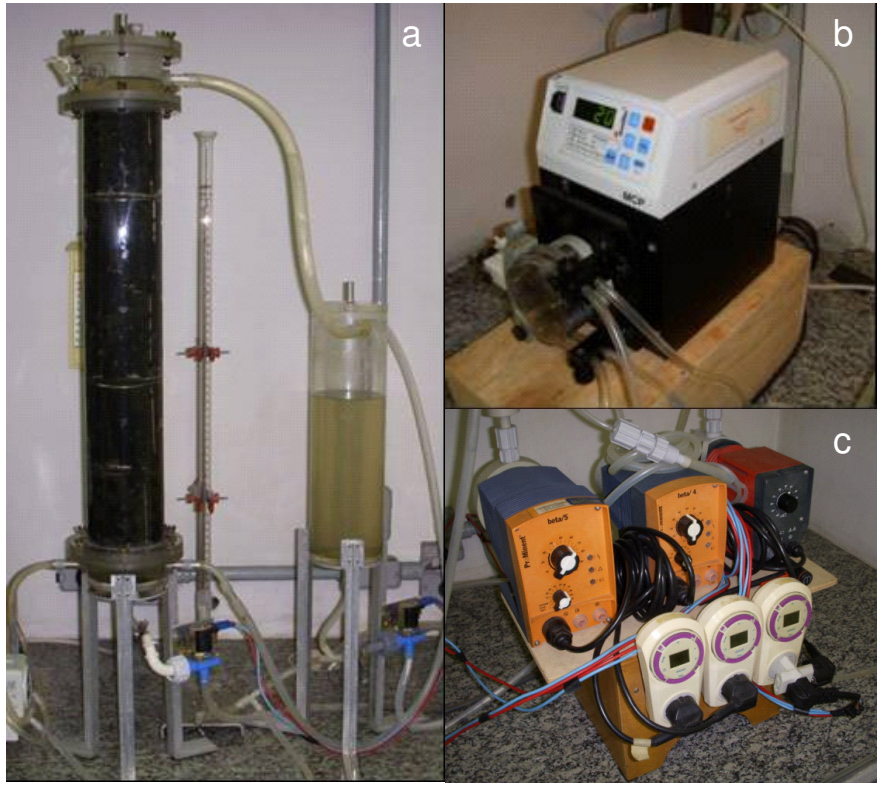

Figura 4.3 - Fotografias: (a) do reator (esquerda), do reservatório (direita) e do tubo graduado (centro), (b) da bomba peristáltica e (c) das bombas de diafragma e dos temporizadores 


\subsubsection{Suporte de imobilização da biomassa}

O material inerte escolhido para a imobilização do inóculo foi espuma de poliuretano na forma de cubos de aproximadamente $1 \mathrm{~cm}$ de aresta, com densidade aparente de $23 \mathrm{~kg} / \mathrm{m}^{3}$ e porosidade próxima a 95\%, sem corantes ou aditivos, produzida pela empresa Indústria e Comércio de Colchões Edmil Ltda., em Elói Mendes, MG. A Figura 4.4 apresenta uma amostra desse suporte.

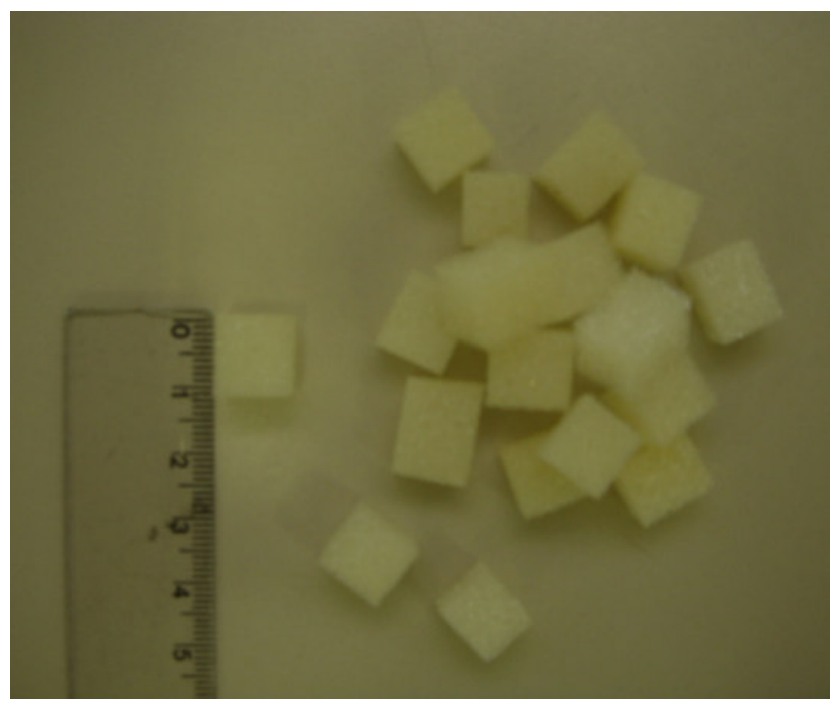

Figura 4.4 - Fotografia dos cubos de espuma de poliuretano

\subsection{ANSBR}

O AnSBR consistia em um frasco de acrílico cilíndrico de 200 mm de altura, 200 mm de diâmetro externo e 3,5 mm de espessura de parede. O sistema de agitação era composto por agitador mecânico (Marconi® MA-259), impelidor tipo hélice com três lâminas de $60 \mathrm{~mm}$ de diâmetro e temporizador (Coel® RTST/20). Bombas de diafragma foram usadas nas operações de alimentação (ProMinent® BT5a_0232) e descarga (ProMinent® CONb_0223) do reator, auxiliadas por temporizadores (Grässlin® Logica 500). O aparato experimental utilizado, apresentado nas Figuras 
4.5 e 4.6, era mantido em câmara isotérmica, com controle de temperatura realizado por um sistema constituído de: sensor, controlador (Novus® N480), microventilador (Ventisilva ${ }^{\circledR}$ E-11 NYCD) e resistência elétrica cônica de rosca (IIE® 032). A Figura 4.7 mostra o reator em detalhes.

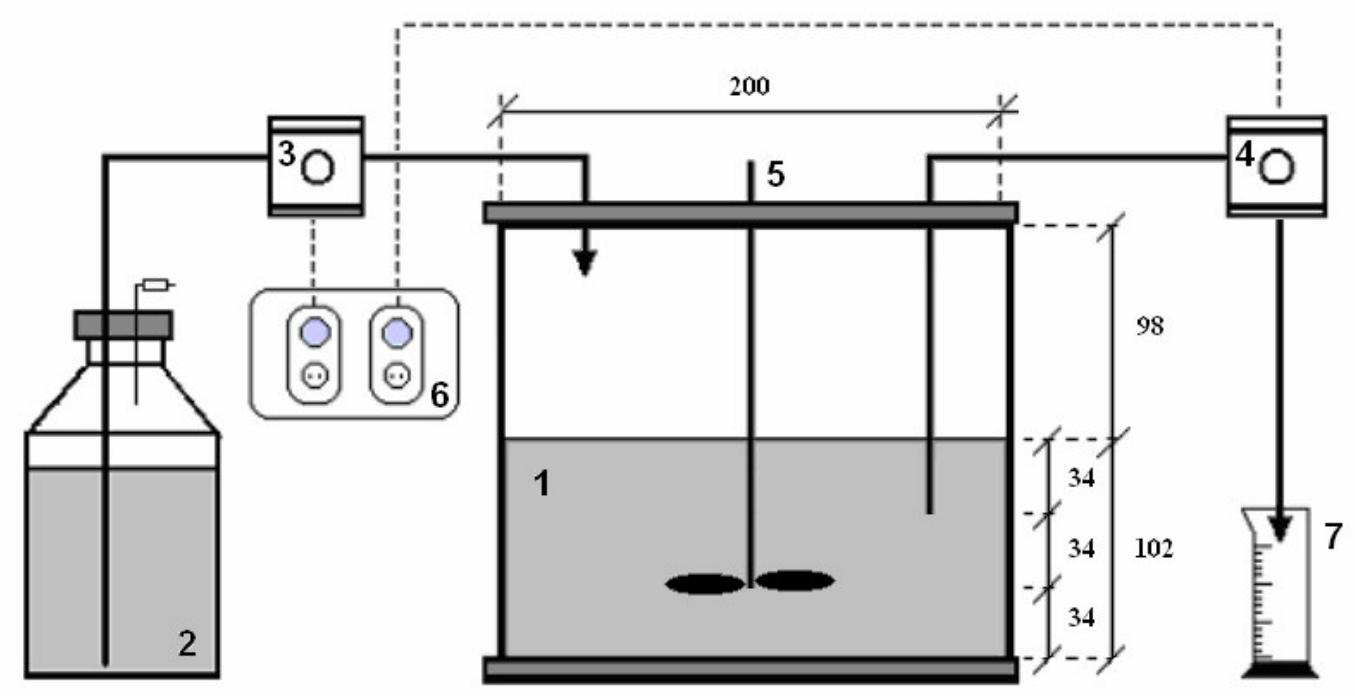

Figura 4.5 - Esquema do aparato experimental do AnSBR [Notação: 1 - reator com biomassa granulada; 2 - reservatório de água residuária; 3 - bomba de alimentação; 4 - bomba de descarga; 5 - agitador mecânico; 6 - unidade de controle; 7 - saída de efluente; - ligações hidráulicas; ----- ligações elétricas; dimensões em milímetros]. (adaptado de SIMAN et al., 2004).

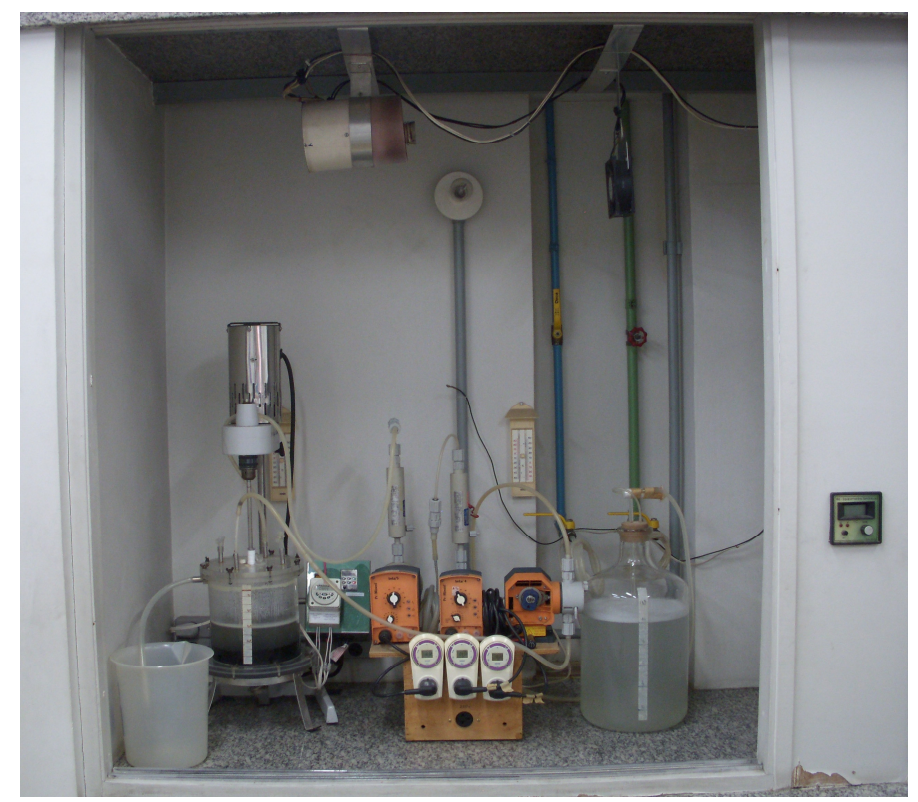

Figura 4.6 - Fotografia do aparato experimental do AnSBR 


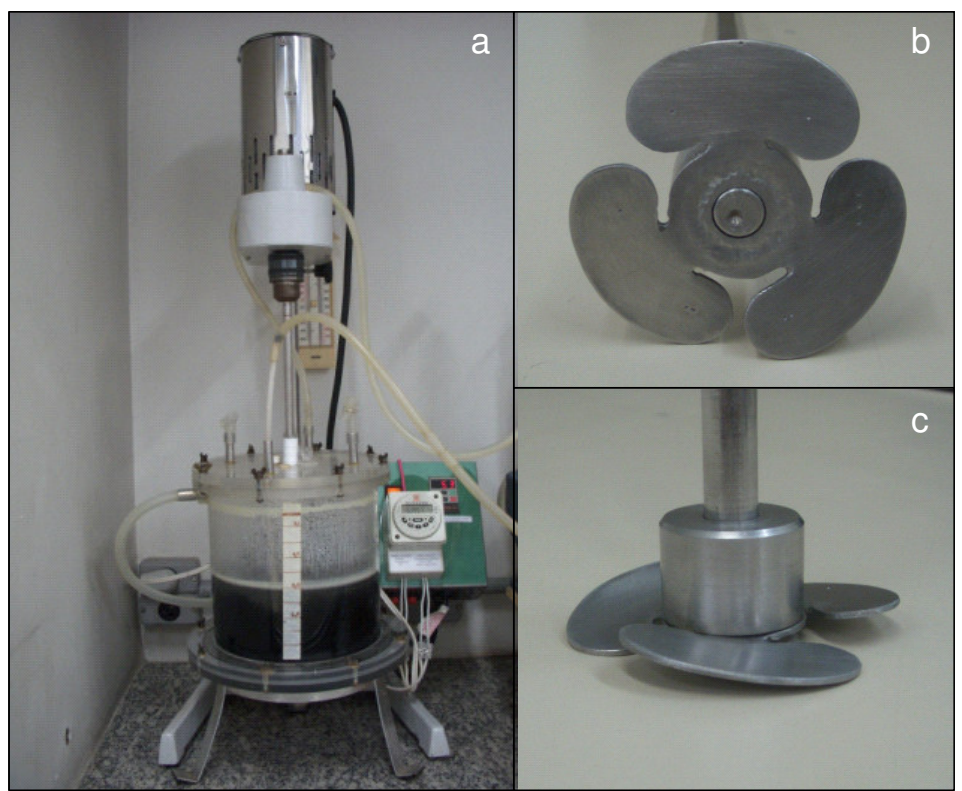

Figura 4.7 - Fotografias: (a) do reator e vistas (b) inferior e (c) lateral do impelidor

\subsection{INÓcULO}

O inóculo utilizado nos experimentos era proveniente de um reator anaeróbio de manta de lodo e escoamento ascendente (UASB) que tratava água residuária da empresa Avícola Dacar Ltda., localizada em Tietê, SP. Seus valores médios de concentração de sólidos totais e sólidos totais voláteis eram respectivamente 62 e $51 \mathrm{~g} / \mathrm{L}$. O uso desse inóculo, apresentado na Figura 4.8, permitiu que a partida do reator fosse acelerada tanto para o AnSBBR quanto para o AnSBR.

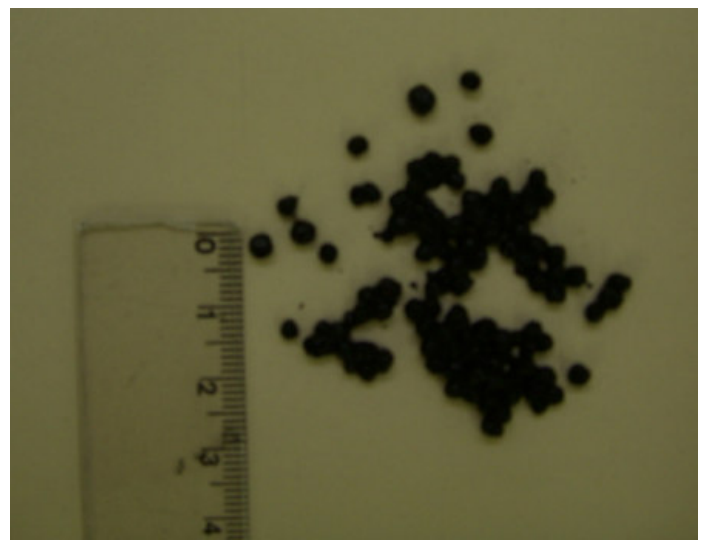

Figura 4.8 - Fotografia do inóculo 


\section{4 ÁGUA RESIDUÁRIA}

A água residuária era preparada a partir da diluição de xampu (produto comercial) e bicarbonato de sódio em água de torneira com auxílio de um agitador magnético com o propósito de simular o líquido de lavagem de reatores de uma unidade de produção de xampu de indústria de produtos de higiene pessoal.

Em uma das condições experimentais do AnSBR, a água residuária foi misturada a um meio sintético a base de sacarose, amido solúvel, celulose, extrato de carne, óleo de soja e sais, a fim de verificar se a substituição de uma fração do volume alimentado de água residuária, por uma água conhecidamente balanceada, poderia mexer com o metabolismo da biomassa, promovendo o aumento da eficiência do processo. Portanto, nesta condição especificamente, o afluente era composto parte por água residuária e parte por meio sintético.

\subsubsection{Xampu}

O nome e a marca do xampu, assim como o nome da empresa fabricante, foram preservados, e sua formulação, por se tratar de segredo industrial, era de conhecimento exclusivo da empresa. Como a variação de uma formulação para outra normalmente é limitada a componentes usados em pequenas quantidades, a base acaba sendo semelhante para xampus de mesma finalidade. A Tabela 4.1 apresenta a formulação de um produto de mesma especificação que o xampu usado no preparo da água residuária. Ressalta-se que a escolha do xampu foi feita em função do modelo de maior volume de produção que, de acordo com a empresa, era o da linha cabelos normais uso diário. 
Tabela 4.1 - Formulação de produto de mesma especificação que o xampu usado no preparo da água residuária

\begin{tabular}{cc}
\hline Componente & $\begin{array}{c}\text { Fração } \\
\text { mássica }\end{array}$ \\
\hline Surfactante & $6-16$ \\
Condicionante & $0,3-2$ \\
Perolizante/Opacificante & $2-6$ \\
Princípio ativo & $0,5-2$ \\
Regulador de pH q.s.p. & $\mathrm{pH}=6,5$ \\
Espessante & $0,3-8$ \\
Conservante & $0,1-0,5$ \\
Corante & $0,1-0,3$ \\
Fragrância & $0,3-0,5$ \\
Solubilizante & $0,5-2$ \\
Água q.s.p & 100 \\
\hline
\end{tabular}

Nota: q.s.p. = quantidade suficiente para. (RACINE, 1999)

Analisando os dados da Tabela 4.1, observa-se que de todos os componentes de natureza orgânica o surfactante é o que aparece em maior quantidade, desempenhando ação umectante, detergente e emulsificante. O surfactante do xampu usado neste trabalho era o lauril éter sulfato de sódio, segundo a composição que aparecia no rótulo da embalagem do produto.

\subsubsection{Bicarbonato de sódio}

O bicarbonato de sódio foi adquirido da empresa Comercial Química Americana Ltda., localizada em Paulínia, SP. Sua adição à água residuária serviu para tamponar o sistema ao longo das condições experimentais, evitando variações bruscas do $\mathrm{pH}$ no meio reacional. 


\subsubsection{Meio sintético}

O meio sintético era constituído de sacarose, amido solúvel e celulose (fontes de carboidrato), extrato de carne (fonte de proteína), óleo de soja (fonte de lipídio) e sais (fontes de metais-traço), além de bicarbonato de sódio para tamponamento e detergente comercial para emulsificação do óleo. As quantidades de cada componente foram determinadas de modo que $50 \%$ da DQO fossem de origem protéica, $40 \%$ de carboidratos e $10 \%$ de lipídios. Este meio foi elaborado por Torres (1992) e usado para simular esgoto sanitário.

No presente trabalho, o meio sintético foi empregado não apenas em uma das condições experimentais do AnSBR, como também nas condições preliminares dos reatores, sempre com a concentração de $500 \mathrm{mgDQO} / \mathrm{L}$. A Tabela 4.2 apresenta a quantidade necessária de cada componente para o preparo de um meio com essa concentração.

Tabela 4.2 - Composição do meio sintético

\begin{tabular}{lc}
\hline \multicolumn{1}{c}{ Composto } & Concentração \\
\hline Sacarose & $35 \mathrm{mg} / \mathrm{L}$ \\
Amido solúvel & $114 \mathrm{mg} / \mathrm{L}$ \\
Celulose & $34 \mathrm{mg} / \mathrm{L}$ \\
Extrato de carne & $208 \mathrm{mg} / \mathrm{L}$ \\
Óleo de soja & $51 \mathrm{mg} / \mathrm{L}$ \\
Detergente comercial & $3 \mathrm{gotas} / \mathrm{L}$ \\
Cloreto de sódio & $250 \mathrm{mg} / \mathrm{L}$ \\
Cloreto de magnésio hexa-hidratado & $7 \mathrm{mg} / \mathrm{L}$ \\
Cloreto de cálcio di-hidratado & $4,5 \mathrm{mg} / \mathrm{L}$ \\
Bicarbonato de sódio & $200 \mathrm{mg} / \mathrm{L}$ \\
\hline
\end{tabular}




\subsubsection{Composição da água residuária}

As composições da água residuária são apresentadas nas Tabelas 4.3 e 4.4 . A Tabela 4.3 apresenta as composições nas oito condições experimentais do AnSBBR, denominadas Condições 1 a 8.

\begin{tabular}{ccc}
\multicolumn{3}{c}{ Tabela 4.3 - Composição da água } \\
residuária nas Condições 1 a 8 \\
\hline Condição & $\begin{array}{c}\text { Xampu } \\
(\mathrm{g} / \mathrm{L})\end{array}$ & $\begin{array}{c}\mathrm{NaHCO}_{3} \\
(\mathrm{~g} / \mathrm{L})\end{array}$ \\
\hline 1 & 1,00 & 0,20 \\
2 & 2,85 & 0,20 \\
3 & 0,60 & 0,20 \\
4 & 1,70 & 0,20 \\
5 & 1,00 & 0,20 \\
6 & 2,85 & 0,20 \\
7 & 0,60 & 0,20 \\
8 & 1,70 & 0,20 \\
\hline
\end{tabular}

Já a Tabela 4.4 apresenta as composições da água residuária nas seis condições experimentais do AnSBR, denominadas Condições 9 a 14.

Tabela 4.4 - Composição da água residuária nas Condições 9 a 14

\begin{tabular}{cccc}
\hline Condição & $\begin{array}{c}\text { Xampu } \\
(\mathrm{g} / \mathrm{L})\end{array}$ & $\begin{array}{c}\mathrm{NaHCO}_{3} \\
(\mathrm{~g} / \mathrm{L})\end{array}$ & $\begin{array}{c}\text { Meio sintético } \\
(\mathrm{L} / \mathrm{L})\end{array}$ \\
\hline 9 & 1,00 & 0,20 & - \\
10 & 1,50 & 0,20 & - \\
11 & 3,00 & 0,20 & - \\
12 & 1,00 & 0,20 & - \\
13 & 1,00 & 0,20 & - \\
14 & 0,70 & 0,20 & 0,43 \\
\hline
\end{tabular}


Analisando os dados da Tabela 4.4, observa-se que houve adição de 0,43 $L$ de meio sintético por litro de água residuária na Condição 14, o que significa dizer que a mistura que compunha o afluente desta condição era formada por $0,30 \mathrm{~L}$ de meio sintético e 0,70 L de água residuária.

\subsection{ANÁLISES FÍSICO-QUÍMICAS}

As análises físico-químicas foram realizadas de acordo com o Standard Methods for the Examination of Water and Wastewater (1995), tanto no monitoramento do afluente e do efluente do AnSBBR e do AnSBR, quanto nos perfis obtidos ao longo de um ciclo de operação desses reatores. As variáveis de interesse foram: concentração de matéria orgânica $\left(C_{S}\right)$ de amostras filtradas e não filtradas, expressa em DQO; pH; concentração de ácidos voláteis totais (AVT); alcalinidade parcial $(A P)$, intermediária $(A I)$, total $(A T)$ e a bicarbonato $(A B)$; e, concentração de sólidos totais (ST), voláteis totais (SVT), em suspensão totais (SST) e em suspensão voláteis (SSV). Os números dos métodos analíticos dessas variáveis são apresentados na Tabela 4.5 . 
Tabela 4.5 - Métodos analíticos do Standard Methods for the Examination of Water and Wastewater (1995)

\begin{tabular}{|c|c|c|c|}
\hline Método & Tipo & Número & Modificação \\
\hline $\begin{array}{l}\text { Ácidos voláteis totais } \\
\text { (AVT) }\end{array}$ & titulométrico & $2310 \mathrm{~B}$ & $\begin{array}{l}\text { Dilallo e Albertson } \\
\text { (1961) }\end{array}$ \\
\hline $\begin{array}{l}\text { Alcalinidade parcial, } \\
\text { intermediária, total e a } \\
\text { bicarbonato } \\
\text { (AP, AI, AT e AB) }\end{array}$ & titulométrico & $2320 \mathrm{~B}$ & $\begin{array}{l}\text { Ripley, Boyle e } \\
\text { Converse } \\
\text { (1986) }\end{array}$ \\
\hline $\begin{array}{l}\text { Sólidos totais e } \\
\text { em suspensão, fixos e } \\
\text { voláteis } \\
\text { (ST, SVT, SST, SSV) }\end{array}$ & gravimétrico & $\begin{array}{l}2540 \mathrm{~B} \\
2540 \mathrm{D} \\
2540 \mathrm{E}\end{array}$ & \\
\hline $\begin{array}{l}\text { Potencial hidrogeniônico } \\
(\mathrm{pH})\end{array}$ & potenciométrico & $4500-\mathrm{H}+\mathrm{B}$ & \\
\hline $\begin{array}{l}\text { Demanda química de } \\
\text { oxigênio } \\
\text { (Cs) }\end{array}$ & espectrofotométrico & $5220 \mathrm{D}$ & \\
\hline
\end{tabular}

\subsection{DETERMINAÇÃo dA CONCENTRAÇÃO dOS ÁCIDOS VOLÁTEIS INTERMEDIÁRIOS}

Os ácidos voláteis intermediários foram analisados por cromatografia em fase gasosa, segundo metodologia proposta por Moraes et al. (2000), utilizando-se o cromatógrafo HP® 6890 Series, equipado com detector de ionização de chama e coluna capilar HP® Innowax $30 \mathrm{~m} \times 0,25 \mathrm{~mm} \times 0,25 \mu \mathrm{m}$. O gás de arraste era hidrogênio, com vazão de $2,0 \mathrm{~mL} / \mathrm{min}$. A temperatura do injetor era $250^{\circ} \mathrm{C}$, e o volume de injeção, 1,0 $\mu \mathrm{L}$. A razão de split era 20:1. Os gases de queima eram hidrogênio e ar sintético, com vazões de 30 e $300 \mathrm{~mL} / \mathrm{min}$, respectivamente. O gás de make-up era nitrogênio, com vazão de $33 \mathrm{~mL} / \mathrm{min}$. A temperatura do detector era $300^{\circ} \mathrm{C}$. Já a temperatura do forno chegava a $200^{\circ} \mathrm{C}$, mas não era mantida neste valor. A temperatura de partida era $100^{\circ} \mathrm{C}$, na qual permanecia durante três minutos. Depois subia a $180^{\circ} \mathrm{C}$, através de uma rampa de aquecimento de $5^{\circ} \mathrm{C} / \mathrm{min}$, na qual 
permanecia por mais 5 minutos. Por fim, no post-run, a temperatura do forno mantinha-se a $200^{\circ} \mathrm{C}$ por 5 minutos, retornando a $100^{\circ} \mathrm{C}$ logo em seguida.

\subsection{DETERMINAÇÃO DA COMPOSIÇÃO E DA PRODUÇÃO DE BIOGÁS}

As concentrações de metano e gás carbônico do biogás foram determinadas por cromatografia em fase gasosa, utilizando-se o cromatógrafo HP® 6890 Series, equipado com detector de condutividade térmica e coluna Porapack Q, 80/100 Mesh, $6 \mathrm{ft}$ x 0,125". O gás de arraste era hidrogênio, com vazão de 50,0 mL/min. A temperatura do injetor era $150^{\circ} \mathrm{C}$, e o volume de injeção, 1,0 mL. As temperaturas do forno, do detector e da válvula de amostragem quando utilizada eram respectivamente 50, 200 e $100^{\circ} \mathrm{C}$. O gás de make-up era nitrogênio, com vazão de $2,5 \mathrm{~mL} / \mathrm{min}$. Por outro lado, a produção de metano foi determinada por gasometria, medindo-se o deslocamento de uma solução de hidróxido de sódio 50 g/L através de um tubo graduado de vidro. O papel da soda cáustica foi reter todo o gás carbônico do biogás como garantia de que a variação de volume observada ocorreu em virtude da liberação de metano apenas.

\subsection{DETERMINAÇÃo DA CONCENTRAÇÃo DE BIOMASSA}

O procedimento usado na determinação das concentrações de biomassa de cada um dos reatores não foi o mesmo, visto que no AnSBBR a biomassa encontrava-se imobilizada em espuma de poliuretano, e no AnSBR, apresentava-se na forma granular autoimobilizada. Assim, no AnSBBR, depois que as condições experimentais foram concluídas, e o reator, desmontado, mediu-se a massa total de espuma com biomassa imobilizada $\left(\mathrm{M}_{\mathrm{e}}\right)$ contida em seu interior. Desse total, retirou- 
se uma amostra de cinco cubos, cuja massa $\left(m_{e i}\right)$ também foi medida. Em seguida, com auxílio de uma pinça metálica, realizou-se a lavagem desses cubos com água destilada, separando-se a biomassa da espuma e coletando-se a água de lavagem em cápsula de porcelana de $50 \mathrm{~mL}$. Desse ponto em diante, a determinação das massas de sólidos totais $\left(m_{S T}\right)$ e sólidos voláteis totais $\left(m_{S V T}\right)$ da amostra seguiu metodologia do Standard Methods for the Examination of Water and Wastewater (1995). As massas de sólidos totais $\left(M_{S T}\right)$ e sólidos voláteis totais ( $\left.M_{S V T}\right)$ de toda a espuma com biomassa imobilizada foram determinadas por meio das Equações 4.1 e 4.2, considerando a hipótese de que os valores das relações $m_{S T} / m_{e i}$ e $m_{S V T} / m_{e i}$ mantiveram-se aproximadamente constantes por toda extensão do reator.

$$
\begin{aligned}
& M_{S T}=\frac{m_{S T}}{m_{e i}} \cdot M_{e i} \\
& M_{S V T}=\frac{m_{S V T}}{m_{e i}} \cdot M_{e i}
\end{aligned}
$$

As concentrações de sólidos totais (ST) e sólidos voláteis totais (SVT) do sistema, por sua vez, foram determinadas dividindo-se os valores de $M_{S T}$ e $M_{S V T}$ pelo volume total de meio líquido $\left(\mathrm{V}_{U}\right)$, de acordo com as Equações 4.3 e 4.4. Os dados de $\mathrm{M}_{S \mathrm{~T}}$ e SVT foram usados para expressar a quantidade de biomassa do sistema.

$$
\begin{gathered}
S T=\frac{M_{S T}}{V_{U}} \\
S V T=\frac{M_{S V T}}{V_{U}}
\end{gathered}
$$


As relações entre as massas de sólidos totais e sólidos voláteis totais e a massa de espuma limpa também constituem importantes dados de processo, pois informam a quantidade de sólidos retidos por grama de espuma no interior do reator. Seus valores foram estimados por meio das Equações 4.5 e 4.6, dividindo-se $\mathrm{m}_{\mathrm{ST}}$ e $\mathrm{m}_{\mathrm{SVT}}$ pela massa dos cinco cubos de espuma de poliuretano $\left(m_{\mathrm{el}}\right)$ da amostra, depois de limpos e desumidificados em estufa a $105^{\circ} \mathrm{C}$ por $24 \mathrm{~h}$.

$$
\begin{gathered}
\mathrm{m}_{\mathrm{ST}} / \mathrm{m}_{\mathrm{el}}=\frac{\mathrm{m}_{\mathrm{ST}}}{\mathrm{m}_{\mathrm{el}}} \\
\mathrm{m}_{\mathrm{SVT}} / \mathrm{m}_{\mathrm{el}}=\frac{\mathrm{m}_{\mathrm{SVT}}}{\mathrm{m}_{\mathrm{el}}}
\end{gathered}
$$

A determinação da concentração de biomassa do AnSBR também foi realizada após o período de operação. Assim que o reator foi desmontado, mediu-se o volume total de lodo anaeróbio $\left(\mathrm{V}_{\text {lodo }}\right)$ contido em seu interior, do qual foi retirado um volume amostral ( $v_{\text {lodo }}$ ) de $10 \mathrm{~mL}$. Com auxílio de uma pisseta, o lodo foi transferido do béquer para uma cápsula de porcelana de $50 \mathrm{~mL}$, visando a determinação da massa de sólidos totais $\left(\mathrm{m}_{\mathrm{ST}}\right)$ e sólidos totais voláteis $\left(\mathrm{m}_{\mathrm{SVT}}\right)$ da amostra, de acordo com o Standard Methods for the Examination of Water and Wastewater (1995). As massas de sólidos totais $\left(\mathrm{M}_{\mathrm{ST}}\right)$ e sólidos totais voláteis $\left(\mathrm{M}_{\mathrm{SVT}}\right)$ de todo o lodo anaeróbio foram obtidas em seguida, extrapolando-se os valores das relações $\mathrm{m}_{\mathrm{ST}} / \mathrm{V}_{\text {lodo }}$ e $\mathrm{m}_{\mathrm{SVT}} / \mathrm{V}_{\text {lodo }}$ para toda extensão do reator, como sugerem as Equações 4.7 e 4.8 .

$$
M_{S T}=\frac{m_{S T}}{v_{\text {lodo }}} \cdot V_{\text {lodo }}
$$




$$
\mathrm{M}_{\mathrm{SVT}}=\frac{\mathrm{m}_{\mathrm{SVT}}}{\mathrm{v}_{\text {lodo }}} \cdot \mathrm{V}_{\text {lodo }}
$$

Finalmente, dividindo-se $M_{S T}$ e $M_{S V t}$ pelo volume total de meio líquido $\left(\mathrm{V}_{\mathrm{U}}\right)$, foram obtidas as concentrações de sólidos totais (ST) e sólidos totais voláteis (SVT), de acordo com as Equações 4.3 e 4.4 já apresentadas. Vale lembrar que os dados de MSVT e SVT foram usados para expressar a quantidade de biomassa do sistema.

\subsection{EXAMES MICROBIOLÓGICOS}

Os exames microbiológicos do inóculo e da biomassa do AnSBBR e do AnSBR foram realizados por microscopia ótica de contraste de fase e fluorescência, de acordo com método proposto por Varesche et al. (1997), utilizando-se o microscópio Olympus $\AA$, modelo BX-41, equipado com sistema de câmara digital Optronics e aquisição de imagens através do software Image Pro-Plus®, versão 4.5.0.

\subsection{FUndAMENTOS TEÓRICOS}

As definições de eficiência de remoção de matéria orgânica, cargas orgânicas volumétricas e específicas, frações molares de metano e gás carbônico, volume específico de metano, volume total do sistema, volume de espuma com biomassa imobilizada e velocidade superficial ascensional do meio líquido, usadas neste trabalho, são apresentadas a seguir. 


\subsubsection{Eficiência de remoção de matéria orgânica}

A eficiência de remoção de matéria orgânica $(\varepsilon)$ foi definida pela relação entre a quantidade de matéria orgânica removida do sistema e a quantidade aplicada, como mostra a Equação 4.9. Nesta equação, $\mathrm{C}_{\mathrm{A}}$ é a concentração de matéria orgânica do afluente, e $\mathrm{C}_{\mathrm{E}}$, a do efluente.

$$
\varepsilon=\frac{C_{A}-C_{E}}{C_{A}}
$$

A concentração de matéria orgânica do efluente foi monitorada em amostras filtradas $\left(\mathrm{C}_{\mathrm{EF}}\right)$ e não filtradas $\left(\mathrm{C}_{\mathrm{ET}}\right)$ ao longo das condições preliminares e experimentais dos dois reatores, gerando valores de eficiência de remoção de matéria orgânica para as mesmas amostras filtradas $\left(\varepsilon_{\mathrm{F}}\right)$ e não filtradas $\left(\varepsilon_{\mathrm{T}}\right)$.

\subsubsection{Carga orgânica volumétrica aplicada}

A carga orgânica volumétrica aplicada (COVA) foi definida como sendo a quantidade de matéria orgânica aplicada ao sistema por unidade de tempo e por unidade de volume, de acordo com a Equação 4.10. Nesta equação, $C_{A}$ é a concentração de matéria orgânica do afluente, $\mathrm{V}_{\mathrm{A}}, \mathrm{O}$ volume total de afluente alimentado, $\mathrm{V}_{\mathrm{U}}, \mathrm{O}$ volume de meio líquido do sistema, e tc, o tempo de ciclo.

$$
\operatorname{cov} A=\frac{C_{A} \cdot V_{A}}{V_{U} \cdot t_{C}}
$$




\subsubsection{Carga orgânica volumétrica removida}

A carga orgânica volumétrica removida (COVR) foi definida como sendo a quantidade de matéria orgânica removida do sistema por unidade de tempo e por unidade de volume, de acordo com a Equação 4.11. Nesta equação, $C_{A}$ é a concentração de matéria orgânica do afluente, $C_{E}$, a concentração de matéria orgânica do efluente, $\mathrm{V}_{\mathrm{A}}$, o volume total de afluente alimentado, $\mathrm{V}_{\mathrm{U}}$, o volume de meio líquido do sistema, e $t_{c}$, o tempo de ciclo.

$$
\operatorname{covR}=\frac{\left(C_{A}-C_{E}\right) \cdot V_{A}}{V_{U} \cdot t_{C}}
$$

Como a concentração de matéria orgânica do efluente foi monitorada em amostras filtradas $\left(C_{E F}\right)$ e não filtradas $\left(C_{E T}\right)$ ao longo das condições experimentais dos dois reatores, também foi possível obter valores de carga orgânica volumétrica removida para as mesmas amostras filtradas $\left(\mathrm{COVR}_{\mathrm{F}}\right)$ e não filtradas $\left(\mathrm{COVR} \mathrm{R}_{\mathrm{T}}\right)$.

\subsubsection{Carga orgânica específica aplicada}

A carga orgânica específica aplicada (COEA) foi definida como sendo a quantidade de matéria orgânica aplicada ao sistema por unidade de tempo e por unidade de massa de microrganismos, de acordo com a Equação 4.12. Nesta equação, $\mathrm{C}_{\mathrm{A}}$ é a concentração de matéria orgânica do afluente, $V_{A}$, o volume total de afluente alimentado, e $t_{C}$, o tempo de ciclo, enquanto $M_{S V T}$ corresponde a massa de microrganismos, expressa como massa de sólidos voláteis totais. 


$$
\operatorname{COEA}=\frac{\mathrm{C}_{\mathrm{A}} \cdot \mathrm{V}_{\mathrm{A}}}{\mathrm{M}_{\mathrm{SVT}} \cdot \mathrm{t}_{\mathrm{C}}}
$$

\subsubsection{Carga orgânica específica removida}

A carga orgânica específica removida (COER) foi definida como sendo a quantidade de matéria orgânica removida do sistema por unidade de tempo e por unidade de massa de microrganismos, de acordo com a Equação 4.13. Nesta equação, $\mathrm{C}_{\mathrm{A}}$ é a concentração de matéria orgânica do afluente, $\mathrm{C}_{\mathrm{E}}$, a concentração de matéria orgânica do efluente, $\mathrm{V}_{\mathrm{A}}$, o volume total de afluente alimentado, $\mathrm{t}_{\mathrm{C}}$, o tempo de ciclo, enquanto $M_{S V T}$ corresponde a massa de microrganismos, expressa como massa de sólidos voláteis totais.

$$
\operatorname{COER}=\frac{\left(\mathrm{C}_{\mathrm{A}}-\mathrm{C}_{\mathrm{E}}\right) \cdot \mathrm{V}_{\mathrm{A}}}{\mathrm{M}_{\mathrm{SVT}} \cdot \mathrm{t}_{\mathrm{C}}}
$$

Como a concentração de matéria orgânica do efluente foi monitorada em amostras filtradas $\left(C_{E F}\right)$ e não filtradas $\left(C_{E T}\right)$ ao longo das condições experimentais dos dois reatores, também foi possível obter valores de carga orgânica específica removida para as mesmas amostras filtradas $\left(\mathrm{COER} \mathrm{R}_{\mathrm{F}}\right)$ e não filtradas $\left(\mathrm{COER} \mathrm{R}_{\mathrm{T}}\right)$.

\subsubsection{Frações molares de metano e gás carbônico}

As frações molares de metano $\left(\mathrm{Y}_{\mathrm{CH} 4}\right)$ e gás carbônico $\left(\mathrm{Y}_{\mathrm{CO} 2}\right)$ foram definidas como sendo as porcentagens de cada um destes compostos no biogás gerado no sistema, de acordo com as Equações 4.14 e 4.15. Nestas equações, $\mathrm{C}_{\mathrm{CH} 4}$ e $\mathrm{C}_{\mathrm{CO} 2}$ são as concentrações de metano e gás carbônico, respectivamente. 


$$
\begin{aligned}
& Y_{\mathrm{CH} 4}=\frac{\mathrm{C}_{\mathrm{CH} 4}}{\mathrm{C}_{\mathrm{CH} 4}+\mathrm{C}_{\mathrm{CO} 2}} \\
& Y_{\mathrm{CO} 2}=\frac{\mathrm{C}_{\mathrm{CO} 2}}{\mathrm{C}_{\mathrm{CH} 4}+\mathrm{C}_{\mathrm{CO} 2}}
\end{aligned}
$$

As frações molares de metano $\left(\mathrm{Y}_{\mathrm{CH} 4, \mathrm{i}}\right)$ e gás carbônico $\left(\mathrm{Y}_{\mathrm{CO} 2, \mathrm{i}}\right)$ determinadas ao longo de um ciclo de operação dos reatores foram definidas nas Equações 4.16 e 4.17, em que $\mathrm{C}_{\mathrm{CH} 4, \mathrm{i}}$ e $\mathrm{C}_{\mathrm{CO} 2, \mathrm{i}}$ são respectivamente as concentrações de metano e gás carbônico obtidas no instante $t_{i}$ do ciclo operacional.

$$
\begin{aligned}
& Y_{\mathrm{CH} 4, \mathrm{i}}=\frac{\mathrm{C}_{\mathrm{CH} 4, \mathrm{i}}}{\mathrm{C}_{\mathrm{CH} 4, \mathrm{i}}+\mathrm{C}_{\mathrm{CO} 2, \mathrm{i}}} \\
& Y_{\mathrm{CO} 2, \mathrm{i}}=\frac{\mathrm{C}_{\mathrm{CO} 2, \mathrm{i}}}{\mathrm{C}_{\mathrm{CH} 4, \mathrm{i}}+\mathrm{C}_{\mathrm{CO} 2, \mathrm{i}}}
\end{aligned}
$$

As definições apresentadas valem-se da hipótese de que as porcentagens de outros gases que compõem o biogás são desprezíveis em comparação com as porcentagens de metano e gás carbônico.

\subsubsection{Volume específico de metano}

O volume específico de metano $\left(V_{\mathrm{CH} 4}\right)$ foi definido como sendo o volume de metano gerado no sistema por unidade de massa de matéria orgânica removida, de acordo com a Equação 4.18. Nesta equação, $\mathrm{V}_{\mathrm{CH} 4}$ é o volume total de metano produzido em um ciclo operacional, enquanto que $\mathrm{C}_{\text {So }}$ é a concentração de matéria orgânica de 
amostra filtrada do meio reacional no início deste ciclo, e $\mathrm{C}_{\mathrm{Sf}}$, a concentração obtida no final do mesmo ciclo.

$$
V_{\mathrm{CH} 4}=\frac{\mathrm{V}_{\mathrm{CH} 4}}{\left(\mathrm{C}_{\mathrm{So}}-\mathrm{C}_{\mathrm{Sf}}\right)}
$$

O volume específico de metano $\left(V_{\mathrm{CH} 4, \mathrm{i}}\right)$ determinado ao longo de um ciclo de operação dos reatores foi definido na Equação 4.19, em que $V_{C H 4, i}$ e $C_{S, i}$ são respectivamente o volume de metano produzido e a concentração de matéria orgânica de amostras filtradas do meio reacional, obtidos no instante $t_{i}$ do ciclo.

$$
V_{\mathrm{CH} 4, \mathrm{i}}=\frac{\mathrm{V}_{\mathrm{CH} 4, \mathrm{i}}}{\left(\mathrm{C}_{\mathrm{So}}-\mathrm{C}_{\mathrm{S}, \mathrm{i}}\right)}
$$

\subsubsection{Volume operacional do sistema}

O volume operacional do sistema $\left(\mathrm{V}_{\mathrm{O}}\right)$ foi definido como sendo o volume de meio reacional contido em seu interior. No caso do AnSBBR, $V_{O}$ corresponde à soma dos volumes totais de espuma com biomassa imobilizada $\left(V_{\text {ei }}\right)$ e meio líquido $\left(V_{U}\right)$, enquanto no AnSBR, corresponde à soma dos volumes totais de lodo $\left(\mathrm{V}_{\text {lodo }}\right)$ e meio líquido $\left(\mathrm{V}_{\mathrm{U}}\right)$, como mostram as Equações 4.20 e 4.21, respectivamente.

$$
\begin{gathered}
V_{\mathrm{O}}=\mathrm{V}_{\text {ei }}+\mathrm{V}_{\mathrm{U}} \\
\mathrm{V}_{\mathrm{O}}=\mathrm{V}_{\text {lodo }}+\mathrm{V}_{\mathrm{U}}
\end{gathered}
$$

Também é possível obter $\mathrm{V}_{\mathrm{O}}$ a partir dos volumes operacionais dos reatores $\left(\mathrm{V}_{\mathrm{O}, \mathrm{RT}}\right)$ e do reservatório $\left(\mathrm{V}_{\mathrm{O}, \mathrm{RS}}\right)$. No caso do AnSBBR, $\mathrm{V}_{\mathrm{O}}$ corresponde à soma de $\mathrm{V}_{\mathrm{O}, \mathrm{RT}} \mathrm{e}$ 
$\mathrm{V}_{\mathrm{O}, \mathrm{RS}}$, enquanto no AnSBR, $\mathrm{V}_{\mathrm{O}}$ é o próprio $\mathrm{V}_{\mathrm{O}, \mathrm{RT}}$, como mostram as Equações 4.22 e 4.23, respectivamente.

$$
\begin{gathered}
\mathrm{V}_{\mathrm{O}}=\mathrm{V}_{\mathrm{O}, \mathrm{RT}}+\mathrm{V}_{\mathrm{O}, \mathrm{RS}} \\
\mathrm{V}_{\mathrm{O}}=\mathrm{V}_{\mathrm{O}, \mathrm{RT}}
\end{gathered}
$$

No caso do AnSBBR, $\mathrm{V}_{\mathrm{O}, \mathrm{RT}}$ corresponde à soma dos volumes totais de espuma com biomassa imobilizada $\left(\mathrm{V}_{\mathrm{ei}}\right)$ e meio líquido do reator $\left(\mathrm{V}_{\mathrm{U}, \mathrm{RT}}\right)$, como mostra a Equação 4.24. Por outro lado, $\mathrm{V}_{\mathrm{O}, \mathrm{RS}}$ corresponde ao volume de meio líquido do reservatório $\left(\mathrm{V}_{\mathrm{U}, \mathrm{RS}}\right)$, de acordo com a Equação 4.25, visto que toda biomassa permanecia confinada no interior do reator apenas.

$$
\begin{gathered}
\mathrm{V}_{\mathrm{O}, \mathrm{RT}}=\mathrm{V}_{\mathrm{ei}}+\mathrm{V}_{\mathrm{U}, \mathrm{RT}} \\
\mathrm{V}_{\mathrm{O}, \mathrm{RS}}=\mathrm{V}_{\mathrm{U}, \mathrm{RS}}
\end{gathered}
$$

Já no caso do AnSBR, $\mathrm{V}_{\mathrm{O}, \mathrm{RT}}$ corresponde à soma dos volumes totais de lodo ( $\left.\mathrm{V}_{\text {lodo }}\right)$ e meio líquido do reator $\left(\mathrm{V}_{U, R T}\right)$, como mostra a Equação 4.26. Sendo $\mathrm{V}_{U}$ igual a $\mathrm{V}_{\mathrm{U}, \mathrm{RT}}$, então $\mathrm{V}_{\mathrm{O}}$ corresponde a $\mathrm{V}_{\mathrm{O}, \mathrm{RT}}$.

$$
\mathrm{V}_{\mathrm{O}, \mathrm{RT}}=\mathrm{V}_{\text {lodo }}+\mathrm{V}_{\mathrm{U}, \mathrm{RT}}
$$

\subsubsection{Volume total do sistema}

$\mathrm{O}$ volume total do sistema $\left(\mathrm{V}_{\mathrm{T}}\right)$ foi definido como sendo o volume máximo de meio reacional que o sistema é capaz de comportar. No caso do AnSBBR, $V_{T}$ 
corresponde à soma dos volume totais do reator $\left(\mathrm{V}_{\mathrm{T}, \mathrm{RT}}\right)$ e do reservatório $\left(\mathrm{V}_{\mathrm{T}, \mathrm{RS}}\right)$, enquanto no AnSBR, corresponde a $\mathrm{V}_{\mathrm{T}, \mathrm{RT}}$ apenas, como mostram as Equações 4.27 e 4.28, respectivamente.

$$
\begin{gathered}
\mathrm{V}_{\mathrm{T}}=\mathrm{V}_{\mathrm{T}, \mathrm{RT}}+\mathrm{V}_{\mathrm{T}, \mathrm{RS}} \\
\mathrm{V}_{\mathrm{T}}=\mathrm{V}_{\mathrm{T}, \mathrm{RT}}
\end{gathered}
$$

Os volumes totais dos reatores $\left(\mathrm{V}_{\mathrm{T}, \mathrm{RT}}\right)$ e do reservatório $\left(\mathrm{V}_{\mathrm{T}, \mathrm{RS}}\right)$ foram definidos nas Equações 4.29 e 4.30 , em que $A_{R T}$ e $H_{R T}$ são respectivamente a área da secção transversal e a altura dos reatores, e $A_{R S}$ e $H_{R S}$, a área da secção transversal e a altura do reservatório. Por sua vez, $H_{R T}$ e $H_{R S}$ são definidas como sendo as distâncias entre o fundo deste recipientes e os bocais de entrada ou saída de meio líquido dos mesmos. Vale lembrar que as Equações 4.29 e 4.30 consideram a hipótese de cilindros perfeitos.

$$
\begin{aligned}
& V_{T, R T}=A_{R T} \cdot H_{R T} \\
& V_{T, R S}=A_{R S} \cdot H_{R S}
\end{aligned}
$$

As áreas das secções transversais dos reatores e do reservatório podem ser calculadas por meio das Equações 4.31 e 4.32, em que $D_{R T}$ e e $e_{R T}$ são respectivamente o diâmetro externo e a espessura de parede dos reatores, e $D_{R S}$ e e $\mathrm{RS}$, o diâmetro externo e a espessura de parede do reservatório. 


$$
\begin{aligned}
& A_{R T}=\frac{\pi \cdot\left(D_{R T}-2 \cdot e_{R T}\right)^{2}}{4} \\
& A_{R S}=\frac{\pi \cdot\left(D_{R S}-2 \cdot e_{R S}\right)^{2}}{4}
\end{aligned}
$$

\subsubsection{Volume de espuma com biomassa imobilizada}

O volume total de espuma com biomassa imobilizada $\left(\mathrm{V}_{\mathrm{ei}}\right)$ aplica-se apenas ao AnSBBR e pode ser obtido a partir da diferença entre o volume total $\left(\mathrm{V}_{\mathrm{T}, \mathrm{RT}}\right)$ e o volume de meio líquido $\left(\mathrm{V}_{U, R T}\right)$ do reator, como mostra a Equação 4.33.

$$
\mathrm{V}_{\mathrm{ei}}=\mathrm{V}_{\mathrm{T}, \mathrm{RT}}-\mathrm{V}_{\mathrm{U}, \mathrm{RT}}
$$

Esta definição só é válida porque o reator operou com volume máximo de meio reacional, em virtude do fluxo ascensional da fase líquida, o que equivale dizer que $\mathrm{V}_{\mathrm{O}, \mathrm{RT}}$ é igual a $\mathrm{V}_{\mathrm{T}, \mathrm{RT}}$.

\subsubsection{Velocidade superficial ascensional do meio líquido}

A definição de velocidade superficial ascensional $\left(v_{S}\right)$ é aplicada apenas ao AnSBBR e corresponde ao deslocamento médio de uma partícula do meio líquido na direção vertical e sentido ascendente dentro do reator por unidade de tempo, como mostra a Equação 4.34. Nesta equação, $Q$ é a vazão de recirculação, $\varphi$, a porosidade do leito, e $A_{R T}$, a área interna da seção transversal do reator. 


$$
v_{S}=\frac{Q}{\varphi \cdot A_{R T}}
$$

\subsubsection{Tempo de detenção hidráulica}

O tempo de detenção hidráulica (TDH) é definido por meio da Equação 4.35, em que $\mathrm{V}_{\mathrm{A}}$ é o volume total de afluente alimentado, $\mathrm{V}_{\mathrm{U}}$, o volume de meio líquido do sistema, e tc, o tempo de ciclo. Essa definição foi usada apenas no item 3.

$$
\mathrm{TDH}=\frac{\mathrm{t}_{\mathrm{C}} \cdot \mathrm{V}_{\mathrm{U}}}{\mathrm{V}_{\mathrm{A}}}
$$

\subsection{Procedimento experimental}

As metodologias empregadas no preparo da água residuária e do meio sintético, nos testes de biodegradabilidade e na operação do AnSBBR e do AnSBR são apresentadas a seguir.

\subsubsection{Preparo da água residuária e do meio sintético}

O preparo da água residuária iniciava com a pesagem de xampu e bicarbonato de sódio em balança semianalítica, usando béquer de polipropileno de $500 \mathrm{~mL}$ e levando em conta os valores de concentração apresentados nas Tabelas 4.3 e 4.4 e o volume de solução a ser preparado. A dissolução de tais compostos era feita com água de torneira e agitação magnética. Com auxílio de uma pisseta, a suspensão formada era transferida do béquer para um recipiente de vidro de $12 \mathrm{~L}$, onde 0 
volume de solução era completado com água de torneira. Por fim, tampava-se o recipiente e homogeneizava-se a solução manualmente.

O meio sintético era preparado da mesma maneira que a água residuária. Primeiramente, pesava-se sacarose, amido solúvel, celulose, extrato de carne, óleo de soja, detergente comercial, sais e bicarbonato de sódio em balança analítica, em béquer de polipropileno de $150 \mathrm{~mL}$, de acordo com os valores de concentração apresentados na Tabela 4.2 e o volume de solução a ser preparado. Os sais eram adicionados na forma de solução, previamente preparada com $60 \mathrm{~g} / \mathrm{L}$ de cloreto de sódio, 1,63 g/L de cloreto de magnésio hexa-hidratado e 1,08 g/L de cloreto de cálcio di-hidratado, e armazenada em recipiente de vidro de 1,0 L, em local refrigerado - em torno de $10^{\circ} \mathrm{C}$. Em seguida, realizava-se a dissolução de tais compostos em água de torneira com auxílio de agitador magnético. A suspensão formada era transferida do béquer para um recipiente de vidro de $12 \mathrm{~L}$, preenchido com água de torneira até atingir o volume de solução. Finalmente, o recipiente era tampado e homogeneizado manualmente. Vale lembrar que o uso isolado de meio sintético só foi feito nas condições preliminares do AnSBBR e do AnSBR.

$\mathrm{Na}$ condição experimental do AnSBR, em que o afluente era formado por $0,70 \mathrm{~L}$ de água residuária e $0,30 \mathrm{~L}$ de meio sintético, seu preparo seguiu a mesma sequência de etapas apresentada, com a diferença que além de xampu e bicarbonato de sódio, foram incluídos na pesagem sacarose, amido solúvel, celulose, extrato de carne, óleo de soja, detergente comercial e sais, conforme os valores de concentração apresentados na Tabela 4.4 e o volume de solução a ser preparado. 


\subsubsection{Ensaios de biodegradabilidade}

Os ensaios de biodegradabilidade foram realizados com o intuito de predizer o comportamento da biomassa no tratamento da água residuária, possibilitando a determinação dos valores das cargas orgânicas posteriormente aplicadas nas condições experimentais do AnSBBR e do AnSBR. Estes ensaios foram feitos em agitador orbital (NBS® Innova 4330), em ciclos de 24 h, a $30^{\circ} \mathrm{C}$ e $150 \mathrm{rpm}$, utilizando-se erlenmeyer de vidro de $250 \mathrm{~mL}$ contendo $50 \mathrm{~mL}$ de lodo anaeróbio e $200 \mathrm{~mL}$ de meio líquido. O volume renovado de um ciclo para outro era de $150 \mathrm{~mL}$, sendo que os $50 \mathrm{~mL}$ restantes provinham do ciclo anterior. Além disso, as operações de carga e descarga eram feitas manualmente. As composições da água residuária usada nas quatro condições experimentais dos ensaios de biodegradabilidade, denominadas Condições S1 a S4, são apresentadas na Tabela 4.6.

\begin{tabular}{ccc}
\multicolumn{3}{l}{$\begin{array}{l}\text { Tabela } \\
\text { residuária nas }\end{array}$} \\
\hline Condição & $\begin{array}{c}\text { Xampu } \\
(\mathrm{g} / \mathrm{L})\end{array}$ & $\begin{array}{c}\mathrm{NaHCO}_{3} \\
(\mathrm{~g} / \mathrm{L})\end{array}$ \\
\hline $\mathrm{S} 1$ & 2,00 & 1,00 \\
$\mathrm{~S} 2$ & 4,00 & 1,00 \\
$\mathrm{~S} 3$ & 5,00 & 1,00 \\
$\mathrm{~S} 4$ & 6,00 & 1,00 \\
\hline
\end{tabular}

As Condições S1 a S4 apresentaram valores de $C_{A}$ entre 1000 e 3000 mgDQO/L, como mostra a Tabela 4.7; com isso, seus valores de COVA ficaram entre 0,75 e 2,25 gDQO/L.d. Ademais, estas condições foram precedidas por uma outra condição, dita preliminar, referente à adaptação da biomassa à operacionalidade do agitador orbital e cujo afluente era constituído de meio sintético com 500 mgDQO/L. 
Tabela 4.7 - Resumo das Condições S1 a S4

\begin{tabular}{ccc}
\hline Condição & $\begin{array}{c}\mathrm{C}_{\mathrm{A}} \\
(\mathrm{mgDQ} / \mathrm{L})\end{array}$ & $\begin{array}{c}\text { COVA } \\
\text { (gDQO/L.d })\end{array}$ \\
\hline S1 & 1000 & 0,75 \\
S2 & 2000 & 1,50 \\
S3 & 2500 & 1,87 \\
S4 & 3000 & 2,25 \\
\hline
\end{tabular}

A avaliação dos ensaios de biodegradabilidade foi feita com base nos resultados do monitoramento de amostras do afluente e do efluente, de acordo com o Standard Methods for the Examination of Water and Wastewater (1995), medindo-se: concentração de matéria orgânica $\left(\mathrm{C}_{\mathrm{S}}\right)$ de amostras filtradas e não filtradas, expressa em DQO; pH; concentração de ácidos voláteis totais (AVT); e, alcalinidade parcial (AP), intermediária (Al), total (AT), e a bicarbonato (AB).

\subsubsection{Operação do AnSBBR}

O AnSBBR foi operado na condição preliminar, que serviu como período de adaptação da biomassa à operacionalidade do sistema, e em oito condições experimentais.

\subsubsection{IMOBILIZAÇÃO DA BIOMASSA ANAERÓBIA}

O lodo anaeróbio do AnSBBR foi imobilizado em partículas cúbicas de espuma de poliuretano de $1 \mathrm{~cm}$ de aresta, conforme metodologia proposta por Zaiat, Cabral e Foresti (1994). Primeiramente, o inóculo foi desgranulado com auxílio de um liquidificador, acionado de 5 a 8 vezes, durante $3 \mathrm{~s}$ cada uma, formando uma pasta que, em seguida, foi colocada em contato com os cubos de espuma por cerca de 
duas horas. Decorrido esse período, as matrizes com biomassa imobilizada foram imersas em meio sintético para lavagem dos sólidos fracamente aderidos. Posteriormente, o meio foi drenado, e a biomassa, alocada no interior do reator. A quantidade de espuma de poliuretano usada na imobilização da biomassa foi de aproximadamente $71 \mathrm{~g}$. A Figura 4.9 apresenta a fotografia de alguns cubos de espuma antes e depois da imobilização.

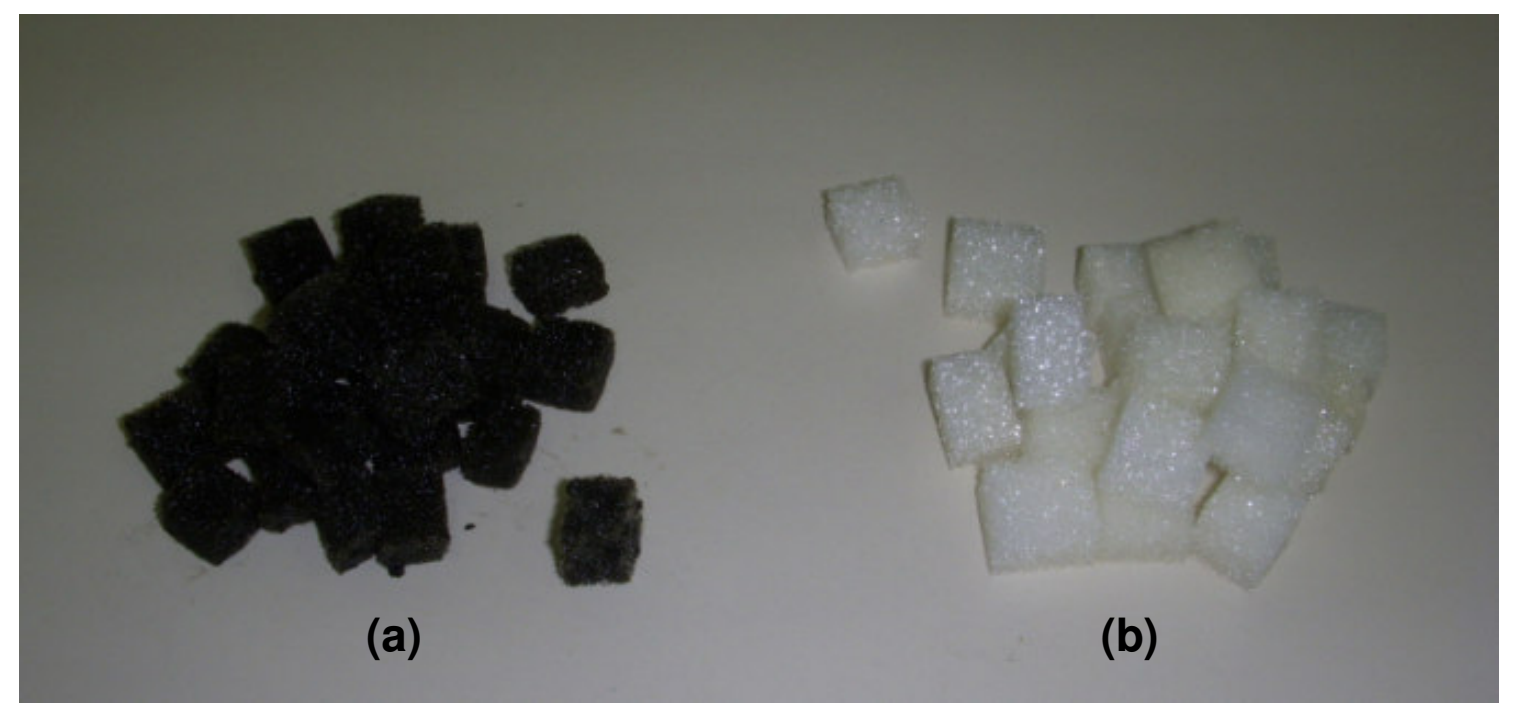

Figura 4.9 - Espuma de poliuretano (b) antes e (a) depois da imobilização

\subsubsection{ANSBBR NA CONDIÇÃO PRELIMINAR}

$\mathrm{Na}$ condição preliminar, o AnSBBR foi operado em batelada, em ciclos de $8 \mathrm{~h}$ (480 min), totalizando três ciclos por dia. O reator era alimentado com 2,50 L de meio sintético em 10 min no início de cada ciclo. A etapa de reação transcorria por 459 min com uma vazão de recirculação de $20 \mathrm{~L} / \mathrm{h}$. Ao término do ciclo, o efluente era descarregado também em $10 \mathrm{~min}$. A fim de evitar o sincronismo no funcionamento das bombas usadas na alimentação, descarga e recirculação, foi estabelecido o intervalo de segurança de um minuto entre uma operação e outra na 
programação dos temporizadores. O reator, assim como todo o aparato experimental, era mantido em câmara isotérmica a $30 \pm 1{ }^{\circ} \mathrm{C}$.

\subsubsection{OTIMIZAÇÃO DA SUPLEMENTAÇÃO DE ALCALINIDADE}

A otimização da suplementação de alcalinidade foi realizada ao longo da primeira condição experimental, denominada Condição 1 e descrita no item 4.11.3.4. A estratégia consistiu em reduzir gradativamente a concentração de bicarbonato de sódio do afluente, procurando chegar a um valor mínimo, sem que isto pudesse comprometer a estabilidade do sistema. Como forma de garantia de que eventuais problemas não decorressem da falta de bicarbonato no meio reacional, a concentração de partida foi estipulada em $800 \mathrm{mg} / \mathrm{L}$, sabendo-se que a concentração de matéria orgânica desta condição era 500 mgDQO/L.

\subsubsection{ANSBBR NAS CONDIÇÕES EXPERIMENTAIS}

Nas condições experimentais, o AnSBBR foi operado em batelada e em batelada alimentada, seguida de batelada, em ciclos de 8 h (480 min), como mostra a Tabela 4.9. Nas operações em batelada (B), o reator era alimentado com um volume aproximado de 0,88 ou 2,50 L de água residuária em 10 min logo no início do ciclo, conforme a condição experimental vigente. Já nas operações em batelada alimentada, seguida de batelada (BA/B), o reator era carregado com 1,62 L em 10 min e $0,88 \mathrm{~L}$ em $4 \mathrm{~h}$, ou simplesmente $0,88 \mathrm{~L}$ em $4 \mathrm{~h}$. Independentemente do modo de operação, nas condições em que o volume alimentado de água residuária era de apenas $0,88 \mathrm{~L}$, completava-se os $2,50 \mathrm{~L}$ de meio líquido com $1,62 \mathrm{~L}$ de residual do ciclo imediatamente anterior. $\mathrm{O}$ volume total de meio líquido mantido no 
interior do reator ao longo de cada batelada era sempre 2,50 L. Além disso, a etapa de reação transcorria por 459 min com uma vazão de recirculação de $20 \mathrm{~L} / \mathrm{h}$. Ao término do ciclo, o efluente era descarregado também em $10 \mathrm{~min}$. A fim de evitar o sincronismo no funcionamento das bombas usadas na alimentação e na descarga, foi estabelecido o intervalo de segurança de um minuto entre uma operação e outra na programação dos temporizadores. O reator, assim como todo o aparato experimental, era mantido em câmara isotérmica a $30 \pm 1{ }^{\circ} \mathrm{C}$.

Tabela 4.8 - Resumo das condições experimentais do AnSBBR

\begin{tabular}{|c|c|c|c|c|c|c|c|}
\hline \multirow{2}{*}{ Condição } & \multirow{2}{*}{ Especificação } & \multirow{2}{*}{$\begin{array}{c}\mathrm{C}_{\mathrm{A}} \\
(\mathrm{mgDQO} / \mathrm{L})\end{array}$} & \multirow{2}{*}{$\begin{array}{c}\text { COVA } \\
\text { (gDQO/L.d) }\end{array}$} & \multicolumn{2}{|c|}{ Batelada } & \multicolumn{2}{|c|}{$\begin{array}{c}\text { Batelada } \\
\text { alimentada }\end{array}$} \\
\hline & & & & $\begin{array}{l}V_{B} \\
(L)\end{array}$ & $\begin{array}{c}t_{B} \\
(\min )\end{array}$ & $\begin{array}{l}\mathrm{V}_{\mathrm{BA}} \\
(\mathrm{L})\end{array}$ & $\begin{array}{l}t_{B A} \\
(h)\end{array}$ \\
\hline 1 & $1,5 B$ & 500 & 1,5 & 2,50 & 10 & - & - \\
\hline 2 & 1,5B-RES & 1425 & 1,5 & 0,88 & 10 & - & - \\
\hline 3 & $0,9 B$ & 300 & 0,9 & 2,50 & 10 & - & - \\
\hline 4 & 0,9B-RES & 850 & 0,9 & 0,88 & 10 & - & - \\
\hline 5 & 1,5BA/B & 500 & 1,5 & 1,62 & 10 & 0,88 & 4,0 \\
\hline 6 & 1,5BA/B-RES & 1425 & 1,5 & - & - & 0,88 & 4,0 \\
\hline 7 & $0,9 B A / B$ & 300 & 0,9 & 1,62 & 10 & 0,88 & 4,0 \\
\hline 8 & 0,9BA/B-RES & 850 & 0,9 & - & - & 0,88 & 4,0 \\
\hline
\end{tabular}

O regime hidrodinâmico do AnSBBR está diretamente relacionado com o tempo de mistura, que corresponde ao tempo necessário para que a composição do meio líquido no interior do reator atinja um determinado grau de homogeneidade. Como a vazão de recirculação adotada era de 20 L/h (RAMOS et al., 2003), o tempo de mistura foi considerado desprezível em relação ao tempo de ciclo (ORRA et al., 2004; CAMARGO et al., 2005; BEZERRA JUNIOR et al., 2007). Camargo et al. (2005) sugerem ainda que o leito do AnSBBR nestas condições apresenta o 
comportamento de um reator pistonado. Por outro lado, a vazão de recirculação do meio líquido de $20 \mathrm{~L} / \mathrm{h}$ corresponde a uma velocidade superficial ascensional de 0,20 $\mathrm{cm} / \mathrm{s}$. Este valor foi obtido por meio da Equação 4.34, considerando a porosidade do leito em torno de 40\% (ZAIAT, VIEIRA e FORESTI, 1997).

\subsubsection{VOLUME OPERACIONAL DO ANSBBR}

Os volumes alimentados de 1,62 e 0,88 L, apresentados na Tabela 4.9, correspondem aos volumes aproximados de meio líquido do reator $\left(\mathrm{V}_{U, R T}\right)$ e do reservatório $\left(\mathrm{V}_{\mathrm{U}, \mathrm{RS}}\right)$, respectivamente, e foram adotados com o propósito de facilitar a operação de descarga do sistema. Dessa forma, era possível descarregar o reator e o reservatório concomitante e separadamente, e ainda medir os volumes descarregados de ambos. Em virtude da alocação da biomassa imobilizada em seu interior, o volume máximo de meio líquido que o reator conseguia comportar era aproximadamente $1,62 \mathrm{~L}$. Por conta disso, $\mathrm{V}_{\mathrm{U}, \mathrm{RS}}$ foi limitado a $0,88 \mathrm{~L}$, de modo que o volume de meio líquido do sistema $\left(\mathrm{V}_{\mathrm{U}}\right)$ fosse mantido em 2,50 L.

O volume operacional do sistema $\left(\mathrm{V}_{\mathrm{O}}\right)$ era aproximadamente 5,14 L. Este valor foi obtido a partir da Equação 4.22, somando-se os volumes operacionais do reator $\left(\mathrm{V}_{\mathrm{O}, \mathrm{RT}}\right)$ e do reservatório $\left(\mathrm{V}_{\mathrm{O}, \mathrm{RS}}\right)$, que eram 4,26 e $0,88 \mathrm{~L}$, respectivamente. $\mathrm{O}$ valor de $\mathrm{V}_{\mathrm{O}, \mathrm{RT}}$ foi obtido a partir da Equação 4.29, por ser igual ao volume total do reator $\left(\mathrm{V}_{\mathrm{T}, \mathrm{RT}}\right)$. Para isso, foi necessário determinar a distância entre o fundo do reator e o bocal de saída do meio líquido $\left(\mathrm{H}_{\mathrm{RT}}\right)$ e calcular a área interna da secção transversal $\left(A_{R T}\right)$, por meio da Equação 4.31. Os valores obtidos de $H_{R T}$ e $A_{R T}$ foram respectivamente $628 \mathrm{~mm}$ e $67,9 \mathrm{~cm}^{2}$. Por outro lado, o volume total do sistema $\left(\mathrm{V}_{\mathrm{T}}\right)$ era 6,36 L, obtido a partir da Equação 4.27, somando-se $\mathrm{V}_{\mathrm{T}, \mathrm{RT}}$ ao volume total do 
reservatório $\left(\mathrm{V}_{\mathrm{T}, \mathrm{RS}}\right)$, que era 2,10 L. Este valor, por sua vez, foi obtido a partir da Equação 4.30, considerando os valores de $310 \mathrm{~mm}$ da distância entre o fundo do reservatório e o bocal de entrada do meio líquido $\left(H_{R S}\right)$ e $67,9 \mathrm{~cm}^{2}$ da área da secção transversal $\left(A_{R S}\right)$.

\subsubsection{MONITORAMENTO E PERFIS DO ANSBBR}

O monitoramento do AnSBBR foi feito com amostras do afluente e do efluente, segundo o Standard Methods for the Examination of Water and Wastewater (1995), medindo-se: concentração de matéria orgânica $\left(C_{S}\right)$ de amostras filtradas e não filtradas, expressa em DQO; pH; concentração de ácidos voláteis totais (AVT); alcalinidade parcial $(A P)$, intermediária $(A I)$, total $(A T)$, e a bicarbonato $(A B)$; concentração de sólidos totais (ST), voláteis totais (SVT), em suspensão totais (SST) e em suspensão voláteis (SSV); e, volume de efluente descarregado do sistema $\left(V_{D}\right)$, do reator $\left(V_{D, R T}\right)$ e do reservatório $\left(V_{D, R S}\right)$, com auxílio de uma proveta de polipropileno de 2,0 L. Essas variáveis foram monitoradas com uma freqüência de pelo menos duas a três vezes por semana.

Quando o sistema atingia a estabilidade operacional, verificada através dos valores aproximadamente constantes das variáveis monitoradas do efluente, eram realizados perfis de algumas dessas e de outras variáveis: concentração de matéria orgânica $\left(\mathrm{C}_{\mathrm{S}}\right)$ de amostras filtradas, expressa em DQO; pH; concentração de ácidos voláteis totais $(\mathrm{AVT})$; alcalinidade a bicarbonato $(\mathrm{AB})$; concentração de ácidos voláteis intermediários (AVI); concentrações de metano $\left(\mathrm{C}_{\mathrm{CH} 4}\right)$ e gás carbônico $\left(\mathrm{C}_{\mathrm{CO} 2}\right)$; frações molares de metano $\left(\mathrm{Y}_{\mathrm{CH} 4}\right)$ e gás carbônico $\left(\mathrm{Y}_{\mathrm{CO} 2}\right)$; produção de metano, expressa em unidade de volume de metano $\left(\mathrm{V}_{\mathrm{CH} 4}\right)$; e, produção específica 
de metano, expressa em unidade de volume específico de metano $\left(V_{\mathrm{CH} 4}\right)$. Os perfis de produção e produção específica de metano só foram realizados nas Condições 1 a 4, em que a operação do AnSBBR era feita por batelada. Nas Condições 5 a 8, em que o reator foi operado em batelada alimentada, seguida de batelada, a variação de volume da fase líquida do sistema interferiu na medição do volume de metano produzido, dificultando a coleta de dados. As metodologias empregadas nos perfis foram apresentadas nos itens 4.5, 4.6 e 4.7 .

As amostras usadas nos perfis eram colhidas a intervalos de tempo de 30 a $180 \mathrm{~min}$, de modo que o volume total removido não ultrapassasse $10 \%$ do volume de meio líquido do reator. Uma nova condição experimental só era iniciada depois de encerrados os perfis da condição anterior. O objetivo da realização desses perfis era possibilitar uma melhor compreensão das rotas de degradação da matéria orgânica ao longo de um ciclo de operação do reator.

\subsubsection{Operação do AnSBR}

O AnSBR foi operado na condição preliminar, que serviu como período de adaptação da biomassa à operacionalidade do sistema, e em seis condições experimentais.

\subsubsection{ANSBR NA CONDIÇÃO PRELIMINAR}

$\mathrm{Na}$ condição preliminar, o AnSBR foi operado em batelada, em ciclos de $8 \mathrm{~h}$ (480 min), totalizando três ciclos por dia. O reator era alimentado com 1,0 L de meio sintético em 10 min no início de cada ciclo. A etapa de reação transcorria por 
429 min com agitação de 150 rpm. Depois disso, seguia-se a etapa de sedimentação da biomassa por $30 \mathrm{~min}$. Ao término do ciclo, o efluente era descarregado também em $10 \mathrm{~min}$. A fim de evitar o sincronismo no funcionamento das bombas usadas na alimentação e descarga, foi estabelecido o intervalo de segurança de um minuto entre uma operação e outra na programação dos temporizadores. O reator, assim como todo o aparato experimental, era mantido em câmara isotérmica a $30 \pm 1{ }^{\circ} \mathrm{C}$.

\subsubsection{ANSBR NAS CONDIÇÕES EXPERIMENTAIS}

Nas condições experimentais, o AnSBR foi operado em batelada, em ciclos de $8 \mathrm{~h}$ (480 min), 12 h (720 min) e 24 h (1440 min), como mostra a Tabela 4.10. O reator era alimentado com $1,0 \mathrm{~L}$ de água residuária em $10 \mathrm{~min}$ no início de cada ciclo. $\mathrm{A}$ etapa de reação transcorria por 429, 669 e 1389 min, para os ciclos de 8, 12 e 24 h, respectivamente, com agitação de $150 \mathrm{rpm}$. Depois disso, seguia-se a etapa de sedimentação da biomassa por $30 \mathrm{~min}$. Ao término do ciclo, o efluente era descarregado em 10 min. $O$ volume total de meio líquido mantido no interior do reator ao longo de cada batelada era 2,0 L. O sistema de agitação permanecia ligado apenas durante a etapa de reação, sendo desligado nas demais etapas de carga, descarga e sedimentação. A fim de evitar o sincronismo no funcionamento das bombas usadas na alimentação e descarga, foi estabelecido o intervalo de segurança de um minuto entre uma operação e outra na programação dos temporizadores. O reator, assim como todo o aparato experimental, era mantido em câmara isotérmica a $30 \pm 1^{\circ} \mathrm{C}$. 
Tabela 4.9 - Resumo das condições experimentais do AnSBR

\begin{tabular}{cccccc}
\hline Condição & Especificação & $\begin{array}{c}\mathrm{C}_{\mathrm{A}} \\
(\mathrm{mgDQO} / \mathrm{L})\end{array}$ & $\begin{array}{c}\text { COVA } \\
(\mathrm{gDQO} / \mathrm{L} . \mathrm{d})\end{array}$ & $\begin{array}{c}\mathrm{t}_{\mathrm{C}} \\
(\mathrm{h})\end{array}$ & $\begin{array}{c}\text { Suplementação } \\
\text { de meio sintético }\end{array}$ \\
\hline 9 & $0,75 \mathrm{~B}-8$ & 500 & 0,75 & 8 & NÃO \\
10 & $0,75 \mathrm{~B}-12$ & 750 & 0,75 & 12 & NÃO \\
11 & $0,75 \mathrm{~B}-24$ & 1500 & 0,75 & 24 & NÃO \\
12 & $0,50 \mathrm{~B}-12$ & 500 & 0,50 & 12 & NÃO \\
13 & $0,25 \mathrm{~B}-24$ & 500 & 0,25 & 24 & NÃO \\
14 & $0,75 \mathrm{~B}-8 \mathrm{SPL}$ & 500 & 0,75 & 8 & SIM \\
\hline
\end{tabular}

O regime hidrodinâmico do AnSBR, assim como o do AnSBBR, também está vinculado ao tempo de mistura. Seu sistema de agitação, com velocidade de 150 rpm e impelidor tipo hélice com três lâminas de 60 mm de diâmetro (MICHELAN et al., 2009), tornou o tempo de mistura desprezível em relação ao tempo de ciclo (RODRIGUES et al., 2003; RODRIGUES et al., 2004; CHEBEL et al., 2006).

\subsubsection{VOLUME OPERACIONAL DO ANSBR}

$\mathrm{O}$ volume operacional do sistema $\left(\mathrm{V}_{\mathrm{O}}\right)$ era aproximadamente 3,0 L. Este valor foi obtido a partir da Equação 4.21, somando-se os volumes totais de lodo $\left(\mathrm{V}_{\text {lodo }}\right)$ e meio líquido do sistema $\left(\mathrm{V}_{\mathrm{U}}\right)$, que eram 1,0 e 2,0 L, respectivamente. Vale lembrar que o volume renovado de um ciclo para outro era apenas $1,0 \mathrm{~L}$. Já o volume total do sistema $\left(\mathrm{V}_{\mathrm{T}}\right)$ era $5,56 \mathrm{~L}$ e foi obtido por meio das Equações 4.28, 4.29 e 4.31, considerando os valores de $190 \mathrm{~mm}$ da distância entre o fundo do reator e o bocal de saída do meio líquido $\left(H_{R T}\right)$, e $292 \mathrm{~cm}^{2}$ da área da secção transversal $\left(A_{R T}\right)$. 


\subsubsection{MONITORAMENTO E PERFIS DO ANSBR}

O monitoramento do AnSBR foi feito com amostras do afluente e do efluente, segundo o Standard Methods for the Examination of Water and Wastewater (1995), medindo-se: concentração de matéria orgânica $\left(\mathrm{C}_{\mathrm{S}}\right)$ de amostras filtradas e não filtradas, expressa em DQO; pH; concentração de ácidos voláteis totais (AVT); alcalinidade parcial (AP), intermediária (AI), total (AT), e a bicarbonato (AB); concentração de sólidos totais (ST), voláteis totais (SVT), em suspensão totais (SST) e em suspensão voláteis (SSV); e, volume de efluente descarregado do sistema $\left(\mathrm{V}_{\mathrm{D}}\right)$, com auxílio de uma proveta de polipropileno de 2,0 L. Essas variáveis foram monitoradas com uma freqüência de pelo menos duas a três vezes por semana.

Quando o sistema atingia a estabilidade operacional, verificada através dos valores aproximadamente constantes das variáveis monitoradas do efluente, eram realizados perfis de algumas dessas e de outras variáveis: concentração de matéria orgânica $\left(\mathrm{C}_{\mathrm{S}}\right)$ de amostras filtradas, expressa em DQO; pH; concentração de ácidos voláteis totais (AVT); alcalinidade a bicarbonato (AB); concentração de ácidos voláteis intermediários $(\mathrm{AVI})$; concentrações de metano $\left(\mathrm{C}_{\mathrm{CH} 4}\right)$ e gás carbônico $\left(\mathrm{C}_{\mathrm{CO} 2}\right)$; e, frações molares de metano $\left(\mathrm{Y}_{\mathrm{CH} 4}\right)$ e gás carbônico $\left(\mathrm{Y}_{\mathrm{CO} 2}\right)$. Os perfis de produção e produção específica de metano não foram realizados nas Condições 9 a 14, pois o reator não dispunha de boa vedação. As metodologias empregadas nos perfis foram apresentadas nos itens $4.5,4.6$ e 4.7 .

As amostras usadas nos perfis eram colhidas a intervalos de tempo de 30 a $240 \mathrm{~min}$, de modo que o volume total removido não ultrapassasse $10 \%$ do volume de meio líquido do reator. Uma nova condição experimental só era iniciada depois de 
encerrados os perfis da condição anterior. O objetivo da realização desses perfis era possibilitar uma melhor compreensão das rotas de degradação da matéria orgânica ao longo de um ciclo de operação do reator. Além disso, os perfis foram adimensionalizados para facilitar a interpretação dos resultados, já que os tempos de ciclo não eram iguais. A adimensionalização foi feita dividindo-se os tempos de coleta das amostras pelo tempo total de um ciclo operacional. 


\section{RESULTADOS E DISCUSSÃO}

Os resultados dos ensaios de biodegradabilidade e das operações do AnSBBR e do AnSBR são apresentados e discutidos a seguir.

\subsection{ENSAIOS DE BIODEGRADABILIDADE}

As condições experimentais dos ensaios de biodegradabilidade diferiram quanto à carga orgânica aplicada. Nas Condições S1 a S4, os valores de COVA foram respectivamente $0,81,1,54,1,98$ e 2,35 gDQO/L.d, e os valores de COEA, 0,076, 0,145, 0,186 e 0,221 gDQO/gSVT.d, como mostra a Tabela 5.1. Vale lembrar que a água residuária foi preparada com 1000 a 3000 mgDQO/L e $1000 \mathrm{mgNaHCO}_{3} / \mathrm{L}$.

Tabela 5.1 - Variáveis monitoradas das Condições S1 a S4

\begin{tabular}{|c|c|c|c|c|c|}
\hline \multirow{2}{*}{ Dia } & \multirow{2}{*}{ Variável } & \multicolumn{4}{|c|}{ Condição } \\
\hline & & S1 & S2 & S3 & S4 \\
\hline \multirow{3}{*}{0} & $\mathrm{C}_{\mathrm{A}}(\mathrm{mgDQO} / \mathrm{L})$ & 1078,9 & 2058,5 & 2646,4 & 3146,9 \\
\hline & COVA (gDQO/L.d) & 0,81 & 1,54 & 1,98 & 2,35 \\
\hline & COEA (gDQO/gSVT.d) & 0,076 & 0,145 & 0,186 & 0,221 \\
\hline \multirow{4}{*}{$1^{0}$} & $\mathrm{C}_{\mathrm{EF}}(\mathrm{mgDQO} / \mathrm{L})$ & 223,1 & 616,6 & 894,3 & 722,1 \\
\hline & $\varepsilon_{F}(\%)$ & 79,3 & 70,0 & 66,2 & 77,1 \\
\hline & $\operatorname{COVR}_{F}(g D Q O / L . d)$ & 0,64 & 1,08 & 1,31 & 1,81 \\
\hline & $\mathrm{COER}_{\mathrm{F}}(\mathrm{gDQO} / \mathrm{gSVT} . \mathrm{d})$ & 0,060 & 0,101 & 0,123 & 0,170 \\
\hline \multirow{4}{*}{$2^{\circ}$} & $\mathrm{C}_{\mathrm{EF}}(\mathrm{mgDQO} / \mathrm{L})$ & 289,5 & 636,6 & 1069,3 & 1009,6 \\
\hline & $\varepsilon_{\mathrm{F}}(\%)$ & 73,2 & 69,1 & 59,6 & 67,9 \\
\hline & $\operatorname{COVR}_{F}(g D Q O / L . d)$ & 0,59 & 1,07 & 1,18 & 1,60 \\
\hline & $\mathrm{COER}_{\mathrm{F}}(\mathrm{gDQO} / \mathrm{gSVT} . \mathrm{d})$ & 0,056 & 0,100 & 0,111 & 0,150 \\
\hline \multirow{4}{*}{$3^{0}$} & $\mathrm{C}_{\mathrm{EF}}(\mathrm{mgDQO} / \mathrm{L})$ & 244,0 & 618,7 & 1170,7 & 1910,8 \\
\hline & $\varepsilon_{F}(\%)$ & 77,4 & 69,9 & 55,8 & 39,3 \\
\hline & $\operatorname{COVR}_{F}(g D Q O / L . d)$ & 0,63 & 1,08 & 1,07 & 0,92 \\
\hline & $\operatorname{cOER}_{F}(g D Q O / g S V T . d)$ & 0,059 & 0,101 & 0,104 & 0,087 \\
\hline
\end{tabular}


O tempo de operação de cada condição experimental foi de apenas três dias, seguindo uma seqüência ininterrupta da Condição S1 a Condição S4. Os afluentes destas condições foram preparados uma única vez, de modo que os resultados apresentados na Tabela 5.1 referem-se às análises realizadas imediatamente após seu preparo. A determinação da concentração de biomassa foi feita de acordo com a metodologia proposta para o AnSBR, já que o lodo se apresentava na forma granular. Observou-se que havia aproximadamente 2,13 gSVT no erlenmeyer usado nos ensaios, que correspondiam a $87 \%$ dos sólidos totais. Como o volume de meio líquido era $200 \mathrm{~mL}$, a concentração de biomassa acabou sendo de 10,6 gSVT/L. Vale lembrar que as Condições S1 a S4 foram precedidas por uma condição preliminar, implementada também por três dias, cujos resultados de monitoramento não foram apresentados.

Analisando os dados da Tabela 5.1, observa-se que a biomassa reagiu bem as COVA de 0,81 e 1,54 gDQO/L.d das Condições S1 e S2, respectivamente. Nestas condições, o sistema permaneceu estável durante os três dias de operação, apresentando valores médios de $\varepsilon_{F}$, COVR $_{F}$ e COER Ce $_{7}$ d6,6\%, 0,62 gDQO/L.d e 0,058 gDQO/gSVT.d, na Condição S1, e 69,6\%, 1,08 gDQO/L.d e 0,101 gDQO/gSVT.d, na Condição S2. Por outro lado, o aumento da COVA nas condições seguintes mostrou que o sistema não foi capaz de atingir a estabilidade. Em três dias, a eficiência caiu de 66,2 para $55,8 \%$ na Condição S3, e de 77,1 para 39,3, na Condição S4, cujas COVA eram respectivamente 1,98 e 2,35 gDQO/L.d, embora os valores de COVR $_{F}$ e COER ainda fossem altos.

A Tabela 5.2 apresenta os resultados do monitoramento de $\mathrm{pH}, \mathrm{Al} / \mathrm{AP}, \mathrm{AVT}$ e $\mathrm{AB}$, apenas do primeiro dia de operação das quatro condições experimentais. Observa- 
se que a concentração residual de ácidos voláteis totais foi baixa, em torno de $30 \mathrm{mgHAc} / \mathrm{L}$, enquanto os valores de $\mathrm{pH}$ se mantiveram na faixa de 6,5 a 7,5 , e de alcalinidade a bicarbonato, entre 511 e $576 \mathrm{mgCaCO}_{3} / \mathrm{L}$.

Tabela 5.2 - Variáveis monitoradas das Condições S1 a S4

\begin{tabular}{cccccc}
\hline \multirow{2}{*}{ Dia } & \multirow{2}{*}{ Variável } & \multicolumn{4}{c}{ Condição } \\
\cline { 3 - 6 } & & $\mathrm{S} 1$ & $\mathrm{~S} 2$ & $\mathrm{~S} 3$ & $\mathrm{~S} 4$ \\
\hline \multirow{3}{*}{$1^{\circ}$} & $\mathrm{pH}_{\mathrm{E}}$ & 6,74 & 7,21 & 7,28 & 7,20 \\
& $(\mathrm{Al} / \mathrm{AP})_{\mathrm{E}}$ & 0,48 & 0,26 & 0,23 & 0,31 \\
& $\mathrm{AVT}_{\mathrm{E}}(\mathrm{mgHAc} / \mathrm{L})$ & 18,7 & 38,4 & 27,4 & 38,1 \\
& $\mathrm{AB}_{\mathrm{E}}\left(\mathrm{mgCaCO}_{3} / \mathrm{L}\right)$ & 553,8 & 511,2 & 543,8 & 576,0 \\
\hline
\end{tabular}

Com base nos resultados obtidos, concluiu-se que os valores de COVA adotados para as operações do AnSBBR e do AnSBR deveriam ser inferiores a 2,0 gDQO/L.d.

\subsection{OPERAÇÃo do ANSBBR}

Os resultados dos monitoramentos e dos perfis das condições experimentais do AnSBBR são apresentados e discutidos a seguir, assim como os da condição preliminar, da análise de sólidos e da microscopia da biomassa.

\subsubsection{AnSBBR na condição preliminar}

Depois de ser preenchido com a biomassa, previamente imobilizada em partículas cúbicas de espuma de poliuretano, o AnSBBR foi operado em batelada, em ciclos de 8 h, durante 20 dias (60 ciclos), tratando meio sintético a base de sacarose, amido solúvel, celulose, extrato de carne, óleo de soja e sais, com concentrações de 
$500 \mathrm{mgDQO} / \mathrm{L}$ e $200 \mathrm{mgNaHCO}_{3} / \mathrm{L}$. Os valores médios das variáveis monitoradas do afluente e do efluente são apresentados nas Figuras 5.1 e 5.2 e na Tabela 5.3.

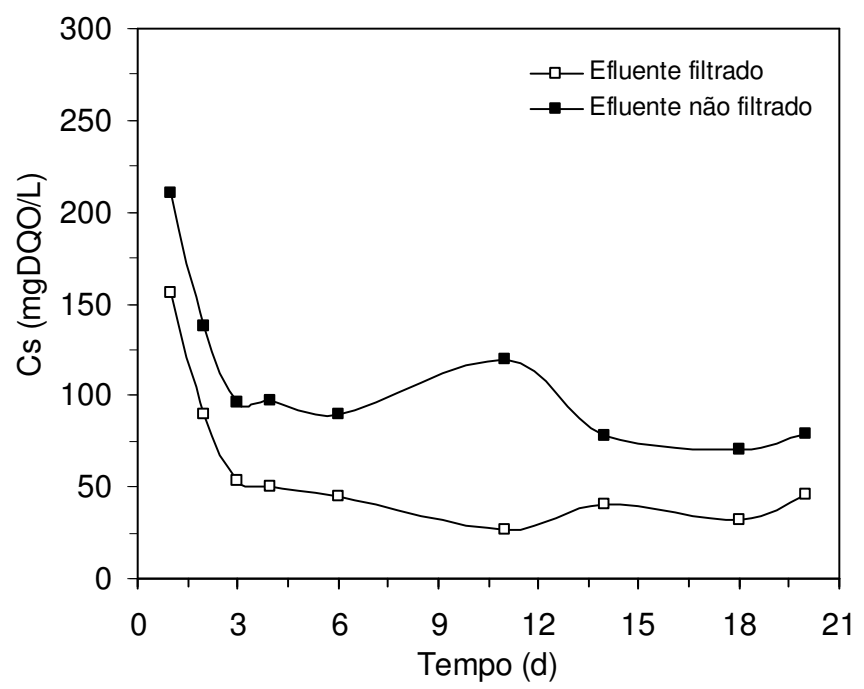

Figura 5.1 - Concentração de matéria orgânica do AnSBBR na condição preliminar

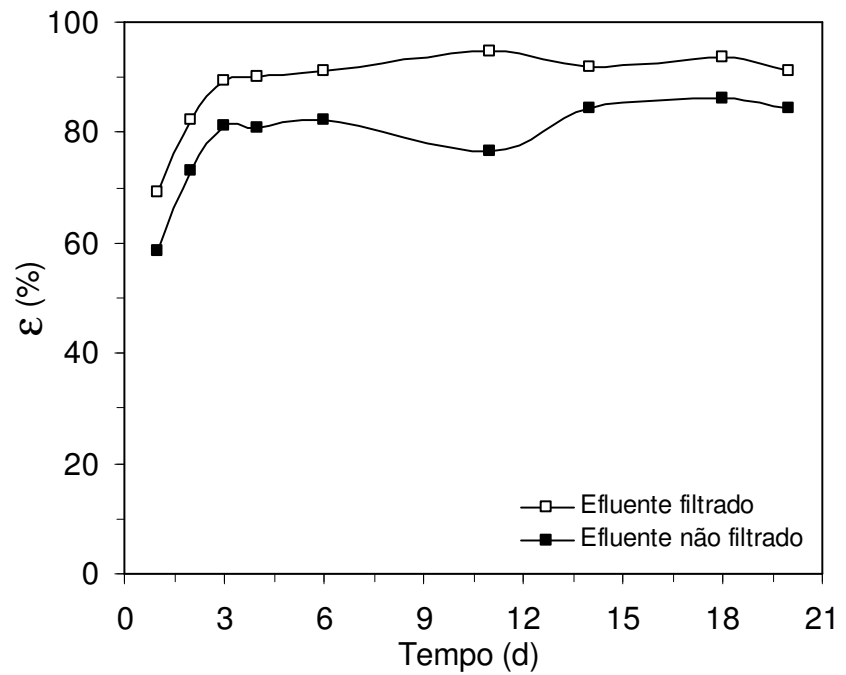

Figura 5.2 - Eficiência de remoção de matéria orgânica do AnSBBR na condição preliminar 
Tabela 5.3 - Variáveis monitoradas do AnSBBR na condição preliminar

\begin{tabular}{cc}
\hline Variável & AnSBBR \\
\hline $\mathrm{C}_{\mathrm{A}}(\mathrm{mgDQO} / \mathrm{L})$ & $507 \pm 9(9)$ \\
$\mathrm{C}_{\mathrm{ET}}(\mathrm{mgDQO} / \mathrm{L})$ & $90 \pm 16(6)$ \\
$\varepsilon_{\mathrm{T}}(\%)$ & $82 \pm 3$ \\
$\mathrm{C}_{\mathrm{EF}}(\mathrm{mgDQO} / \mathrm{L})$ & $42 \pm 10(6)$ \\
$\varepsilon_{\mathrm{F}}(\%)$ & $92 \pm 2$ \\
\hline $\mathrm{V}_{\mathrm{D}}(\mathrm{L})$ & $2537 \pm 46(9)$ \\
\hline $\mathrm{COVA}(\mathrm{gDQO} / \mathrm{L} . \mathrm{d})$ & $1,52 \pm 0,08$ \\
$\mathrm{COVR}_{\mathrm{T}}(\mathrm{gDQO} / \mathrm{L} . \mathrm{d})$ & $1,25 \pm 0,13$ \\
$\mathrm{COVR}_{\mathrm{F}}(\mathrm{gDQO} / \mathrm{L} . \mathrm{d})$ & $1,40 \pm 0,10$ \\
\hline $\mathrm{COEA}(\mathrm{gDQO} / \mathrm{gSVT} . \mathrm{d})$ & $0,076 \pm 0,003$ \\
$\mathrm{COER}_{\mathrm{T}}(\mathrm{gDQO} / \mathrm{gSVT} . \mathrm{d})$ & $0,063 \pm 0,005$ \\
$\mathrm{COER}_{\mathrm{F}}(\mathrm{gDQO} / \mathrm{gSVT} . \mathrm{d})$ & $0,070 \pm 0,004$ \\
\hline $\mathrm{pH} \mathrm{A}_{\mathrm{A}}$ & $8,0 \pm 0,1(3)$ \\
$\mathrm{pH} \mathrm{E}_{\mathrm{E}}$ & $7,5 \pm 0,1(3)$ \\
\hline$(\mathrm{Al} / \mathrm{AP})_{\mathrm{A}}$ & $0,30 \pm 0,01$ \\
$(\mathrm{Al} / \mathrm{AP})_{\mathrm{E}}$ & $0,24 \pm 0,02$ \\
\hline $\mathrm{AVT}_{\mathrm{A}}(\mathrm{mgHAc} / \mathrm{L})$ & $28 \pm 8(3)$ \\
$\mathrm{AVT}_{\mathrm{E}}(\mathrm{mgHAc} / \mathrm{L})$ & $35 \pm 8(3)$ \\
\hline $\mathrm{AB}_{\mathrm{A}}\left(\mathrm{mgCaCO}_{3} / \mathrm{L}\right)$ & $295 \pm 14(3)$ \\
$\mathrm{AB}_{\mathrm{E}}\left(\mathrm{mgCaCO}_{3} / \mathrm{L}\right)$ & $415 \pm 11(3)$ \\
\hline $\mathrm{Na}(\mathrm{m})$ &
\end{tabular}

Nota: ( ) número de amostras usadas no cálculo do valor médio das variáveis.

Analisando os dados apresentados na Tabela 5.3, observa-se que os valores médios de eficiência de remoção de matéria orgânica de amostras filtradas e não filtradas do efluente foram respectivamente 92 e $82 \%$. Além disso, o pH permaneceu estável e houve geração de alcalinidade no sistema, sugerindo que o reator atingiu a estabilidade durante o período considerado, estando apto a receber água residuária para o início das operações das condições experimentais. 


\subsubsection{AnSBBR nas condições experimentais}

O AnSBBR foi submetido a oito condições experimentais. Em todas elas, o sistema operou por 25 dias (75 ciclos), tratando 2,50 L de água residuária a base de xampu (produto comercial) e bicarbonato de sódio, em ciclos de $8 \mathrm{~h}$, com concentrações de 300 a $1425 \mathrm{mgDQO} / \mathrm{L}$ e $200 \mathrm{mgNaHCO} / \mathrm{L}$. Os dados dos monitoramentos e dos perfis destas condições são apresentados nos Apêndices A e B. Ressalta-se que os resultados dos perfis de concentração de ácidos voláteis intermediários ficaram abaixo do limite de detecção nas oito condições experimentais.

\subsubsection{CARACTERIZAÇÃo do AFLUENTE}

As concentrações de matéria orgânica do afluente foram analisadas em amostras filtradas $\left(C_{A F}\right)$ e não filtradas $\left(C_{A T}\right)$, em duplicata, em todas as condições experimentais, mostrando que $20 \pm 1 \%$ da DQO provinha de sólidos em suspensão. Os valores destas concentrações são apresentados no Apêndice C.

\subsubsection{OTIMIZAÇÃO DA SUPLEMENTAÇÃO DE ALCALINIDADE}

Em virtude da otimização da suplementação de alcalinidade, a Condição 1 foi dividida em três etapas, denominadas Condições 1A, 1B e 1C. Na Condição 1A, o sistema operou por sete dias, tratando água residuária com $500 \mathrm{mgDQO} / \mathrm{L}$ e concentrações de bicarbonato de sódio que variaram de 800 a 100 mgNaHCO$/ 2 / L$, nesta ordem, gradativamente. A decisão de diminuir a concentração de bicarbonato foi motivada pelas baixas concentrações de ácidos voláteis totais obtidas do monitoramento do afluente e do efluente nesta etapa, sempre inferiores a 
$20 \mathrm{mgHAc/L}$, como mostra a Tabela 5.4. Por outro lado, a eficiência média de remoção de matéria orgânica de amostras filtradas do efluente ficou em $52 \%$, o que se deve não somente à variação da concentração de bicarbonato de sódio, como também à adaptação da biomassa à água residuária, por ser esta a primeira condição experimental do AnSBBR. Elevados valores de desvio padrão podem ser observados entre os resultados de $C_{E F}, C_{E T}, A_{A}$ e $A B_{E}$ desta condição.

Tabela 5.4 - Variáveis monitoradas do AnSBBR na Condição 1

\begin{tabular}{|c|c|c|c|}
\hline Variável & $1 \mathrm{~A}$ & $1 \mathrm{~B}$ & $1 C$ \\
\hline $\mathrm{C}_{\mathrm{A}}(\mathrm{mgDQO} / \mathrm{L})$ & $520 \pm 8(6)$ & $509 \pm 7(6)$ & $509 \pm 4(6)$ \\
\hline $\mathrm{C}_{\mathrm{ET}}(\mathrm{mgDQO} / \mathrm{L})$ & $338-238(6)$ & $213 \pm 13(6)$ & $226 \pm 13(6)$ \\
\hline$\varepsilon_{\mathrm{T}}(\%)$ & $45 \pm 10$ & $58 \pm 3$ & $56 \pm 2$ \\
\hline $\mathrm{C}_{\mathrm{EF}}(\mathrm{mgDQO} / \mathrm{L})$ & $295-203(6)$ & $191 \pm 11(6)$ & $205 \pm 11(6)$ \\
\hline$\varepsilon_{\mathrm{F}}(\%)$ & $52 \pm 9$ & $63 \pm 2$ & $60 \pm 2$ \\
\hline $\mathrm{V}_{\mathrm{D}, \mathrm{RT}}(\mathrm{L})$ & $1717 \pm 14(6)$ & $1703 \pm 23(6)$ & $1615 \pm 32(6)$ \\
\hline $\mathrm{V}_{\mathrm{D}, \mathrm{RS}}(\mathrm{L})$ & $802 \pm 8(6)$ & $838 \pm 13(6)$ & $905 \pm 34(6)$ \\
\hline $\mathrm{V}_{\mathrm{D}}(\mathrm{L})$ & $2518 \pm 10(6)$ & $2542 \pm 16(6)$ & $2520 \pm 6(6)$ \\
\hline COVA (gDQO/L.d) & $1,56 \pm 0,04$ & $1,53 \pm 0,04$ & $1,53 \pm 0,02$ \\
\hline $\mathrm{COVR}_{\mathrm{T}}(\mathrm{gDQO} / \mathrm{L.d})$ & $0,70 \pm 0,18$ & $0,89 \pm 0,07$ & $0,85 \pm 0,06$ \\
\hline $\mathrm{COVR}_{\mathrm{F}}(\mathrm{gDQO} / \mathrm{L} . \mathrm{d})$ & $0,81 \pm 0,17$ & $0,95 \pm 0,07$ & $0,91 \pm 0,05$ \\
\hline COEA (gDQO/L.d) & $0,078 \pm 0,002$ & $0,077 \pm 0,002$ & $0,076 \pm 0,001$ \\
\hline $\mathrm{COER}_{\mathrm{T}}(\mathrm{gDQO} / \mathrm{L} . \mathrm{d})$ & $0,035 \pm 0,009$ & $0,045 \pm 0,003$ & $0,042 \pm 0,003$ \\
\hline $\mathrm{COER}_{\mathrm{F}}(\mathrm{gDQO} / \mathrm{L} . \mathrm{d})$ & $0,041 \pm 0,008$ & $0,048 \pm 0,003$ & $0,045 \pm 0,002$ \\
\hline $\mathrm{pH}_{\mathrm{A}}$ & $8,1 \pm 0,2(6)$ & $7,8 \pm 0,2(6)$ & $7,9 \pm 0,1(3)$ \\
\hline $\mathrm{pH}_{\mathrm{E}}$ & $7,8 \pm 0,1(5)$ & $7,5 \pm 0,2(5)$ & $7,6 \pm 0,2(3)$ \\
\hline$(\mathrm{Al} / \mathrm{AP})_{\mathrm{A}}$ & $0,25 \pm 0,02$ & $0,26 \pm 0,04$ & $0,30 \pm 0,05$ \\
\hline$(\mathrm{Al} / \mathrm{AP})_{\mathrm{E}}$ & $0,29 \pm 0,03$ & $0,27 \pm 0,06$ & $0,32 \pm 0,03$ \\
\hline $\mathrm{AVT}_{\mathrm{A}}(\mathrm{mgHAc} / \mathrm{L})$ & $16 \pm 4(6)$ & $13 \pm 1(6)$ & $17 \pm 4(3)$ \\
\hline $\mathrm{AVT}_{\mathrm{E}}(\mathrm{mgHAc} / \mathrm{L})$ & $13 \pm 2(5)$ & $12 \pm 1(5)$ & $16 \pm 2(3)$ \\
\hline $\mathrm{AB}_{\mathrm{A}}\left(\mathrm{mgCaCO}_{3} / \mathrm{L}\right)$ & $464-156(6)$ & $81 \pm 7(6)$ & $196 \pm 10(3)$ \\
\hline $\mathrm{AB}_{\mathrm{E}}\left(\mathrm{mgCaCO}_{3} / \mathrm{L}\right)$ & $410-156(5)$ & $74 \pm 20(5)$ & $199 \pm 6(3)$ \\
\hline
\end{tabular}

Nota: ( ) número de amostras usadas no cálculo do valor médio das variáveis. 
$\mathrm{Na}$ Condição 1B, o sistema operou sem bicarbonato por oito dias, apresentando eficiência de $63 \%$. No entanto, a alcalinidade começou a cair paulatinamente, chegando a $46,8 \mathrm{mgCaCO}_{3} / \mathrm{L}$. Assim, a suplementação foi retomada, fixando-se a concentração de $200 \mathrm{mgNaHCO} / \mathrm{L}$ para todas as demais condições experimentais do projeto, a começar pela Condição $1 \mathrm{C}$, na qual o sistema operou por dez dias. A Condição 1C também foi a etapa escolhida para a realização dos perfis da Condição 1. A Tabela 5.5 resume as composições da água residuária nas três etapas de otimização da suplementação de alcalinidade.

\begin{tabular}{ccc}
\multicolumn{3}{l}{$\begin{array}{l}\text { Tabela } \\
\text { residuária na Condição } 1\end{array}$} \\
\hline Condição & $\begin{array}{c}\text { Xampu } \\
(\mathrm{g} / \mathrm{L})\end{array}$ & $\begin{array}{c}\mathrm{NaHCO}_{3} \\
(\mathrm{~g} / \mathrm{L})\end{array}$ \\
\hline 1A & 1,00 & $0,80-0,10$ \\
1B & 1,00 & - \\
1C & 1,00 & 0,20 \\
\hline
\end{tabular}

\subsubsection{MONITORAMENTO E PERFIS DAS CONDIÇÕES 1 A 4}

Recordando as estratégias de alimentação adotadas, observa-se que as Condições 1 a 4 diferiram quanto à carga orgânica aplicada e quanto ao uso de volume residual. Nas Condições 1 e 2, a COVA era 1,5 gDQO/L.d, e nas Condições 3 e 4, 0,9 gDQO/L.d. Por outro lado, nas Condições 1 e 3 o AnSBBR era carregado e descarregado por inteiro, ao passo que nas Condições 2 e 4 apenas 35\% desse volume era renovado de um ciclo para outro. Como o volume de meio líquido do sistema era 2,50 L, nas Condições 2 e 4, especificamente, o reator era alimentado com $0,88 \mathrm{~L}$ de água residuária, enquanto os $1,62 \mathrm{~L}$ restantes provinham do ciclo imediatamente anterior. Já nas Condições 1 e 3, o volume de água residuária 
alimentado por ciclo era 2,50 L. Em todas elas o sistema operou em batelada, com alimentação e descarga sendo realizadas em $10 \mathrm{~min}$. Os resultados obtidos do monitoramento das Condições 1 a 4 são apresentados nas Figuras 5.3 e 5.4 e na Tabela 5.6, e os dos perfis, nas Figuras 5.5 a 5.14 .

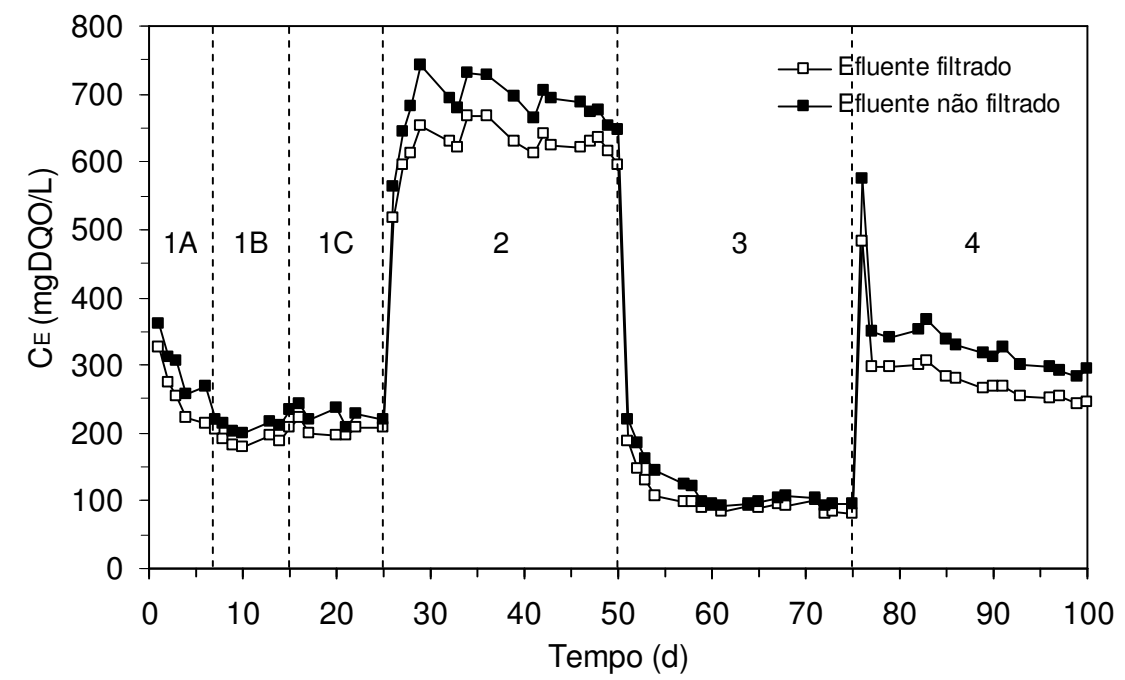

Figura 5.3 - Concentração de matéria orgânica na saída do AnSBBR nas Condições 1 a 4

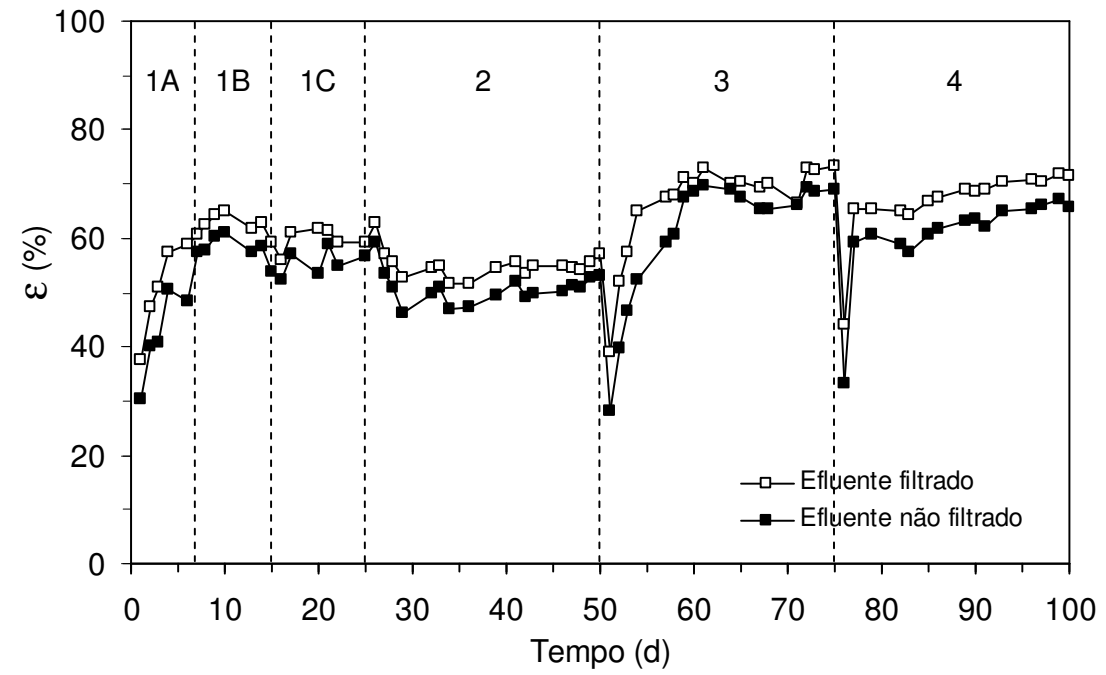

Figura 5.4 - Eficiência de remoção de matéria orgânica do AnSBBR nas Condições 1 a 4 
Tabela 5.6 - Variáveis monitoradas do AnSBBR nas Condições 1 a 4

\begin{tabular}{|c|c|c|c|c|}
\hline Condição & 1 & 2 & 3 & 4 \\
\hline Especificação & $1,5 \mathrm{~B}$ & 1,5B-RES & $0,9 \mathrm{~B}$ & 0,9B-RES \\
\hline $\mathrm{C}_{\mathrm{A}}(\mathrm{mgDQO} / \mathrm{L})$ & $509 \pm 4(6)$ & $1382 \pm 20(18)$ & $306 \pm 10(18)$ & $860 \pm 13(14)$ \\
\hline $\mathrm{C}_{\mathrm{ET}}(\mathrm{mgDQO} / \mathrm{L})$ & $226 \pm 13(6)$ & $690 \pm 28(15)$ & $98 \pm 5(11)$ & $306 \pm 16(9)$ \\
\hline$\varepsilon_{\top}(\%)$ & $56 \pm 2$ & $50 \pm 2$ & $68 \pm 2$ & $64 \pm 2$ \\
\hline $\mathrm{C}_{\mathrm{EF}}(\mathrm{mgDQO} / \mathrm{L})$ & $205 \pm 11(6)$ & $630 \pm 20(15)$ & $89 \pm 6(11)$ & $259 \pm 12(9)$ \\
\hline$\varepsilon_{\mathrm{F}}(\%)$ & $60 \pm 2$ & $54 \pm 1$ & $71 \pm 2$ & $70 \pm 1$ \\
\hline $\mathrm{V}_{\mathrm{D}, \mathrm{RT}}(\mathrm{L})$ & $1615 \pm 32(6)$ & $1622 \pm 4(13)$ & $1968 \pm 40(15)$ & $1637 \pm 5(14)$ \\
\hline $\mathrm{V}_{\mathrm{D}, \mathrm{RS}}(\mathrm{L})$ & $905 \pm 34(6)$ & $877 \pm 8(13)$ & $530 \pm 41(15)$ & $866 \pm 22(14)$ \\
\hline $\mathrm{V}_{\mathrm{D}}(\mathrm{L})$ & $2520 \pm 6(6)$ & $2499 \pm 8(13)$ & $2498 \pm 21(15)$ & $2504 \pm 20(14)$ \\
\hline COVA & $1,53 \pm 0,02$ & $1,45 \pm 0,04$ & $0,92 \pm 0,05$ & $0,89 \pm 0,04$ \\
\hline $\mathrm{COVR}_{T}$ & $0,85 \pm 0,06$ & $0,73 \pm 0,06$ & $0,62 \pm 0,06$ & $0,57 \pm 0,05$ \\
\hline $\mathrm{COVR}_{\mathrm{F}}$ & $0,91 \pm 0,05$ & $0,79 \pm 0,05$ & $0,65 \pm 0,06$ & $0,62 \pm 0,05$ \\
\hline COEA & $0,076 \pm 0,001$ & $0,072 \pm 0,002$ & $0,045 \pm 0,002$ & $0,044 \pm 0,002$ \\
\hline $\mathrm{COER}_{\mathrm{T}}$ & $0,042 \pm 0,003$ & $0,036 \pm 0,003$ & $0,031 \pm 0,002$ & $0,028 \pm 0,002$ \\
\hline $\mathrm{COER}_{\mathrm{F}}$ & $0,045 \pm 0,002$ & $0,039 \pm 0,002$ & $0,032 \pm 0,003$ & $0,031 \pm 0,002$ \\
\hline $\mathrm{pH}_{\mathrm{A}}$ & $7,9 \pm 0,1(3)$ & $7,9 \pm 0,1(5)$ & $7,9 \pm 0,1(8)$ & $7,9 \pm 0,1(6)$ \\
\hline $\mathrm{pH}_{\mathrm{E}}$ & $7,6 \pm 0,2(3)$ & $7,7 \pm 0,1(5)$ & $7,9 \pm 0,1(7)$ & $7,8 \pm 0,1(8)$ \\
\hline$(\mathrm{Al} / \mathrm{AP})_{\mathrm{A}}$ & $0,30 \pm 0,05$ & $0,32 \pm 0,06$ & $0,24 \pm 0,03$ & $0,27 \pm 0,02$ \\
\hline$(\mathrm{Al} / \mathrm{AP})_{\mathrm{E}}$ & $0,32 \pm 0,03$ & $0,27 \pm 0,02$ & $0,24 \pm 0,03$ & $0,27 \pm 0,03$ \\
\hline $\mathrm{AVT}_{\mathrm{A}}(\mathrm{mgHAc} / \mathrm{L})$ & $17 \pm 4(3)$ & $24 \pm 4(5)$ & $17 \pm 1(8)$ & $17 \pm 1(6)$ \\
\hline $\mathrm{AVT}_{\mathrm{E}}(\mathrm{mgHAc} / \mathrm{L})$ & $16 \pm 2(3)$ & $24 \pm 1(5)$ & $18 \pm 1(7)$ & $18 \pm 2(8)$ \\
\hline $\mathrm{AB}_{\mathrm{A}}\left(\mathrm{mgCaCO}_{3} / \mathrm{L}\right)$ & $196 \pm 10(3)$ & $216 \pm 14(5)$ & $237 \pm 3(8)$ & $200 \pm 11(6)$ \\
\hline $\mathrm{AB}_{\mathrm{E}}\left(\mathrm{mgCaCO}_{3} / \mathrm{L}\right)$ & $199 \pm 6(3)$ & $269 \pm 14(5)$ & $274 \pm 2(7)$ & $243 \pm 15(8)$ \\
\hline $\mathrm{ST}_{\mathrm{A}}(\mathrm{mg} / \mathrm{L})$ & $590 \pm 45(2)$ & $1039 \pm 24(3)$ & $582 \pm 13(3)$ & $847 \pm 40(3)$ \\
\hline $\mathrm{ST}_{\mathrm{E}}(\mathrm{mg} / \mathrm{L})$ & $641 \pm 44(2)$ & $825 \pm 30(2)$ & $621 \pm 36(3)$ & $761 \pm 18(2)$ \\
\hline $\mathrm{SVT}_{\mathrm{A}}(\mathrm{mg} / \mathrm{L})$ & $336 \pm 28(2)$ & $649 \pm 23(3)$ & $322 \pm 18(3)$ & $546 \pm 4(3)$ \\
\hline $\mathrm{SVT}_{\mathrm{E}}(\mathrm{mg} / \mathrm{L})$ & $448 \pm 124(2)$ & $505 \pm 27(2)$ & $409 \pm 18(3)$ & $500 \pm 42(2)$ \\
\hline $\mathrm{SST}_{\mathrm{A}}(\mathrm{mg} / \mathrm{L})$ & $51 \pm 7(2)$ & $126 \pm 2(3)$ & $32 \pm 0$ (3) & $95 \pm 9(3)$ \\
\hline $\mathrm{SST}_{\mathrm{E}}(\mathrm{mg} / \mathrm{L})$ & $9 \pm 4(2)$ & $36 \pm 3(2)$ & $13 \pm 3(3)$ & $33 \pm 1(2)$ \\
\hline $\mathrm{SSV}_{\mathrm{A}}(\mathrm{mg} / \mathrm{L})$ & $40 \pm 14(2)$ & $108 \pm 6(3)$ & $27 \pm 2(3)$ & $66 \pm 2(3)$ \\
\hline $\mathrm{SSV}_{\mathrm{E}}(\mathrm{mg} / \mathrm{L})$ & $6 \pm 0(2)$ & $30 \pm 3(2)$ & $11 \pm 1(3)$ & $21 \pm 1(2)$ \\
\hline
\end{tabular}

Nota: ( ) número de amostras usadas no cálculo do valor médio das variáveis. Unidades: $[\mathrm{COVA}]=\left[\mathrm{COVR} T=\left[\mathrm{COVR} F=\mathrm{gDQO} / \mathrm{L} . \mathrm{d} ;[\mathrm{COEA}]=\left[\mathrm{COER} \mathrm{R}_{\mathrm{T}}\right]=\left[\mathrm{COER} \mathrm{R}_{\mathrm{F}}\right]=\right.\right.$ = gDQO/gSVT.d. 
As Figuras 5.3 e 5.4 apresentam dados de concentração e eficiência de remoção de matéria orgânica para amostras filtradas e não filtradas do efluente ao longo das Condições 1 a 4. Quedas repentinas de eficiência podem ser observadas na transição da Condição 2 para a Condição 3, e desta para a Condição 4, motivadas não apenas pela mudança da COVA, como também pela descompactação do leito do AnSBBR, realizada manualmente sempre antes do início das condições experimentais. Este processo pode ter causado o desprendimento de biomassa do sistema por alguns ciclos, aumentando momentaneamente os valores de concentração de matéria orgânica do efluente. Já os baixos valores de eficiência encontrados no início da Condição 1, sendo esta a primeira condição implementada, devem-se mais à adaptação da biomassa à água residuária e ao sistema como um todo que aos motivos previamente discutidos. De qualquer modo, observa-se que o sistema atingiu a estabilidade em todas as condições experimentais logo após os primeiros dias de operação.

Além da eficiência de remoção de matéria orgânica, existem outras variáveis que podem ser avaliadas e eventualmente usadas para corroborar a hipótese de estabilidade do sistema ao longo de uma determinada condição experimental, tais como pH, AVT e AB. Analisando os resultados apresentados na Tabela 5.6, observa-se que os dados de $\mathrm{pH}$ mantiveram-se entre 7,4 e 8,0, e os dados de AVT, abaixo de $30 \mathrm{mgHAc/L}$. Além disso, os dados de AB sugerem que houve geração de alcalinidade no sistema, com exceção da Condição 1, cujos valores médios do afluente e do efluente eram próximos entre si. Provavelmente, o aumento da demanda de $A B$ nesta condição especificamente ocorreu em razão da readaptação da biomassa ao sistema após duas etapas críticas do estudo de otimização da suplementação de alcalinidade com bicarbonato de sódio. 
A concentração do bicarbonato de sódio usado no preparo da água residuária deveria ter sido corrigida em função das concentrações de matéria orgânica de cada uma das condições experimentais, e não simplesmente mantida em 200 mg/L. Desse modo, as cargas volumétricas de bicarbonato de 0,60 g/L.d, obtidas para as Condições 1 e 3, e 0,20 g/L.d, para as Condições 2 e 4, teriam sido 0,60 g/L.d para as Condições 1 e 2, e 0,36 gDQO/L.d, para as Condições 3 e 4. Apesar disso, observa-se que as concentrações de ácidos voláteis totais mantiveram-se baixas e estáveis, o que pode ser atribuído às características da água residuária.

Comparando a Condição 1 com a 3, e a 2 com a 4, nota-se que as condições com maiores valores de COVA e COEA, no caso as Condições 1 e 2, foram as que apresentaram também maiores valores de COVR e COER. Isto sugere que a mesma biomassa, mantida no AnSBBR ao longo das quatro condições experimentais, é capaz de remover quantidades maiores de matéria orgânica desde que haja substrato disponível. Contudo, os maiores valores de eficiência foram encontrados justamente nas Condições 3 e 4, em que a COVA e a COEA eram menores. A explicação para isto está atrelada à biodegradabilidade dos inúmeros compostos que faziam parte da formulação do xampu usado no preparo da água residuária. $\mathrm{Na}$ presença de tais compostos, supõe-se que a biomassa consumia mais rapidamente os de fácil que os de difícil biodegradabilidade. Dessa forma, nas condições em que a COVA era maior, e conseqüentemente a quantidade de compostos de fácil biodegradabilidade também era maior, a biomassa degradou estes primeiro; o consumo dos compostos de difícil biodegradabilidade ocorreu paralelamente, mas numa velocidade inferior. Portanto, no final do ciclo, os compostos de fácil biodegradabilidade já tinham sido quase que completamente convertidos a metano, enquanto os de difícil estavam, em sua maioria, parcialmente degradados e 
distribuídos pela fase líquida. Por outro lado, nas condições em que a COVA era menor, as velocidades de consumo dos compostos de fácil e difícil biodegradabilidade deveriam ter diminuído, em virtude da redução da concentração deles no meio reacional. Mesmo assim, a biomassa foi capaz de degradar uma quantidade proporcionalmente maior destes compostos, revelando que pelo menos a velocidade média de consumo dos mesmos acabou sendo maior nas Condições 3 e 4 em comparação às Condições 1 e 2.

Agora comparando a Condição 1 com a 2, e a 3 com a 4, nota-se que as condições que fizeram uso do volume residual para compor parte do meio líquido do ciclo seguinte, no caso as Condições 2 e 4, apresentaram menores valores de eficiência, COVR e COER. De certo, a incorporação da matéria orgânica proveniente da degradação parcial sofrida principalmente pelos compostos de difícil biodegradabilidade no ciclo anterior, além de aumentar a carga orgânica aplicada, também interferiu na velocidade média de consumo do substrato, que teve seu valor diminuído, assim como os valores de COVR, COER e eficiência. Na prática, observou-se que para COVA de 0,9 gDQO/L.d não houve uma diferença significativa entre os dados obtidos. Já para COVA de 1,5 gDQO/L.d, a Condição 1 apresentou maiores valores de eficiência, de COVR e COEA que a Condição 2; entretanto, deve-se notar que a COVA e a COEA da Condição 1 eram ligeiramente superiores às da Condição 2, como mostra a Tabela 5.6.

A Figura 5.5 apresenta os resultados dos perfis de concentração de matéria orgânica obtidos ao longo de um ciclo de operação nas Condições 1 a 4 . Nas Condições 1 e 2, as concentrações medidas logo no início dos ciclos foram 355 e 783 mgDQO/L, e ao final, 208 e $646 \mathrm{mgDQO} / \mathrm{L}$, respectivamente. Já nas Condições 3 e 4, as 
concentrações iniciais ficaram em 146 e 374 mgDQO/L, e as residuais, em 87 e $282 \mathrm{mgDQO} / \mathrm{L}$, respectivamente.

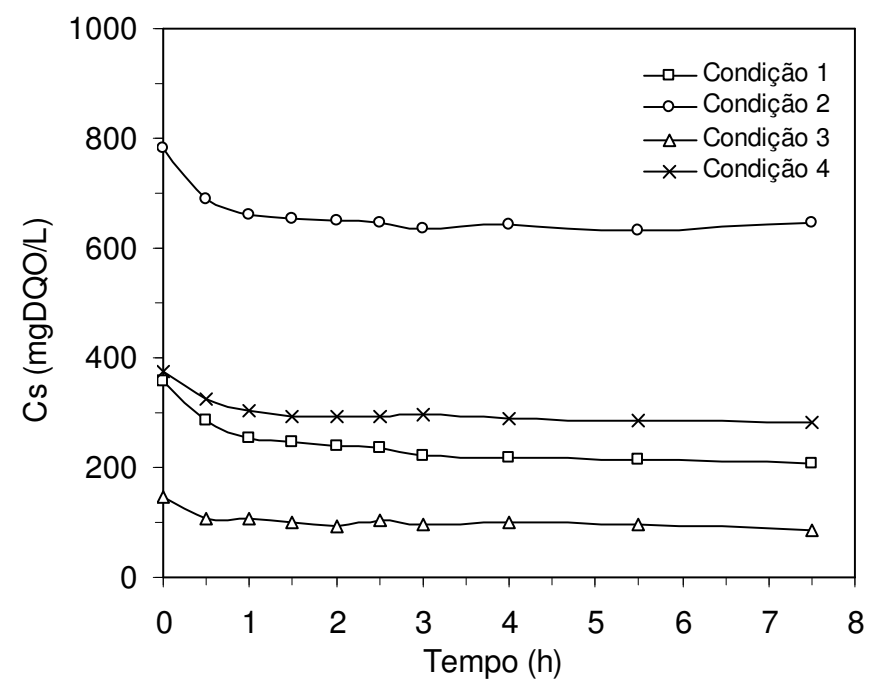

Figura 5.5 - Perfil de concentração de matéria orgânica do AnSBBR nas Condições 1 a 4

A Figura 5.5 sugere ainda que a conversão da matéria orgânica a metano foi interrompida com duas horas do inicio do ciclo nas Condições 2, 3 e 4 e, com três horas, na Condição 1. No entanto, isto se deve a uma limitação do método utilizado na quantificação da matéria orgânica presente no meio reacional, que não leva em conta as transformações bioquímicas que ocorrem ao longo do ciclo, contabilizando apenas a fração convertida a metano. Portanto, a variação de concentração de matéria orgânica ocorrida no início dos ciclos das Condições 1 a 4 está relacionada com o consumo dos compostos de fácil biodegradabilidade, rapidamente convertidos a metano. No período restante, em que esta variação é quase imperceptível, os compostos de difícil biodegradabilidade continuaram sendo processados e convertidos a metano e a outros compostos de cadeias carbônicas menores. 
As Figuras 5.6 e 5.7 apresentam respectivamente os resultados dos perfis de $\mathrm{pH}$ e de concentração de ácidos voláteis totais. Observa-se que as curvas de $\mathrm{pH}$ mantiveram-se dentro da faixa de monitoramento, que foi de 7,4 a 8,0 . Apenas a Condição 1 apresentou alguns pontos um pouco fora desta faixa. Já as curvas de AVT mostraram comportamento bastante similar e estável, sem formação de picos. Assim como no monitoramento, os valores de concentração de ácidos voláteis totais ficaram abaixo de $30 \mathrm{mgHAc} / \mathrm{L}$.

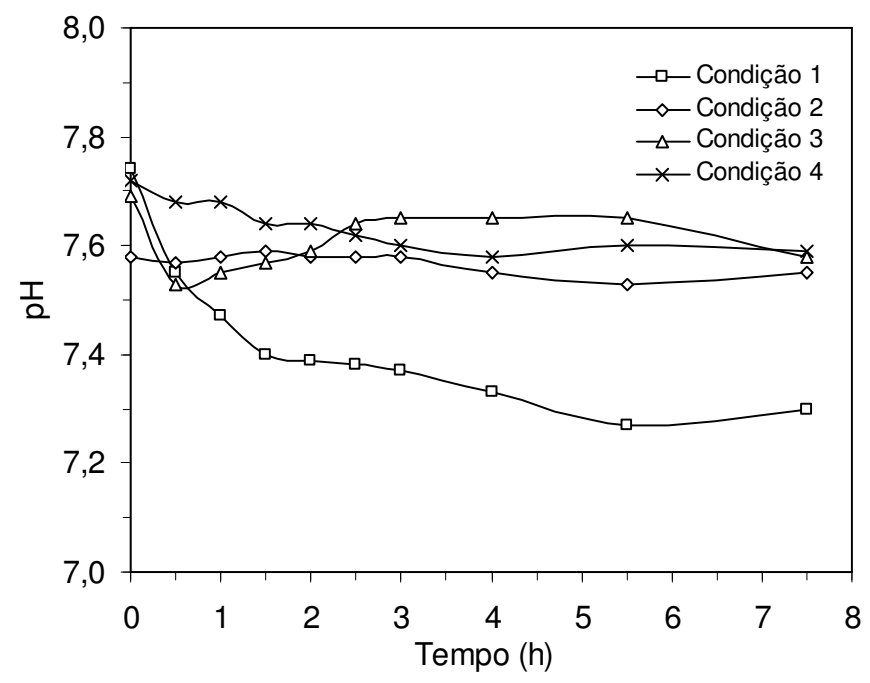

Figura 5.6 - Perfil de $\mathrm{pH}$ do AnSBBR nas Condições 1 a 4

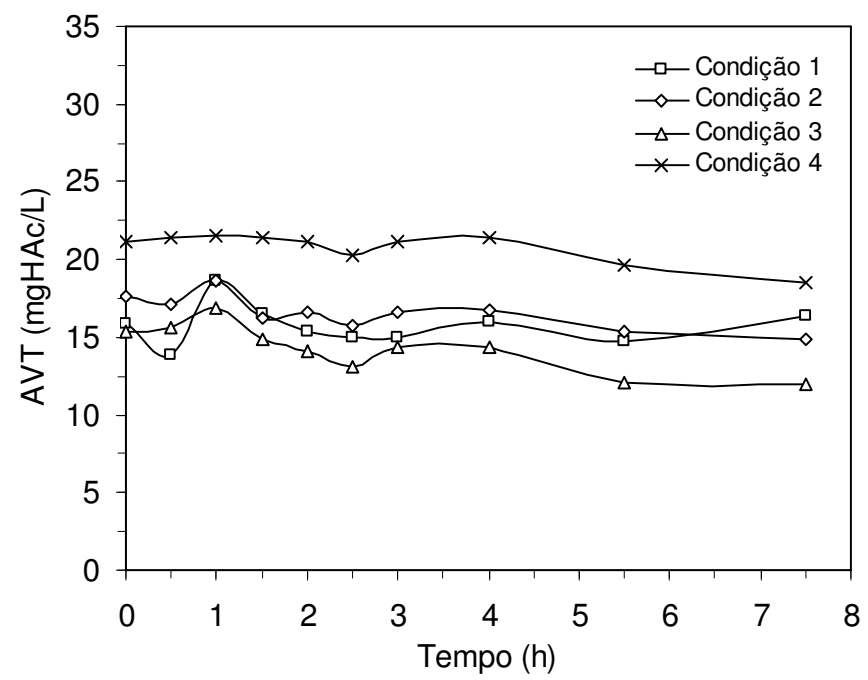

Figura 5.7 - Perfil de concentração de ácidos voláteis totais do AnSBBR nas Condições 1 a 4 
A Figura 5.8 apresenta os resultados dos perfis de alcalinidade a bicarbonato, obtidos ao longo de um ciclo de operação nas Condições 1 a 4 . Nesta figura, é possível observar que houve uma pequena geração de alcalinidade nas três últimas condições, passando de 198 para $209 \mathrm{mgCaCO}_{3} / \mathrm{L}$, na Condição 2, de 216 para $244 \mathrm{mgCaCO}_{3} / \mathrm{L}$, na Condição 3, e de 210 para $234 \mathrm{mgCaCO}_{3} / \mathrm{L}$, na Condição 4 . Na Condição 1, AB manteve-se estável em 188 mgCaCO $3 / \mathrm{L}$.

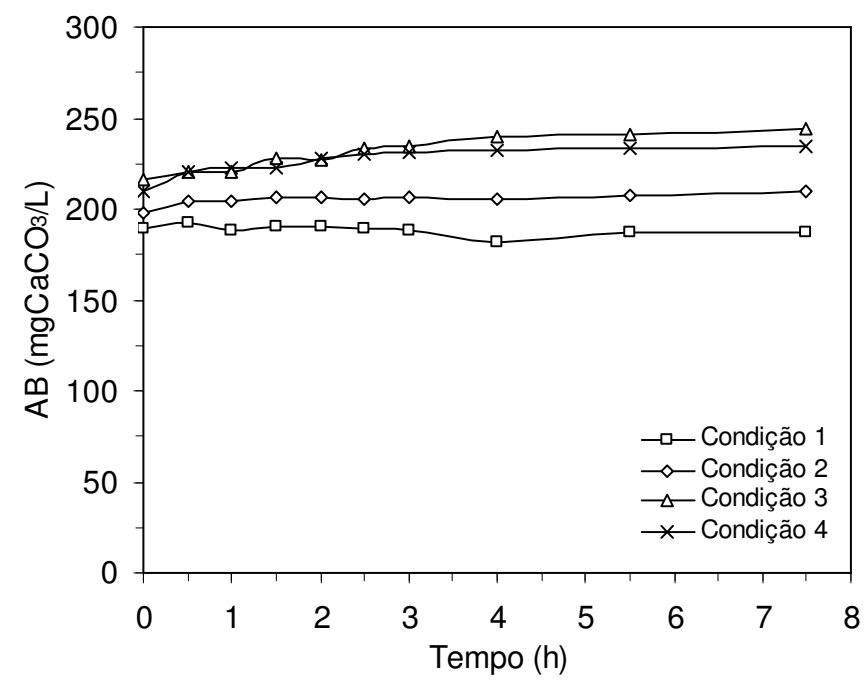

Figura 5.8 - Perfil de alcalinidade a bicarbonato do AnSBBR nas Condições 1 a 4

Nas Figuras 5.9 e 5.10 são apresentados os resultados dos perfis de concentração de metano e gás carbônico obtidos ao longo de um ciclo de operação nas Condições 1 a 4. Os maiores valores de concentração de metano deveriam ter sido encontrados nos perfis das Condições 1 e 2, que apresentaram os maiores valores de COVR e COER, seguidas das Condições 3 e 4, nesta ordem; isto porque as Condições 1 e 3 apresentaram valores maiores de eficiência de remoção de matéria orgânica que as Condições 2 e 4. Contudo, observa-se que ao final de oito horas de ciclo, a Condição 2 estava com 0,41 mmol/L, a Condição 1 e a Condição 4, com 0,26 mmol/L, e a Condição 3, com 0,22 mmol/L, o que pode ter sido motivado por 
problemas de vedação do sistema durante a realização dos perfis. Por outro lado, os valores de concentração de gás carbônico foram maiores nas Condições 1 e 3, com 0,85 mmol/L, seguidas da Condição 2, com 0,76 mmol/L, e da Condição 4, com $0,68 \mathrm{mmol} / \mathrm{L}$. De um modo geral, observa-se que os valores de concentração de metano e gás carbônico foram baixos.

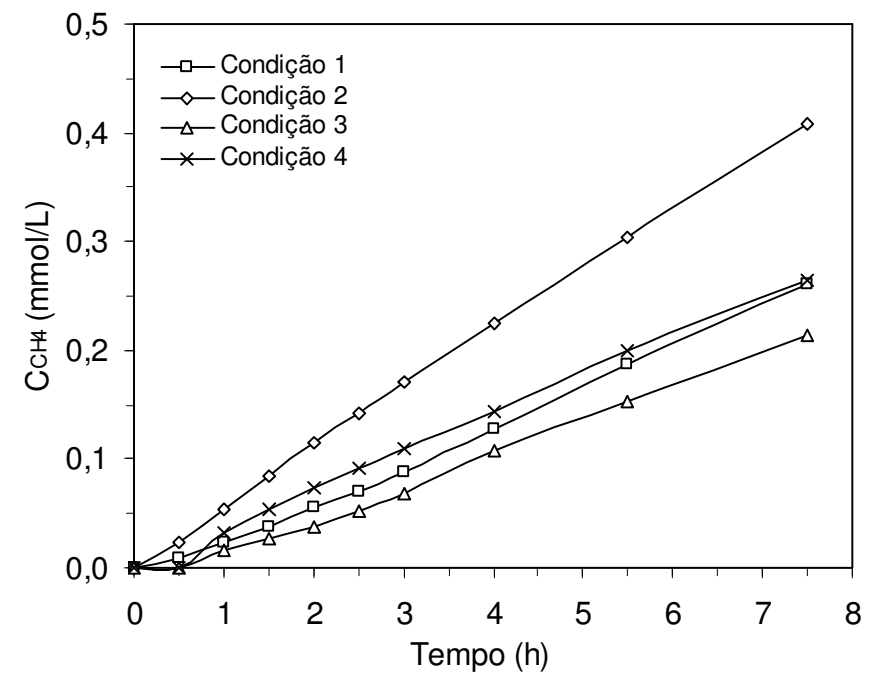

Figura 5.9 - Perfil de concentração de metano do AnSBBR nas Condições 1 a 4

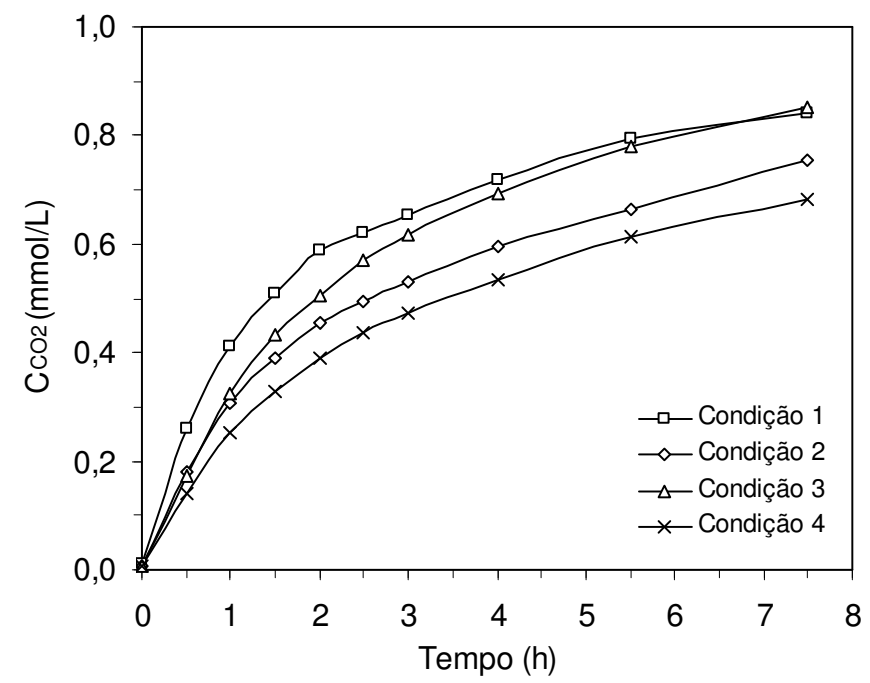

Figura 5.10 - Perfil de concentração de gás carbônico do AnSBBR nas Condições 1 a 4 
Os perfis de fração molar de metano e gás carbônico das Condições 1 a 4 são apresentados nas Figuras 5.11 e 5.12. Observa-se que a Condição 2 apresentou a maior fração molar de metano, cerca de $35,1 \%$, seguida das Condições 4,1 e 3 , com 27,8, 23,6 e 20,1\%, respectivamente. Estes resultados mostram que o biogás gerado continha mais gás carbônico que metano em sua composição.

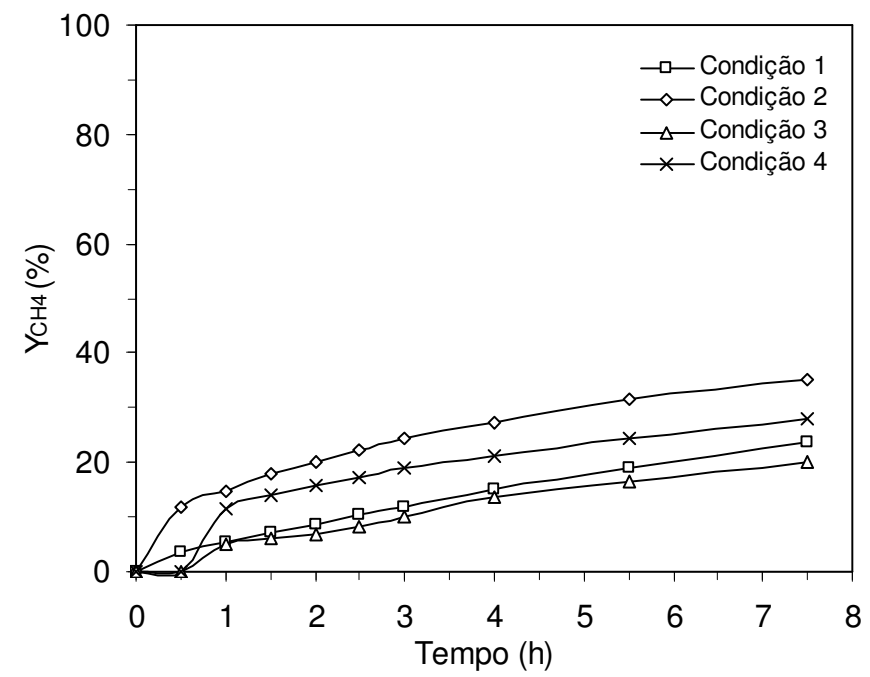

Figura 5.11 - Perfil de fração molar de metano do AnSBBR nas Condições 1 a 4

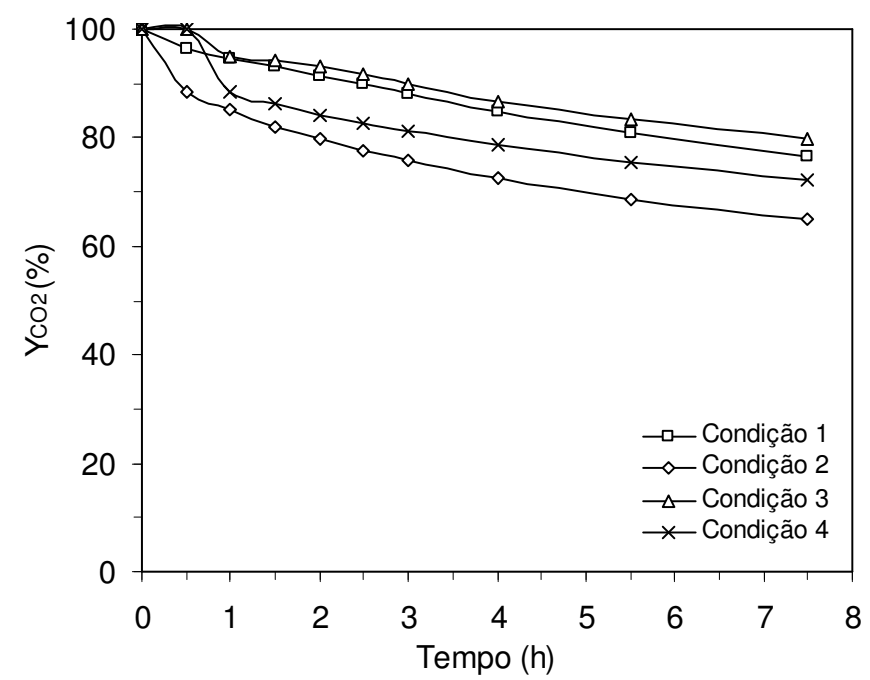

Figura 5.12 - Perfil de fração molar de gás carbônico do AnSBBR nas Condições 1 a 4 
Na Figura 5.13 são apresentados os resultados dos perfis de produção de metano do AnSBBR obtidos ao longo de um ciclo de operação nas Condições 1 a 4. Observa-se que a produção foi maior na Condição 1, com 7,58 mL, seguida pelas Condições 3, com 5,94 mL, 4, com 5,61 mL, e 2, com 4,92 mL. Estes resultados diferem dos obtidos nos perfis de concentração, mas também não estão de acordo com o que era esperado, visto que os maiores valores de produção de metano deveriam ter sido encontrados nas condições em que os valores de COVR e COER também eram maiores, ou seja, Condições 1 a 4, nesta ordem.

A Figura 5.13 também sugere que as Condições 3 e 4 possam ter atingido a máxima produção de metano com 4 ou 5 horas passadas do início de seus ciclos, contrariando a hipótese de que os compostos de difícil biodegradabilidade e seus intermediários ainda estivessem sendo degradados durante as 3 ou 4 horas restantes. Como os dados de monitoramento comprovam a existência de uma concentração residual no efluente das duas condições, é possível que tenha ocorrido algum tipo de inibição, ou tenha faltado substrato orgânico no meio reacional, ou simplesmente a assimilação do mesmo passou a ser energeticamente desfavorável para a biomassa; nos três casos, a energia usada pelos microrganismos até o início do próximo ciclo teria que ser retirada de suas reservas internas. Por outro lado, a produção de metano nas Condições 1 e 2 foi contínua durante todo ciclo de operação.

Ainda com relação à Figura 5.13, observa-se que o tempo de ciclo adotado para as Condições 3 e 4 foi superestimado, podendo ser reduzido em 3 ou 4 horas sem prejuízo para o sistema. Já nas Condições 1 e 2, mesmo sem atingir o valor máximo, é possível perceber que a produção de metano chegaria a um patamar de 
estabilização, caso o tempo de ciclo fosse maior. Desse modo, sugere-se um estudo de otimização do tempo de ciclo das quatro condições experimentais.

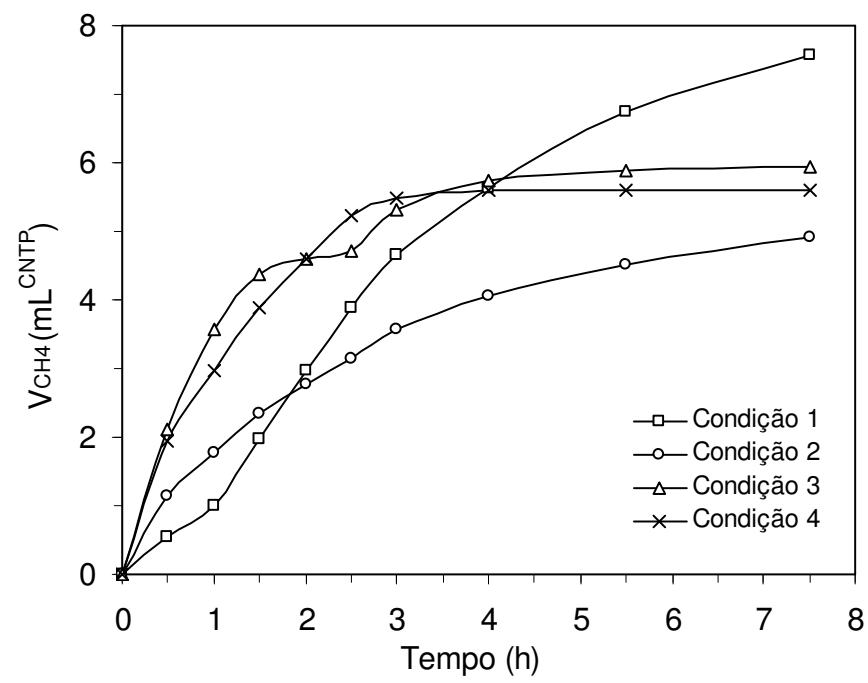

Figura 5.13 - Perfil de produção de metano do AnSBBR nas Condições 1 a 4

Na Figura 5.14 são apresentados os resultados dos perfis de produção específica de metano, medidos em função da massa de matéria orgânica removida do sistema. Observa-se que a Condição 3 apresentou o maior valor, cerca de $101 \mathrm{~mL} / \mathrm{gDQO}$, seguida das Condições 4, com $61 \mathrm{~mL} / \mathrm{gDQO}, 1$, com $52 \mathrm{~mL} / \mathrm{gDQO}$, e 2, com $36 \mathrm{~mL} / g D Q O$. Essa sequência é a mesma que a esperada, pois na prática a produção específica de metano depende da eficiência de remoção de matéria orgânica do sistema, uma vez que qualquer aumento da COVR e da COER implica aumento do volume de metano produzido. Além disso, o comportamento irregular das curvas deste perfil deve-se aos erros inerentes à determinação dos dados dos perfis de concentração de matéria orgânica e produção de metano. 


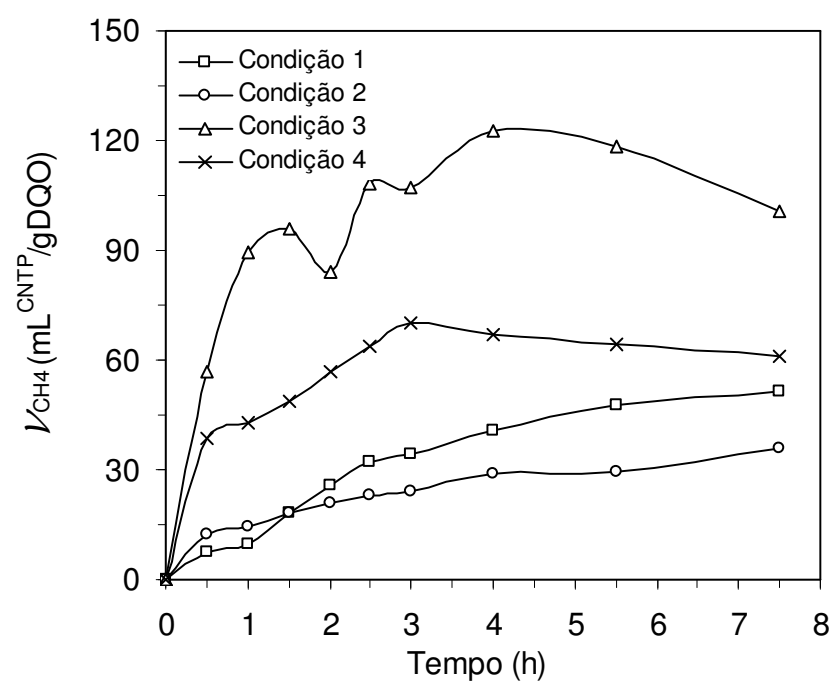

Figura 5.14 - Perfil de produção específica de metano do AnSBBR nas Condições 1 a 4

\subsubsection{MONITORAMENTO E PERFIS DAS CONDIÇÕES 5 A 8}

As Condições 5 a 8 diferiram quanto à carga orgânica aplicada e quanto ao uso de volume residual, assim como as Condições 1 a 4; mas ao contrário delas, que foram operadas em batelada, o modo de operação escolhido para as Condições 5 a 8 foi batelada alimentada, seguida de batelada. Nas Condições 5 e 6, a COVA era 1,5 gDQO/L.d, e nas Condições 7 e 8, 0,9 gDQO/L.d. Por outro lado, nas Condições 5 e 7, o reator era alimentado com 1,62 L de água residuária em 10 min, seguidos de mais $0,88 \mathrm{~L}$, em $4 \mathrm{~h}$, sendo que o total de 2,50 L era descarregado em $10 \mathrm{~min}$ logo após o término da etapa de reação. Já nas Condições 6 e 8, apenas 0,88 L do meio reacional era renovado de um ciclo para o outro, de modo que os 1,62 L restantes provinham do ciclo anterior como volume residual. Os resultados obtidos do monitoramento destas condições são apresentados nas Figuras 5.15 e 5.16 e na Tabela 5.7, e os dos perfis, nas Figuras 5.17 a 5.24 . 


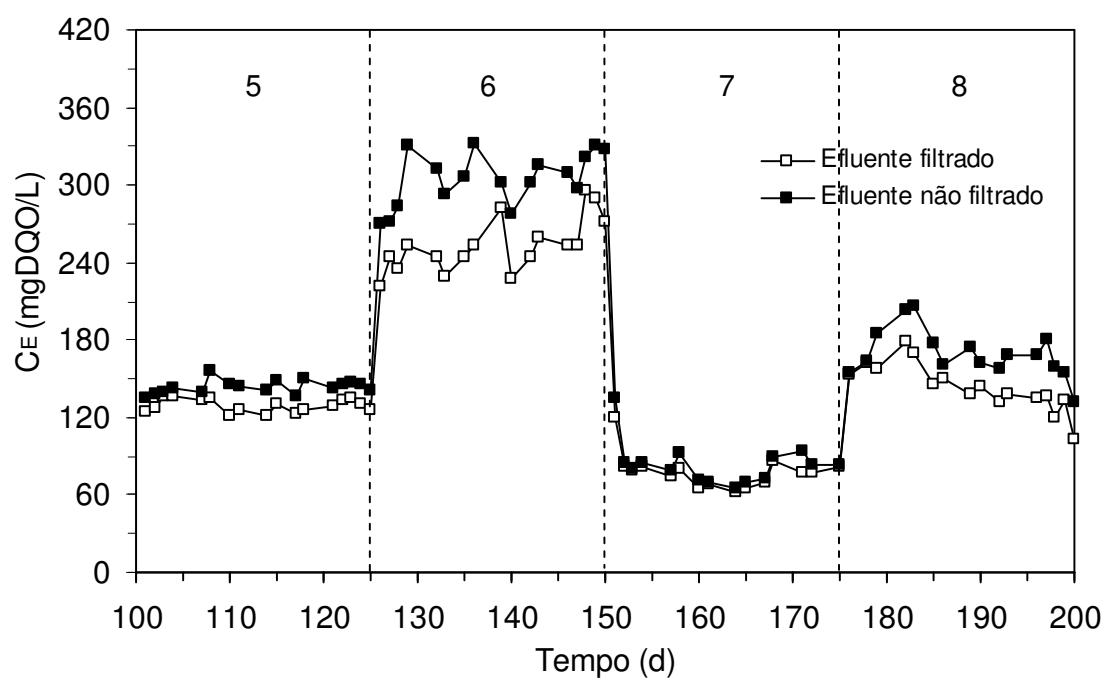

Figura 5.15 - Concentração de matéria orgânica na saída do AnSBBR nas Condições 5 a 8

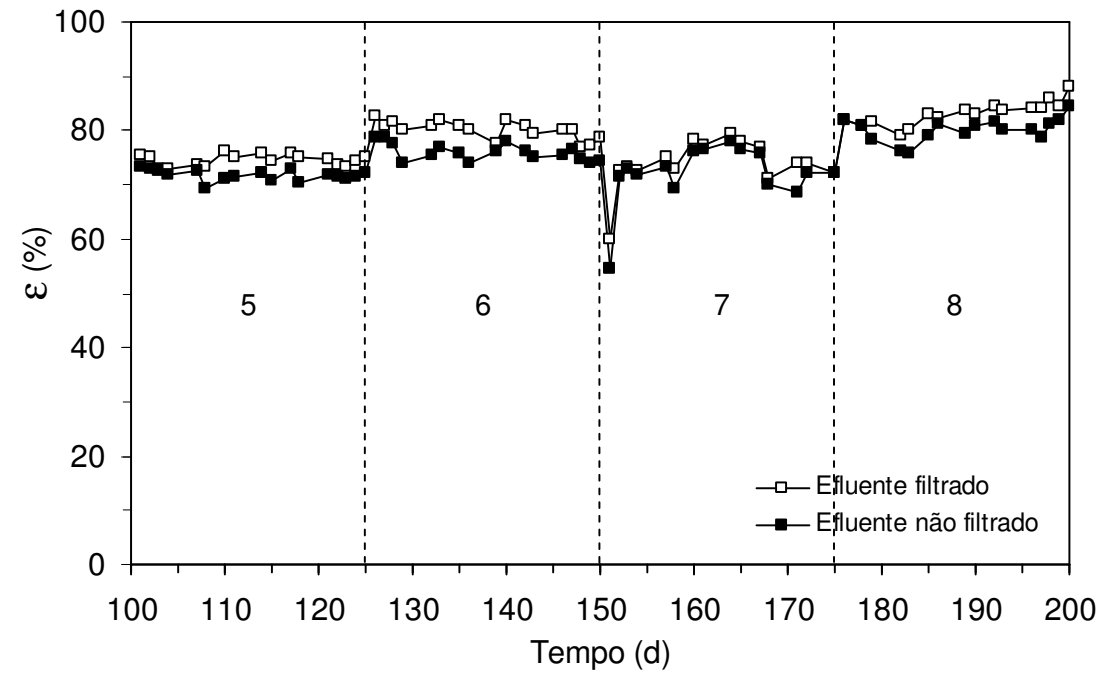

Figura 5.16 - Eficiência de remoção de matéria orgânica do AnSBBR nas Condições 5 a 8 
Tabela 5.7 - Variáveis monitoradas do AnSBBR nas Condições 5 a 8

\begin{tabular}{|c|c|c|c|c|}
\hline Condição & 5 & 6 & 7 & 8 \\
\hline Especificação & $1,5 \mathrm{BA} / \mathrm{B}$ & 1,5BA/B-RES & $0,9 \mathrm{BA} / \mathrm{B}$ & 0,9BA/B-RES \\
\hline $\mathrm{C}_{\mathrm{A}}(\mathrm{mgDQO} / \mathrm{L})$ & $507 \pm 8(17)$ & $1298 \pm 65(17)$ & $298 \pm 7(16)$ & $921 \pm 73(16)$ \\
\hline $\mathrm{C}_{\mathrm{ET}}(\mathrm{mgDQO} / \mathrm{L})$ & $144 \pm 5(15)$ & $311 \pm 16(14)$ & $80 \pm 9(14)$ & $163 \pm 14(11)$ \\
\hline$\varepsilon_{\mathrm{T}}(\%)$ & $72 \pm 1$ & $76 \pm 1$ & $73 \pm 3$ & $82 \pm 1$ \\
\hline $\mathrm{C}_{\mathrm{EF}}(\mathrm{mgDQO} / \mathrm{L})$ & $129 \pm 5(15)$ & $257 \pm 21(14)$ & $75 \pm 8(14)$ & $134 \pm 13(11)$ \\
\hline$\varepsilon_{\mathrm{F}}(\%)$ & $74 \pm 1$ & $80 \pm 2$ & $75 \pm 3$ & $85 \pm 1$ \\
\hline $\mathrm{V}_{\mathrm{D}, \mathrm{RT}}(\mathrm{L})$ & $1784 \pm 77(17)$ & $1506 \pm 10(16)$ & $1870 \pm 36(11)$ & $1655 \pm 54(16)$ \\
\hline $\mathrm{V}_{\mathrm{D}, \mathrm{RS}}(\mathrm{L})$ & $706 \pm 55$ (17) & $968 \pm 38(16)$ & $633 \pm 40(11)$ & $846 \pm 68(16)$ \\
\hline $\mathrm{V}_{\mathrm{D}}(\mathrm{L})$ & $2489 \pm 45(17)$ & $2474 \pm 32(16)$ & $2503 \pm 25(11)$ & $2501 \pm 31(16)$ \\
\hline COVA & $1,52 \pm 0,08$ & $1,52 \pm 0,16$ & $0,89 \pm 0,04$ & $0,93 \pm 0,16$ \\
\hline $\mathrm{COVR}_{\mathrm{T}}$ & $1,09 \pm 0,08$ & $1,16 \pm 0,16$ & $0,65 \pm 0,06$ & $0,77 \pm 0,16$ \\
\hline $\mathrm{COVR}_{\mathrm{F}}$ & $1,13 \pm 0,08$ & $1,22 \pm 0,16$ & $0,67 \pm 0,06$ & $0,80 \pm 0,16$ \\
\hline COEA & $0,075 \pm 0,003$ & $0,075 \pm 0,007$ & $0,044 \pm 0,001$ & $0,046 \pm 0,007$ \\
\hline $\mathrm{COER}_{\mathrm{T}}$ & $0,054 \pm 0,003$ & $0,057 \pm 0,007$ & $0,032 \pm 0,003$ & $0,038 \pm 0,007$ \\
\hline $\mathrm{COER}_{\mathrm{F}}$ & $0,056 \pm 0,003$ & $0,060 \pm 0,007$ & $0,033 \pm 0,003$ & $0,040 \pm 0,007$ \\
\hline $\mathrm{pH}_{\mathrm{A}}$ & $8,2 \pm 0,1$ (8) & $8,0 \pm 0,1$ (8) & $7,9 \pm 0,1$ (8) & $8,1 \pm 0,1(8)$ \\
\hline $\mathrm{pH}_{\mathrm{E}}$ & $7,5 \pm 0,1(8)$ & $7,5 \pm 0,1(8)$ & $7,6 \pm 0,1(7)$ & $7,6 \pm 0,1(8)$ \\
\hline$(\mathrm{Al} / \mathrm{AP})_{\mathrm{A}}$ & $0,23 \pm 0,02$ & $0,28 \pm 0,02$ & $0,26 \pm 0,02$ & $0,25 \pm 0,02$ \\
\hline$(\mathrm{Al} / \mathrm{AP})_{\mathrm{E}}$ & $0,24 \pm 0,01$ & $0,29 \pm 0,02$ & $0,26 \pm 0,02$ & $0,25 \pm 0,03$ \\
\hline $\mathrm{AVT}_{\mathrm{A}}(\mathrm{mgHAc} / \mathrm{L})$ & $23 \pm 1(8)$ & $19 \pm 1(8)$ & $18 \pm 3(8)$ & $15 \pm 1(8)$ \\
\hline $\mathrm{AVT}_{\mathrm{E}}(\mathrm{mgHAc} / \mathrm{L})$ & $23 \pm 1(8)$ & $19 \pm 1(8)$ & $18 \pm 3(7)$ & $14 \pm 1(8)$ \\
\hline $\mathrm{AB}_{\mathrm{A}}(\mathrm{mgCaCO} / \mathrm{L})$ & $205 \pm 2(8)$ & $202 \pm 2(8)$ & $222 \pm 2(8)$ & $211 \pm 1(8)$ \\
\hline $\mathrm{AB}_{\mathrm{E}}\left(\mathrm{mgCaCO}{ }_{3} / \mathrm{L}\right)$ & $242 \pm 1(8)$ & $260 \pm 5(8)$ & $256 \pm 6(7)$ & $272 \pm 4(8)$ \\
\hline $\mathrm{ST}_{\mathrm{A}}(\mathrm{mg} / \mathrm{L})$ & $731 \pm 33(2)$ & $1124 \pm 30(3)$ & $626 \pm 19(3)$ & $954 \pm 14(3)$ \\
\hline $\mathrm{ST}_{\mathrm{E}}(\mathrm{mg} / \mathrm{L})$ & $691 \pm 33(2)$ & $895 \pm 25(3)$ & $656 \pm 31(2)$ & $738 \pm 21(3)$ \\
\hline $\mathrm{SVT}_{\mathrm{A}}(\mathrm{mg} / \mathrm{L})$ & $474 \pm 20(2)$ & $765 \pm 38(3)$ & $371 \pm 28(3)$ & $635 \pm 48(3)$ \\
\hline $\mathrm{SVT}_{\mathrm{E}}(\mathrm{mg} / \mathrm{L})$ & $496 \pm 11(2)$ & $590 \pm 33(3)$ & $462 \pm 48(2)$ & $483 \pm 38(3)$ \\
\hline $\mathrm{SST}_{\mathrm{A}}(\mathrm{mg} / \mathrm{L})$ & $50 \pm 3(2)$ & $123 \pm 7(3)$ & $33 \pm 3(3)$ & $95 \pm 6(3)$ \\
\hline $\mathrm{SST}_{\mathrm{E}}(\mathrm{mg} / \mathrm{L})$ & $5 \pm 1(2)$ & $33 \pm 11(3)$ & $7 \pm 1(2)$ & $57 \pm 1(3)$ \\
\hline $\mathrm{SSV}_{\mathrm{A}}(\mathrm{mg} / \mathrm{L})$ & $44 \pm 0(2)$ & $103 \pm 3(3)$ & $30 \pm 2(3)$ & $85 \pm 6(3)$ \\
\hline $\mathrm{SSV}_{\mathrm{E}}(\mathrm{mg} / \mathrm{L})$ & $4 \pm 3(2)$ & $25 \pm 10(3)$ & $7 \pm 1(2)$ & $53 \pm 6(3)$ \\
\hline
\end{tabular}

Nota: ( ) número de amostras usadas no cálculo do valor médio das variáveis. Unidades: $[\mathrm{COVA}]=\left[\mathrm{COVR} T=\left[\mathrm{COVR}_{\mathrm{F}}\right]=\mathrm{gDQO} / \mathrm{L} . \mathrm{d} ;[\mathrm{COEA}]=\left[\mathrm{COER} \mathrm{R}_{\mathrm{T}}\right]=\left[\mathrm{COER}_{\mathrm{F}}\right]=\right.$ $=$ gDQO/gSVT.d. 
Nas Figuras 5.15 e 5.16 são apresentados dados de concentração e eficiência de remoção de matéria orgânica para amostras filtradas e não filtradas do efluente ao longo das Condições 5 a 8. Observa-se que o sistema atingiu a estabilidade em todas as condições experimentais logo nos primeiros dias de operação, sugerindo que a mudança da estratégia de alimentação de batelada para batelada alimentada, seguida de batelada, melhorou a resposta do sistema às perturbações causadas pelas alterações na COVA e pela descompactação do leito do reator. É possível perceber, por exemplo, que a queda de eficiência na transição das Condições 6 e 7, motivada por uma das causas supracitadas, foi rapidamente amortecida.

A Tabela 5.7 apresenta os dados obtidos do monitoramento de algumas variáveis das Condições 5 a 8. Observa-se que os valores médios de $\mathrm{pH}$ do afluente e do efluente apresentaram pequenas diferenças entre si nas quatro condições experimentais, oscilando entre 7,4 e 8,3. No caso da concentração de ácidos voláteis totais, os valores foram inferiores a $30 \mathrm{mgHAc} / \mathrm{L}$ e praticamente sem diferenças. Por outro lado, os valores médios de alcalinidade a bicarbonato do afluente e do efluente sugerem que houve geração de alcalinidade. Isto mostra que mesmo a aplicação da carga volumétrica de bicarbonato não sendo coerente com a concentração de matéria orgânica, o AnSBBR foi capaz de operar sem comprometimento do sistema, o que só foi possível em virtude das características da água residuária. Ressalta-se que as cargas volumétricas de bicarbonato foram 0,60 g/L.d, nas Condições 5 e 7, e 0,20 g/L.d, nas Condições 6 e 8, quando deveriam ter sido 0,60 g/L.d nas Condições 5 e 6, e 0,36 g/L.d nas Condições 7 e 8.

Comparando a Condição 5 com a 7, e a 6 com a 8, nota-se que as condições com valores maiores de COVA e COEA, no caso as Condições 5 e 6 , foram as que 
apresentaram valores maiores de COVR e COER, mas também valores menores de eficiência. Mais uma vez, a explicação para isto está relacionada à biodegradabilidade da matéria orgânica encontrada na água residuária. Nas Condições 5 e 6 o consumo dos compostos de difícil e, principalmente, de fácil biodegradabilidade foi maior, motivado pela maior concentração deles no meio reacional. Contudo, nas Condições 7 e 8 , em que a quantidade destes compostos era menor, a biomassa conseguiu degradar uma fração proporcionalmente maior dos mesmos, o que culminou com o aumento da eficiência do processo. Novamente, a velocidade média de consumo do substrato acabou sendo maior nas condições de menor COVA, sugerindo a ocorrência de alguma interferência no mecanismo de reação, advinda provavelmente da própria reação, já que a temperatura e a velocidade de recirculação eram as mesmas em todas as condições experimentais.

Comparando agora a Condição 5 com a 6 , e a 7 com a 8, observa-se que as condições que fizeram uso do volume residual para compor parte do meio líquido do ciclo seguinte, no caso as Condições 6 e 8, também foram as que apresentaram valores maiores de eficiência de remoção de matéria orgânica, COVR e COER. O efeito de diluição do volume residual sobre a água residuária, associado a operação do sistema em batelada alimentada, mantinha baixos os valores de concentração de substrato no meio reacional, o que resultava em baixas velocidades de consumo de matéria orgânica. Por outro lado, nas Condições 5 e 7, em que não se fez uso do volume residual, a redução da velocidade não foi tão grande, pois o volume de partida do sistema continha bastante substrato, considerando que parte da água residuária era alimentada em 10 min logo após a operação de descarga do ciclo anterior. Mesmo assim, a velocidade média de consumo do substrato acabou sendo maior nas condições em que essa velocidade, pelo menos na teoria, deveria ter sido 
menor, reforçando a idéia de ocorrência de algum tipo de interferência no mecanismo de reação.

A Figura 5.17 apresenta os resultados dos perfis de concentração de matéria orgânica das Condições 5 a 8. Analisando estes dados, observa-se dois tipos de comportamento. Nas Condições 5 e 7, os perfis são decrescentes ao longo de todo ciclo operacional, revelando que a velocidade de consumo do substrato era maior que a vazão específica de entrada do mesmo no sistema. Como nestas duas condições o reator era previamente alimentado com água residuária, os valores de concentração de substrato conseguiam atingir um patamar suficientemente elevado para, desde o início do ciclo, manter a velocidade de consumo acima da vazão específica de entrada. Por outro lado, os perfis obtidos nas Condições 6 e 8 mostram um comportamento crescente durante parte do ciclo, e decrescente na outra parte. Ocorre que nesta primeira parte, a vazão específica de entrada do substrato no sistema era maior que a velocidade de consumo do mesmo, visto que logo início do ciclo, a concentração de matéria orgânica no meio reacional era muito baixa e correspondia à concentração residual do ciclo anterior. Aos poucos, porém, a concentração do substrato foi aumentando justamente por conta da alimentação, e a velocidade de consumo cresceu proporcionalmente. A segunda parte do perfil, na qual se observa o comportamento decrescente, só teve início quando a velocidade de consumo do substrato conseguiu superar a vazão específica de entrada, como na Condição 8, ou simplesmente quando a alimentação foi suspensa, que é o que sugere o perfil da Condição 6. 


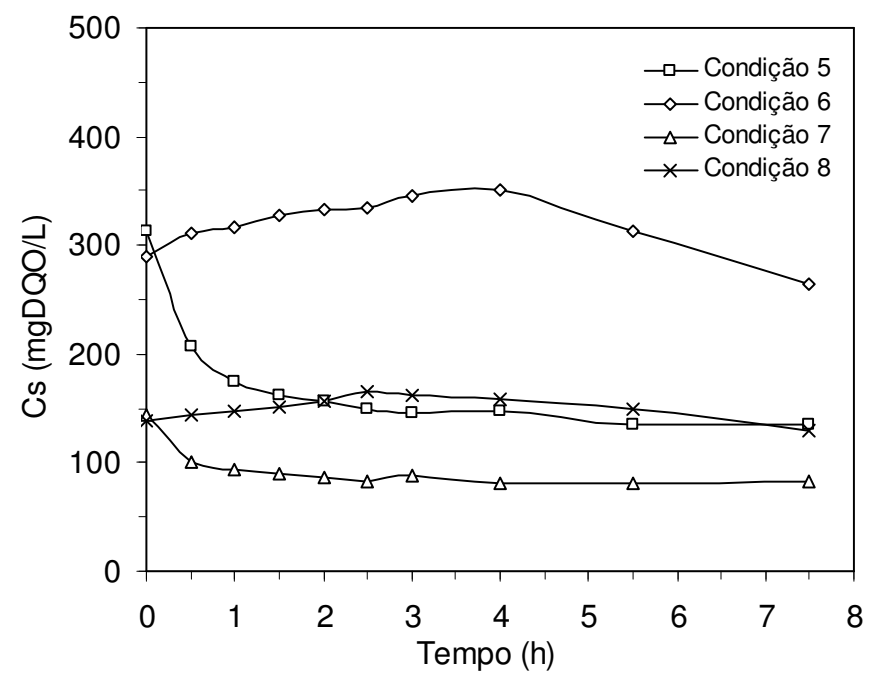

Figura 5.17 - Perfil de concentração de matéria orgânica do AnSBBR nas Condições 5 a 8

A Figura 5.18 apresenta os resultados dos perfis de $\mathrm{pH}$ obtidos ao longo de um ciclo de operação nas Condições 5 a 8 . Observa-se que as curvas mostraram comportamento estável, dentro da faixa de monitoramento, que foi de 7,4 a 8,3.

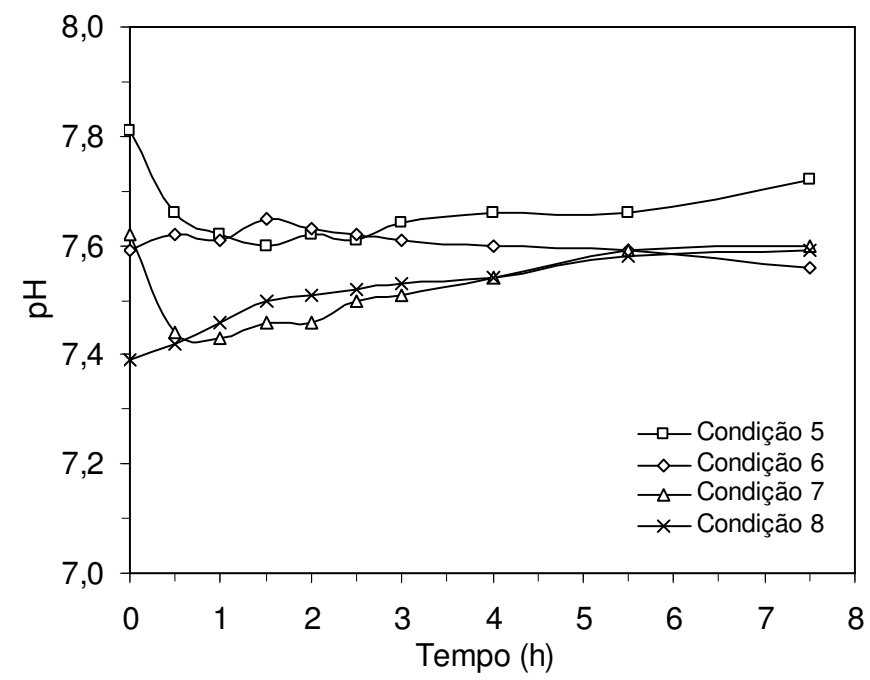

Figura 5.18 - Perfil de $\mathrm{pH}$ do AnSBBR nas Condições 5 a 8

Na Figura 5.19 são apresentados os resultados dos perfis de concentração de ácidos voláteis totais do AnSBBR obtidos nas Condições 5 a 8 . Observa-se que não 
houve variações de concentração ao longo dos ciclos, com pontos sempre abaixo de $30 \mathrm{mgHAc} / \mathrm{L}$.

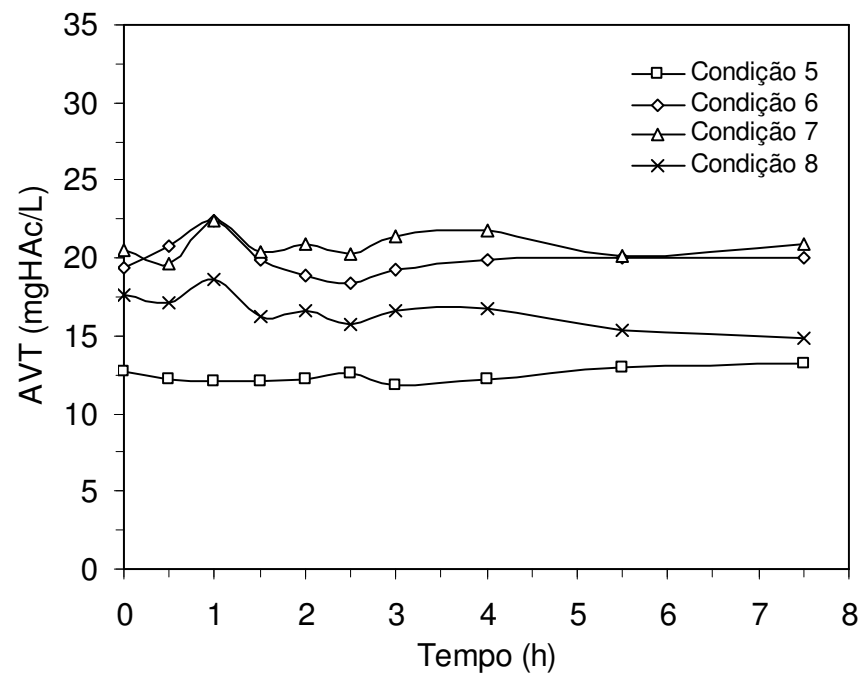

Figura 5.19 - Perfil de concentração de ácidos voláteis totais do AnSBBR nas Condições 5 a 8

A Figura 5.20 apresenta os resultados dos perfis de alcalinidade a bicarbonato do AnSBBR obtidos ao longo dos ciclos operacionais das Condições 5 a 8 . Observa-se que não houve geração de alcalinidade nas Condições 6 e 8. Nesta última, por exemplo, a concentração manteve-se estável, entre 252 e 257 mgCaCO $3 / L$.

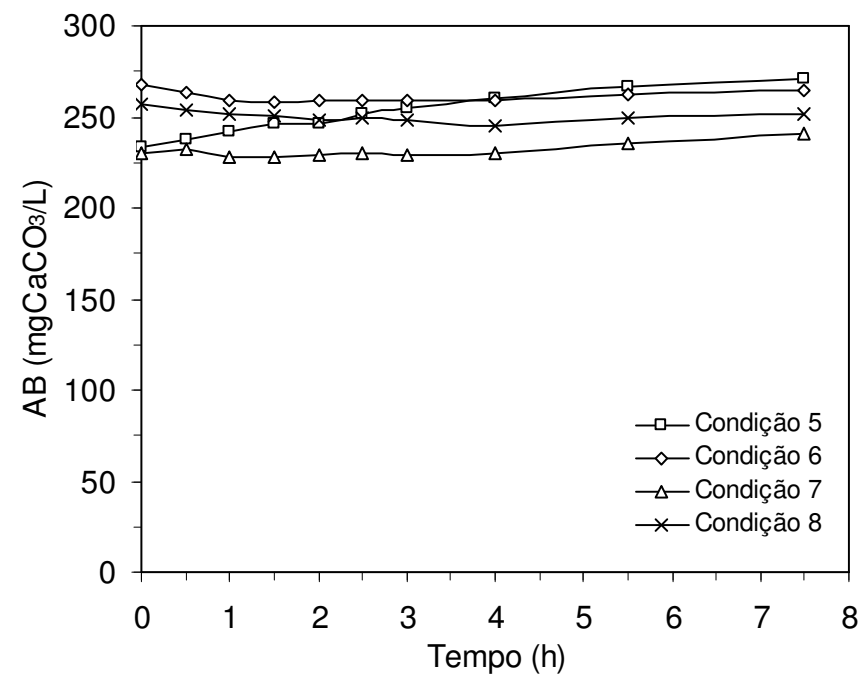

Figura 5.20 - Perfil de alcalinidade a bicarbonato do AnSBBR nas Condições 5 a 8 
As Figuras 5.21 e 5.22 apresentam os resultados dos perfis de concentração de metano e gás carbônico obtidos nas Condições 5 a 8. Os maiores valores de concentração de metano foram encontrados na Condição 6, com 1,56 mmol/L, seguida das Condições 8, com 0,97 mmol/L, 5, com 0,47 mmol/L, e 7, com $0,13 \mathrm{mmol} / \mathrm{L}$. No entanto, a ordem correta seria encabeçada pela Condição 6, seguida das Condições 5, 8 e 7, já que os valores de concentração de metano estão diretamente relacionados com os valores de COVR e COER. Provavelmente, problemas de vedação do sistema durante a realização dos perfis impediram a obtenção de resultados mais confiáveis. Por outro lado, os maiores valores de concentração de gás carbônico foram obtidos nas Condições 6 e 8, com 1,36 e $0,92 \mathrm{mmolCO}_{2} / \mathrm{L}$, respectivamente, seguidas das Condições $7, \mathrm{com} 0,82 \mathrm{mmol} / \mathrm{L}$, e 5 , com $0,74 \mathrm{mmol} / \mathrm{L}$.

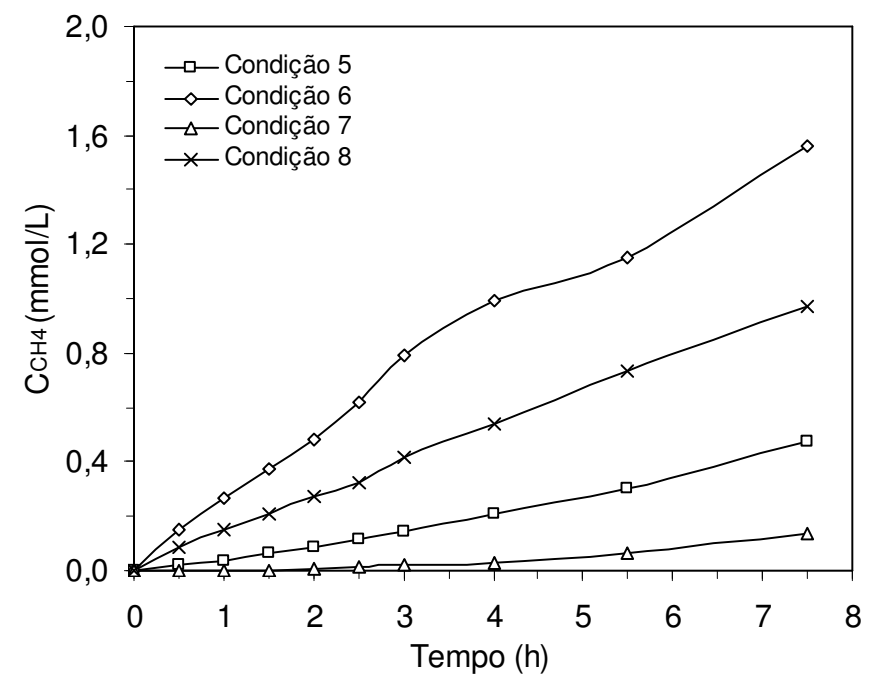

Figura 5.21 - Perfil de concentração de metano do AnSBBR nas Condições 5 a 8 


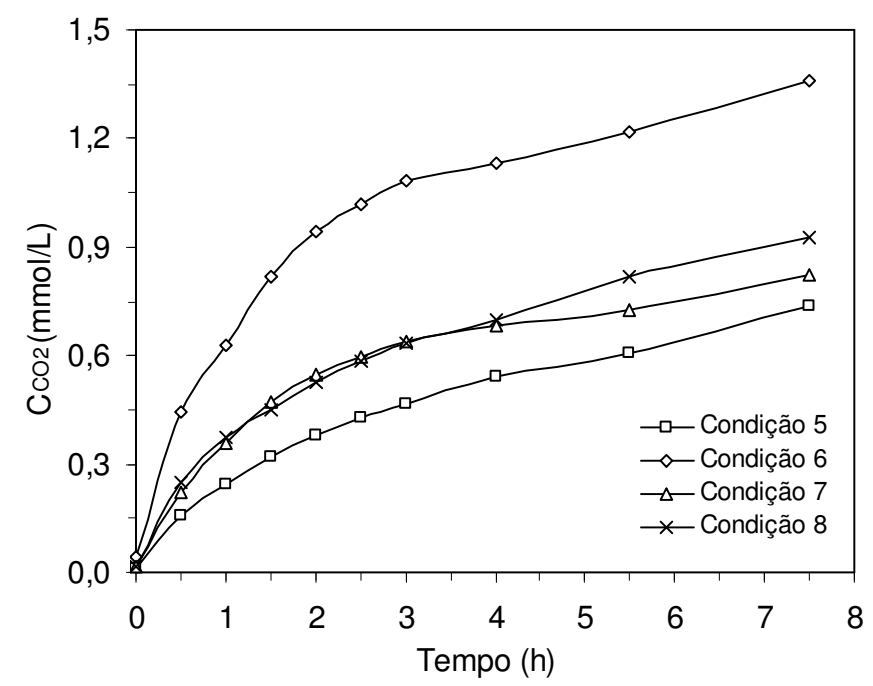

Figura 5.22 - Perfil de concentração de gás carbônico do AnSBBR nas Condições 5 a 8

Nas Figuras 5.23 e 5.24 são apresentados os resultados dos perfis de fração molar de metano e gás carbônico obtidos ao longo de um ciclo de operação nas Condições 5 a 8 . Observa-se que as Condições 6 e 8 apresentaram praticamente os mesmos valores de fração molar, cerca de $53 \%$ de metano e $47 \%$ de gás carbônico, na Condição 6 e, 51\% de metano e 49\% de gás carbônico, na Condição 8 . Na sequência, vem a Condição 5, com 39\% de metano e $61 \%$ de gás carbônico, e a Condição 7, com 14\% de metano e $86 \%$ de gás carbônico.

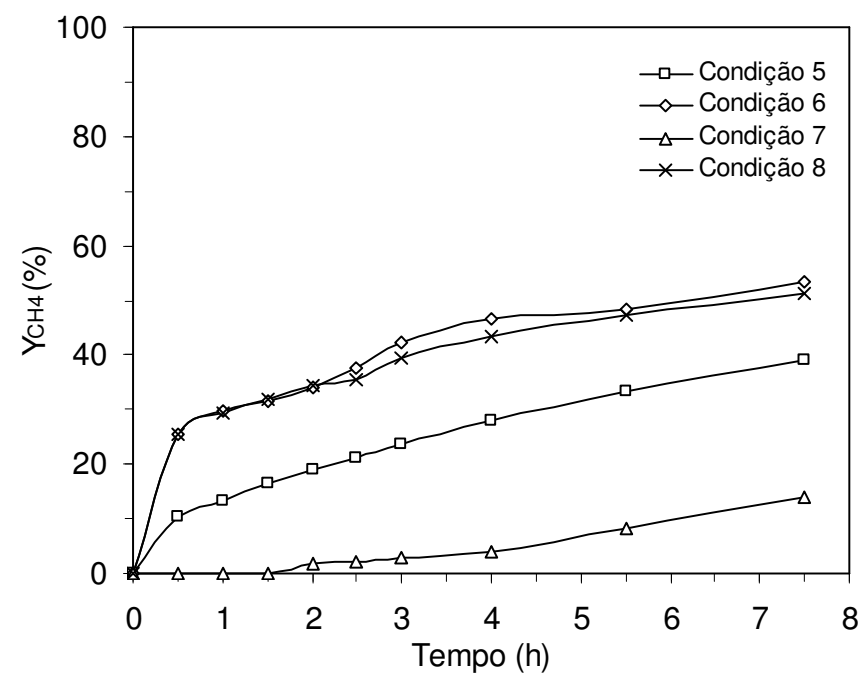

Figura 5.23 - Perfil de fração molar de metano do AnSBBR nas Condições 5 a 8 


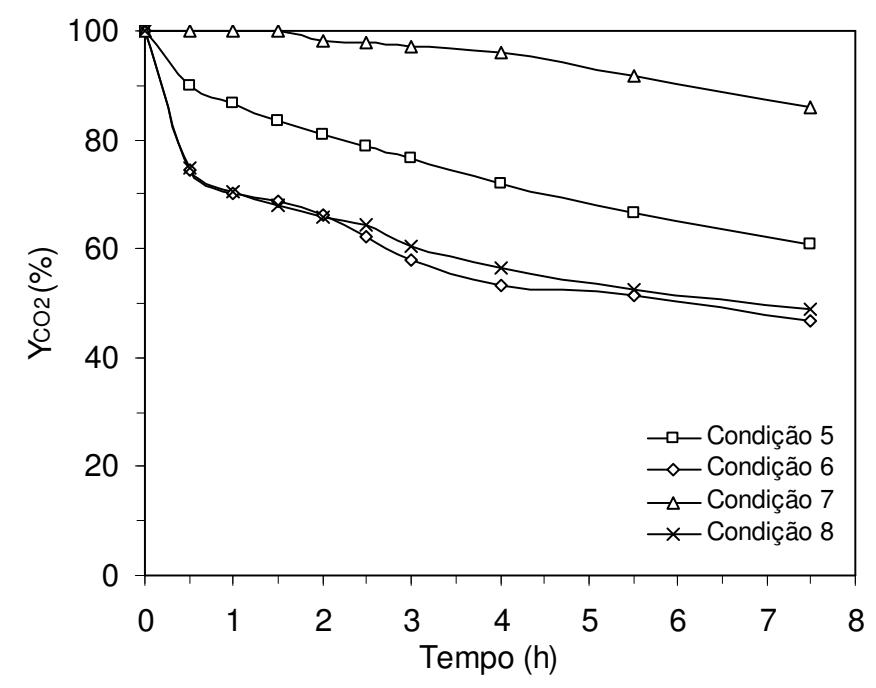

Figura 5.24 - Perfil de fração molar de gás carbônico do AnSBBR nas Condições 5 a 8

\subsubsection{ESTUDO COMPARATIVO DAS CONDIÇÕES EXPERIMENTAIS DO ANSBBR}

O controle do volume de meio reacional do sistema foi bastante complicado, pois à medida que o leito compactava ao longo de cada condição, motivado pela retenção de sólidos, o volume do reator diminuía e o do reservatório aumentava. Com isso, era necessário fazer ajustes nos valores de concentração de matéria orgânica para manter a COVA, principalmente nas condições em que se fez uso do volume residual. A diferença é que nestas condições o meio reacional era descarregado apenas pelo reservatório, enquanto que nas outras, sem residual, a descarga era feita tanto pelo reservatório quanto pelo reator, não deixando o leito tão estático. A Tabela 5.8 apresenta um quadro resumo das condições experimentais do AnSBBR e seu principais resultados. 
Tabela 5.8 - Quadro resumo das condições experimentais do AnSBBR

\begin{tabular}{|c|c|c|c|c|c|c|c|c|}
\hline Condição & 1 & 2 & 3 & 4 & 5 & 6 & 7 & 8 \\
\hline $\begin{array}{c}\text { COVA } \\
\text { (gDQO/L.d) }\end{array}$ & 1,5 & 1,5 & 0,9 & 0,9 & 1,5 & 1,5 & 0,9 & 0,9 \\
\hline $\begin{array}{l}\text { Estratégia de } \\
\text { operação }\end{array}$ & B & B & B & B & $\mathrm{BA} / \mathrm{B}$ & $\mathrm{BA} / \mathrm{B}$ & $\mathrm{BA} / \mathrm{B}$ & $\mathrm{BA} / \mathrm{B}$ \\
\hline $\begin{array}{l}\text { Volume } \\
\text { Residual }\end{array}$ & NÃO & SIM & NÃO & SIM & NÃO & SIM & NÃO & SIM \\
\hline $\begin{array}{l}\varepsilon_{F} \\
(\%)\end{array}$ & 60 & 54 & 71 & 70 & 74 & 80 & 75 & 85 \\
\hline $\begin{array}{c}\text { COVR }_{F} \\
\text { (gDQO/L.d) }\end{array}$ & 0,91 & 0,79 & 0,65 & 0,62 & 1,13 & 1,22 & 0,67 & 0,80 \\
\hline $\begin{array}{c}\text { COER }_{\mathrm{F}} \\
\text { (gDQO/gSVT.d) }\end{array}$ & 0,045 & 0,039 & 2 & 031 & 0,056 & 0,060 & 0,033 & 0,040 \\
\hline
\end{tabular}

Ao comparar a Condição 1 com a 5, e a 3 com 7, observa-se que as Condições 5 e 7, operadas em batelada alimentada, seguida de batelada (BA/B), apresentaram valores maiores de eficiência, COVA e COER, que as Condições 1 e 3, operadas apenas em batelada (B). Inclusive, as diferenças entre os valores obtidos foram mais acentuadas nas Condições 1 e 5, de maior COVA. Nas Condições 1 e 3, o reator era alimentado com 2,5 L de água residuária logo no início do ciclo, ao passo que, nas Condições 5 e 7, apenas $65 \%$ deste volume era alimentado da mesma forma; os $35 \%$ restantes eram alimentados durante $4 \mathrm{~h}$. Esta mudança de estratégia diminuiu a oferta de substrato no início do ciclo, reduzindo a velocidade de consumo de substrato. Dessa forma, esperava-se pela diminuição dos valores de eficiência, COVR e COER, mas o que se obteve foi justamente o contrário. Portanto, algum tipo de interferência ocorreu na degradação da matéria orgânica no meio reacional ao longo destas condições experimentais, que só com a operação do AnSBBR em batelada alimentada é que se conseguiu minimizar seus efeitos. 
Comparando a Condição 2 com a 6 , e a 4 com a 8 , chega-se as mesmas conclusões. As Condições 6 e 8, operadas em batelada alimentada, seguida de batelada, foram as que apresentaram maiores valores de eficiência, COVR e COER, e as Condições 2 e 6, de maior COVA, as que apresentaram as maiores diferenças entre estes valores. Por outro lado, a estratégia de alimentação empregada nas Condições 2 e 4 consistia em carregar o reator com 0,88L de água residuária em 10 min, logo no início do ciclo, enquanto que, nas Condições 6 e 8, este mesmo volume era alimentado em $4 \mathrm{~h}$. Em todas elas, o volume residual do ciclo anterior era usado para completar os $2,50 \mathrm{~L}$ de meio reacional do ciclo seguinte. Portanto, a concentração inicial de substrato no meio foi muito maior nas Condições 2 e 4 que nas Condições 6 e 8, o que se reproduziu na cinética das transformações bioquímicas, curiosamente favorecendo as condições em que a velocidade de consumo de substrato parecia ser menor. Novamente, a justificativa recai na ocorrência de interferência no processo de conversão da matéria orgânica a metano.

A dificuldade de degradação da matéria orgânica observada entre as condições experimentais não poderia ser justificada por ação do substrato, visto que as condições de maior COVA, caso das Condições 1, 2, 5 e 6, apresentaram os maiores valores de COVR e COER. Além disso, este tipo de interferência não explicaria a ocorrência de interrupções no processo de conversão da matéria orgânica a metano, como as que aconteceram nas Condições 3 e 4, tendo em vista que a concentração do substrato nestas duas condições é máxima logo no início do ciclo. Interferência por ação do produto final também foi descartada, já que a produção de metano em todas as condições experimentais foi baixa demais para sustentar esta hipótese; além do que, todo metano gerado é liberado do sistema. Por outro lado, a dificuldade de degradação da matéria orgânica pode ter sido 
motivada por ação de algum produto intermediário. Numa rápida avaliação, observase que seus efeitos aumentariam à medida que sua concentração no meio reacional também aumentasse, o que dependeria diretamente da concentração inicial de substrato e da estratégia de alimentação utilizada, como de fato se observou ao longo das condições experimentais. Esta explicação serve inclusive de justificativa para a interrupção da degradação da matéria orgânica nas Condições 3 e 4, depois que as hipóteses de falta de substrato e de consumo energeticamente desfavorável foram descartadas, em razão da obtenção de valores maiores de eficiência nas Condições 7 e 8, em que a COVA era exatamente a mesma. O que de fato aconteceu foi que a concentração de produtos intermediários chegou a um valor limite, acima do qual a biomassa tinha extrema dificuldade de converter substrato a metano dentro de um período correspondente ao final do ciclo.

Um ponto que também precisa ser esclarecido é o uso do volume residual que, nas Condições 1 a 4, provocou a diminuição da eficiência de remoção de matéria orgânica do sistema, enquanto que, nas Condições 5 a 8, propiciou seu aumento. De fato, o volume residual por si só não traz benefícios ao sistema, pois corresponde a um volume de meio reacional com matéria orgânica parcialmente degradada, em sua maioria produtos intermediários da decomposição dos compostos de difícil biodegradabilidade, visto que os de fácil eram consumidos ao longo do ciclo. Por outro lado, este mesmo volume é capaz de exercer um efeito de diluição sobre a água residuária alimentada, reduzindo os valores de concentração de substrato no meio e, consequentemente, minimizando os efeitos da dificuldade de degradação da matéria orgânica. Portanto, o uso do volume residual deve ser interpretado apenas como parte da estratégia de alimentação adotada. Como nas Condições 1 a 40 AnSBBR foi operado em batelada, o volume residual acabou contribuindo com o 
aumento da COVA e da concentração de intermediários no meio reacional, reduzindo assim os valores de eficiência, COVR e COER. Já nas Condições 5 a 8, em que o reator foi operado em batelada alimentada, seguida de batelada, o efeito de diluição proporcionado pelo volume residual culminou com a aumento da velocidade média de reação, propiciando valores mais altos de eficiência, COVR e COER, justamente por minimizar o acúmulo dos produtos intermediários que interferiam na conversão de matéria orgânica a metano.

\subsubsection{Análise de sólidos do AnSBBR}

A análise de sólidos feita com a biomassa do AnSBBR mostrou que havia aproximadamente 50,5 gSVT no interior do reator, que correspondiam a $84 \%$ dos sólidos totais. Como o volume de meio líquido do sistema era 2,50 L, a concentração de biomassa ficou em 20,2 gSVT/L. Ademais, a imobilização em espuma de poliuretano proporcionou uma relação de $0,71 \mathrm{gSVT} / \mathrm{gESPUMA}$. O volume total de espuma com biomassa imobilizada também foi determinado, e estimado em 2,64 L. Este valor foi obtido a partir da Equação 4.33, subtraindo-se o volume de meio líquido do reator de 2,50 $\mathrm{L}$ do volume total do reator, que era de 5,14 L.

\subsubsection{Exames microbiológicos do AnSBBR}

Amostras do inóculo e da biomassa do AnSBBR foram coletadas e examinadas por microscopia ótica de contraste de fase e fluorescência, gerando as imagens apresentadas nas Figuras 5.25 a 5.29. A Figura 5.25 mostra que o inóculo concentrava um número maior de organismos com a forma de pequenos cocos e também de filamentos. 


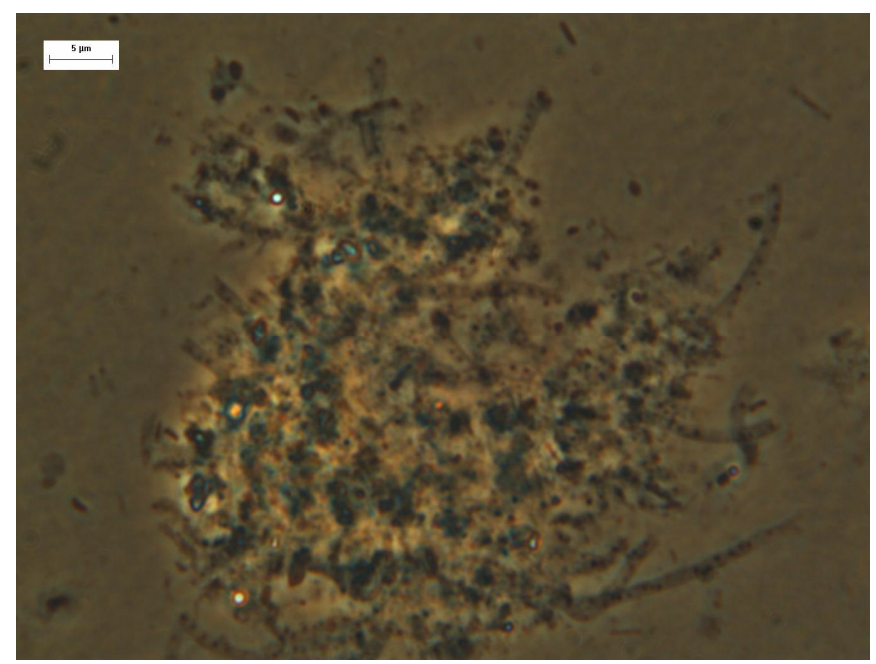

Figura 5.25 - Exame microbiológico do inóculo

As Figuras 5.26 e 5.27 apresentam imagens distintas do mesmo grupo de organismos, a primeira por microscopia de contraste de fase, e a segunda, por fluorescência. Observa-se que estes organismos assemelham-se a Methanosarcina sp. não apenas no formato de cocos, mas também na manifestação de autofluorescência, reforçando a caracterização do inóculo como lodo metanogênico.

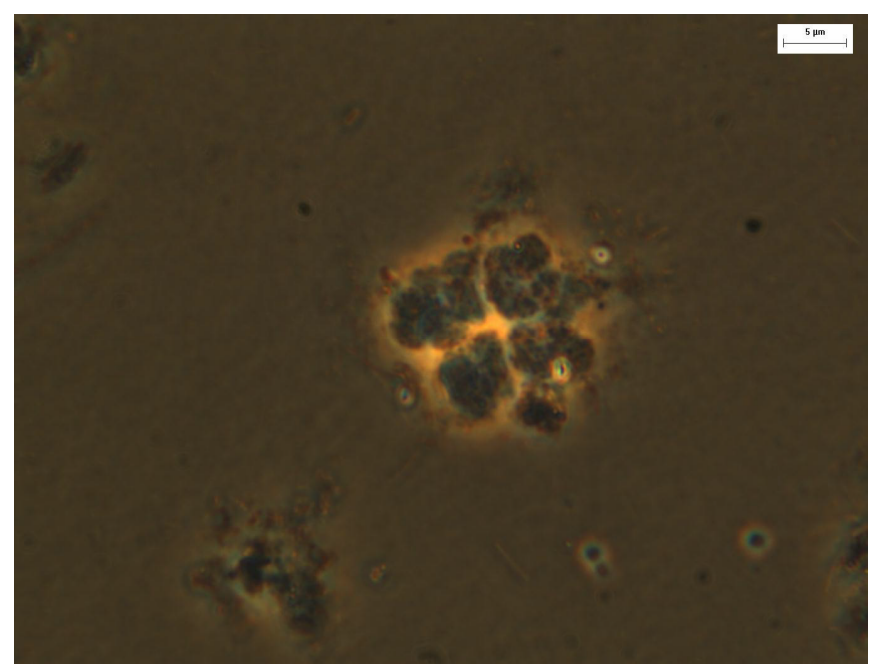

Figura 5.26 - Exame microbiológico do inóculo 


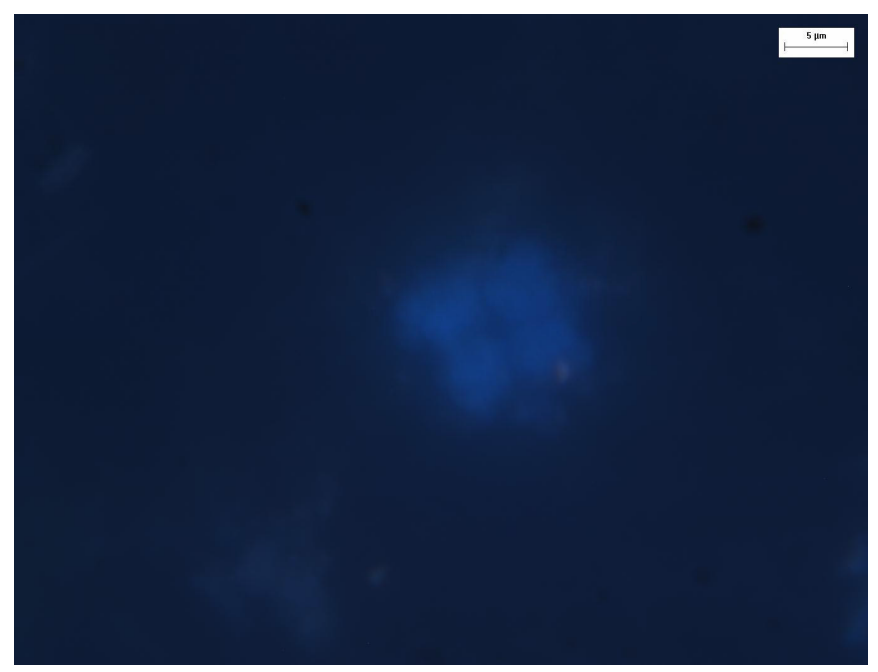

Figura 5.27 - Exame microbiológico do inóculo

Nas Figuras 5.28 e 5.29 são apresentadas imagens da biomassa do AnSBBR após o período de operação do reator. Comparando estas imagens com as obtidas do exame microbiológico do inóculo, observa-se que ocorreram mudanças na comunidade microbiana. A predominância que antes era de organismos na forma de cocos pequenos e filamentos, passou a ser de cocos grandes e bacilos. Inclusive, a presença destes bacilos, que provavelmente eram bactérias acidogênicas, poderia justificar a elevada atividade de produção de compostos intermediários, sugerindo, em contraposição, a redução da atividade metanogênica de modo proporcional. De certo, as mudanças do tipo de água residuária e de sistema tratamento, somadas à ocorrência de inibição durante o período de operação do AnSBR, fizeram com que o número de organismos metanogênicos no inóculo diminuísse; mesmo assim, é possível identificar alguns organismos filamentosos semelhantes a Methanosaeta sp, arqueia responsável pela produção de metano no sistema. 


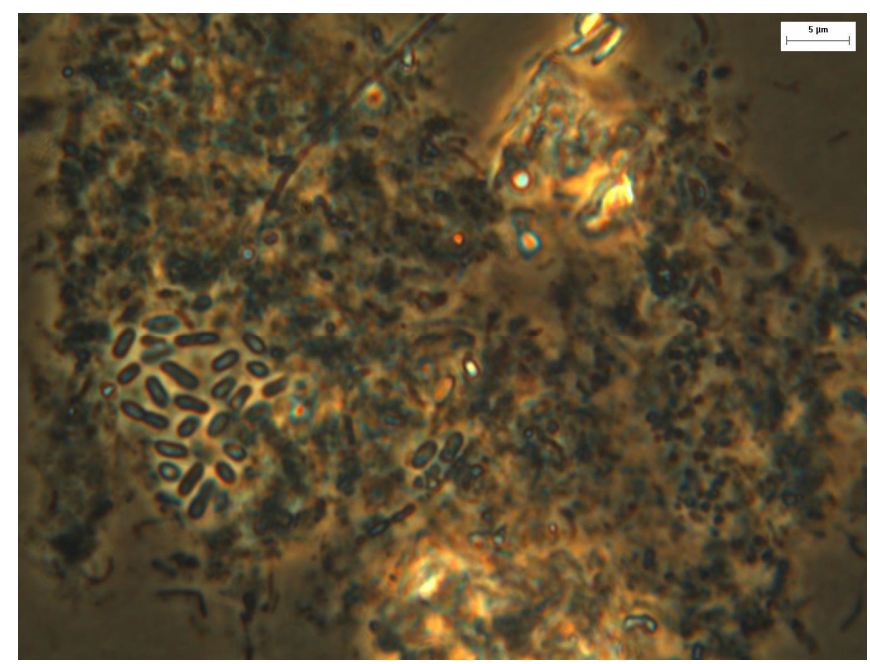

Figura 5.28 - Exame microbiológico da biomassa do AnSBBR

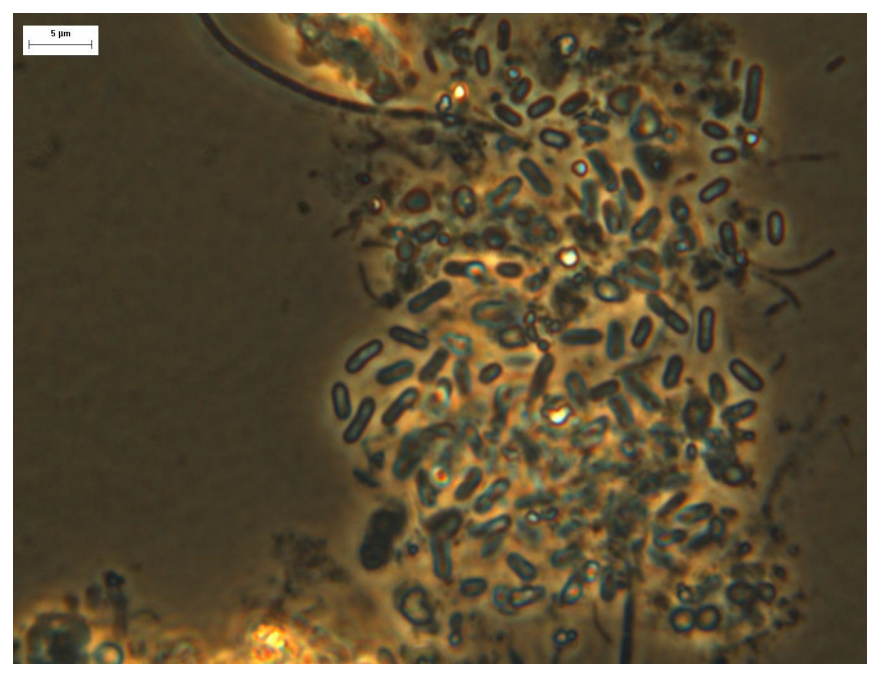

Figura 5.29 - Exame microbiológico da biomassa do AnSBBR 


\subsection{OperaçÃo do ANSBR}

A proposta de operação do AnSBR surgiu do interesse de aprofundar o conhecimento sobre o tratamento da água residuária em estudo, visto que os primeiros resultados da operação no AnSBBR, caso das Condições 1 e 2, não foram satisfatórios. A idéia era trabalhar com outras variáveis do sistema, como tempo de ciclo e suplementação de nutrientes. Ao todo, foram seis condições experimentais, além da condição preliminar.

\subsubsection{AnSBR na condição preliminar}

Inicialmente, o AnSBR foi montado e preenchido com 1,0 L de biomassa granulada e 2,0 L de meio sintético a base de sacarose, amido solúvel, celulose, extrato de carne, óleo de soja e sais, com concentrações de $500 \mathrm{mgDQO} / \mathrm{L}$ e $200 \mathrm{mgNaHCO}_{3} / \mathrm{L}$. Depois disso, ajustaram-se as bombas de alimentação e descarga, os temporizadores, a temperatura da câmara e a rotação do impelidor. Dada a partida do sistema, o AnSBR foi operado por 5 dias (15 ciclos), em batelada, em ciclos de $8 \mathrm{~h}$, tratando o meio sintético mencionado. Os valores médios das variáveis monitoradas do afluente e do efluente são apresentados nas Figuras 5.30 e 5.31 e na Tabela 5.9. 


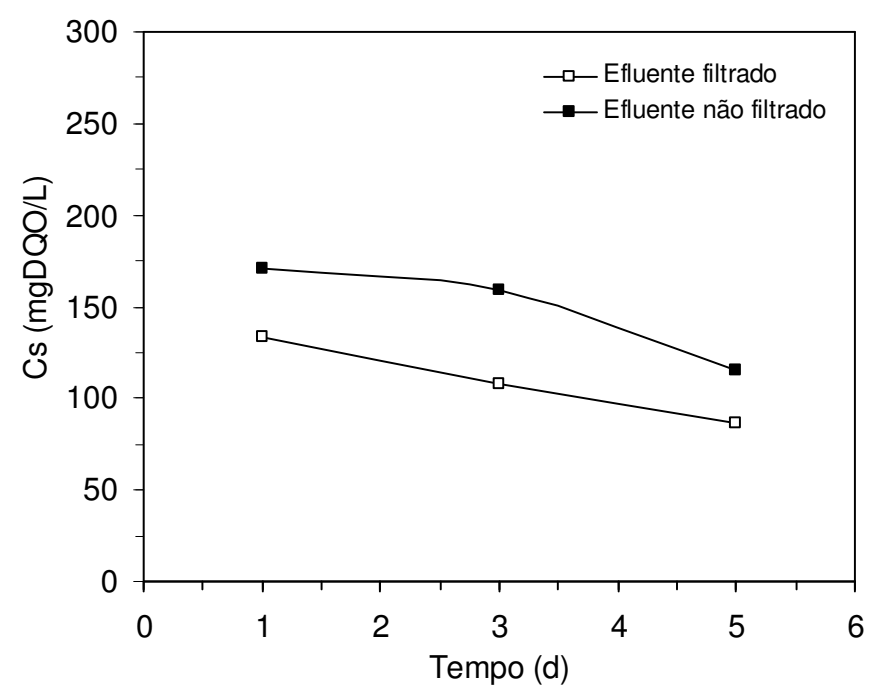

Figura 5.30 - Concentração de matéria orgânica do AnSBR na condição preliminar

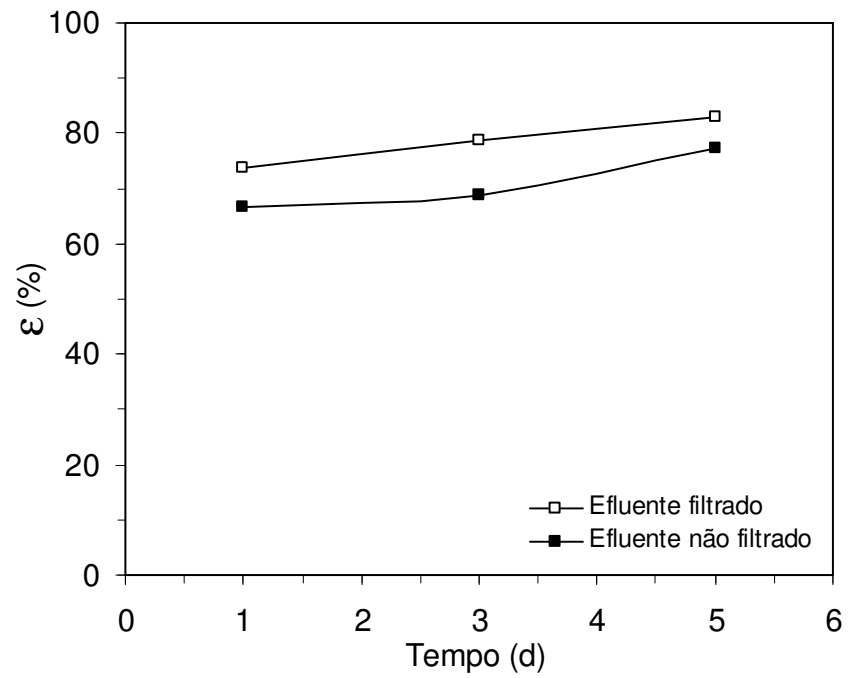

Figura 5.31 - Eficiência de remoção de matéria orgânica do AnSBR na condição preliminar 
Tabela 5.9 - Variáveis monitoradas do AnSBR na condição preliminar

\begin{tabular}{|c|c|}
\hline Variável & AnSBR \\
\hline $\mathrm{C}_{\mathrm{A}}(\mathrm{mgDQO} / \mathrm{L})$ & $509(1)$ \\
\hline $\mathrm{C}_{\mathrm{ET}}(\mathrm{mgDQO} / \mathrm{L})$ & $148 \pm 29(3)$ \\
\hline$\varepsilon_{\mathrm{T}}(\%)$ & $71 \pm 6$ \\
\hline $\mathrm{C}_{\mathrm{EF}}(\mathrm{mgDQO} / \mathrm{L})$ & $109 \pm 23(3)$ \\
\hline$\varepsilon_{\mathrm{F}}(\%)$ & $79 \pm 5$ \\
\hline$V_{D}(L)$ & $1030 \pm 36(3)$ \\
\hline COVA (gDQO/L.d) & $0,78 \pm 0,04$ \\
\hline $\mathrm{COVR}_{\top}(\mathrm{gDQO} / \mathrm{L} . \mathrm{d})$ & $0,55 \pm 0,07$ \\
\hline $\operatorname{coVR}_{\mathrm{F}}(\mathrm{gDQO} / \mathrm{L} . \mathrm{d})$ & $0,61 \pm 0,07$ \\
\hline COEA (gDQO/gSVT.d) & $0,037 \pm 0,001$ \\
\hline $\mathrm{COER}_{\mathrm{T}}(\mathrm{gDQO} / \mathrm{gSVT} . \mathrm{d})$ & $0,026 \pm 0,003$ \\
\hline COER $_{F}(g D Q O / g S V T . d)$ & $0,029 \pm 0,003$ \\
\hline $\mathrm{pH}_{\mathrm{A}}$ & $8,2(1)$ \\
\hline $\mathrm{pH}_{\mathrm{E}}$ & $7,5 \pm 0,1(2)$ \\
\hline$(\mathrm{Al} / \mathrm{AP})_{\mathrm{A}}$ & 0,35 \\
\hline$(\mathrm{Al} / \mathrm{AP})_{\mathrm{E}}$ & $0,32 \pm 0,04$ \\
\hline $\mathrm{AVT}_{\mathrm{A}}(\mathrm{mgHAc} / \mathrm{L})$ & $36(1)$ \\
\hline $\mathrm{AVT}_{\mathrm{E}}(\mathrm{mgHAc} / \mathrm{L})$ & $30 \pm 3(2)$ \\
\hline $\mathrm{AB}_{\mathrm{A}}\left(\mathrm{mgCaCO}_{3} / \mathrm{L}\right)$ & $216(1)$ \\
\hline $\mathrm{AB}_{\mathrm{E}}\left(\mathrm{mgCaCO}_{3} / \mathrm{L}\right)$ & $328 \pm 9(2)$ \\
\hline
\end{tabular}

Nota: ( ) número de amostras usadas no cálculo do valor médio das variáveis.

Analisando os dados apresentados na Tabela 5.9, observa-se que a eficiência de remoção de matéria orgânica de amostras filtradas ficou em 79\%. Também houve geração de alcalinidade, que é um indicativo de estabilidade do sistema. Portanto, pode-se considerar que o AnSBR estava pronto para operar com água residuária nas condições experimentais programadas. 


\subsubsection{AnSBR nas condições experimentais}

O AnSBR foi submetido a seis condições experimentais, operadas em batelada, a $30^{\circ} \mathrm{C}$ e $150 \mathrm{rpm}$, tratando $2,0 \mathrm{~L}$ de água residuária, em ciclos de 8,12 e 24 h, com concentrações de 500, 750 e $1500 \mathrm{mgDQO} / \mathrm{L}$ e $200 \mathrm{mgNaHCO} / \mathrm{L}$, ao longo de 20 dias cada. Os dados dos monitoramentos e dos perfis destas condições são apresentados nos Apêndices A e B. Deve-se ressaltar que os perfis destas condições foram adimensionalizados para facilitar a interpretação dos resultados. Além disso, os resultados dos perfis de concentração de ácidos voláteis intermediários ficaram abaixo do limite de detecção em todas as condições.

\subsubsection{CARACTERIZAÇÃo do AFLUENTE}

As concentrações de matéria orgânica do afluente foram analisadas em amostras filtradas $\left(\mathrm{C}_{\mathrm{AF}}\right)$ e não filtradas $\left(\mathrm{C}_{\mathrm{AT}}\right)$, em duplicata, em todas as condições experimentais. Nas Condições 9 a 13, em que o afluente era constituído apenas de água residuária, observou-se que a porcentagem da DQO atribuída aos sólidos em suspensão era $21 \pm 1 \%$, concordando com o resultado obtido nas Condições 1 a 8 . Já na Condição 14, em que o afluente era formado por $70 \%$ de água residuária e $30 \%$ de meio sintético, a porcentagem reduziu para $18 \pm 1 \%$. Os dados de concentração são apresentados no Apêndice C.

\subsubsection{MONITORAMENTO E PERFIS DAS CONDIÇÕES 9, 10 E 11}

Nas Condições 9, 10 e 11, o AnSBR foi operado com a mesma COVA, mas com diferentes $t_{C}$ e $C_{A}$. Na Condição 9 , tc era igual a $8 \mathrm{~h}$, e $C_{A}$, igual a $500 \mathrm{mg} / \mathrm{L}$. Na 
Condição 10, tc era igual a 12 h, e $C_{A}$, igual a 750 gDQO/L. Já na Condição 11, tc era igual a $24 \mathrm{~h}$, e $\mathrm{C}_{\mathrm{A}}$, igual a $1500 \mathrm{mgDQO} / \mathrm{L}$. $\mathrm{O}$ volume de água residuária alimentada por ciclo era 1,0 L e correspondia a metade do volume de meio líquido do reator. Portanto, a COVA era igual a 0,75 gDQO/L.d. Os resultados obtidos do monitoramento das Condições 9, 10 e 11 são apresentados nas Figuras 5.32 e 5.33 e na Tabela 5.10, e os dos perfis, nas Figuras 5.34 a 5.41.

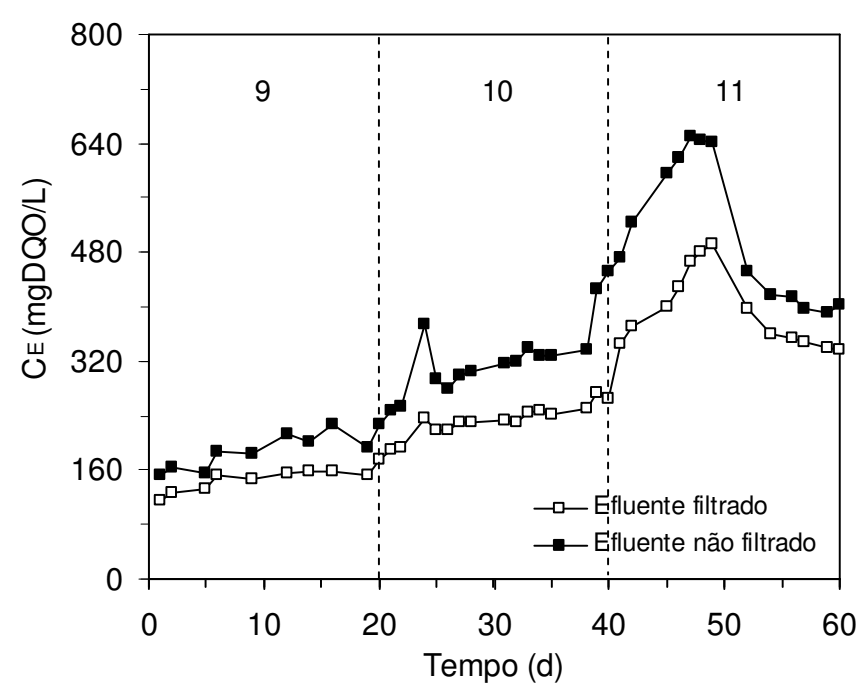

Figura 5.32 - Concentração de matéria orgânica na saída do AnSBR nas Condições 9, 10 e 11

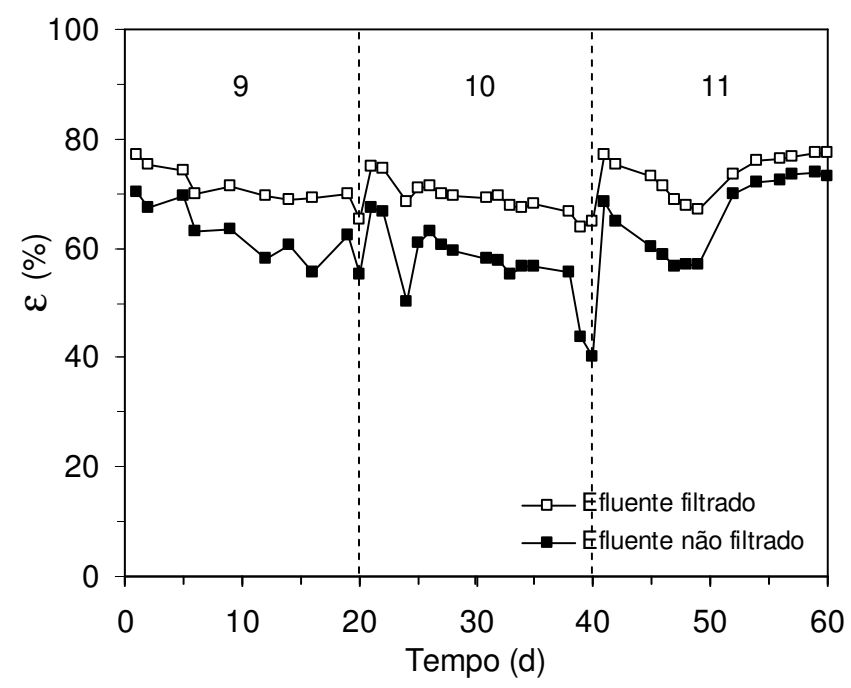

Figura 5.33 - Eficiência de remoção de matéria orgânica do AnSBR nas Condições 9, 10 e 11 
Tabela 5.10 - Variáveis monitoradas do AnSBR nas Condições 9, 10 e 11

\begin{tabular}{|c|c|c|c|}
\hline Variável & 9 & 10 & 11 \\
\hline Especificação & $0,75 B-8$ & $0,75 B-12$ & $0,75 B-24$ \\
\hline $\mathrm{C}_{\mathrm{A}}(\mathrm{mgDQO} / \mathrm{L})$ & $508 \pm 5(10)$ & $756 \pm 7(15)$ & $1498 \pm 12(12)$ \\
\hline $\mathrm{C}_{\mathrm{ET}}(\mathrm{mgDQO} / \mathrm{L})$ & $205 \pm 18(7)$ & $338 \pm 51(13)$ & $404 \pm 11(5)$ \\
\hline$\varepsilon_{\mathrm{T}}(\%)$ & $60 \pm 3$ & $55 \pm 7$ & $73 \pm 1$ \\
\hline $\mathrm{C}_{\mathrm{EF}}(\mathrm{mgDQO} / \mathrm{L})$ & $157 \pm 9(7)$ & $239 \pm 16(13)$ & $348 \pm 10(5)$ \\
\hline$\varepsilon_{\mathrm{F}}(\%)$ & $69 \pm 2$ & $68 \pm 2$ & $77 \pm 1$ \\
\hline$V_{D}(L)$ & $1016 \pm 5(10)$ & $1002 \pm 9(15)$ & $998 \pm 4(12)$ \\
\hline COVA (gDQO/L.d) & $0,768 \pm 0,013$ & $0,757 \pm 0,017$ & $0,748 \pm 0,010$ \\
\hline $\mathrm{COVR}_{\mathrm{T}}(\mathrm{gDQO} / \mathrm{L} . \mathrm{d})$ & $0,458 \pm 0,038$ & $0,418 \pm 0,064$ & $0,546 \pm 0,015$ \\
\hline $\mathrm{COVR}_{\mathrm{F}}(\mathrm{gDQO} / \mathrm{L} . \mathrm{d})$ & $0,531 \pm 0,025$ & $0,518 \pm 0,030$ & $0,574 \pm 0,014$ \\
\hline COEA (gDQO/gSVT.d) & $0,036 \pm 0,001$ & $0,036 \pm 0,001$ & $0,035 \pm 0,001$ \\
\hline $\mathrm{COER}_{\mathrm{T}}(\mathrm{gDQO} / \mathrm{gSVT} . \mathrm{d})$ & $0,022 \pm 0,002$ & $0,020 \pm 0,003$ & $0,026 \pm 0,001$ \\
\hline $\mathrm{COER}_{\mathrm{F}}(\mathrm{gDQO} / \mathrm{gSVT} . \mathrm{d})$ & $0,025 \pm 0,001$ & $0,024 \pm 0,001$ & $0,027 \pm 0,001$ \\
\hline $\mathrm{pH}_{\mathrm{A}}$ & $7,9 \pm 0,2(4)$ & $8,0 \pm 0,1(4)$ & $7,8 \pm 0,1(4)$ \\
\hline $\mathrm{pH}_{\mathrm{E}}$ & $7,5 \pm 0,1(4)$ & $7,7 \pm 0,1(4)$ & $7,6 \pm 0,1(5)$ \\
\hline$(\mathrm{Al} / \mathrm{AP})_{\mathrm{A}}$ & $0,30 \pm 0,06$ & $0,29 \pm 0,04$ & $0,28 \pm 0,04$ \\
\hline$(\mathrm{Al} / \mathrm{AP})_{\mathrm{E}}$ & $0,32 \pm 0,08$ & $0,29 \pm 0,04$ & $0,31 \pm 0,03$ \\
\hline $\mathrm{AVT}_{\mathrm{A}}(\mathrm{mgHAc} / \mathrm{L})$ & $15 \pm 2(4)$ & $21 \pm 1(4)$ & $21 \pm 1(4)$ \\
\hline $\mathrm{AVT}_{\mathrm{E}}(\mathrm{mgHAc} / \mathrm{L})$ & $15 \pm 1(4)$ & $23 \pm 1(4)$ & $21 \pm 1(5)$ \\
\hline $\mathrm{AB}_{\mathrm{A}}(\mathrm{mgCaCO} / \mathrm{L})$ & $201 \pm 5(4)$ & $221 \pm 11(4)$ & $205 \pm 3(4)$ \\
\hline $\mathrm{AB}_{\mathrm{E}}\left(\mathrm{mgCaCO}_{3} / \mathrm{L}\right)$ & $238 \pm 16(4)$ & $287 \pm 10(4)$ & $239 \pm 15(5)$ \\
\hline $\mathrm{ST}_{\mathrm{A}}(\mathrm{mg} / \mathrm{L})$ & - & $703 \pm 16(2)$ & $1110 \pm 51(2)$ \\
\hline $\mathrm{ST}_{\mathrm{E}}(\mathrm{mg} / \mathrm{L})$ & - & $549 \pm 33(2)$ & $869 \pm 41(2)$ \\
\hline $\mathrm{SVT}_{\mathrm{A}}(\mathrm{mg} / \mathrm{L})$ & - & $410 \pm 28(2)$ & $705 \pm 13(2)$ \\
\hline $\mathrm{SVT}_{\mathrm{E}}(\mathrm{mg} / \mathrm{L})$ & - & $272 \pm 6(2)$ & $495 \pm 24(2)$ \\
\hline $\mathrm{SST}_{\mathrm{A}}(\mathrm{mg} / \mathrm{L})$ & - & $36 \pm 17(2)$ & $136 \pm 3(2)$ \\
\hline $\mathrm{SST}_{\mathrm{E}}(\mathrm{mg} / \mathrm{L})$ & - & $75 \pm 13(2)$ & $148 \pm 11(2)$ \\
\hline $\mathrm{SSV}_{\mathrm{A}}(\mathrm{mg} / \mathrm{L})$ & - & $26 \pm 3(2)$ & $117 \pm 4(2)$ \\
\hline $\mathrm{SSV}_{\mathrm{E}}(\mathrm{mg} / \mathrm{L})$ & - & $63 \pm 16(2)$ & $129 \pm 13(2)$ \\
\hline
\end{tabular}

Nota: ( ) número de amostras usadas no cálculo do valor médio das variáveis. 
As Figuras 5.32 e 5.33 apresentam dados de concentração e eficiência de remoção de matéria orgânica de amostras filtradas e não filtradas do efluente ao longo das Condições 9, 10 e 11. Problemas no mecanismo de agitação do reator provocaram a perda de quase $300 \mathrm{~mL}$ de biomassa na Condição 11. Não se sabe ao certo a data do ocorrido, mas os dados sugerem que tenha sido entre o primeiro e o terceiro dias de operação; de qualquer modo, a reposição de biomassa só foi feita no nono dia. Por este motivo, o sistema demorou mais de doze dias para atingir a estabilidade na Condição 11, enquanto que nas Condições 9 e 10, o tempo foi de apenas cinco dias.

A Tabela 5.10 apresenta os valores médios de algumas variáveis monitoradas nas Condições 9, 10 e 11. Observa-se que os valores de concentração efluente e eficiência apresentaram desvios-padrão inferiores a 5\%, confirmando a estabilidade do sistema no período considerado. Apenas os valores referentes às amostras não filtradas do efluente da Condição 10 apresentaram desvios-padrão um pouco mais altos, provavelmente por contribuição de grânulos de biomassa que podem ter deixado o reator junto do efluente. $\mathrm{O}$ pH e a concentração de ácidos voláteis totais também se mantiveram estáveis ao longo do período de análise. Os valores de pH permaneceram dentro de uma faixa de 7,4 a 8,1 , enquanto que os valores de AVT ficaram abaixo de $30 \mathrm{mgHAc/L}$. Por outro lado, os valores médios de alcalinidade a bicarbonato sugerem que houve geração de alcalinidade. Na Condição 10, por exemplo, $\mathrm{AB}$ passou de 221 para $287 \mathrm{mgCaCO}_{3} / \mathrm{L}$. Contudo, deve-se salientar que a carga aplicada de bicarbonato de sódio não foi a mesma em todas as condições como deveria ter sido, pois o valor de concentração foi mantido em 200 mg/L. Assim, a carga esperada de 0,30 g/L.d só foi obtida na Condição 9; nas Condições 10 e 11, estes valores caíram para 0,20 e 0,10 g/L.d, respectivamente. 
Ao comparar as Condições 9, 10 e 11, observa-se que os maiores valores de eficiência, COVR e COER foram obtidos na Condição 11, que apresentou também os maiores valores de concentração afluente e tempo de ciclo. O elevado valor da concentração afluente desta condição, se analisado isoladamente, resultaria em um valor menor de eficiência, como ficou provado nas operações do AnSBBR em batelada com a mesma água residuária. No entanto, o aumento do tempo de ciclo possibilitou a conversão de uma fração maior dos compostos de difícil biodegradabilidade a metano, reforçando a idéia de que os produtos intermediários que interferem na degradação da matéria orgânica como um todo também são substrato para a biomassa. O mesmo não ocorreu na Condição 10, que apresentou resultados muito similares aos da Condição 9, apesar do seu tempo de ciclo ser maior. Provavelmente esse aumento não foi suficiente para promover o aumento da eficiência do sistema. Deve-se ressaltar que os valores de concentração inicial de substrato nas três condições foram menores que os valores das concentrações afluentes, pois a água residuária alimentada no inicio de cada ciclo era diluída em $1,0 \mathrm{~L}$ de volume residual do ciclo anterior.

A Figura 5.34 apresenta os resultados dos perfis de concentração de matéria orgânica ao longo de um ciclo de operação das Condições 9, 10 e 11. Nestas condições, as concentrações medidas logo no início dos ciclos foram respectivamente 246, 381 e $656 \mathrm{mgDQO} / \mathrm{L}$, e ao final, 180, 273 e $379 \mathrm{mgDQO} / \mathrm{L}$, mostrando que os maiores valores de concentração residual foram encontrados nas condições cujas concentrações afluentes também eram maiores. Observa-se que o sistema parece não mais promover a conversão de matéria orgânica a metano a partir da segunda ou terceira hora do início do ciclo nas três condições experimentais, mas como foi discutido anteriormente, ainda ocorrem transformações 
bioquímicas no meio reacional. Acontece que o método usado na determinação da concentração de matéria orgânica é incapaz de identificar estas transformações, pois as variações da quantidade de substrato no meio são medidas em função da liberação de metano para o ambiente.

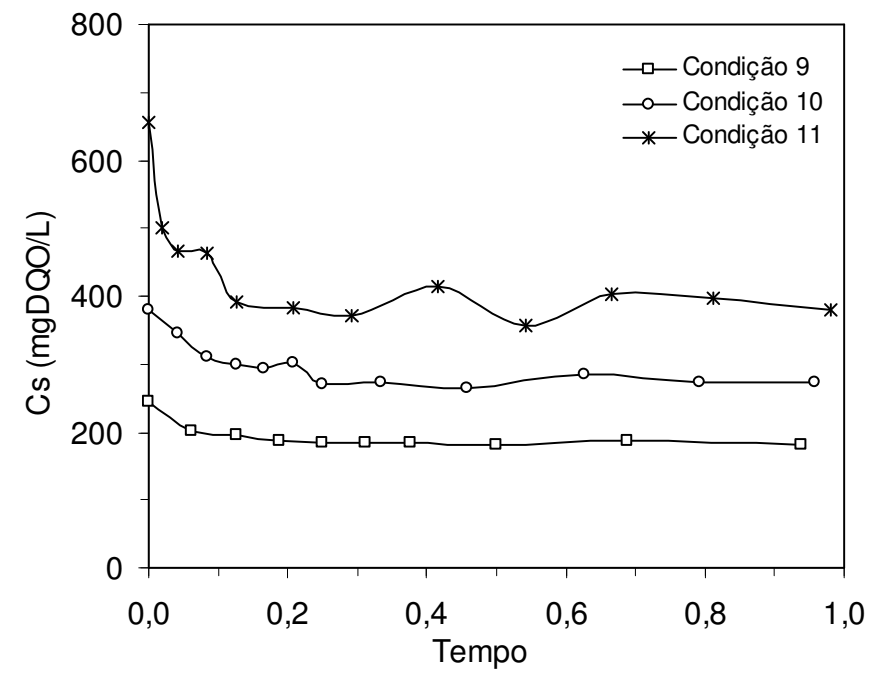

Figura 5.34 - Perfil de concentração de matéria orgânica do AnSBR nas Condições 9, 10 e 11

A Figura 5.35 apresenta os perfis de pH das Condições 9, 10 e 11. Nas três condições, as curvas mantiveram-se dentro da faixa de monitoramento, de 7,4 a 8,1.

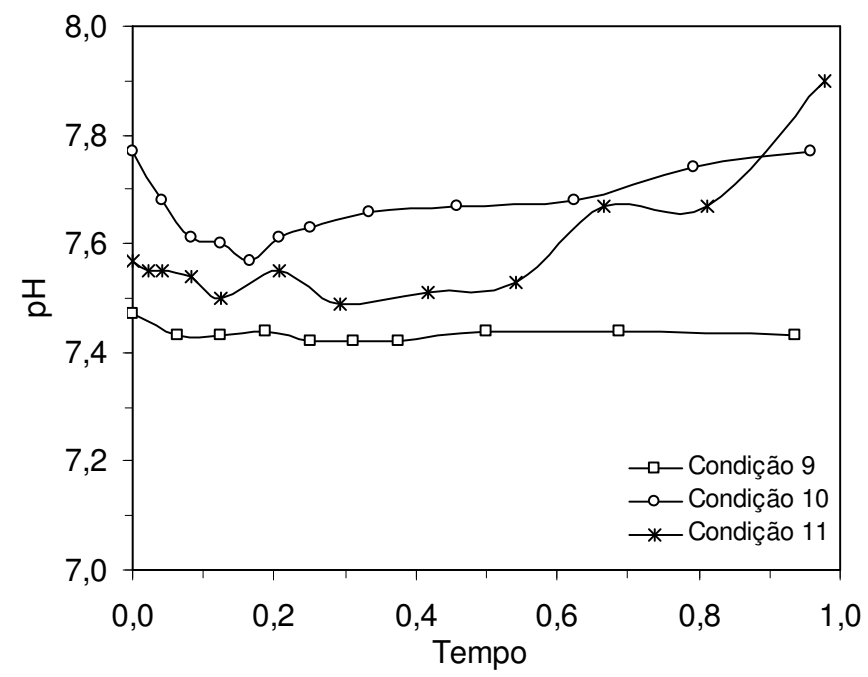

Figura 5.35 - Perfil de pH do AnSBR nas Condições 9, 10 e 11 
Na Figura 5.36 são apresentados os resultados dos perfis de concentração de ácidos voláteis totais obtidos ao longo de um ciclo operacional das Condições 9, 10 e 11. Apesar do comportamento bastante aleatório das curvas dos perfis, observa-se que não houve acúmulo de ácidos voláteis.

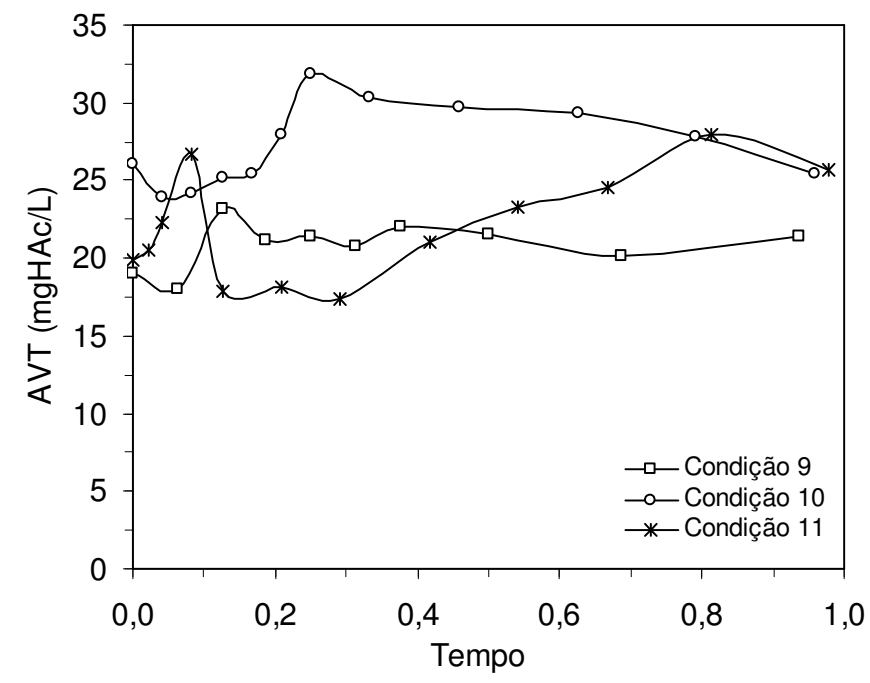

Figura 5.36 - Perfil de concentração de ácidos voláteis totais do AnSBR nas Condições 9, 10 e 11

A Figura 5.37 apresenta os perfis de alcalinidade a bicarbonato das Condições 9, 10 e 11. Os resultados sugerem que a alcalinidade se manteve praticamente constante ao longo de um ciclo de operação nas três condições experimentais. Por outro lado, somente os resultados da Condição 9 conferem com os resultados obtidos do monitoramento. Nesta condição, a alcalinidade passou de 227 para 238 mgCaCO$/ \mathrm{L}$. Já nas Condições 10 e 11, a alcalinidade passou de 209 para 223 mgCaCO$/ L$ na primeira, e de 204 para $228 \mathrm{mgCaCO}_{3} / \mathrm{L}$, na segunda. 


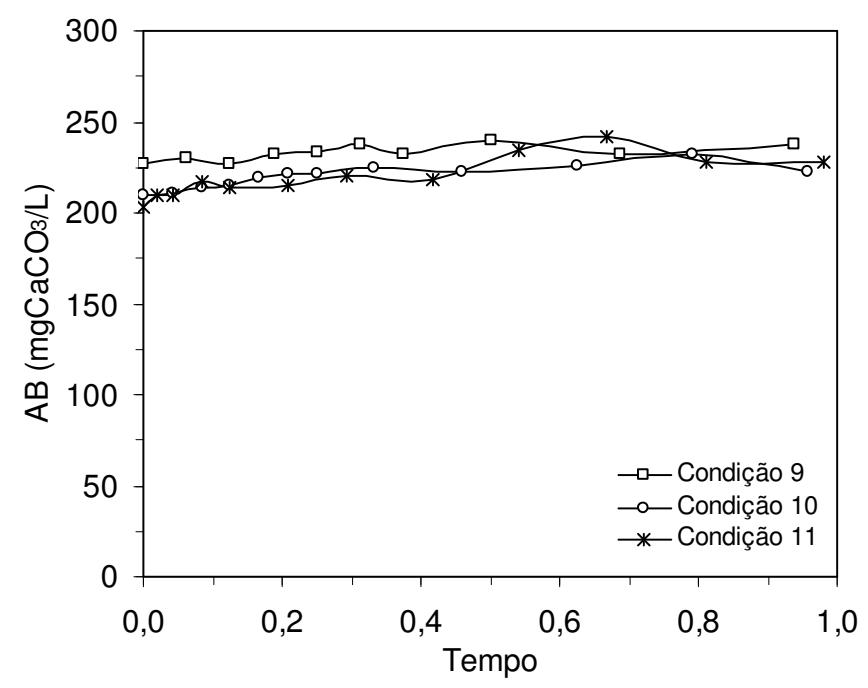

Figura 5.37 - Perfil de alcalinidade a bicarbonato do AnSBR nas Condições 9, 10 e 11

Nas Figuras 5.38 e 5.39 são apresentados os resultados dos perfis de concentração de metano e gás carbônico obtidos ao longo de um ciclo de operação das Condições 9, 10 e 11. A Figura 5.38 mostra que o maior valor de concentração de metano foi encontrado na Condição 11, com 1,01mmol/L, seguida da Condição 9, com 0,65 mmol/L, e da Condição 10, com 0,28 mmol/L. A ordem apresentada confere com os dados de COVR e COER; porém, a julgar por estes dados, a diferença de valores de concentração de metano das Condições 9 e 10 deveria ser menor. Já na Figura 5.39, observa-se que os resultados de concentração de gás carbônico seguem a mesma ordem de resultados da concentração de metano, com a ressalva de que pudesse haver alguma alteração se as cargas de bicarbonato de sódio, aplicadas às Condições 10 e 11, fossem corrigidas em função de suas COVA. As concentrações de gás carbônico obtidas foram $0,75 \mathrm{mmol} / \mathrm{L}$, na Condição 11 , 0,57 mmol/L, na Condição 9, e 0,43 mmol/L, na Condição 10. 


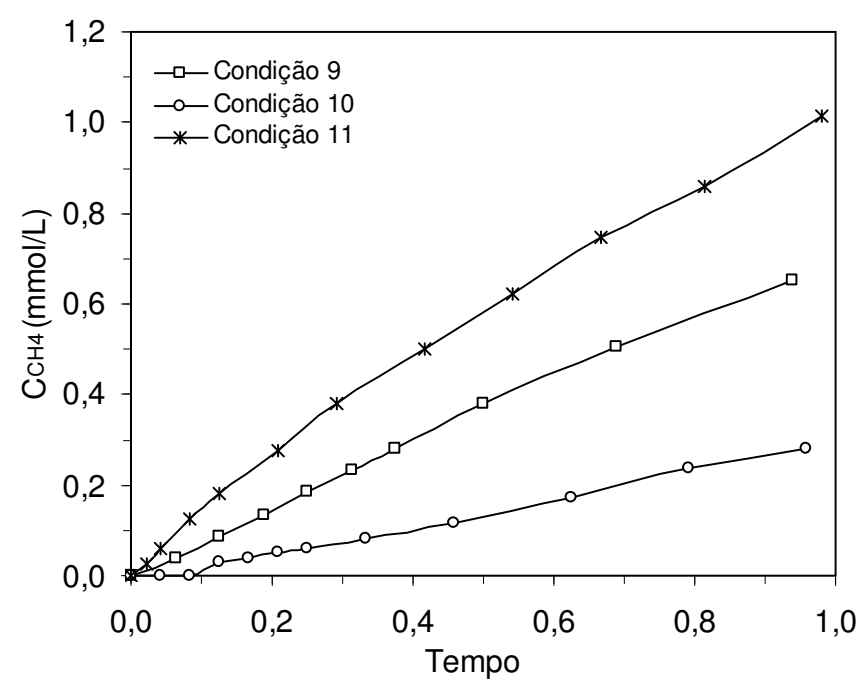

Figura 5.38 - Perfil de concentração de metano do AnSBR nas Condições 9, 10 e 11

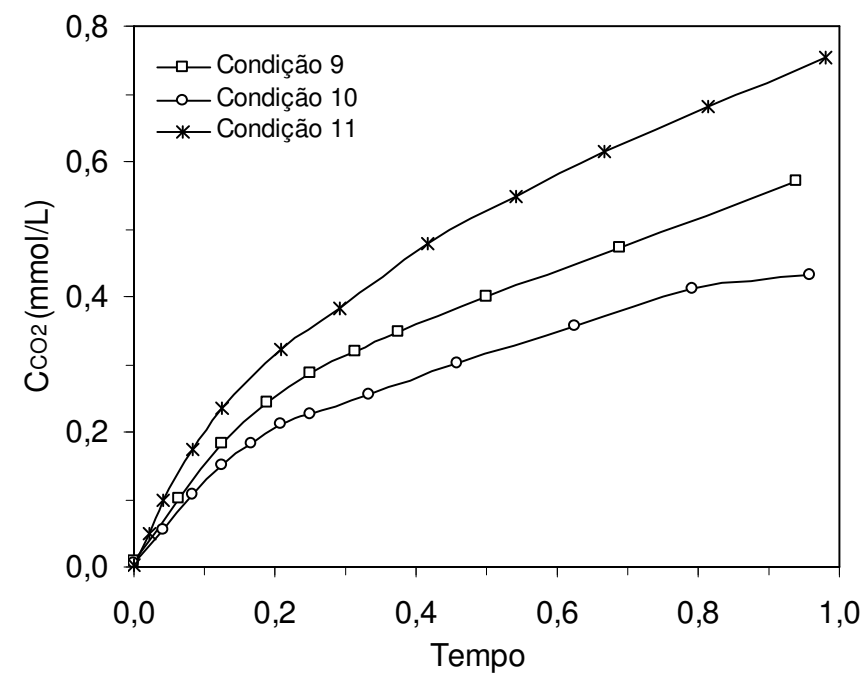

Figura 5.39 - Perfil de concentração de gás carbônico do AnSBR nas Condições 9, 10 e 11

Nas Figuras 5.40 e 5.41 são apresentados os resultados dos perfis de fração molar de metano e gás carbônico das Condições 9, 10 e 11. Observa-se que a Condição 11 apresentou o maior valor de fração molar de metano no biogás, em torno de 57\%, seguida da Condição 9, com 53\%, e da Condição 10, com 39\%. 


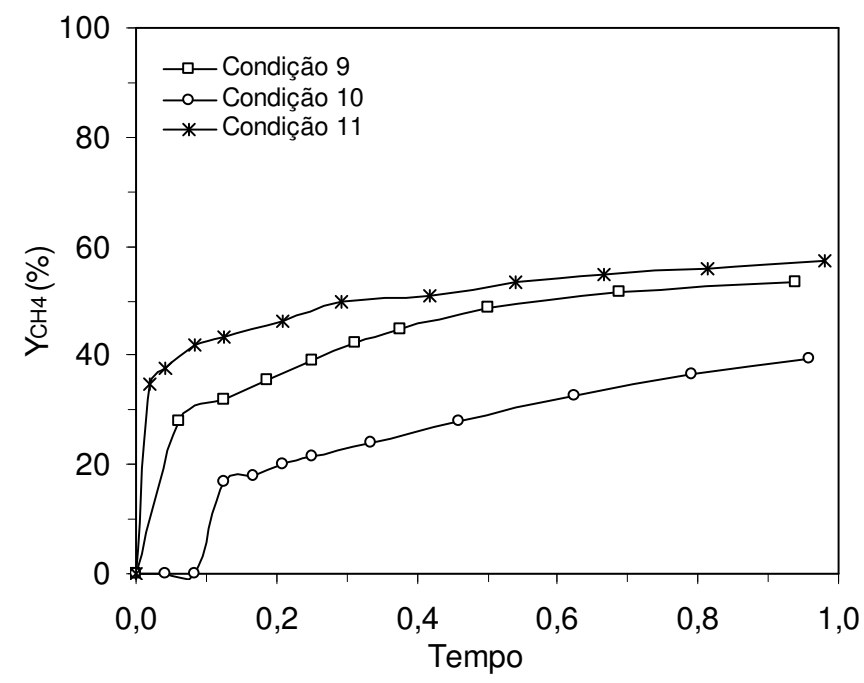

Figura 5.40 - Perfil de fração molar de metano do AnSBR nas Condições 9, 10 e 11

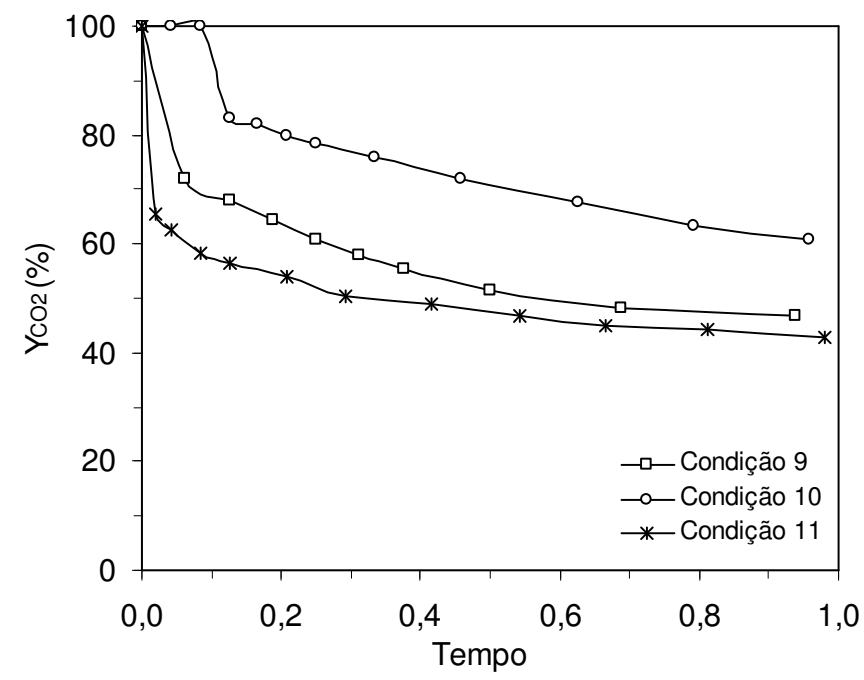

Figura 5.41 - Perfil de fração molar de gás carbônico do AnSBR nas Condições 9, 10 e 11

\subsubsection{MONITORAMENTO DAS CONDIÇÕES 9, 12 E 13}

Nas Condições 9, 12 e 13, o AnSBR foi operado com a mesma concentração afluente, mas com diferentes tempos de ciclo, o que resultou em diferentes valores de COVA. Na Condição 9, tc era igual a 8 h e, nas Condições 12 e 13, igual a 12 e 24 h. Como $C_{A}$ foi mantida em $500 \mathrm{mg} / \mathrm{L}$, os valores de COVA obtidos para as 
Condições 9, 12 e 13 foram respectivamente $0,75,0,50$ e 0,25 gDQO/L.d. Os resultados obtidos do monitoramento dessas três condições são apresentados nas Figuras 5.42 e 5.43 e na Tabela 5.11, e os dos perfis, nas Figuras 5.44 a 5.51 .

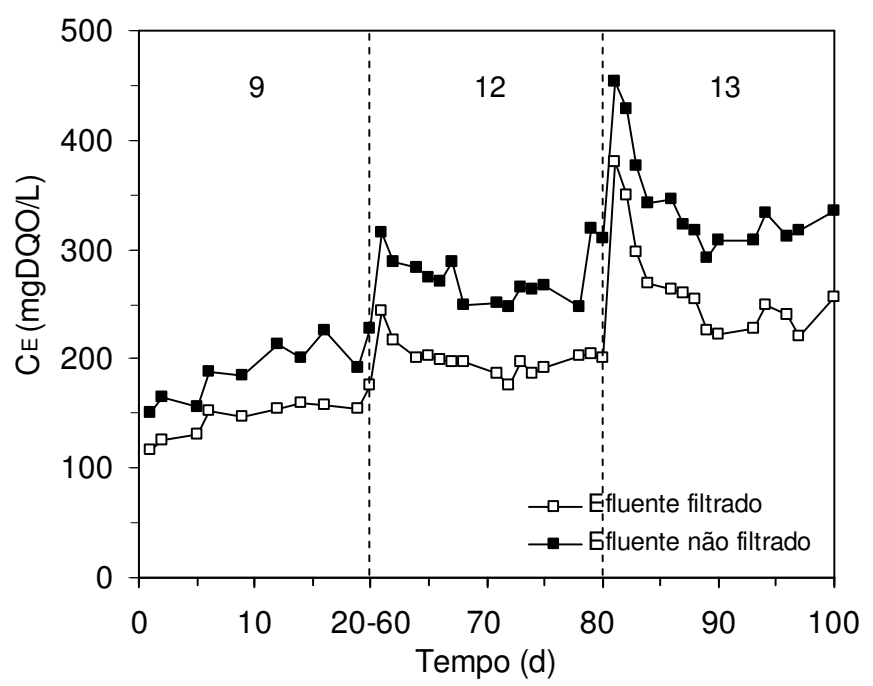

Figura 5.42 - Concentração de matéria orgânica na saída do AnSBR nas Condições 9, 12 e 13

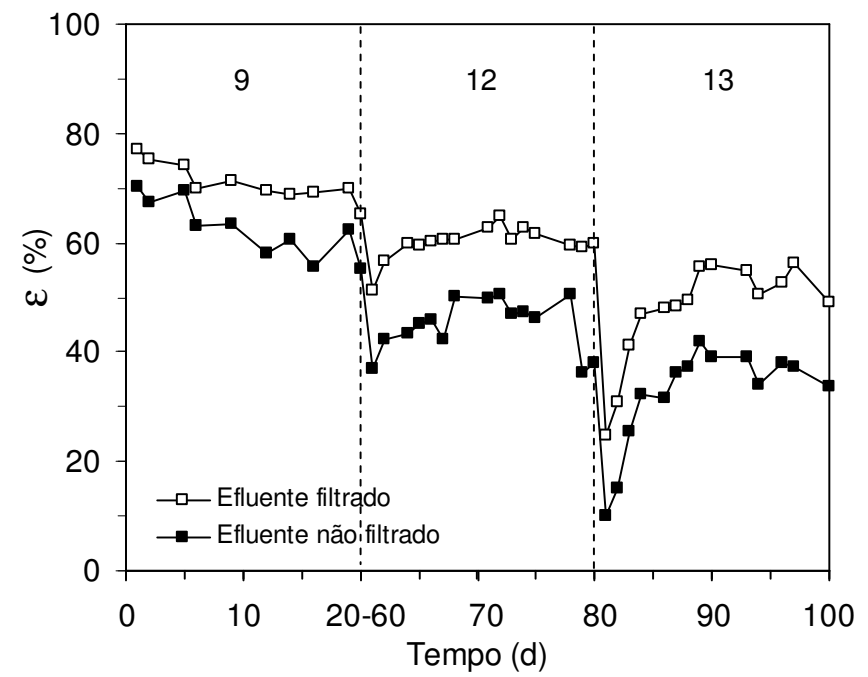

Figura 5.43 - Eficiência de remoção de matéria orgânica do AnSBR nas Condições 9, 12 e 13 
Tabela 5.11 - Variáveis monitoradas do AnSBR nas Condições 9, 12 e 13

\begin{tabular}{|c|c|c|c|}
\hline Condição & 9 & 12 & 13 \\
\hline Especificação & $0,75 B-8$ & $0,50 \mathrm{~B}-12$ & $0,25 B-24$ \\
\hline $\mathrm{C}_{\mathrm{A}}(\mathrm{mgDQO} / \mathrm{L})$ & $508 \pm 5(10)$ & $500 \pm 8(15)$ & $505 \pm 9(13)$ \\
\hline $\mathrm{C}_{\mathrm{ET}}(\mathrm{mgDQO} / \mathrm{L})$ & $205 \pm 18(7)$ & $272 \pm 23(13)$ & $319 \pm 15(10)$ \\
\hline$\varepsilon_{\mathrm{T}}(\%)$ & $60 \pm 3$ & $46 \pm 5$ & $37 \pm 3$ \\
\hline $\mathrm{C}_{\mathrm{EF}}(\mathrm{mgDQO} / \mathrm{L})$ & $157 \pm 9(7)$ & $196 \pm 8(13)$ & $242 \pm 17(10)$ \\
\hline$\varepsilon_{\mathrm{F}}(\%)$ & $69 \pm 2$ & $61 \pm 2$ & $52 \pm 3$ \\
\hline$V_{D}(L)$ & $1016 \pm 5(10)$ & $1008 \pm 23(15)$ & $1004 \pm 13(13)$ \\
\hline COVA (gDQO/L.d) & $0,768 \pm 0,013$ & $0,502 \pm 0,025$ & $0,253 \pm 0,009$ \\
\hline $\mathrm{COVR}_{\mathrm{T}}(\mathrm{gDQO} / \mathrm{L} . \mathrm{d})$ & $0,458 \pm 0,038$ & $0,229 \pm 0,039$ & $0,093 \pm 0,014$ \\
\hline $\mathrm{COVR}_{\mathrm{F}}(\mathrm{gDQO} / \mathrm{L} . \mathrm{d})$ & $0,531 \pm 0,025$ & $0,305 \pm 0,027$ & $0,132 \pm 0,016$ \\
\hline COEA (gDQO/gSVT.d) & $0,036 \pm 0,001$ & $0,024 \pm 0,001$ & $0,012 \pm 0,001$ \\
\hline $\mathrm{COER}_{\mathrm{T}}(\mathrm{gDQO} / \mathrm{gSVT} . \mathrm{d})$ & $0,022 \pm 0,002$ & $0,011 \pm 0,002$ & $0,004 \pm 0,001$ \\
\hline COER $_{F}(g D Q O / g S V T . d)$ & $0,025 \pm 0,001$ & $0,014 \pm 0,001$ & $0,006 \pm 0,001$ \\
\hline $\mathrm{pH}_{\mathrm{A}}$ & $7,9 \pm 0,2(4)$ & $7,9 \pm 0,1(7)$ & $7,9 \pm 0,1(7)$ \\
\hline $\mathrm{pH}_{\mathrm{E}}$ & $7,5 \pm 0,1(4)$ & $7,7 \pm 0,1(7)$ & $7,8 \pm 0,1(7)$ \\
\hline$(\mathrm{Al} / \mathrm{AP})_{\mathrm{A}}$ & $0,30 \pm 0,06$ & $0,25 \pm 0,02$ & $0,25 \pm 0,02$ \\
\hline$(\mathrm{Al} / \mathrm{AP})_{\mathrm{E}}$ & $0,32 \pm 0,08$ & $0,27 \pm 0,02$ & $0,26 \pm 0,02$ \\
\hline $\mathrm{AVT}_{\mathrm{A}}(\mathrm{mgHAc} / \mathrm{L})$ & $15 \pm 2(4)$ & $19 \pm 2(7)$ & $18 \pm 1(7)$ \\
\hline $\mathrm{AVT}_{\mathrm{E}}(\mathrm{mgHAc} / \mathrm{L})$ & $15 \pm 1(4)$ & $20 \pm 2(7)$ & $22 \pm 2(7)$ \\
\hline $\mathrm{AB}_{\mathrm{A}}\left(\mathrm{mgCaCO}_{3} / \mathrm{L}\right)$ & $201 \pm 5(4)$ & $222 \pm 3(7)$ & $235 \pm 1(7)$ \\
\hline $\mathrm{AB}_{\mathrm{E}}\left(\mathrm{mgCaCO}_{3} / \mathrm{L}\right)$ & $238 \pm 16(4)$ & $251 \pm 5(7)$ & $258 \pm 20(7)$ \\
\hline $\mathrm{ST}_{\mathrm{A}}(\mathrm{mg} / \mathrm{L})$ & - & $688 \pm 20(3)$ & $608 \pm 3(2)$ \\
\hline $\mathrm{ST}_{\mathrm{E}}(\mathrm{mg} / \mathrm{L})$ & - & $701 \pm 30(3)$ & $671 \pm 47(2)$ \\
\hline $\mathrm{SVT}_{\mathrm{A}}(\mathrm{mg} / \mathrm{L})$ & - & $396 \pm 31(3)$ & $339 \pm 4(2)$ \\
\hline $\mathrm{SVT}_{\mathrm{E}}(\mathrm{mg} / \mathrm{L})$ & - & $419 \pm 14(3)$ & $397 \pm 4(2)$ \\
\hline $\mathrm{SST}_{\mathrm{A}}(\mathrm{mg} / \mathrm{L})$ & - & $47 \pm 1(3)$ & $43 \pm 1(2)$ \\
\hline $\mathrm{SST}_{\mathrm{E}}(\mathrm{mg} / \mathrm{L})$ & - & $75 \pm 5(3)$ & $71 \pm 1(2)$ \\
\hline $\mathrm{SSV}_{\mathrm{A}}(\mathrm{mg} / \mathrm{L})$ & - & $45 \pm 1(3)$ & $39 \pm 4(2)$ \\
\hline $\mathrm{SSV}_{\mathrm{E}}(\mathrm{mg} / \mathrm{L})$ & - & $73 \pm 6(3)$ & $60 \pm 3(2)$ \\
\hline
\end{tabular}

Nota: ( ) número de amostras usadas no cálculo do valor médio das variáveis. 
As Figuras 5.42 e 5.43 mostram que o sistema atingiu a estabilidade entre o segundo e o quinto dia de operação nas três condições experimentais. Os dados de concentração efluente e eficiência, apresentados na Tabela 5.11, confirmam esta estabilidade. Os dados de $\mathrm{pH}$, assim como os de concentração de ácidos voláteis e alcalinidade a bicarbonato, também se mantiveram estáveis durante o período considerado. $\mathrm{O} \mathrm{pH}$ variou dentro de uma faixa de 7,4 a 8,1 , enquanto que os valores de AVT ficaram abaixo de $30 \mathrm{mgHAc} / \mathrm{L}$. Os valores de alcalinidade, por sua vez, chegaram a $258 \mathrm{mgCaCO}_{3} / \mathrm{L}$ na Condição 13, por exemplo. Ressalta-se que a redução da carga aplicada de bicarbonato de sódio em função da manutenção da concentração de $200 \mathrm{mg} / \mathrm{L}$ e da redução de $t_{c}$ manteve a proporcionalidade em relação a concentração de matéria orgânica, de modo que na Condição 9 era de 0,30 g/L.d, na Condição 12, 0,20 g/L.d, e na Condição 13, 0,10 g/L.d.

Comparando as Condições 9, 12 e 13, observa-se que a redução da COVA em função do aumento do tempo de ciclo provocou a redução dos valores de eficiência, COVR e COER. Assim, a Condição 9, cuja COVA era 0,75 gDQO/L.d, apresentou $\varepsilon_{\mathrm{F}}$ de $69 \%$ e COVR $_{F}$ de 0,53 gDQO/L.d, contra apenas $61 \%$ e 0,30 gDQO/L.d, da Condição 12, cuja COVA era 0,50 gDQO/L.d, e 52\% e 0,13 gDQO/L.d, da Condição 13, cuja COVA era 0,25 gDQO/L.d. A concentração afluente foi a mesma nas três condições experimentais, sugerindo que os valores de eficiência pudessem ser similares, já que não dependiam do tempo de ciclo como COVR e COER. Contudo, foi justamente o tempo de ciclo que proporcionou uma dinâmica de ação diferente por parte da biomassa. Depois que o reator era alimentado, a biomassa iniciava a degradação da matéria orgânica, priorizando os compostos de fácil aos de difícil biodegradabilidade. À medida que a concentração dos produtos intermediários aumentava, a velocidade media de reação diminuía. O problema é que além da 
dificuldade de tirar proveito dos intermediários, a concentração deles no meio reacional era muito baixa para prover à biomassa a energia necessária para sua sobrevivência, dentro de um intervalo de tempo que correspondia exatamente ao tempo de ciclo. Com isso, bactérias e arqueias precisaram reduzir o metabolismo celular, passando a retirar energia de suas reservas internas até que um novo ciclo fosse iniciado. Obviamente que mesmo as concentrações iniciais de substrato sendo iguais, o aumento do tempo de ciclo alterou o rendimento da biomassa, provocando queda dos valores de eficiência, COVR e COER.

A Figura 5.44 apresenta os resultados dos perfis de concentração de matéria orgânica das Condições 9, 12 e 13. Observa-se que as Condições 12 e 13 apresentaram praticamente o mesmo valor residual, cerca de $220 \mathrm{mgDQO} / \mathrm{L}$, contrariando os dados obtidos do monitoramento, que foram 196 e 242 mgDQO/L, respectivamente. No caso da Condição 9, o valor do perfil foi $180 \mathrm{mgDQO} / \mathrm{L}$, e o do monitoramento, $157 \mathrm{mgDQO} / \mathrm{L}$.

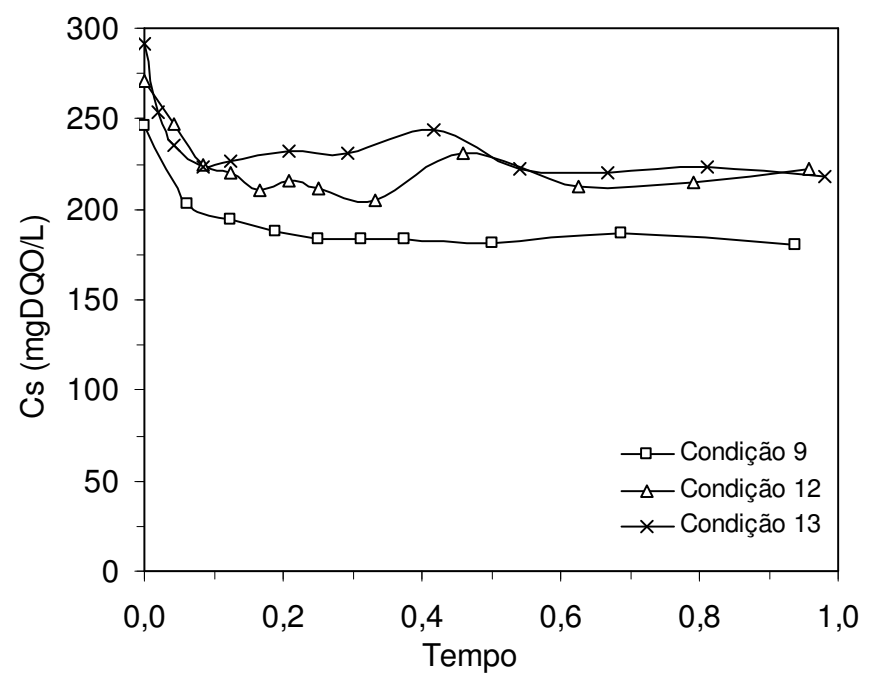

Figura 5.44 - Perfil de concentração de matéria orgânica do AnSBR nas Condições 9, 12 e 13 
Na Figura 5.45 são apresentados os perfis de pH das Condições 9, 12 e 13. Observa-se que o comportamento das curvas obtidas é totalmente aleatório. No entanto, todas elas respeitam a faixa de variação do monitoramento, de 7,4 a 8,1, mostrando estabilidade ao longo do ciclo das condições experimentais.

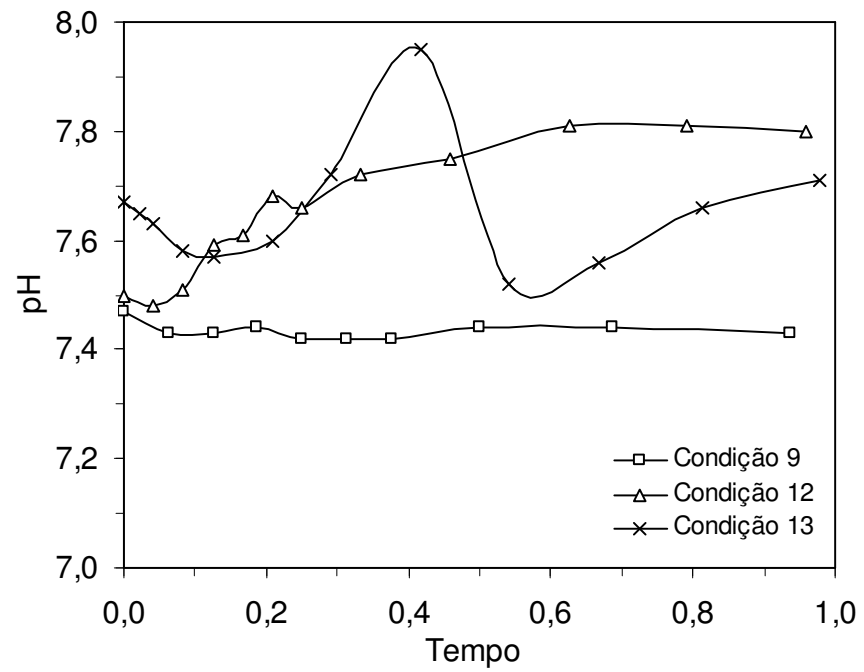

Figura 5.45 - Perfil de $\mathrm{pH}$ do AnSBR nas Condições 9, 12 e 13

A Figura 5.46 apresenta os resultados dos perfis de concentração de ácidos voláteis totais obtidos ao longo de um ciclo operacional das Condições 9, 12 e 13. Observase que o comportamento das curvas, assim como nos perfis de $\mathrm{pH}$, é bastante aleatório, mas apresentando valores inferiores a $35 \mathrm{mgHAc} / \mathrm{L}$, que sugerem estabilidade no sistema. 


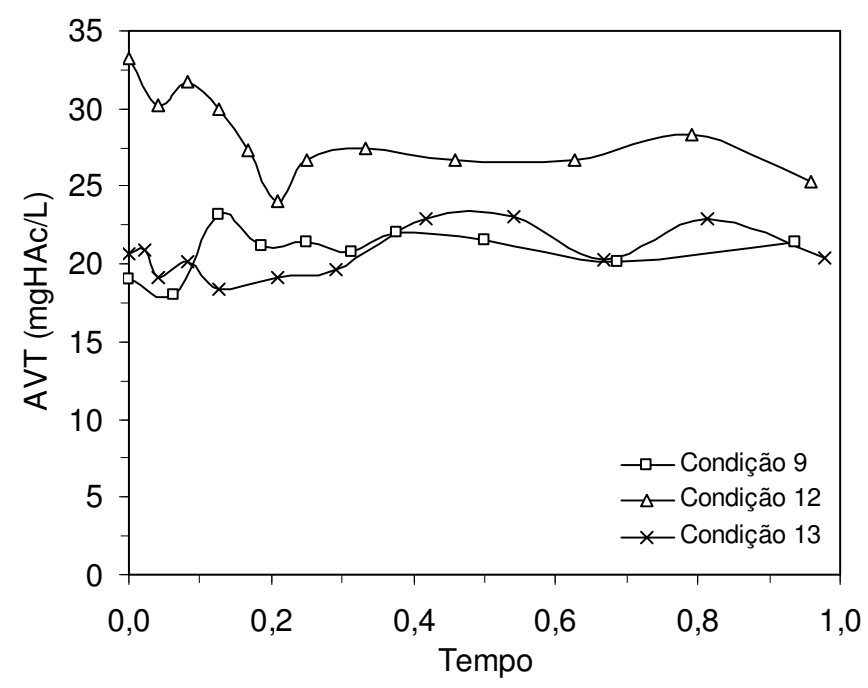

Figura 5.46 - Perfil de concentração de ácidos voláteis totais do AnSBR nas Condições 9, 12 e 13

Na Figura 5.47 são apresentados os perfis de alcalinidade a bicarbonato obtidos ao longo de um ciclo de operação das Condições 9, 12 e 13. Os resultados sugerem que houve um pequeno consumo da alcalinidade em duas das três condições experimentais. $\mathrm{Na}$ Condição 9, a alcalinidade passou de 227 para $238 \mathrm{mgCaCO}_{3} / \mathrm{L}$, enquanto nas Condições 12 e 13, caiu de 247 e 215 para 243 e 213 mgCaCO$/ / L$, respectivamente. Mesmo assim, é possível observar que houve uma ligeira geração de alcalinidade ao longo do ciclo das Condições 12 e 13, mas rapidamente consumida em razão das adversidades do meio reacional. Além disso, os dados da Condição 13 especificamente não conferem com os obtidos do monitoramento, cujo valor de $\mathrm{AB}$ do efluente era $258 \mathrm{mgCaCO}_{3} / \mathrm{L}$. 


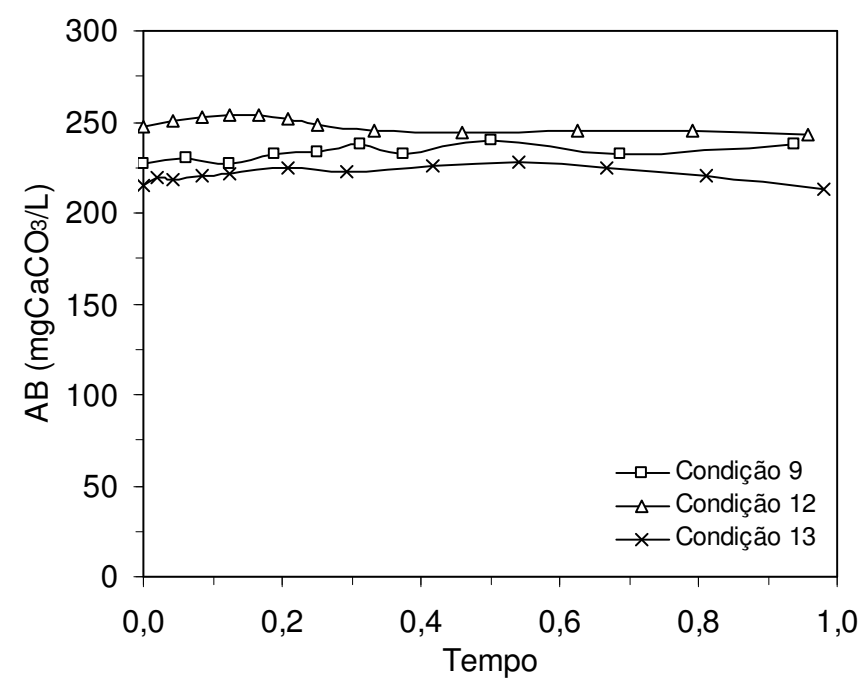

Figura 5.47 - Perfil de alcalinidade a bicarbonato do AnSBR nas Condições 9, 12 e 13

Nas Figuras 5.48 e 5.49 são apresentados os resultados dos perfis de concentração de metano e gás carbônico das Condições 9, 12 e 13. Observa-se na Figura 5.48 que o valor de concentração de metano da Condição 9 foi $0,65 \mathrm{mmol} / \mathrm{L}$, enquanto que nas Condições 12 e 13, ficou próximo dos 0,15 mmol/L. Porém, como a COVR e a COER da Condição 12 foram maiores que as da Condição 13, seu valor de concentração de metano também deveria ter sido maior. Provavelmente, problemas de vedação do sistema durante a realização dos perfis impediram a obtenção de resultados mais confiáveis. Por outro lado, observa-se que as diferenças dos valores de concentração de gás carbônico das condições 9, 12 e 13 são pequenas. Na Condição 9 foi $0,57 \mathrm{mmol} / \mathrm{L}$, e na Condição $13,0,53 \mathrm{mmol} / \mathrm{L}$, enquanto na Condição 12, ficou em $0,48 \mathrm{mmol} / \mathrm{L}$. 


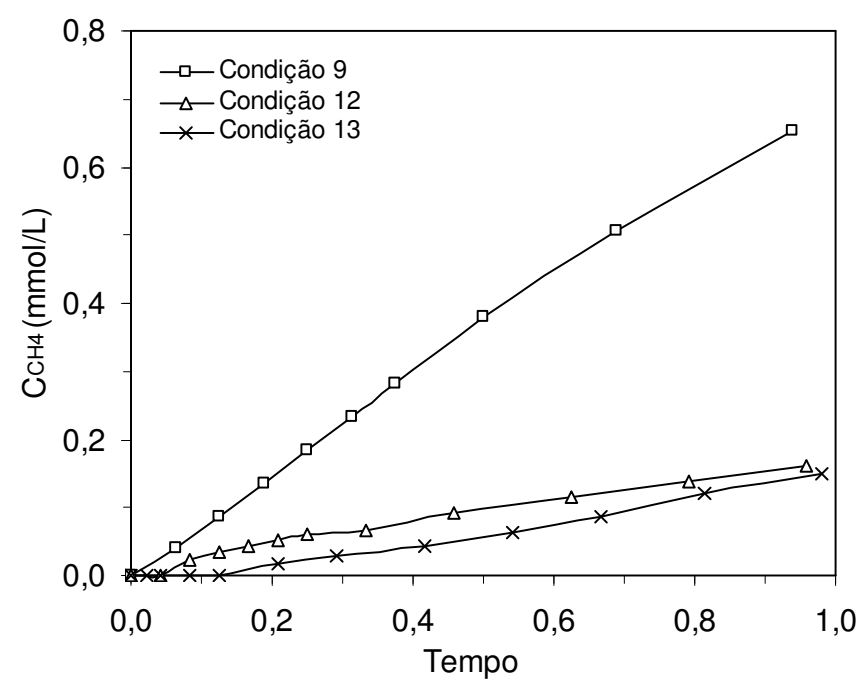

Figura 5.48 - Perfil de concentração de metano do AnSBR nas Condições 9, 12 e 13

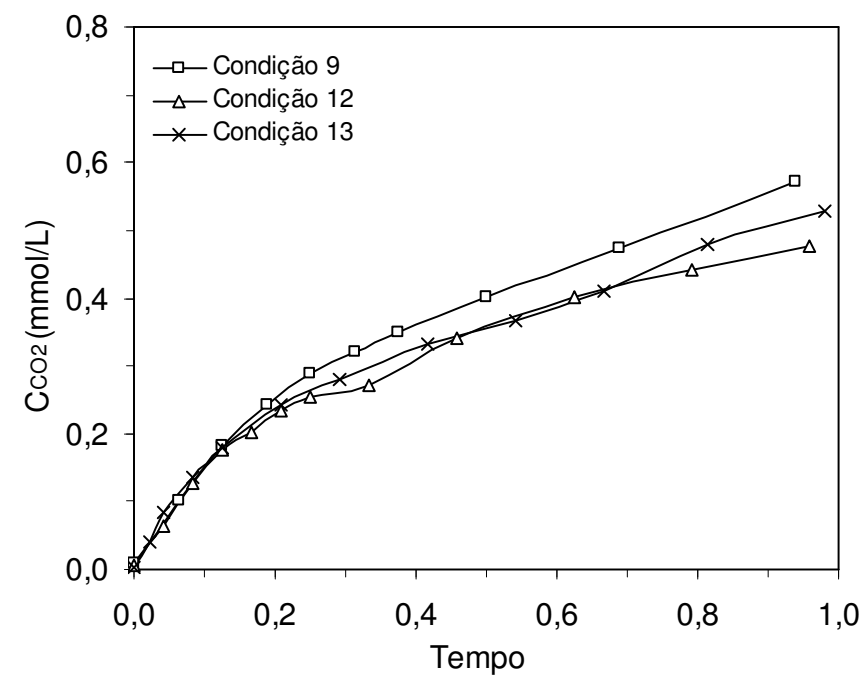

Figura 5.49 - Perfil de concentração de gás carbônico do AnSBR nas Condições 9, 12 e 13

Nas Figuras 5.50 e 5.51 são apresentados os resultados dos perfis de fração molar de metano e gás carbônico das Condições 9, 12 e 13. Como os valores de concentração de gás carbônico foram muito próximos uns dos outros, a seqüência das condições de maior fração molar de metano acabou sendo a mesma das de maior concentração de metano. Observa-se que a Condição 9 apresentou o maior valor, em torno de 53\%, seguida das Condições 12, com 25\%, e 13, com 22\%. 


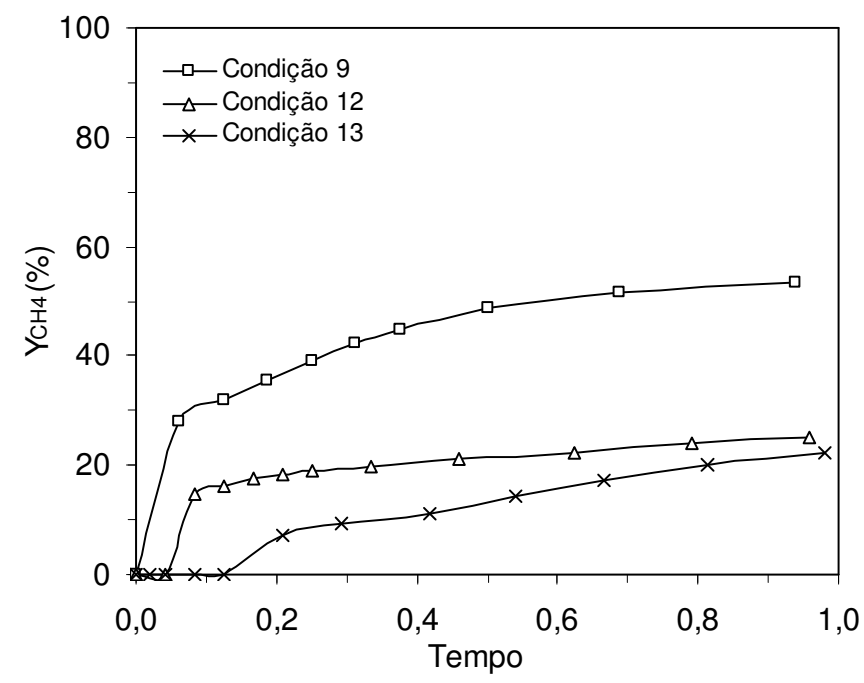

Figura 5.50 - Perfil de fração molar de metano do AnSBR nas Condições 9, 12 e 13

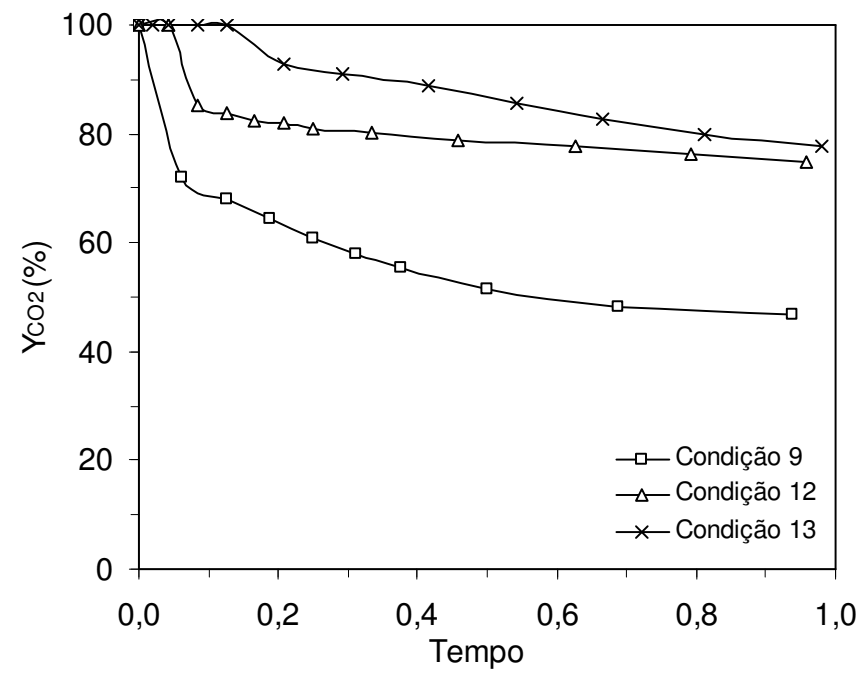

Figura 5.51 - Perfil de fração molar de gás carbônico do AnSBR nas Condições 9, 12 e 13

\subsubsection{MONITORAMENTO DAS CONDIÇÕES 9 E 14}

Nas Condições 9 e 14, o AnSBR foi operado com a mesma COVA, o mesmo tempo de ciclo e a mesma concentração afluente; o que diferia uma condição da outra era a composição do volume alimentado. $\mathrm{Na}$ Condição 9, alimentou-se apenas água residuária, enquanto que na Condição 14, 30\% do volume alimentado foi substituído 
por um meio sintético a base de sacarose, amido solúvel, celulose, extrato de carne, óleo de soja e sais, com a mesma concentração da água residuária. Os resultados obtidos do monitoramento das Condições 9 e 14 são apresentados nas Figuras 5.52 e 5.53 e na Tabela 5.12, e os dos perfis, nas Figuras 5.54 a 5.61 .

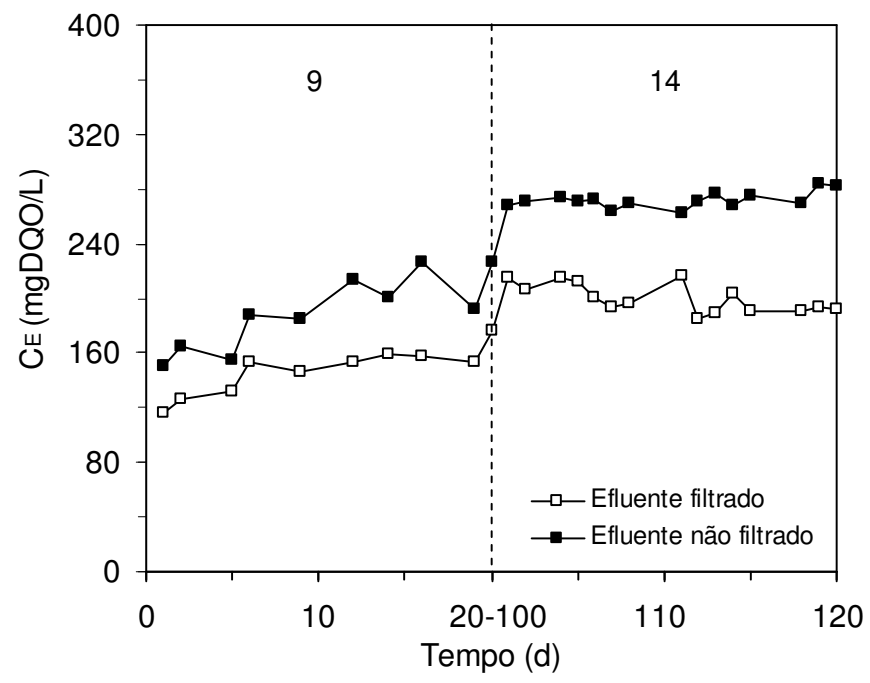

Figura 5.52 - Concentração de matéria orgânica na saída do AnSBR nas Condições 9 e 14

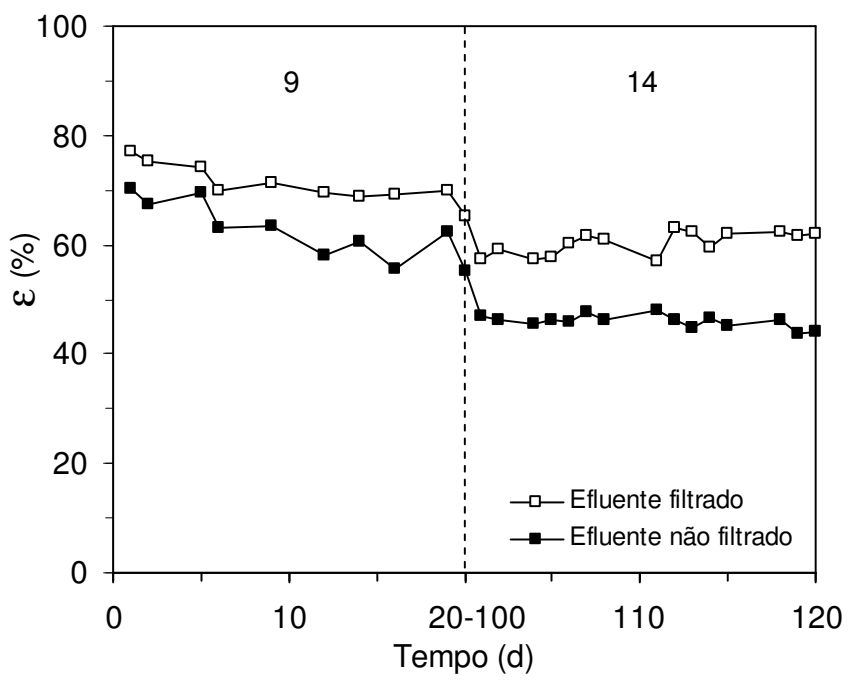

Figura 5.53 - Eficiência de remoção de matéria orgânica do AnSBR nas Condições 9 e 14 
Tabela 5.12 - Variáveis monitoradas do AnSBR nas Condições 9 e 14

\begin{tabular}{|c|c|c|}
\hline Condição & 9 & 14 \\
\hline Especificação & 0,75B-8 & 0,75B-8SPL \\
\hline $\mathrm{C}_{\mathrm{A}}(\mathrm{mgDQO} / \mathrm{L})$ & $508 \pm 5(10)$ & $504 \pm 11(15)$ \\
\hline $\mathrm{C}_{\mathrm{ET}}(\mathrm{mgDQO} / \mathrm{L})$ & $205 \pm 18(7)$ & $272 \pm 6(14)$ \\
\hline$\varepsilon_{\top}(\%)$ & $60 \pm 3$ & $46 \pm 1$ \\
\hline $\mathrm{C}_{\mathrm{EF}}(\mathrm{mgDQO} / \mathrm{L})$ & $157 \pm 9(7)$ & $199 \pm 10(14)$ \\
\hline$\varepsilon_{\mathrm{F}}(\%)$ & $69 \pm 2$ & $60 \pm 2$ \\
\hline $\mathrm{V}_{\mathrm{D}}(\mathrm{L})$ & $1016 \pm 5(10)$ & $1011 \pm 10(15)$ \\
\hline COVA (gDQO/L.d) & $0,768 \pm 0,013$ & $0,760 \pm 0,028$ \\
\hline $\operatorname{coVR}_{\mathrm{T}}(\mathrm{gDQO} / \mathrm{L} . \mathrm{d})$ & $0,458 \pm 0,038$ & $0,350 \pm 0,031$ \\
\hline $\operatorname{coVR}_{F}(g D Q O / L . d)$ & $0,531 \pm 0,025$ & $0,460 \pm 0,039$ \\
\hline COEA (gDQO/gSVT.d) & $0,036 \pm 0,001$ & $0,036 \pm 0,002$ \\
\hline $\mathrm{COER}_{\mathrm{T}}(\mathrm{gDQO} / \mathrm{gSVT} . \mathrm{d})$ & $0,022 \pm 0,002$ & $0,016 \pm 0,001$ \\
\hline COER $_{F}(g D Q O / g S V T . d)$ & $0,025 \pm 0,001$ & $0,022 \pm 0,002$ \\
\hline $\mathrm{pH}_{\mathrm{A}}$ & $7,9 \pm 0,2(4)$ & $8,1 \pm 0,1(7)$ \\
\hline $\mathrm{pH}_{\mathrm{E}}$ & $7,5 \pm 0,1(4)$ & $7,7 \pm 0,1(7)$ \\
\hline$(\mathrm{Al} / \mathrm{AP})_{\mathrm{A}}$ & $0,30 \pm 0,06$ & $0,25 \pm 0,01$ \\
\hline$(\mathrm{Al} / \mathrm{AP})_{\mathrm{E}}$ & $0,32 \pm 0,08$ & $0,27 \pm 0,02$ \\
\hline $\mathrm{AVT}_{\mathrm{A}}(\mathrm{mgHAc} / \mathrm{L})$ & $15 \pm 2(4)$ & $29 \pm 1(7)$ \\
\hline $\mathrm{AVT}_{\mathrm{E}}(\mathrm{mgHAc} / \mathrm{L})$ & $15 \pm 1(4)$ & $31 \pm 2(7)$ \\
\hline $\mathrm{AB}_{\mathrm{A}}(\mathrm{mgCaCO} / \mathrm{L})$ & $201 \pm 5(4)$ & $202 \pm 3(7)$ \\
\hline $\mathrm{AB}_{\mathrm{E}}\left(\mathrm{mgCaCO} \mathrm{C}_{3} / \mathrm{L}\right)$ & $238 \pm 16(4)$ & $245 \pm 3(7)$ \\
\hline $\mathrm{ST}_{\mathrm{A}}(\mathrm{mg} / \mathrm{L})$ & - & $805 \pm 21(2)$ \\
\hline $\mathrm{ST}_{\mathrm{E}}(\mathrm{mg} / \mathrm{L})$ & - & $793 \pm 16(2)$ \\
\hline $\mathrm{SVT}_{\mathrm{A}}(\mathrm{mg} / \mathrm{L})$ & - & $509 \pm 1(2)$ \\
\hline $\mathrm{SVT}_{\mathrm{E}}(\mathrm{mg} / \mathrm{L})$ & - & $509 \pm 1(2)$ \\
\hline $\mathrm{SST}_{\mathrm{A}}(\mathrm{mg} / \mathrm{L})$ & - & $49 \pm 4(2)$ \\
\hline $\mathrm{SST}_{\mathrm{E}}(\mathrm{mg} / \mathrm{L})$ & - & $86 \pm 3(2)$ \\
\hline $\mathrm{SSV}_{\mathrm{A}}(\mathrm{mg} / \mathrm{L})$ & - & $48 \pm 3(2)$ \\
\hline$S S V_{E}(\mathrm{mg} / \mathrm{L})$ & - & $85 \pm 4(2)$ \\
\hline
\end{tabular}

Nota: ( ) número de amostras usadas no cálculo do valor médio das variáveis. 
As Figuras 5.52 e 5.53 apresentam dados de concentração e eficiência de remoção de matéria orgânica para amostras filtradas e não filtradas do efluente ao longo das Condições 9 e 14. Observa-se que o sistema atingiu a estabilidade em ambas logo nos primeiros dias de operação. A Tabela 5.12 apresenta os valores médios destas e de outras variáveis monitoradas que confirmam a estabilidade de operação do sistema no período considerado. $\mathrm{O}$ pH oscilou em um faixa de 7,4 a 8,2 . A concentração de ácidos voláteis totais ficou em torno de 15 mgHAc/L na Condição 9, e $30 \mathrm{mgHAc} / \mathrm{L}$ na Condição 14, mostrando que a suplementação de nutrientes favoreceu a formação destes ácidos. A alcalinidade a bicarbonato do efluente obtida nas duas condições foi próxima, cerca de $240 \mathrm{mgCaCO}_{3} / \mathrm{L}$. Ressalta-se ainda que a carga aplicada de bicarbonato de sódio foi a mesma e igual a 0,30 g/L.d.

Comparando as Condições 9 e 14, observa-se que a Condição 9, que não fez uso da suplementação, foi a que apresentou melhores resultados de eficiência, COVR e COER. Isto sugere que não apenas a água residuária era balanceada do ponto de vista da concentração de nutrientes, como a biomassa também já estava adaptada à degradação daquele tipo de matéria orgânica.

Na Figura 5.54 são apresentados os resultados dos perfis de concentração de matéria orgânica obtidos ao longo de um ciclo de operação das Condições 9 e 14. Observa-se que as curvas de ambas as condições tem comportamento similar. Porém, os dados de monitoramento mostram que o residual da Condição 9 para amostras filtradas do efluente era $157 \mathrm{mgDQO} / \mathrm{L}$, enquanto que na Condição 14 chegava a $199 \mathrm{mgDQO} / \mathrm{L}$. Em contrapartida, nos perfis destas duas condições, o residual ficou em torno de $183 \mathrm{mgDQO} / \mathrm{L}$. 


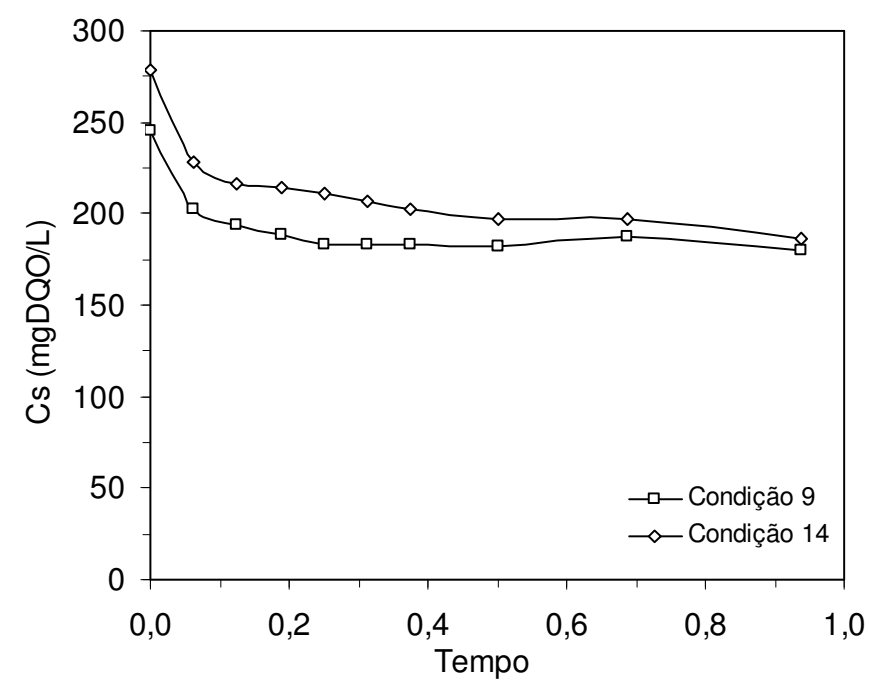

Figura 5.54 - Perfil de concentração de matéria orgânica do AnSBR nas Condições 9 e 14

Na Figura 5.55 são apresentados os perfis de pH das Condições 9 e 14. Observa-se que o pH permaneceu estável ao longo do perfil das duas condições, com valores coerentes com os obtidos do monitoramento.

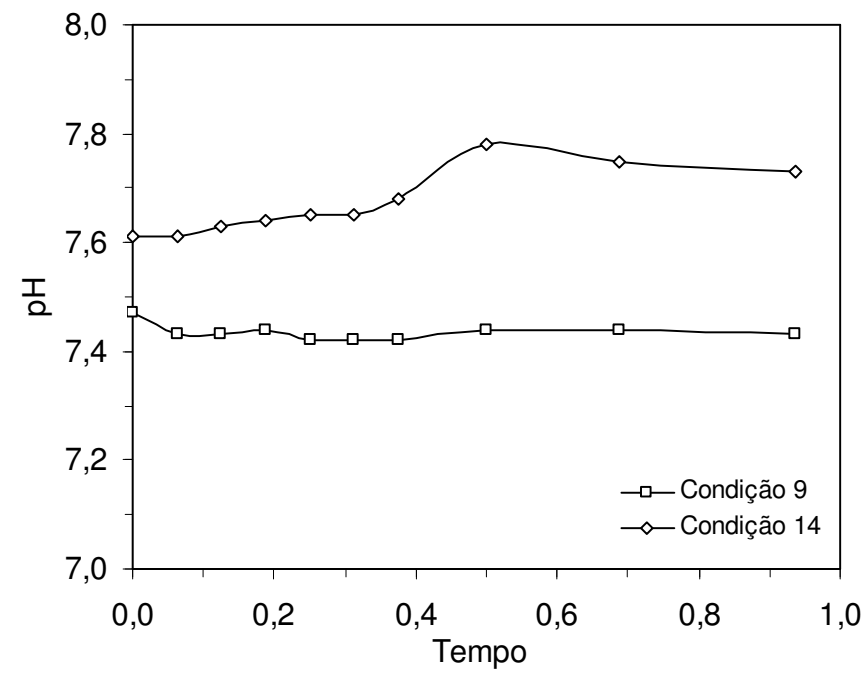

Figura 5.55 - Perfil de pH do AnSBR nas Condições 9 e 14

A Figura 5.56 apresenta os resultados dos perfis de concentração de ácidos voláteis totais obtidos ao longo de um ciclo operacional das Condições 9 e 14. Observa-se 
que o comportamento dos perfis é similar, inclusive em relação aos valores obtidos. Entretanto, esperava-se que a Condição 14 apresentasse valores de AVT dobrados em relação aos valores da Condição 9, mantendo a diferença observada nos dados de monitoramento. Além disso, é possível perceber que mesmo com a suplementação de nutrientes, que certamente aumentou a disponibilidade de compostos de fácil biodegradabilidade no meio reacional, não houve acúmulo de ácidos voláteis em nenhum ponto do perfil.

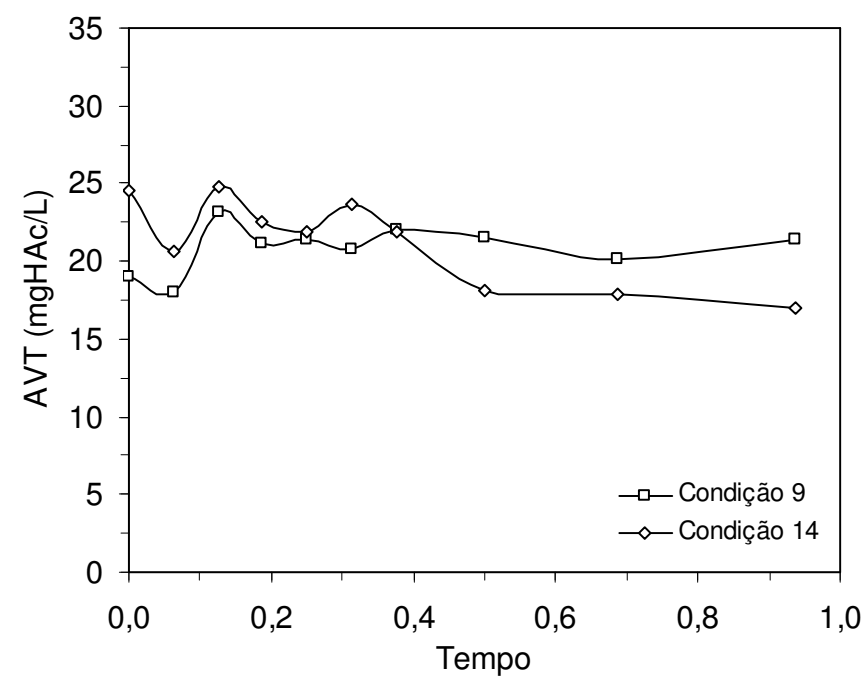

Figura 5.56 - Perfil de concentração de ácidos voláteis totais do AnSBR nas Condições 9 e 14

A Figura 5.57 apresenta os perfis de alcalinidade a bicarbonato das Condições 9 e 14. Os resultados sugerem que houve geração de alcalinidade tanto na Condição 9, que passou de 227 para $238 \mathrm{mgCaCO}_{3} / \mathrm{L}$, quanto na Condição 14, que foi de 252 a $275 \mathrm{mgCaCO}_{3} / \mathrm{L}$. 


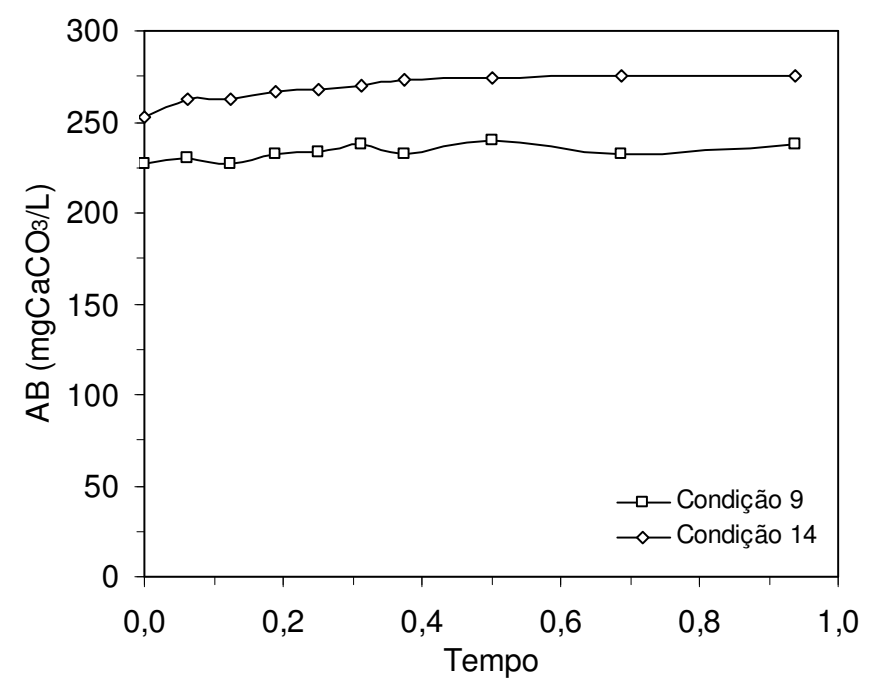

Figura 5.57 - Perfil de alcalinidade a bicarbonato do AnSBR nas Condições 9 e 14

Nas Figuras 5.58 e 5.59 são apresentados os resultados dos perfis de concentração de metano e gás carbônico obtidos ao longo de um ciclo operacional das Condições 9 e 14. Observa-se que a Condição 9 apresentou os maiores valores de concentração, sendo $0,65 \mathrm{mmol} / \mathrm{L}$ de metano e $0,57 \mathrm{mmol} / \mathrm{L}$ de gás carbônico. $\mathrm{Na}$ Condição 14, estes valores foram apenas $0,19 \mathrm{mmol} / \mathrm{L}$ e $0,44 \mathrm{mmol} / \mathrm{L}$, respectivamente. O resultado já era esperado visto que a Condição 9 apresentou também os maiores valores de COVR.

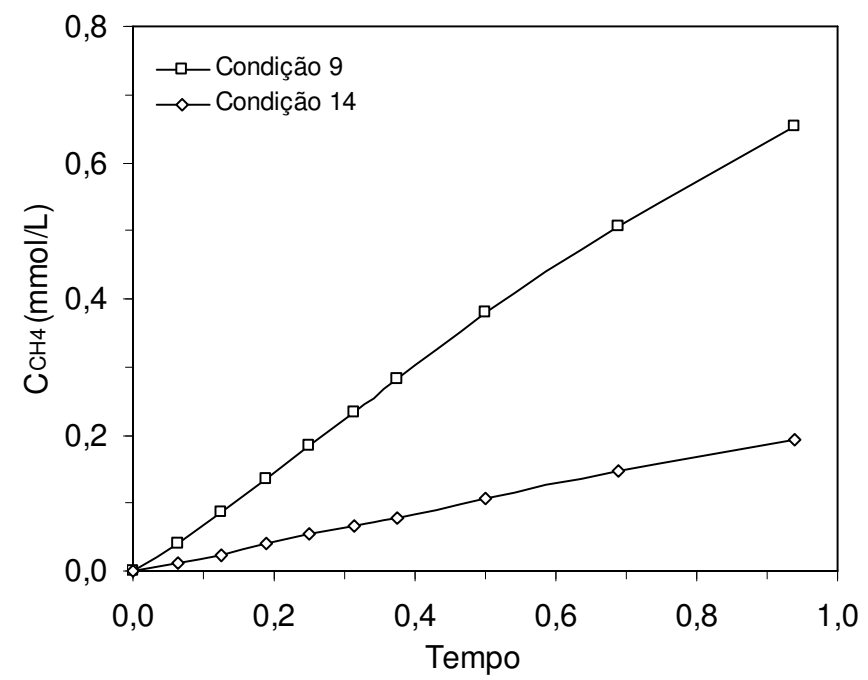

Figura 5.58 - Perfil de concentração de metano do AnSBR nas Condições 9 e 14 


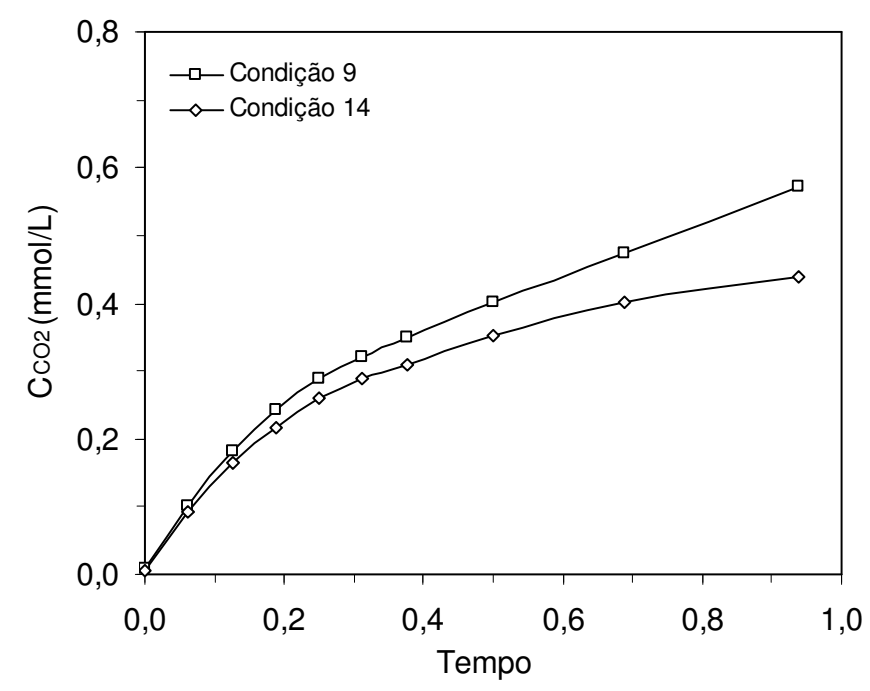

Figura 5.59 - Perfil de concentração de gás carbônico do AnSBR nas Condições 9 e 14

As Figuras 5.60 e 5.61 apresentam os resultados dos perfis de fração molar de metano e gás carbônico das Condições 9 e 14. Observa-se que a maior fração de metano também foi obtida na Condição 9, cerca de 53\%, enquanto que na Condição 14 foi de apenas $31 \%$.

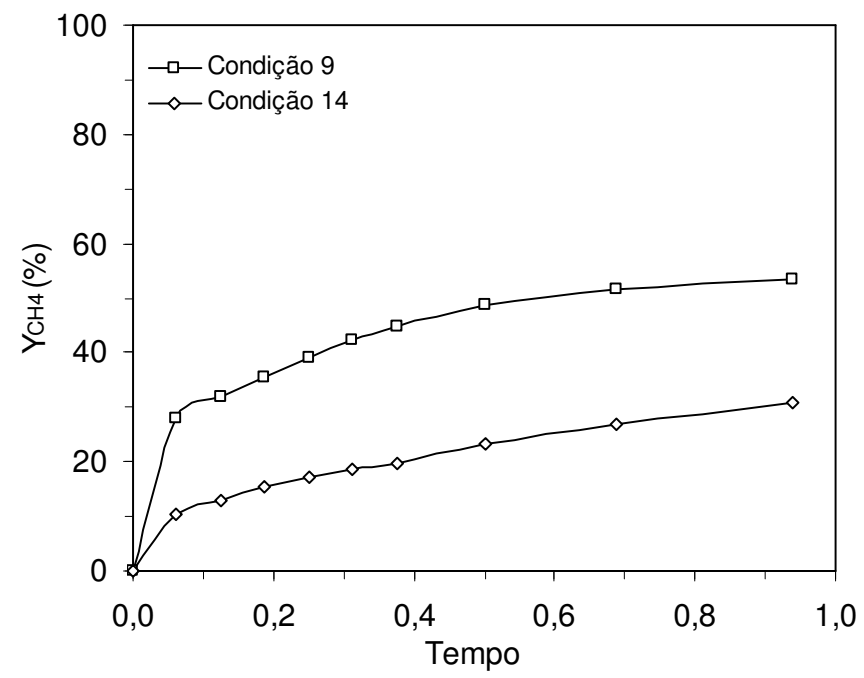

Figura 5.60 - Perfil de fração molar de metano do AnSBR nas Condições 9 e 14 


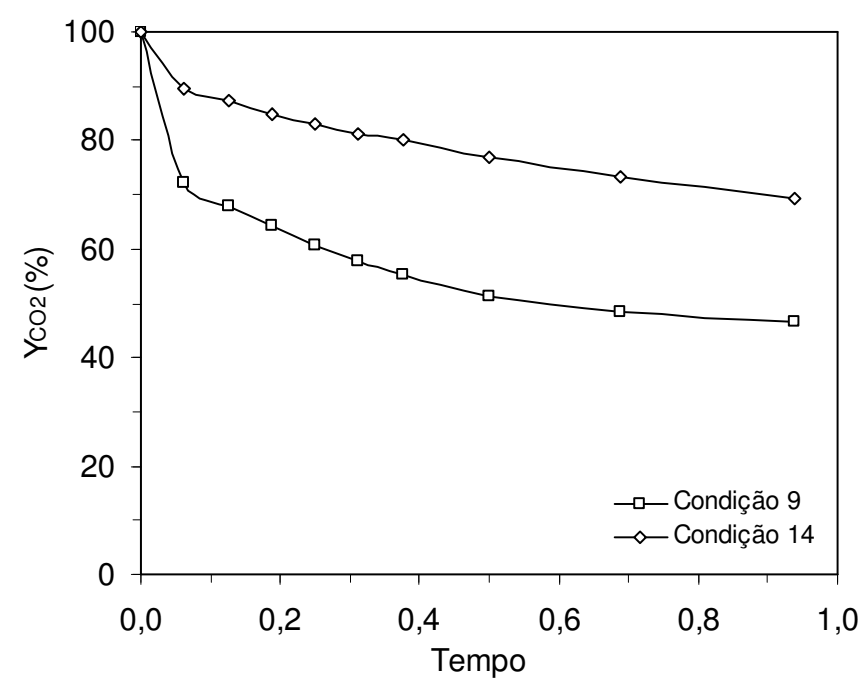

Figura 5.61 - Perfil de fração molar de gás carbônico do AnSBR nas Condições 9 e 14

\subsubsection{ESTUDO COMPARATIVO DAS CONDIÇÕES EXPERIMENTAIS DO ANSBR}

O AnSBR atingiu a estabilidade em todas as condições experimentais. A Tabela 5.13 apresenta um quadro resumo destas condições e seus principais resultados.

Tabela 5.13 - Quadro resumo das condições experimentais do AnSBR

\begin{tabular}{|c|c|c|c|c|c|c|}
\hline Condição & 9 & 10 & 11 & 12 & 13 & 14 \\
\hline $\begin{array}{c}\text { COVA } \\
\text { (gDQO/L.d) }\end{array}$ & 0,75 & 0,75 & 0,75 & 0,50 & 0,25 & 0,75 \\
\hline $\begin{array}{c}\mathrm{C}_{\mathrm{A}} \\
(\mathrm{mgDQO} / \mathrm{L})\end{array}$ & 500 & 750 & 1500 & 500 & 500 & 500 \\
\hline $\begin{array}{l}t_{c} \\
\text { (h) }\end{array}$ & 8 & 12 & 24 & 12 & 24 & 8 \\
\hline $\begin{array}{l}\text { Suplementação } \\
\text { de meio sintético }\end{array}$ & NÃO & NÃO & NÃO & NÃO & NÃO & SIM \\
\hline $\begin{array}{c}\varepsilon_{\mathrm{F}} \\
(\%)\end{array}$ & 69 & 68 & 77 & 61 & 52 & 60 \\
\hline $\begin{array}{c}\text { COVR }_{\mathrm{F}} \\
(\mathrm{gDQO} / \mathrm{L} . \mathrm{d})\end{array}$ & 0,53 & 0,52 & 0,57 & 0,31 & 0,13 & 0,46 \\
\hline $\begin{array}{c}\text { COER }_{F} \\
(g D Q O / g S V T . d)\end{array}$ & 0,025 & 0,024 & 0,027 & 0,014 & 0,006 & 0,022 \\
\hline
\end{tabular}


Ao comparar as Condições 9, 10 e 11, de mesma COVA, observa-se que o aumento da concentração afluente e do tempo de ciclo contribuiu para o aumento dos valores de eficiência, COVR e COER. Na Condição 9, com $\mathrm{C}_{\mathrm{A}}$ de $500 \mathrm{mgDQO} / \mathrm{L}$ e tc de $8 \mathrm{~h}$, a eficiência de remoção da matéria orgânica para amostras filtradas do efluente foi $69 \%$, ao passo que na Condição 11, com $\mathrm{C}_{\mathrm{A}}$ de $1500 \mathrm{mgDQO} / \mathrm{L}$ e $\mathrm{t}_{\mathrm{C}}$ de $24 \mathrm{~h}$, este valor chegou a 77\%. Os valores de COVR e COER também foram maiores na Condição 11. Enquanto na Condição 9 obteve-se 0,53 gDQO/L.d e 0,025 gDQO/gSVT.d, os mesmos chegaram a 0,57 gDQO/L.d e 0,027 gDQO/gSVT.d na Condição 11. A Condição 10, porém, sugere que o comportamento não é linear, visto que o aumento do $t_{c}$ de 8 para $12 \mathrm{~h}$ não correspondeu a um aumento de eficiência quando $C_{A}$ passou de 500 para $750 \mathrm{mgDQO} / \mathrm{L}$.

Comparando as Condições 9, 12 e 13, observa-se que a redução da COVA por meio do aumento do tempo de ciclo não representou ganho de eficiência; pelo contrário, os dados obtidos mostram que houve queda significativa de eficiência de 69 para $61 \%$ e, depois, para 52\%, quando o AnSBR foi operado com $500 \mathrm{mgDQO} / \mathrm{L}$ em ciclos de 8, 12 e 24 h, respectivamente. Também houve redução da eficiência quando $30 \%$ da matéria orgânica do sistema foi substituída por meio sintético. Para uma COVA de 0,75 gDQO/L.d, a eficiência foi de apenas $60 \%$ contra os $69 \%$ obtidos somente com água residuária.

\subsubsection{Análise de sólidos do AnSBR}

A análise de sólidos feita com a biomassa do AnSBR mostrou que havia aproximadamente 42,7 gSVT no interior do reator, que correspondiam a $87 \%$ dos 
sólidos totais. Como o volume de meio líquido do sistema era 2,0 L, a concentração de biomassa ficou em 21,4 gSVT/L.

\subsubsection{Exames microbiológicos do AnSBR}

O inóculo usado no AnSBR era o mesmo do AnSBBR, no qual se verificou a predominância de organismos com forma de cocos pequenos e de filamentos. Além disso, os resultados da microscopia de contraste de fase e fluorescência da biomassa do AnSBR também foram iguais aos do AnSBBR. Houve predominância de cocos grandes e bacilos, como mostram as Figuras 5.62 e 5.63, e a presença de organismos filamentosos semelhantes a Methanosaeta sp.

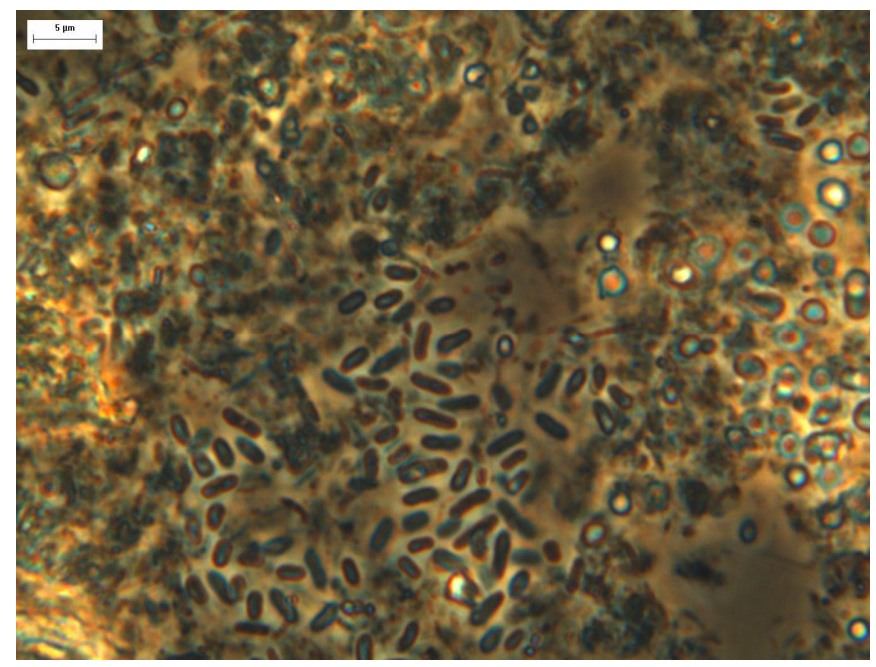

Figura 5.62 - Exame microbiológico da biomassa do AnSBR 


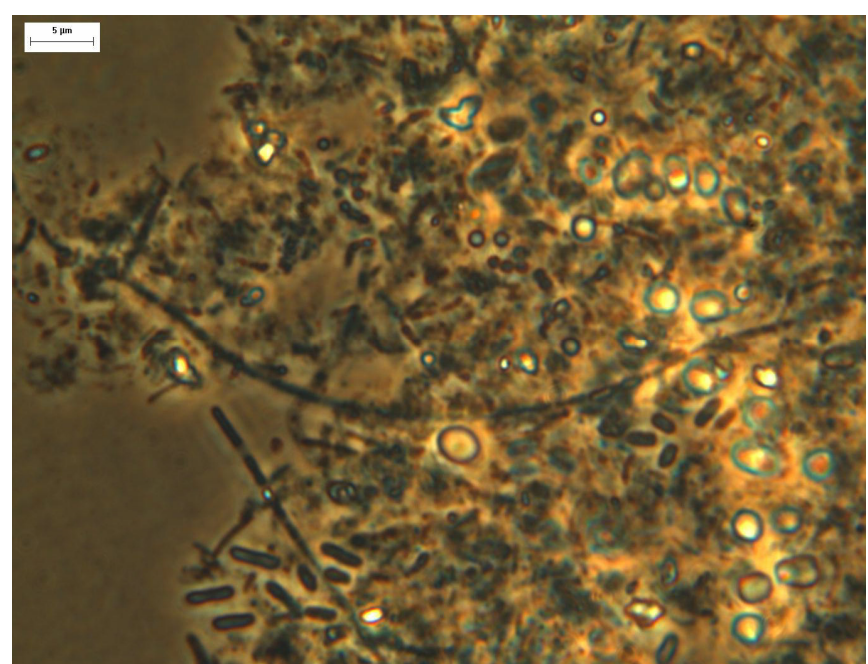

Figura 5.63 - Exame microbiológico da biomassa do AnSBR

A Figura 5.64 comprova que os bacilos encontrados em grandes quantidades, tanto na biomassa do AnSBR quanto na do AnSBBR, realmente vieram do inóculo, onde apareciam em menor número.

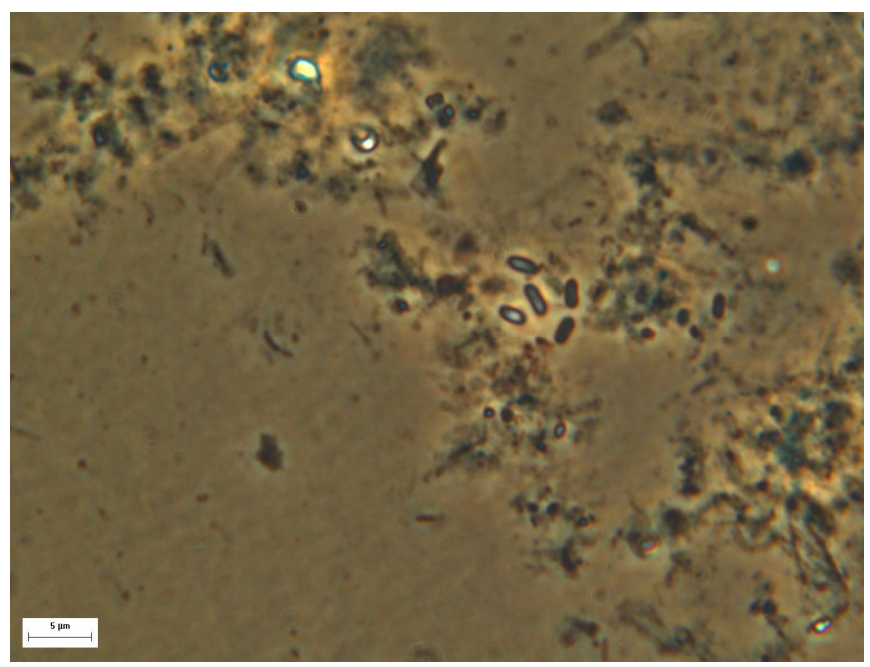

Figura 5.64 - Exame microbiológico do inóculo 



\section{CONCLUSÕES}

Os resultados mostraram que o AnSBBR, com recirculação da fase líquida e biomassa imobilizada em espuma de poliuretano, e o AnSBR, com agitação mecânica e biomassa granulada, atingiram a estabilidade em sua respectivas condições experimentais, tratando água residuária que simulava o efluente de uma indústria de produtos de higiene pessoal. A concentração de biomassa no AnSBBR chegou a 20,2 gSVT/L, enquanto no AnSBR foi de 21,4 gSVT/L. Além disso, a retenção de sólidos em quase todas as condições sugere que não houve lavagem da biomassa no AnSBBR, nem desgranulação no AnSBR.

O estudo de otimização da suplementação de alcalinidade mostrou que a água residuária não seria capaz de suprir a demanda da biomassa nas condições experimentais implementadas, caso não fosse adicionada a ela qualquer composto com este propósito. Contudo, a adição de bicarbonato de sódio na concentração de 0,20 $\mathrm{g} / \mathrm{L}$ parece ter sido mais que suficiente para garantir a reserva de alcalinidade, levando-se em conta que em algumas condições a carga volumétrica de bicarbonato não foi corrigida em função da carga orgânica volumétrica e, mesmo assim, não representou problema algum para a estabilidade operacional dos reatores.

A operação do AnSBBR em batelada alimentada, seguida de batelada, proporcionou valores maiores de eficiência e carga orgânica removida que a operação em batelada, porque evitou o acúmulo dos produtos intermediários de difícil biodegradabilidade que retardavam a degradação da matéria orgânica proveniente da água residuária - e da qual eram oriundos. Dessa forma, a biomassa conseguiu converter uma fração maior de substrato a metano, inclusive de intermediários. 
O uso do volume residual de um ciclo anterior como parte integrante do meio líquido do ciclo seguinte trouxe vantagens apenas para as condições em que o AnSBBR foi operado em batelada alimentada, seguida de batelada, pois o efeito da diluição sobre o substrato permitiu que a degradação ocorresse sem acúmulo dos produtos intermediários que dificultavam a conversão da matéria orgânica a metano. Já na operação em batelada, como toda água residuária era alimentada logo no início do ciclo, o uso do volume residual resultou no aumento da concentração inicial de substrato, justamente pela incorporação da matéria orgânica parcialmente degradada desse volume; e considerando que parte dessa matéria orgânica era formada por compostos intermediários, a velocidade média de consumo do substrato acabou diminuindo.

O AnSBR apresentou valores maiores de eficiência e carga orgânica removida nas condições de maior tempo de ciclo, quando submetido à mesma carga orgânica volumétrica aplicada. O aumento da concentração inicial de substrato deve ter proporcionado um aumento da velocidade media de reação e, consequentemente, um aumento da concentração de produtos intermediários no meio reacional; mas o longo tempo de ciclo permitiu que a biomassa convertesse uma fração maior de substrato a metano se comparado às outras condições de ciclos mais curtos. $O$ mesmo não aconteceu quando o valor da carga orgânica aplicada foi reduzido em função do aumento do tempo de ciclo, pois a concentração de substrato no meio reacional acabou sendo baixa demais para garantir a demanda energética da biomassa por períodos tão longos. Neste caso, o aumento do tempo de ciclo provocou a diminuição dos valores de eficiência e carga orgânica removida. 
A suplementação de nutrientes à água residuária também não trouxe benefícios para o sistema na condição experimental estudada. Nessa condição em que $30 \%$ do volume alimentado de água residuária foi substituído por um meio sintético a base de sacarose, amido solúvel, celulose, extrato de carne, óleo de soja e sais, os valores de eficiência e carga orgânica removida diminuíram consideravelmente, mostrando que além de balanceada, a água residuária em estudo tinha condicionado a adaptação da biomassa.

Considerando os resultados obtidos nas condições experimentais, o modo mais apropriado para tratar a água residuária em estudo seria em batelada alimentada, fazendo uso de volume residual e de longos tempos de ciclo, o que permitiria a aplicação de valores elevados de carga orgânica volumétrica. Neste contexto, sugere-se ainda um estudo voltado especificamente para a otimização da relação entre o volume de meio líquido do sistema e o volume residual e para a implementação de uma estratégia de alimentação que minimize ainda mais o acúmulo dos compostos intermediários que dificultavam a degradação da matéria orgânica. Dessa forma, propõe-se que o volume residual seja descarregado do sistema e alimentado junto do afluente, em batelada alimentada, mas separadamente, ou seja, utilizando-se duas bombas dosadoras para evitar a contaminação do afluente. 



\section{REFERÊNCIAS BIBLIOGRÁFICAS}

AMERICAN PUBLIC HEALTH ASSOCIATION; AMERICAN WATER WORKS ASSOCIATION; WATER ENVIRONMENT FEDERATION. Standard Methods for the Examination of Water and Wastewater. $19^{\text {th }}$ ed. Washington DC, United States of America: APHA, 1995.

ANGENENT, L. T.; DAGUE, R. R. (1995). A laboratory-scale comparison of the UASB and ASBR processes. In: PURDUE INDUSTRIAL WASTE CONFERENCE, 50, West Lafayette, IN, United States of America. Proceedings of the $50^{\text {th }}$ Industrial Waste Conference. Chelsea, MI, United States of America: Ann Arbor Press, Inc., 1996. p. 365-377.

BAGLEY, D. M.; BRODKORB, T. S. (1999). Modeling microbial kinetics in an anaerobic sequencing batch reactor: model development and experimental validation. Water Environment Research, v. 71, n. 7, p. 1320-1332.

BAUMANN, U.; MÜLLER, M. T. (1997). Determination of anaerobic biodegradability with a simple continuous fixed-bed reactor. Water Research, v.31, n.6, p.1513-1517.

BELTRÁN-HEREDIA, J.; SÁNCHEZ-MARTíN, J. (2009). Removal of sodium lauryl sulphate by coagulation/flocculation with Moringa oleifera seed extract. Journal of Hazardous Materials, v. 164, n. 2-3, p. 713-719.

BEZERRA JUNIOR, R. A.; RODRIGUES, J. A. D.; RATUSZNEI, S. M.; ZAIAT, M.; FORESTI, E. (2007). Whey treatment by AnSBBR with circulation: effects of organic

De acordo com: ASSOCIAÇÃO BRASILEIRA DE NORMAS TÉCNICAS. NBR 6023: informação e documentação: referências: elaboração. Rio de Janeiro, 2002. 
loading, shock loads, and alkalinity supplementation. Applied Biochemistry and Biotechnology, v. 143, n. 3, p.257-275.

BEZERRA JUNIOR, R. A.; RODRIGUES, J. A. D.; RATUSZNEI, S. M.; ZAIAT, M.; FORESTI, E; BORZANI, W. (2005). Performance of anaerobic sequencing batch biofilm reactor submitted to different influent volume feeds and cycle time periods maintaining organic loading. Applied Biochemistry and Biotechnology, v. 126, n. 3, p.189-203.

BORGES, A. C.; SIMAN, R. R.; RODRIGUES, J. A. D.; RATUSZNEI, S. M.; ZAIAT, M.; FORESTI, E; BORZANI, W. (2004). Stirred anaerobic sequencing batch reactor containing immobilized biomass: a behavior study when submitted to different fill times. Water Science and Technology, v. 49, n.11-12, p. 311-318.

CAMARGO, E. F. M.; CANTO, C. S. A.; RATUSZNEI, S. M.; RODRIGUES, J. A. D; ZAIAT, M.; BORZANI, W. (2005). Hydrodynamic analysis of an anaerobic sequencing batch biofilm reactor with liquid-phase external circulation. Interciencia, v. 30 , n. 4 , p. $188-194$.

CAMARGO, E. F. M.; RATUSZNEI, S. M.; RODRIGUES, J. A. D; ZAIAT, M.; BORZANI, W. (2002). Treatment of low-strength wastewater using immobilized biomass in a sequencing batch external loop reactor: influence of the medium superficial velocity on the stability and performance. Brazilian Journal of Chemical Engineering, v. 19, n. 3, p. 267-275. 
CAMPOS, J. R. (Coord.). Tratamento de esgotos sanitários por processo anaeróbio e disposição controlada no solo. $1^{\underline{a}}$ ed. Rio de Janeiro, RJ, Brasil: ABES, 1999. 435 p. Projeto PROSAB.

CHEBEL, F. X.; RATUSZNEI, S. M.; RODRIGUES, J. A. D.; ZAIAT, M.; FORESTI, E. (2006). Analysis of performance of an anaerobic sequencing batch reactor submitted to increasing organic load with different influent concentrations and cycle lengths. Applied Biochemistry and Biotechnology, v. 133, n. 2, p. 171-187.

CSERHÁTI, T.; FORGÁCS, E.; OROS, G. (2002). Biological activity and environmental impact of anionic surfactants. Environment International, v. 28, n. 5, p. 337-348.

DAGUE, R. R.; BANIK, G. C.; ELLIS, T. G. (1998). Anaerobic sequencing batch reactor treatment of dilute wastewater at psychrophilic temperatures. Water Environment Research, v. 70, n. 2, p.155-160.

DAGUE, R. R.; HABBEN, C. E.; PIDAPARTI, S. R. (1992). Initial studies on the anaerobic sequencing batch reactor. Water Science and Technology, v. 26, n. 9-11, p. 2429-2432.

DAMASCENO, L. H. S.; RODRIGUES, J. A. D.; RATUSZNEI, S. M.; ZAIAT, M.; FORESTI, E. (2007). Effects of feeding time and organic loading in an anaerobic sequencing batch biofilm reactor (ASBBR) treating diluted whey. Journal of Environmental Management, v. 85, n. 4, p. 927-935. 
DILALLO, R.; ALBERTSON, O. E. (1961). Volatile acids by direct titration. Journal of Water Pollution Control Federation, v. 33, n. 4, p. 356-365.

HARPER, S. R.; POHLAND, F. G. (1986). Recent developments in hydrogen management during anaerobic biological wastewater treatment. Biotechnology and Bioengineering, v.28, n. 4, p. 585-602.

HOLLOPETER, J. A.; DAGUE, R. R. (1994). Anaerobic sequencing batch reactor treatment of landfill leachate. In: PURDUE INDUSTRIAL WASTE CONFERENCE, 49, West Lafayette, IN, United States of America. Proceedings of the $49^{\text {th }}$ Industrial Waste Conference. Chelsea, MI, United States of America: Lewis Publishers, 1995. p. 277-284.

KENNEDY, K. J.; SANCHEZ, W. A.; HAMODA, M. F.; DROSTE, R. L. (1991). Performance of anaerobic sludge blanket sequencing batch reactors. Journal of Water Pollution Control Federation, v. 63, n. 1, p. 75-83.

LENS, P. N. L.; VISSER, A.; JANSSEN, A. J. H.; HULSHOFF POL, L. W.; LETTINGA, G. (1998). Biotechnological treatment of sulfate-rich wastewaters. Critical Reviews in Environmental Science and Technology, v. 28, n. 1, p. 41-88.

MASSÉ, D. I.; DROSTE, R. L.; KENNEDY, K. J.; PATNI, N. K.; MUNROE, J. A. (1997). Potencial for the psychrophilic anaerobic treatment of swine manure using a sequencing batch reactor. Canadian Agricultural Engineering, v. 39, n. 1, p. 25-33.

MICHELAN, R.; ZIMMER, T. R.; RODRIGUES, J. A. D.; RATUSZNEI, S. M.; MORAES, D.; ZAIAT, M.; FORESTI, E. (2009). Effect of impeller type and 
mechanical agitation on the mass transfer and power consumption aspects of ASBR operation treating synthetic wastewater. Journal of Environmental Management, v. 90, n. 3, p. 1357-1364.

MIQUELETO, A. P.; RODRIGUES, J. A. D.; RATUSZNEI, S. M.; FORESTI, E.; ZAIAT, M. (2005). Treatment of easily degradable wastewater in a stirred anaerobic sequencing batch biofilm reactor. Water Research, v. 39, n. 11, p. 2376-2384.

MOCKAITIS, G.; RATUSZNEI, S. M.; RODRIGUES, J. A. D.; ZAIAT, M.; FORESTI, E. (2006). Anaerobic whey treatment by a stirred sequencing batch reactor (ASBR): effects of organic loading and supplemented alkalinity. Journal of Environmental Management, v. 79, n. 2, p. 198-206.

MOHAN, S. V.; BABU, V. L.; BHASKAR, Y. V.; SARMA, P. N. (2007). Influence of recirculation on the performance of anaerobic sequencing batch biofilm reactor (AnSBBR) treating hypersaline composite chemical wastewater. Bioresource Technology, v. 98, n. 7, p. 1373-1379.

MORAES, E. M.; ADORNO, M. A. T.; ZAIAT, M.; FORESTI, E. (2000). Determinação de ácidos voláteis totais por cromatografia gasosa em efluentes de reatores anaeróbios tratando resíduos líquidos e sólidos. In: OFICINA E SEMINÁRIO LATINO-AMERICANO DE DIGESTÃO ANAERÓBIA, 6, Recife, PE, Brasil. Anais da VI Oficina e Seminário Latino-Americano de Digestão Anaeróbia. Recife, PE, Brasil: Editora Universitária UFPE, 2000. v. 2, p. 235-238.

MOREIRA, M. B.; RATUSZNEI, S. M.; RODRIGUES, J. A. D.; ZAIAT, M.; FORESTI, E. (2008). Influence of organic shock loads in an ASBBR treating synthetic 
wastewater with different concentration levels. Bioresource Technology, v. 99, n. 8, p. $3256-3266$.

ORRA, A. A.; RATUSZNEI, S. M.; RODRIGUES, J. A. D.; FORESTI, E.; ZAIAT, M. (2004). Effects of feeding strategies on the performance of an anaerobic discontinuous reactor containing immobilized biomass with circulation system for liquid-phase mixing. Water Science and Technology, v. 49, n. 11-12, p. 303-310.

ORTEGA, F. S.; ROCHA, K. M.; ZAIAT, M.; PANDOLFELLI, V. C. (2001). Aplicação de espumas cerâmicas produzidas via "gelcasting" em biorreator para tratamento anaeróbio de águas residuárias. Cerâmica, v. 47, n. 304, p. 199-203.

PATEL, P.; MADAMWAR, D. (1998). Surfactants in anaerobic digestion of salty cheese whey using upflow fixed film reactor for improved biomethanation. Process Biochemistry, v. 33, n. 2, p. 199-203.

RACINE. Shampoos, condicionadores e sabonetes: aspectos técnicos e práticos para o desenvolvimento de formulações. São Paulo, SP, Brasil: Racine, 1999. 91 p.

RAMOS, A. C. T.; RATUSZNEI, S. M.; RODRIGUES, J. A. D.; ZAIAT, M. (2003). Mass transfer improvement of a fixed-bed anaerobic sequencing batch reactor with liquid-phase circulation. Interciencia, v. 28, n. 4, p. 214-219.

RATUSZNEI, S. M.; RODRIGUES, J. A. D.; CAMARGO, E. F. M.; ZAIAT, M.; BORZANI, W. (2000). Feasibility of a stirred anaerobic sequencing batch reactor containing immobilized biomass for wastewater treatment. Bioresource Technology, v. 75, n. 2, p.127-132. 
RATUSZNEI, S. M.; RODRIGUES, J. A. D.; ZAIAT, M. (2003). Operating feasibility of anaerobic whey treatment in a stirred sequencing batch reactor containing immobilized biomass. Water Science and Technology, v. 48, n. 6, p.179-186.

RIPLEY, L. E.; BOYLE, W. C.; CONVERSE, J. C. (1986). Improved alkalimetric monitoring for anaerobic digestion of high-strength wastes. Journal of Water Pollution Control Federation, v. 58, n. 5, p. 406-411.

RODRIGUES, J. A. D.; PINTO, A. G.; RATUSZNEI, S. M.; ZAIAT, M.; GEDRAITE, R. (2004). Enhancement of the performance of an anaerobic sequencing batch reactor treating low-strength wastewater through implementation of a variable stirring rate program. Brazilian Journal of Chemical Engineering, v. 21, n. 3, p. 423-434.

RODRIGUES, J. A. D.; RATUSZNEI, S. M.; CAMARGO, E. F. M.; ZAIAT, M. (2003). Influence of agitation rate on the performance of an anaerobic sequencing batch reactor containing granulated biomass treating low-strength wastewater. Advances in Environmental Research, v. 7, n. 2, p. 405-410.

SARTI, A.; GARCIA, M. L.; ZAIAT, M.; FORESTI, E. (2007). Domestic sewage treatment in a pilot-scale anaerobic sequencing batch biofilm reactor (ASBBR). Resources, Conservation and Recycling, v. 51, n. 1, p. 237-247.

SIMAN, R. R.; BORGES, A. C.; RATUSZNEI, S. M.; RODRIGUES, J. A. D.; ZAIAT, M.; FORESTI, E.; BORZANI, W. (2004). Influence of organic loading on an anaerobic sequencing biofilm batch reactor (ASBBR) as a function of cycle period and wastewater concentration. Journal of Environmental Management, v. 72, n. 4, p. 241-247. 
SUNG, S.; DAGUE, R. R. (1995). Laboratory studies on the anaerobic sequencing batch reactor. Water Environment Research, v. 67, n. 3, p. 294-301.

TIMUR, H.; ÖZTURK, I. (1999). Anaerobic sequencing batch reactor treatment of landfill leachate. Water Research, v. 33, n. 15, p. 3225-3230.

TORRES, P. Desempenho de um reator anaeróbio de manta de lodo (UASB) de bancada no tratamento de substrato sintético simulando esgoto sanitário sob diferentes condições de operação. 1992. 174 p. Dissertação (Mestrado em Engenharia Hidráulica e Saneamento) - Escola de Engenharia de São Carlos, Universidade de São Paulo, São Carlos, 1992.

VARESCHE, M. B.; ZAIAT, M.; VIEIRA, L. G. T.; VAZOLLER, R. F.; FORESTI, E. (1997). Microbial colonization of polyurethane foam matrices in horizontal-flow anaerobic immobilized-sludge reactor. Applied Microbiology Biotechnology, v. 48, n. 4 , p. 534-538.

ZAIAT, M.; CABRAL, A. K. A.; FORESTI, E. (1994). Reator anaeróbio horizontal de leito fixo para tratamento de águas residuárias: concepção e avaliação preliminar de desempenho. Revista Brasileira de Engenharia Química, v. 11, n. 2, p. 33-42.

ZAIAT, M.; RODRIGUES, J. A. D.; RATUSZNEI, S. M.; CAMARGO, E. F. M.; BORZANI, W. (2001). Anaerobic sequencing batch reactors for wastewater treatment: a developing technology. Applied Microbiology and Biotechnology, v. 55, n. 1, p. 29-35. 
ZAIAT, M.; VIEIRA, L. G. T.; FORESTI, E. (1997). Intrinsic kinetic parameters of substrate utilization by immobilized anaerobic sludge. Biotechnology and Bioengineering, v. 53, n. 2, p. 220-225. 



\section{APÊNDICE A - TABELAS DE MONITORAMENTO}

Tabela A.1 - Dados de concentração de matéria orgânica $\left(C_{A}\right), p H$, alcalinidade parcial (AP), intermediária (Al), total (AT) e a bicarbonato $(A B)$, razão $A l / A P$ e concentração de ácidos voláteis totais (AVT), obtidos do monitoramento do afluente na Condição 1

\begin{tabular}{|c|c|c|c|c|c|c|c|c|c|}
\hline$t_{\mathrm{OP}}\left(\mathrm{C}_{\mathrm{OP}}\right)$ & M & $\mathrm{C}_{\mathrm{A}}$ & $\mathrm{pH}$ & AP & $\mathrm{Al}$ & $\mathrm{Al} / \mathrm{AP}$ & AT & AVT & $A B$ \\
\hline $0(1)$ & M1 & 529,2 & 8,17 & 478,9 & 103,8 & 0,22 & 582,7 & 23,7 & 565,8 \\
\hline $1(4)$ & M2 & 519,9 & 8,16 & 312,0 & 77,2 & 0,25 & 389,3 & 16,4 & 377,7 \\
\hline $2(7)$ & M3 & 528,1 & 8,25 & 267,5 & 66,7 & 0,25 & 334,3 & 14,2 & 324,2 \\
\hline $3(10)$ & M4 & 516,6 & 8,18 & 221,2 & 52,5 & 0,24 & 273,7 & 13,5 & 264,1 \\
\hline $4(13)$ & M5 & 506,7 & 7,84 & 167,5 & 45,7 & 0,27 & 213,2 & 14,9 & 202,6 \\
\hline $6(19)$ & M6 & 517,9 & 7,82 & 105,8 & 28,7 & 0,27 & 134,5 & 13,2 & 125,1 \\
\hline 7 (22) & M7 & 500,2 & 7,89 & 75,3 & 19,7 & 0,26 & 94,9 & 12,4 & 86,1 \\
\hline $8(25)$ & M8 & 508,8 & 7,87 & 74,2 & 20,2 & 0,27 & 94,4 & 12,6 & 85,5 \\
\hline $9(28)$ & M9 & 507,1 & 7,82 & 66,5 & 16,0 & 0,24 & 82,5 & 12,4 & 73,7 \\
\hline $10(31)$ & M10 & 504,9 & 7,97 & 66,7 & 15,0 & 0,22 & 81,7 & 13,8 & 71,9 \\
\hline $13(40)$ & M11 & 519,3 & 7,86 & 75,7 & 18,6 & 0,25 & 94,3 & 13,0 & 85,1 \\
\hline $14(43)$ & M12 & 515,4 & 7,43 & 71,4 & 23,5 & 0,33 & 94,9 & 11,7 & 86,6 \\
\hline $15(46)$ & M13 & 513,7 & - & - & - & - & - & - & - \\
\hline $16(49)$ & M14 & 508,8 & - & - & - & - & - & - & - \\
\hline $17(52)$ & M15 & 505,5 & 7,84 & 152,3 & 47,9 & 0,31 & 200,2 & 21,9 & 184,7 \\
\hline $20(61)$ & M16 & 508,7 & 7,87 & 156,6 & 52,3 & 0,33 & 208,9 & 14,6 & 198,5 \\
\hline $21(64)$ & M17 & 515,1 & - & - & - & - & - & - & - \\
\hline $22(67)$ & M18 & 504,6 & 8,04 & 173,2 & 42,2 & 0,24 & 215,3 & 15,0 & 204,7 \\
\hline
\end{tabular}


Tabela A.2 - Dados de concentração de sólidos totais (ST), voláteis totais (SVT), em suspensão totais (SST) e em suspensão voláteis (SSV), obtidos do monitoramento do afluente na Condição 1

\begin{tabular}{cccccc}
\hline tOP $_{\text {(COP) }}$ & M & ST & SVT & SST & SSV \\
\hline $21(64)$ & M17 & 558 & 356 & 56 & 50 \\
$23(70)$ & M18 & 622 & 316 & 46 & 30 \\
\hline
\end{tabular}

Nota: $t_{O P}$ - tempo de operação, $\mathrm{c}_{\mathrm{OP}}$ - ciclo de operação, M - identificação do meio. Unidades: $\left[\mathrm{t}_{\mathrm{OP}}\right]=\mathrm{d},[\mathrm{ST}]=[\mathrm{SVT}]=[\mathrm{SST}]=[\mathrm{SSV}]=\mathrm{mg} / \mathrm{L}$.

Tabela A.3 - Dados de concentração de matéria orgânica de amostras filtradas $\left(\mathrm{C}_{\mathrm{SF}}\right)$ e não filtradas $\left(\mathrm{C}_{\mathrm{ST}}\right)$, eficiência de remoção de matéria orgânica de amostras filtradas $\left(\varepsilon_{F}\right)$ e não filtradas $\left(\varepsilon_{T}\right)$ e volume descarregado do reator $\left(V_{D, R T}\right)$, do reservatório $\left(V_{D, R S}\right)$ e do sistema $\left(V_{D}\right)$, obtidos do monitoramento do efluente na Condição 1

\begin{tabular}{ccccccccc}
\hline$t_{O P}\left(C_{O P}\right)$ & $M$ & $C_{S T}$ & $\varepsilon_{T}$ & $C_{S F}$ & $\varepsilon_{F}$ & $V_{D, R T}$ & $V_{D, R S}$ & $V_{D}$ \\
\hline $1(3)$ & $M 1$ & 361,7 & 30,4 & 325,1 & 37,4 & 1690 & 810 & 2500 \\
$2(6)$ & $M 2$ & 312,2 & 39,9 & 274,8 & 47,1 & 1720 & 810 & 2530 \\
$3(9)$ & $M 3$ & 307,4 & 40,9 & 255,5 & 50,8 & 1720 & 800 & 2520 \\
$4(12)$ & $M 4$ & 256,7 & 50,6 & 222,3 & 57,2 & 1720 & 800 & 2520 \\
$6(18)$ & $M 5$ & 268,5 & 48,3 & 213,8 & 58,9 & 1730 & 790 & 2520 \\
$7(21)$ & $M 6$ & 220,7 & 57,5 & 204,2 & 60,7 & 1720 & 800 & 2520 \\
$8(24)$ & $M 7$ & 214,3 & 57,9 & 192,0 & 62,3 & 1730 & 830 & 2560 \\
$9(27)$ & $M 8$ & 202,4 & 60,3 & 181,5 & 64,4 & 1720 & 840 & 2560 \\
$10(30)$ & $M 9$ & 198,4 & 61,0 & 177,9 & 65,1 & 1720 & 820 & 2540 \\
$13(39)$ & $M 10$ & 216,5 & 57,5 & 195,0 & 61,7 & 1690 & 840 & 2530 \\
$14(42)$ & $M 11$ & 212,2 & 58,3 & 189,1 & 62,9 & 1680 & 840 & 2520 \\
$15(45)$ & $M 12$ & 235,2 & 53,8 & 208,0 & 59,2 & 1680 & 860 & 2540 \\
$16(48)$ & $M 13$ & 242,9 & 52,3 & 223,7 & 56,1 & 1660 & 860 & 2520 \\
$17(51)$ & $M 14$ & 219,3 & 56,9 & 199,4 & 60,9 & 1650 & 870 & 2520 \\
$20(60)$ & $M 15$ & 237,7 & 53,3 & 195,7 & 61,6 & 1580 & 950 & 2530 \\
$21(63)$ & $M 16$ & 209,1 & 59,0 & 196,1 & 61,5 & 1600 & 920 & 2520 \\
$22(66)$ & $M 17$ & 229,0 & 55,0 & 208,1 & 59,1 & 1600 & 910 & 2510 \\
$25(75)$ & $M 18$ & 220,9 & 56,6 & 207,1 & 59,3 & 1600 & 920 & 2520 \\
\hline
\end{tabular}

Nota: toP - tempo de operação, $\mathrm{C}_{\mathrm{OP}}$ - ciclo de operação, $M$ - identificação do meio. Unidades: $\left[\mathrm{t}_{\mathrm{OP}}\right]=\mathrm{d},\left[\mathrm{C}_{\mathrm{ST}}\right]=\left[\mathrm{C}_{\mathrm{SF}}\right]=\mathrm{mgDQO} / \mathrm{L},\left[\varepsilon_{\mathrm{T}}\right]=\left[\varepsilon_{\mathrm{F}}\right]=\%$, $\left[\mathrm{V}_{\mathrm{D}, \mathrm{RT}}\right]=\left[\mathrm{V}_{\mathrm{D}, \mathrm{RS}}\right]=\left[\mathrm{V}_{\mathrm{D}}\right]=\mathrm{L}$. 
Tabela A.4 - Dados de pH, alcalinidade parcial (AP), intermediária (AI), total (AT) e a bicarbonato $(A B)$, razão $A l / A P$ e concentração de ácidos voláteis totais (AVT), obtidos do monitoramento do efluente na Condição 1

\begin{tabular}{|c|c|c|c|c|c|c|c|c|}
\hline top (CoP) & M & $\mathrm{pH}$ & AP & $\mathrm{Al}$ & $\mathrm{Al} / \mathrm{AP}$ & AT & AVT & $A B$ \\
\hline $2(6)$ & M2 & 8,02 & 362,7 & 103,2 & 0,28 & 465,9 & 13,7 & 456,2 \\
\hline $3(9)$ & M3 & 7,88 & 278,7 & 92,7 & 0,33 & 371,4 & 11,7 & 363,0 \\
\hline $4(12)$ & M4 & 7,74 & 207,6 & 58,7 & 0,28 & 266,3 & 15,2 & 255,5 \\
\hline $6(18)$ & M5 & 7,75 & 164,7 & 40,9 & 0,25 & 205,6 & 13,2 & 196,2 \\
\hline 7 (21) & M6 & 7,64 & 115,6 & 35,2 & 0,30 & 150,8 & 10,9 & 143,0 \\
\hline $8(24)$ & M7 & 7,70 & 87,7 & 21,2 & 0,24 & 108,9 & 10,4 & 101,5 \\
\hline $9(27)$ & M8 & 7,64 & 63,6 & 16,6 & 0,26 & 80,2 & 11,2 & 72,2 \\
\hline $10(30)$ & M9 & 7,48 & 63,9 & 13,2 & 0,21 & 77,1 & 12,5 & 68,2 \\
\hline 13 (39) & M10 & 7,59 & 69,7 & 17,7 & 0,25 & 87,4 & 11,7 & 79,1 \\
\hline $15(45)$ & M12 & 7,13 & 40,4 & 14,8 & 0,37 & 55,2 & 11,8 & 46,8 \\
\hline $20(60)$ & M15 & 7,39 & 149,9 & 51,9 & 0,35 & 201,8 & 13,5 & 192,3 \\
\hline $22(66)$ & M17 & 7,78 & 166,7 & 47,3 & 0,28 & 214,1 & 16,8 & 202,1 \\
\hline $25(75)$ & M18 & 7,63 & 160,9 & 52,9 & 0,33 & 213,9 & 17,8 & 201,2 \\
\hline
\end{tabular}

Tabela A.5 - Dados de concentração de sólidos totais (ST), voláteis totais (SVT), em suspensão totais (SST) e em suspensão voláteis (SSV), obtidos do monitoramento do efluente na Condição 1

\begin{tabular}{cccccc}
\hline$t_{\text {OP }}\left(\mathrm{C}_{\mathrm{OP}}\right)$ & $\mathrm{M}$ & $\mathrm{ST}$ & $\mathrm{SVT}$ & $\mathrm{SST}$ & $\mathrm{SSV}$ \\
\hline $16(48)$ & $\mathrm{M} 13$ & 610 & 536 & 6 & 6 \\
$23(69)$ & $\mathrm{M} 18$ & 672 & 360 & 12 & 6 \\
\hline
\end{tabular}

Nota: toP - tempo de operação, $C_{O P}$ - ciclo de operação, M - identificação do meio. Unidades: $\left[\mathrm{t}_{\mathrm{OP}}\right]=\mathrm{d},[\mathrm{ST}]=[\mathrm{SVT}]=[\mathrm{SST}]=[\mathrm{SSV}]=\mathrm{mg} / \mathrm{L}$. 
Tabela A.6 - Dados de concentração de matéria orgânica $\left(\mathrm{C}_{\mathrm{A}}\right), \mathrm{pH}$, alcalinidade parcial $(A P)$, intermediária $(A \mathrm{I})$, total $(A T)$ e a bicarbonato $(A B)$, razão $A \mathrm{l} / \mathrm{AP}$ e concentração de ácidos voláteis totais (AVT), obtidos do monitoramento do afluente na Condição 2

\begin{tabular}{|c|c|c|c|c|c|c|c|c|c|}
\hline$t_{\mathrm{OP}}\left(\mathrm{C}_{\mathrm{OP}}\right)$ & $M$ & $\mathrm{C}_{\mathrm{A}}$ & $\mathrm{pH}$ & AP & $\mathrm{Al}$ & $\mathrm{Al} / \mathrm{AP}$ & AT & AVT & $A B$ \\
\hline $0(1)$ & M1 & 1385,4 & - & - & - & - & - & - & - \\
\hline $1(4)$ & M2 & 1422,1 & - & - & - & - & - & - & - \\
\hline $2(7)$ & M3 & 1386,5 & 7,71 & 150,0 & 62,3 & 0,42 & 212,4 & 18,7 & 199,1 \\
\hline $3(10)$ & M4 & 1397,1 & - & - & - & - & - & - & - \\
\hline $4(13)$ & M5 & 1406,5 & - & - & - & - & - & - & - \\
\hline 7 (22) & M6 & 1390,3 & 7,98 & 192,0 & 56,2 & 0,29 & 248,2 & 26,1 & 229,6 \\
\hline $8(25)$ & M7 & 1385,7 & - & - & - & - & - & - & - \\
\hline $9(28)$ & M8 & 1343,6 & 7,99 & 175,2 & 47,5 & 0,27 & 222,7 & 26,4 & 203,9 \\
\hline $10(31)$ & M9 & 1353,2 & - & - & - & - & - & - & - \\
\hline $11(34)$ & M10 & 1388,1 & - & - & - & - & - & - & - \\
\hline $14(43)$ & M11 & 1350,4 & 7,96 & 188,9 & 55,7 & 0,30 & 244,6 & 20,7 & 229,9 \\
\hline $16(49)$ & M12 & 1397,9 & - & - & - & - & - & - & - \\
\hline $17(52)$ & M13 & 1375,6 & - & - & - & - & - & - & - \\
\hline $18(55)$ & M14 & 1361,5 & 7,90 & 175,0 & 60,7 & 0,35 & 235,7 & 27,2 & 216,3 \\
\hline $21(64)$ & M15 & 1385,3 & - & - & - & - & - & - & - \\
\hline $22(67)$ & M16 & 1377,6 & - & - & - & - & - & - & - \\
\hline $23(70)$ & M17 & 1377,7 & - & - & - & - & - & - & - \\
\hline $24(73)$ & M18 & 1391,0 & - & - & - & - & - & - & - \\
\hline
\end{tabular}

Nota: toP - tempo de operação, $\mathrm{C}_{O P}$ - ciclo de operação, $M$ - identificação do meio. Unidades: $\left[\mathrm{t}_{\mathrm{OP}}\right]=\mathrm{d},\left[\mathrm{C}_{\mathrm{A}}\right]=\mathrm{mgDQO} / \mathrm{L},[\mathrm{AP}]=[\mathrm{Al}]=[\mathrm{AT}]=[\mathrm{AB}]=\mathrm{mgCaCO}_{3} / \mathrm{L}$, $[\mathrm{AVT}]=\mathrm{mgHAc} / \mathrm{L}$.

Tabela A.7 - Dados de concentração de sólidos totais (ST), voláteis totais (SVT), em suspensão totais (SST) e em suspensão voláteis (SSV), obtidos do monitoramento do afluente na Condição 2

\begin{tabular}{cccccc}
\hline$t_{\mathrm{OP}}\left(\mathrm{C}_{\mathrm{OP}}\right)$ & $\mathrm{M}$ & ST & SVT & SST & SSV \\
\hline $10(31)$ & M9 & 1012 & 622 & 126 & 102 \\
$15(46)$ & $\mathrm{M} 11$ & 1048 & 658 & 124 & 108 \\
$22(67)$ & $\mathrm{M} 16$ & 1058 & 666 & 128 & 114 \\
\hline
\end{tabular}

Nota: top - tempo de operação, cop - ciclo de operação, M - identificação do meio. Unidades: $\left[\mathrm{t}_{\mathrm{OP}}\right]=\mathrm{d},[\mathrm{ST}]=[\mathrm{SVT}]=[\mathrm{SST}]=[\mathrm{SSV}]=\mathrm{mg} / \mathrm{L}$. 
Tabela A.8 - Dados de concentração de matéria orgânica de amostras filtradas $\left(\mathrm{C}_{\mathrm{SF}}\right)$ e não filtradas $\left(\mathrm{C}_{\mathrm{ST}}\right)$, eficiência de remoção de matéria orgânica de amostras filtradas $\left(\varepsilon_{F}\right)$ e não filtradas $\left(\varepsilon_{T}\right)$ e volume descarregado do reator $\left(\mathrm{V}_{\mathrm{D}, \mathrm{RT}}\right)$, do reservatório $\left(\mathrm{V}_{\mathrm{D}, \mathrm{RS}}\right)$ e do sistema $\left(\mathrm{V}_{\mathrm{D}}\right)$, obtidos do monitoramento do efluente na Condição 2

\begin{tabular}{ccccccccc}
\hline$t_{\mathrm{OP}}\left(\mathrm{C}_{\mathrm{OP}}\right)$ & $\mathrm{M}$ & $\mathrm{C}_{\mathrm{ST}}$ & $\varepsilon_{\mathrm{T}}$ & $\mathrm{C}_{\mathrm{SF}}$ & $\varepsilon_{\mathrm{F}}$ & $\mathrm{V}_{\mathrm{D}, \mathrm{RT}}$ & $\mathrm{V}_{\mathrm{D}, \mathrm{RS}}$ & $\mathrm{V}_{\mathrm{D}}$ \\
\hline $1(3)$ & $\mathrm{M} 1$ & 562,3 & 59,3 & 516,1 & 62,7 & - & - & - \\
$2(6)$ & $\mathrm{M} 2$ & 643,2 & 53,5 & 594,8 & 57,0 & 1630 & 880 & 2510 \\
$3(9)$ & $\mathrm{M} 3$ & 680,6 & 50,8 & 611,2 & 55,8 & 1630 & 860 & 2490 \\
$4(12)$ & $\mathrm{M} 4$ & 742,8 & 46,3 & 652,9 & 52,8 & 1630 & 880 & 2510 \\
$7(21)$ & $\mathrm{M} 5$ & 694,3 & 49,8 & 628,2 & 54,5 & - & - & - \\
$8(24)$ & $\mathrm{M} 6$ & 679,8 & 50,8 & 621,9 & 55,0 & 1620 & 880 & 2500 \\
$9(27)$ & $\mathrm{M} 7$ & 732,1 & 47,0 & 668,1 & 51,7 & 1620 & 880 & 2500 \\
$11(33)$ & $\mathrm{M} 9$ & 727,2 & 47,4 & 666,4 & 51,8 & 1620 & 890 & 2510 \\
$14(42)$ & $\mathrm{M} 10$ & 696,2 & 49,6 & 629,7 & 54,4 & - & - & - \\
$16(48)$ & $\mathrm{M} 11$ & 665,1 & 51,9 & 612,5 & 55,7 & 1620 & 880 & 2500 \\
$17(51)$ & $\mathrm{M} 12$ & 705,7 & 48,9 & 641,3 & 53,6 & 1620 & 880 & 2500 \\
$18(54)$ & $\mathrm{M} 13$ & 692,7 & 49,9 & 624,5 & 54,8 & - & - & - \\
$21(63)$ & $\mathrm{M} 14$ & 687,0 & 50,3 & 622,0 & 55,0 & 1620 & 870 & 2490 \\
$22(66)$ & $\mathrm{M} 15$ & 674,1 & 51,2 & 628,6 & 54,5 & 1620 & 880 & 2500 \\
$23(69)$ & $\mathrm{M} 16$ & 676,1 & 51,1 & 634,8 & 54,1 & 1620 & 880 & 2500 \\
$24(72)$ & $\mathrm{M} 17$ & 652,5 & 52,8 & 614,6 & 55,5 & 1620 & 870 & 2490 \\
$25(75)$ & $\mathrm{M} 18$ & 647,0 & 53,2 & 595,2 & 56,9 & 1620 & 870 & 2490 \\
\hline
\end{tabular}

Nota: toP - tempo de operação, $\mathrm{C}_{\mathrm{OP}}$ - ciclo de operação, $M$ - identificação do meio. Unidades: $\left[\mathrm{t}_{\mathrm{OP}}\right]=\mathrm{d},\left[\mathrm{C}_{\mathrm{ST}}\right]=\left[\mathrm{C}_{\mathrm{SF}}\right]=\mathrm{mgDQO} / \mathrm{L},\left[\varepsilon_{\mathrm{T}}\right]=\left[\varepsilon_{\mathrm{F}}\right]=\%$, $\left[\mathrm{V}_{\mathrm{D}, \mathrm{RT}}\right]=\left[\mathrm{V}_{\mathrm{D}, \mathrm{RS}}\right]=\left[\mathrm{V}_{\mathrm{D}}\right]=\mathrm{L}$. Os dados referentes aos meios M1 e M2 não foram incluídos no cálculo dos valores médios de $\mathrm{C}_{\mathrm{ST}}, \mathrm{C}_{\mathrm{SF}}, \varepsilon_{\mathrm{T}}$ e $\varepsilon_{\mathrm{F}}$ da Condição 2. 
Tabela A.9 - Dados de $\mathrm{pH}$, alcalinidade parcial (AP), intermediária (Al), total (AT) e a bicarbonato $(A B)$, razão Al/AP e concentração de ácidos voláteis totais (AVT), obtidos do monitoramento do efluente na Condição 2

\begin{tabular}{ccccccccc}
\hline tOP $_{\text {(CP) }}$ & $\mathrm{M}$ & $\mathrm{pH}$ & $\mathrm{AP}$ & $\mathrm{Al}$ & $\mathrm{Al} / \mathrm{AP}$ & $\mathrm{AT}$ & $\mathrm{AVT}$ & $\mathrm{AB}$ \\
\hline $4(12)$ & $\mathrm{M} 4$ & 7,89 & 209,3 & 52,0 & 0,25 & 261,3 & 22,4 & 245,4 \\
$7(21)$ & $\mathrm{M} 5$ & 7,69 & 231,9 & 62,6 & 0,27 & 294,5 & 24,7 & 276,9 \\
$9(27)$ & $\mathrm{M} 7$ & 7,71 & 235,9 & 60,9 & 0,26 & 296,8 & 24,7 & 279,3 \\
$14(42)$ & $\mathrm{M} 10$ & 7,68 & 219,6 & 64,5 & 0,29 & 284,1 & 23,4 & 267,5 \\
$18(54)$ & $\mathrm{M} 13$ & 7,75 & 227,4 & 65,4 & 0,29 & 292,8 & 24,4 & 275,5 \\
\hline
\end{tabular}

Nota: toP - tempo de operação, $\mathrm{C}_{O P}$ - ciclo de operação, $M$ - identificação do meio. Unidades: $\left[\mathrm{t}_{\mathrm{OP}}\right]=\mathrm{d},[\mathrm{AP}]=[\mathrm{Al}]=[\mathrm{AT}]=[\mathrm{AB}]=\mathrm{mgCaCO}_{3} / \mathrm{L}$, $[\mathrm{AVT}]=\mathrm{mgHAc} / \mathrm{L}$.

Tabela A.10 - Dados de concentração de sólidos totais (ST), voláteis totais (SVT), em suspensão totais (SST) e em suspensão voláteis (SSV), obtidos do monitoramento do efluente na Condição 2

\begin{tabular}{|c|c|c|c|c|c|}
\hline top (COP) & $M$ & ST & SVT & SST & SSV \\
\hline $10(30)$ & M8 & 804 & 486 & 38 & 32 \\
\hline $15(45)$ & M11 & 846 & 524 & 34 & 28 \\
\hline
\end{tabular}


Tabela $A .11$ - Dados de concentração de matéria orgânica $\left(C_{A}\right), p H$, alcalinidade parcial $(\mathrm{AP})$, intermediária $(\mathrm{Al})$, total $(\mathrm{AT})$ e a bicarbonato $(\mathrm{AB})$, razão $\mathrm{Al} / \mathrm{AP}$ e concentração de ácidos voláteis totais (AVT), obtidos do monitoramento do afluente na Condição 3

\begin{tabular}{|c|c|c|c|c|c|c|c|c|c|}
\hline top (COP) & $M$ & $\mathrm{C}_{\mathrm{A}}$ & $\mathrm{pH}$ & $\mathrm{AP}$ & $\mathrm{Al}$ & $\mathrm{Al} / \mathrm{AP}$ & AT & AVT & $A B$ \\
\hline $0(1)$ & M1 & 317,0 & - & - & - & - & - & - & - \\
\hline $1(4)$ & M2 & 322,0 & - & - & - & - & - & - & - \\
\hline $2(7)$ & M3 & 319,9 & - & - & - & - & - & - & - \\
\hline $3(10)$ & M4 & 301,6 & - & - & - & - & - & - & - \\
\hline $4(13)$ & M5 & 298,7 & 7,99 & 198,8 & 45,8 & 0,23 & 244,5 & 18,8 & 231,2 \\
\hline $7(22)$ & M6 & 286,9 & 7,95 & 199,6 & 50,1 & 0,25 & 249,7 & 16,6 & 237,9 \\
\hline $8(25)$ & M7 & 304,6 & - & - & - & - & - & - & - \\
\hline $9(28)$ & M8 & 298,6 & 7,86 & 199,0 & 52,5 & 0,26 & 251,5 & 16,0 & 240,1 \\
\hline $10(31)$ & M9 & 306,7 & - & - & - & - & - & - & - \\
\hline $11(34)$ & M10 & 290,7 & 7,85 & 195,3 & 53,7 & 0,28 & 249,1 & 15,6 & 238,0 \\
\hline $14(43)$ & M11 & 302,0 & 7,92 & 198,4 & 48,8 & 0,25 & 247,2 & 17,6 & 234,7 \\
\hline $15(46)$ & M12 & 313,7 & 7,88 & 200,5 & 50,7 & 0,25 & 251,2 & 18,8 & 237,9 \\
\hline 17 (52) & M13 & 304,2 & - & - & - & - & - & - & - \\
\hline $18(55)$ & M14 & 310,2 & 8,00 & 200,2 & 46,7 & 0,23 & 246,9 & 17,6 & 234,4 \\
\hline $21(64)$ & M15 & 318,3 & 7,94 & 212,4 & 38,2 & 0,18 & 250,6 & 16,5 & 238,8 \\
\hline $22(67)$ & M16 & 301,7 & - & - & - & - & - & - & - \\
\hline $23(70)$ & M17 & 303,1 & - & - & - & - & - & - & - \\
\hline 24 (73) & M18 & 302,4 & - & - & - & - & - & - & - \\
\hline
\end{tabular}

Nota: top - tempo de operação, cop - ciclo de operação, $M$ - identificação do meio. Unidades: $\left[\mathrm{t}_{\mathrm{OP}}\right]=\mathrm{d},\left[\mathrm{C}_{\mathrm{A}}\right]=\mathrm{mgDQO} / \mathrm{L},[\mathrm{AP}]=[\mathrm{Al}]=[\mathrm{AT}]=[\mathrm{AB}]=\mathrm{mgCaCO}_{3} / \mathrm{L}$, $[\mathrm{AVT}]=\mathrm{mgHAc} / \mathrm{L}$.

Tabela A.12 - Dados de concentração de sólidos totais (ST), voláteis totais (SVT), em suspensão totais (SST) e em suspensão voláteis (SSV), obtidos do monitoramento do afluente na Condição 3

\begin{tabular}{cccccc}
\hline$t_{\text {OP }}\left(\mathrm{C}_{\mathrm{OP}}\right)$ & $\mathrm{M}$ & $\mathrm{ST}$ & $\mathrm{SVT}$ & $\mathrm{SST}$ & $\mathrm{SSV}$ \\
\hline $15(46)$ & $\mathrm{M} 12$ & 568 & 316 & 32 & 26 \\
$22(67)$ & $\mathrm{M} 16$ & 584 & 342 & 32 & 30 \\
$24(73)$ & $\mathrm{M} 18$ & 594 & 308 & 32 & 26 \\
\hline
\end{tabular}

Nota: toP - tempo de operação, $\mathrm{c}_{\mathrm{OP}}$ - ciclo de operação, $M$ - identificação do meio. Unidades: $\left[\mathrm{t}_{\mathrm{OP}}\right]=\mathrm{d},[\mathrm{ST}]=[\mathrm{SVT}]=[\mathrm{SST}]=[\mathrm{SSV}]=\mathrm{mg} / \mathrm{L}$. 
Tabela A.13 - Dados de concentração de matéria orgânica de amostras filtradas $\left(\mathrm{C}_{\mathrm{SF}}\right)$ e não filtradas $\left(\mathrm{C}_{\mathrm{ST}}\right)$, eficiência de remoção de matéria orgânica de amostras filtradas $\left(\varepsilon_{F}\right)$ e não filtradas $\left(\varepsilon_{T}\right)$ e volume descarregado do reator $\left(\mathrm{V}_{\mathrm{D}, \mathrm{RT}}\right)$, do reservatório $\left(\mathrm{V}_{\mathrm{D}, \mathrm{RS}}\right)$ e do sistema $\left(\mathrm{V}_{\mathrm{D}}\right)$, obtidos do monitoramento do efluente na Condição 3

\begin{tabular}{ccccccccc}
\hline$t_{\mathrm{OP}}\left(\mathrm{C}_{\mathrm{OP}}\right)$ & $\mathrm{M}$ & $\mathrm{C}_{\mathrm{ST}}$ & $\varepsilon_{\mathrm{T}}$ & $\mathrm{C}_{\mathrm{SF}}$ & $\varepsilon_{\mathrm{F}}$ & $\mathrm{V}_{\mathrm{D}, \mathrm{RT}}$ & $\mathrm{V}_{\mathrm{D}, \mathrm{RS}}$ & $\mathrm{V}_{\mathrm{D}}$ \\
\hline $1(3)$ & $\mathrm{M} 1$ & 219,8 & 28,1 & 186,3 & 39,1 & - & - & - \\
$2(6)$ & $\mathrm{M} 2$ & 184,1 & 39,8 & 146,8 & 52,0 & 1940 & 540 & 2480 \\
$3(9)$ & $\mathrm{M} 3$ & 163,1 & 46,6 & 130,7 & 57,2 & 1960 & 480 & 2440 \\
$4(12)$ & $\mathrm{M} 4$ & 145,5 & 52,4 & 107,2 & 64,9 & 2020 & 510 & 2530 \\
$7(21)$ & $\mathrm{M} 5$ & 124,7 & 59,2 & 99,2 & 67,5 & 2010 & 500 & 2510 \\
$8(24)$ & $\mathrm{M} 6$ & 120,2 & 60,7 & 97,9 & 68,0 & 2020 & 500 & 2520 \\
$9(27)$ & $\mathrm{M} 7$ & 99,6 & 67,4 & 88,5 & 71,0 & 2000 & 500 & 2500 \\
$10(30)$ & $\mathrm{M} 8$ & 96,0 & 68,6 & 91,8 & 70,0 & 2010 & 500 & 2510 \\
$11(33)$ & $\mathrm{M} 9$ & 92,6 & 69,7 & 83,0 & 72,8 & 2000 & 480 & 2480 \\
$14(42)$ & $\mathrm{M} 10$ & 94,8 & 69,0 & 91,2 & 70,2 & 1970 & 520 & 2490 \\
$15(48)$ & $\mathrm{M} 11$ & 99,5 & 67,4 & 90,5 & 70,4 & 1960 & 530 & 2490 \\
$17(51)$ & $\mathrm{M} 12$ & 105,4 & 65,5 & 94,3 & 69,2 & 1950 & 550 & 2500 \\
$18(54)$ & $\mathrm{M} 13$ & 105,5 & 65,5 & 91,8 & 70,0 & 1940 & 560 & 2500 \\
$21(63)$ & $\mathrm{M} 14$ & 103,2 & 66,2 & 102,4 & 66,5 & - & - & - \\
$22(66)$ & $\mathrm{M} 15$ & 93,3 & 69,5 & 82,3 & 73,1 & 1920 & 580 & 2500 \\
$23(69)$ & $\mathrm{M} 16$ & 96,4 & 68,5 & 84,4 & 72,4 & 1920 & 580 & 2500 \\
$25(75)$ & $\mathrm{M} 18$ & 94,7 & 69,0 & 82,1 & 73,1 & 1900 & 620 & 2520 \\
\hline
\end{tabular}

Nota: toP - tempo de operação, $\mathrm{C}_{\mathrm{OP}}$ - ciclo de operação, $M$ - identificação do meio. Unidades: $\left[\mathrm{t}_{\mathrm{OP}}\right]=\mathrm{d},\left[\mathrm{C}_{\mathrm{ST}}\right]=\left[\mathrm{C}_{\mathrm{SF}}\right]=\mathrm{mgDQO} / \mathrm{L},\left[\varepsilon_{\mathrm{T}}\right]=\left[\varepsilon_{\mathrm{F}}\right]=\%$, $\left[\mathrm{V}_{\mathrm{D}, \mathrm{RT}}\right]=\left[\mathrm{V}_{\mathrm{D}, \mathrm{RS}}\right]=\left[\mathrm{V}_{\mathrm{D}}\right]=\mathrm{L}$. Os dados referentes aos meios M1 a M6 não foram incluídos no cálculo dos valores médios de $\mathrm{C}_{\mathrm{ST}}, \mathrm{C}_{\mathrm{SF}}, \varepsilon_{\mathrm{T}}$ e $\varepsilon_{\mathrm{F}}$ da Condição 3 . 
Tabela A.14 - Dados de pH, alcalinidade parcial (AP), intermediária (Al), total (AT) e a bicarbonato $(\mathrm{AB})$, razão $\mathrm{Al} / \mathrm{AP}$ e concentração de ácidos voláteis totais (AVT), obtidos do monitoramento do efluente na Condição 3

\begin{tabular}{ccccccccc}
\hline tOP $\left._{(\mathrm{OP}}\right)$ & $\mathrm{M}$ & $\mathrm{pH}$ & $\mathrm{AP}$ & $\mathrm{Al}$ & $\mathrm{Al} / \mathrm{AP}$ & $\mathrm{AT}$ & $\mathrm{AVT}$ & $\mathrm{AB}$ \\
\hline $9(27)$ & $\mathrm{M} 7$ & 7,86 & 227,4 & 60,1 & 0,26 & 287,5 & 17,0 & 275,5 \\
$11(33)$ & $\mathrm{M} 9$ & 7,83 & 222,8 & 64,1 & 0,29 & 286,9 & 16,2 & 275,4 \\
$14(42)$ & $\mathrm{M} 10$ & 7,81 & 232,3 & 55,2 & 0,24 & 287,5 & 17,8 & 274,9 \\
$15(45)$ & $\mathrm{M} 11$ & 7,98 & 228,9 & 57,1 & 0,25 & 286,0 & 18,2 & 273,0 \\
$17(51)$ & $\mathrm{M} 12$ & 8,02 & 236,5 & 49,1 & 0,21 & 285,7 & 20,8 & 270,9 \\
$18(54)$ & $\mathrm{M} 13$ & 7,97 & 231,4 & 55,5 & 0,24 & 286,9 & 16,8 & 274,9 \\
$21(63)$ & $\mathrm{M} 14$ & 7,99 & 234,7 & 53,4 & 0,23 & 288,1 & 17,9 & 275,4 \\
\hline
\end{tabular}

Nota: toP - tempo de operação, $\mathrm{C}_{\mathrm{OP}}$ - ciclo de operação, $M$ - identificação do meio. Unidades: $\left[\mathrm{t}_{\mathrm{OP}}\right]=\mathrm{d},[\mathrm{AP}]=[\mathrm{Al}]=[\mathrm{AT}]=[\mathrm{AB}]=\mathrm{mgCaCO}_{3} / \mathrm{L}$, $[\mathrm{AVT}]=\mathrm{mgHAc} / \mathrm{L}$.

Tabela A.15 - Dados de concentração de sólidos totais (ST), voláteis totais (SVT), em suspensão totais (SST) e em suspensão voláteis (SSV), obtidos do monitoramento do efluente na Condição 3

\begin{tabular}{cccccc}
\hline$t_{O P}\left(\mathrm{C}_{\mathrm{OP}}\right)$ & $\mathrm{M}$ & $\mathrm{ST}$ & $\mathrm{SVT}$ & $\mathrm{SST}$ & $\mathrm{SSV}$ \\
\hline $15(45)$ & $\mathrm{M} 11$ & 606 & 410 & 14 & 12 \\
$17(51)$ & $\mathrm{M} 12$ & 662 & 390 & 16 & 12 \\
$22(66)$ & $\mathrm{M} 15$ & 594 & 426 & 10 & 10 \\
\hline
\end{tabular}

Nota: top - tempo de operação, $\mathrm{C}_{\mathrm{OP}}$ - ciclo de operação, M - identificação do meio. Unidades: $\left[\mathrm{t}_{\mathrm{OP}}\right]=\mathrm{d},[\mathrm{ST}]=[\mathrm{SVT}]=[\mathrm{SST}]=[\mathrm{SSV}]=\mathrm{mg} / \mathrm{L}$. 
Tabela A.16 - Dados de concentração de matéria orgânica $\left(C_{A}\right), p H$, alcalinidade parcial $(A P)$, intermediária $(A I)$, total $(A T)$ e a bicarbonato $(A B)$, razão $A \mathrm{l} / A P$ e concentração de ácidos voláteis totais (AVT), obtidos do monitoramento do afluente na Condição 4

\begin{tabular}{cccccccccc}
\hline$t_{\mathrm{OP}}(\mathrm{COP})$ & $\mathrm{M}$ & $\mathrm{C}_{\mathrm{A}}$ & $\mathrm{pH}$ & $\mathrm{AP}$ & $\mathrm{Al}$ & $\mathrm{Al} / \mathrm{AP}$ & $\mathrm{AT}$ & $\mathrm{AVT}$ & $\mathrm{AB}$ \\
\hline $0(1)$ & $\mathrm{M} 1$ & 857,6 & - & - & - & - & - & - & - \\
$1(4)$ & $\mathrm{M} 2$ & 856,1 & - & - & - & - & - & - & - \\
$2(7)$ & $\mathrm{M} 3$ & 854,4 & - & - & - & - & - & - & - \\
$4(13)$ & $\mathrm{M} 4$ & 856,3 & - & - & - & - & - & - & - \\
$7(22)$ & $\mathrm{M} 5$ & 854,7 & - & - & - & - & - & - & - \\
$8(25)$ & $\mathrm{M} 6$ & 846,7 & - & - & - & - & - & - & - \\
$10(31)$ & $\mathrm{M} 7$ & 874,2 & 7,91 & 149,5 & 43,7 & 0,29 & 193,2 & 16,6 & 181,4 \\
$11(34)$ & $\mathrm{M} 8$ & 877,1 & 7,85 & 171,8 & 47,9 & 0,28 & 219,7 & 17,1 & 207,6 \\
$14(43)$ & $\mathrm{M} 9$ & 857,0 & 7,91 & 164,6 & 43,2 & 0,26 & 207,8 & 17,1 & 195,6 \\
$15(46)$ & $\mathrm{M} 10$ & 837,4 & - & - & - & - & - & - & - \\
$16(49)$ & $\mathrm{M} 11$ & 862,1 & 7,89 & 163,9 & 44,5 & 0,27 & 208,5 & 16,7 & 196,6 \\
$18(55)$ & $\mathrm{M} 12$ & 849,4 & 8,00 & 173,0 & 43,9 & 0,25 & 216,8 & 18,7 & 203,6 \\
$21(64)$ & $\mathrm{M} 13$ & 885,0 & 7,75 & 174,9 & 50,9 & 0,29 & 225,8 & 18,2 & 212,9 \\
$24(73)$ & M14 & 869,7 & - & - & - & - & - & - & - \\
\hline
\end{tabular}

Nota: toP - tempo de operação, cop - ciclo de operação, $M$ - identificação do meio. Unidades: $\left[\mathrm{t}_{\mathrm{OP}}\right]=\mathrm{d},\left[\mathrm{C}_{\mathrm{A}}\right]=\mathrm{mgDQO} / \mathrm{L},[\mathrm{AP}]=[\mathrm{Al}]=[\mathrm{AT}]=[\mathrm{AB}]=\mathrm{mgCaCO}_{3} / \mathrm{L}$, $[\mathrm{AVT}]=\mathrm{mgHAc} / \mathrm{L}$.

Tabela A.17 - Dados de concentração de sólidos totais (ST), voláteis totais (SVT), em suspensão totais (SST) e em suspensão voláteis (SSV), obtidos do monitoramento do afluente na Condição 4

\begin{tabular}{cccccc}
\hline tOP $_{(\mathrm{OP})}$ & $\mathrm{M}$ & ST & SVT & SST & SSV \\
\hline $10(31)$ & M7 & 892 & 542 & 94 & 68 \\
$15(46)$ & M10 & 834 & 550 & 86 & 66 \\
$24(73)$ & M14 & 816 & 546 & 104 & 64 \\
\hline
\end{tabular}

Nota: toP - tempo de operação, $C_{O P}$ - ciclo de operação, M - identificação do meio. Unidades: $\left[\mathrm{t}_{\mathrm{OP}}\right]=\mathrm{d},[\mathrm{ST}]=[\mathrm{SVT}]=[\mathrm{SST}]=[\mathrm{SSV}]=\mathrm{mg} / \mathrm{L}$. 
Tabela A.18 - Dados de concentração de matéria orgânica de amostras filtradas $\left(\mathrm{C}_{\mathrm{SF}}\right)$ e não filtradas $\left(\mathrm{C}_{\mathrm{ST}}\right)$, eficiência de remoção de matéria orgânica de amostras filtradas $\left(\varepsilon_{F}\right)$ e não filtradas $\left(\varepsilon_{T}\right)$ e volume descarregado do reator $\left(\mathrm{V}_{\mathrm{D}, \mathrm{RT}}\right)$, do reservatório $\left(\mathrm{V}_{\mathrm{D}, \mathrm{RS}}\right)$ e do sistema $\left(\mathrm{V}_{\mathrm{D}}\right)$, obtidos do monitoramento do efluente na Condição 4

\begin{tabular}{ccccccccc}
\hline $\mathrm{t}_{\mathrm{OP}}\left(\mathrm{C}_{\mathrm{OP}}\right)$ & $\mathrm{M}$ & $\mathrm{C}_{\mathrm{ST}}$ & $\varepsilon_{\mathrm{T}}$ & $\mathrm{C}_{\mathrm{SF}}$ & $\varepsilon_{\mathrm{F}}$ & $\mathrm{V}_{\mathrm{D}, \mathrm{RT}}$ & $\mathrm{V}_{\mathrm{D}, \mathrm{RS}}$ & $\mathrm{V}_{\mathrm{D}}$ \\
\hline $1(3)$ & $\mathrm{M} 1$ & 573,3 & 33,3 & 482,2 & 43,9 & 1630 & 880 & 2510 \\
$2(6)$ & $\mathrm{M} 2$ & 350,4 & 59,2 & 298,2 & 65,3 & 1630 & 880 & 2510 \\
$4(12)$ & $\mathrm{M} 3$ & 339,4 & 60,5 & 298,9 & 65,2 & 1630 & 890 & 2520 \\
$7(21)$ & $\mathrm{M} 4$ & 353,5 & 58,9 & 299,7 & 65,1 & 1630 & 870 & 2500 \\
$8(24)$ & $\mathrm{M} 5$ & 367,5 & 57,3 & 306,1 & 64,4 & 1640 & 820 & 2460 \\
$10(30)$ & $\mathrm{M} 6$ & 339,2 & 60,6 & 284,1 & 67,0 & 1640 & 860 & 2500 \\
$11(33)$ & $\mathrm{M} 7$ & 330,3 & 61,6 & 279,3 & 67,5 & 1640 & 880 & 2520 \\
$14(42)$ & $\mathrm{M} 8$ & 317,5 & 63,1 & 266,4 & 69,0 & 1640 & 860 & 2500 \\
$15(45)$ & $\mathrm{M} 9$ & 312,8 & 63,6 & 269,5 & 68,7 & 1640 & 880 & 2520 \\
$16(48)$ & $\mathrm{M} 10$ & 325,7 & 62,1 & 268,5 & 68,8 & 1640 & 880 & 2520 \\
$18(54)$ & $\mathrm{M} 11$ & 300,8 & 65,0 & 254,9 & 70,4 & 1640 & 820 & 2460 \\
$21(63)$ & $\mathrm{M} 12$ & 298,8 & 65,2 & 251,2 & 70,8 & 1640 & 870 & 2510 \\
$22(66)$ & $\mathrm{M} 13$ & 292,0 & 66,0 & 254,5 & 70,4 & 1640 & 880 & 2520 \\
$24(72)$ & $\mathrm{M} 13$ & 283,9 & 67,0 & 243,1 & 71,7 & - & - & - \\
$25(75)$ & $\mathrm{M} 14$ & 295,9 & 65,6 & 244,7 & 71,5 & 1640 & 860 & 2500 \\
\hline
\end{tabular}

Nota: $t_{O P}$ - tempo de operação, $\mathrm{c}_{\mathrm{OP}}$ - ciclo de operação, $\mathrm{M}$ - identificação do meio. Unidades: $\left[\mathrm{t}_{\mathrm{OP}}\right]=\mathrm{d},\left[\mathrm{C}_{\mathrm{ST}}\right]=\left[\mathrm{C}_{\mathrm{SF}}\right]=\mathrm{mgDQO} / \mathrm{L},\left[\varepsilon_{\mathrm{T}}\right]=\left[\varepsilon_{\mathrm{F}}\right]=\%$, $\left[\mathrm{V}_{\mathrm{D}, \mathrm{RT}}\right]=\left[\mathrm{V}_{\mathrm{D}, \mathrm{RS}}\right]=\left[\mathrm{V}_{\mathrm{D}}\right]=\mathrm{L}$. Os dados referentes aos meios M1 a M6 não foram incluídos no cálculo dos valores médios de $\mathrm{C}_{\mathrm{ST}}, \mathrm{C}_{\mathrm{SF}}, \varepsilon_{\mathrm{T}}$ e $\varepsilon_{\mathrm{F}}$ da Condição 4. 
Tabela A.19 - Dados de pH, alcalinidade parcial (AP), intermediária (Al), total (AT) e a bicarbonato (AB), razão Al/AP e concentração de ácidos voláteis totais (AVT), obtidos do monitoramento do efluente na Condição 4

\begin{tabular}{ccccccccc}
\hline tOP $\left._{\text {(COP }}\right)$ & $\mathrm{M}$ & $\mathrm{pH}$ & $\mathrm{AP}$ & $\mathrm{Al}$ & $\mathrm{Al} / \mathrm{AP}$ & $\mathrm{AT}$ & $\mathrm{AVT}$ & $\mathrm{AB}$ \\
\hline $11(33)$ & $\mathrm{M} 7$ & 7,72 & 171,4 & 55,0 & 0,32 & 226,4 & 15,5 & 215,4 \\
$14(42)$ & $\mathrm{M} 8$ & 7,77 & 190,8 & 51,3 & 0,27 & 242,1 & 16,3 & 230,6 \\
$16(48)$ & $\mathrm{M} 10$ & 7,89 & 200,1 & 50,9 & 0,25 & 251,0 & 15,5 & 240,0 \\
$18(54)$ & $\mathrm{M} 11$ & 7,89 & 207,1 & 46,6 & 0,22 & 253,7 & 19,6 & 239,8 \\
$21(63)$ & $\mathrm{M} 12$ & 7,86 & 208,5 & 59,5 & 0,29 & 268,1 & 18,5 & 255,0 \\
$22(66)$ & $\mathrm{M} 13$ & 7,82 & 204,3 & 62,1 & 0,30 & 266,4 & 19,7 & 252,5 \\
$24(72)$ & $\mathrm{M} 13$ & 7,92 & 209,7 & 57,9 & 0,28 & 267,6 & 18,5 & 254,5 \\
$25(75)$ & $\mathrm{M} 14$ & 7,81 & 217,4 & 56,3 & 0,26 & 273,7 & 21,8 & 258,2 \\
\hline
\end{tabular}

Nota: toP - tempo de operação, $\mathrm{C}_{\mathrm{OP}}$ - ciclo de operação, $M$ - identificação do meio. Unidades: $\left[\mathrm{t}_{\mathrm{OP}}\right]=\mathrm{d},[\mathrm{AP}]=[\mathrm{Al}]=[\mathrm{AT}]=[\mathrm{AB}]=\mathrm{mgCaCO}_{3} / \mathrm{L}$, $[\mathrm{AVT}]=\mathrm{mgHAc} / \mathrm{L}$.

Tabela A.20 - Dados de concentração de sólidos totais (ST), voláteis totais (SVT), em suspensão totais (SST) e em suspensão voláteis (SSV), obtidos do monitoramento do efluente na Condição 4

\begin{tabular}{cccccc}
\hline$t_{\mathrm{OP}}\left(\mathrm{C}_{\mathrm{OP}}\right)$ & $\mathrm{M}$ & $\mathrm{ST}$ & SVT & SST & SSV \\
\hline $15(45)$ & $\mathrm{M} 9$ & 748 & 530 & 32 & 20 \\
$24(72)$ & $\mathrm{M} 13$ & 774 & 470 & 34 & 22 \\
\hline
\end{tabular}

Nota: top - tempo de operação, $\mathrm{C}_{\mathrm{OP}}$ - ciclo de operação, M - identificação do meio. Unidades: $\left[\mathrm{t}_{\mathrm{OP}}\right]=\mathrm{d},[\mathrm{ST}]=[\mathrm{SVT}]=[\mathrm{SST}]=[\mathrm{SSV}]=\mathrm{mg} / \mathrm{L}$. 
Tabela A.21 - Dados de concentração de matéria orgânica $\left(C_{A}\right), p H$, alcalinidade parcial $(\mathrm{AP})$, intermediária $(\mathrm{Al})$, total $(\mathrm{AT})$ e a bicarbonato $(\mathrm{AB})$, razão $\mathrm{Al} / \mathrm{AP}$ e concentração de ácidos voláteis totais (AVT), obtidos do monitoramento do afluente na Condição 5

\begin{tabular}{cccccccccc}
\hline$t_{\mathrm{OP}}(\mathrm{COP})$ & $\mathrm{M}$ & $\mathrm{C}_{\mathrm{A}}$ & $\mathrm{pH}$ & $\mathrm{AP}$ & $\mathrm{Al}$ & $\mathrm{Al} / \mathrm{AP}$ & $\mathrm{AT}$ & $\mathrm{AVT}$ & $\mathrm{AB}$ \\
\hline $0(1)$ & $\mathrm{M} 1$ & 509,9 & - & - & - & - & - & - & - \\
$1(4)$ & $\mathrm{M} 2$ & 514,4 & - & - & - & - & - & - & - \\
$2(7)$ & $\mathrm{M} 3$ & 500,1 & 8,18 & 183,8 & 39,0 & 0,21 & 222,8 & 24,0 & 205,8 \\
$3(10)$ & $\mathrm{M} 4$ & 501,7 & - & - & - & - & - & - & - \\
$4(13)$ & $\mathrm{M} 5$ & 515,5 & 8,08 & 183,8 & 39,0 & 0,21 & 222,8 & 23,6 & 206,1 \\
$7(22)$ & $\mathrm{M} 6$ & 498,9 & - & - & - & - & - & - & - \\
$8(25)$ & $\mathrm{M} 7$ & 506,0 & - & - & - & - & - & - & - \\
$10(31)$ & $\mathrm{M} 8$ & 501,3 & 8,26 & 176,5 & 39,7 & 0,22 & 216,1 & 22,6 & 200,1 \\
$11(34)$ & $\mathrm{M} 9$ & 498,3 & 8,26 & 180,8 & 40,7 & 0,22 & 221,4 & 23,0 & 205,1 \\
$14(43)$ & $\mathrm{M} 10$ & 507,3 & - & - & - & - & - & - & - \\
$15(46)$ & $\mathrm{M} 11$ & 513,1 & 8,17 & 179,1 & 43,3 & 0,24 & 222,4 & 23,6 & 205,6 \\
$17(52)$ & $\mathrm{M} 12$ & 506,8 & 8,15 & 176,8 & 45,3 & 0,26 & 222,1 & 23,5 & 205,4 \\
$18(55)$ & $\mathrm{M} 13$ & 510,3 & 8,18 & 179,8 & 41,0 & 0,23 & 220,8 & 24,6 & 203,3 \\
$21(64)$ & $\mathrm{M} 14$ & 502,9 & - & - & - & - & - & - & - \\
$22(67)$ & $\mathrm{M} 15$ & 494,5 & - & - & - & - & - & - & - \\
$23(70)$ & $\mathrm{M} 16$ & 525,2 & 8,20 & 182,4 & 39,7 & 0,22 & 222,1 & 21,3 & 206,9 \\
$24(73)$ & $\mathrm{M} 17$ & 506,5 & - & - & - & - & - & - & - \\
\hline
\end{tabular}

Nota: toP - tempo de operação, coP - ciclo de operação, $M$ - identificação do meio. Unidades: $\left[\mathrm{t}_{\mathrm{OP}}\right]=\mathrm{d},\left[\mathrm{C}_{\mathrm{A}}\right]=\mathrm{mgDQO} / \mathrm{L},[\mathrm{AP}]=[\mathrm{Al}]=[\mathrm{AT}]=[\mathrm{AB}]=\mathrm{mgCaCO}_{3} / \mathrm{L}$, $[\mathrm{AVT}]=\mathrm{mgHAc} / \mathrm{L}$.

Tabela A.22 - Dados de concentração de sólidos totais (ST), voláteis totais (SVT), em suspensão totais (SST) e em suspensão voláteis (SSV), obtidos do monitoramento do afluente na Condição 5

\begin{tabular}{cccccc}
\hline$t_{\mathrm{OP}}\left(\mathrm{C}_{\mathrm{OP}}\right)$ & $\mathrm{M}$ & $\mathrm{ST}$ & $\mathrm{SVT}$ & $\mathrm{SST}$ & $\mathrm{SSV}$ \\
\hline $10(31)$ & $\mathrm{M} 8$ & 754 & 488 & 52 & 44 \\
$17(52)$ & $\mathrm{M} 12$ & 708 & 460 & 48 & 44 \\
\hline
\end{tabular}

Nota: toP - tempo de operação, $\mathrm{C}_{\mathrm{OP}}$ - ciclo de operação, $M$ - identificação do meio. Unidades: $\left[\mathrm{t}_{\mathrm{OP}}\right]=\mathrm{d},[\mathrm{ST}]=[\mathrm{SVT}]=[\mathrm{SST}]=[\mathrm{SSV}]=\mathrm{mg} / \mathrm{L}$. 
Tabela A.23 - Dados de concentração de matéria orgânica de amostras filtradas $\left(\mathrm{C}_{\mathrm{SF}}\right)$ e não filtradas $\left(\mathrm{C}_{\mathrm{ST}}\right)$, eficiência de remoção de matéria orgânica de amostras filtradas $\left(\varepsilon_{F}\right)$ e não filtradas $\left(\varepsilon_{T}\right)$ e volume descarregado do reator $\left(\mathrm{V}_{\mathrm{D}, \mathrm{RT}}\right)$, do reservatório $\left(\mathrm{V}_{\mathrm{D}, \mathrm{RS}}\right)$ e do sistema $\left(\mathrm{V}_{\mathrm{D}}\right)$, obtidos do monitoramento do efluente na Condição 5

\begin{tabular}{ccccccccc}
\hline $\mathrm{t}_{\mathrm{OP}}\left(\mathrm{C}_{\mathrm{OP}}\right)$ & $\mathrm{M}$ & $\mathrm{C}_{\mathrm{ST}}$ & $\varepsilon_{\mathrm{T}}$ & $\mathrm{C}_{\mathrm{SF}}$ & $\varepsilon_{\mathrm{F}}$ & $\mathrm{V}_{\mathrm{D}, \mathrm{RT}}$ & $\mathrm{V}_{\mathrm{D}, \mathrm{RS}}$ & $\mathrm{V}_{\mathrm{D}}$ \\
\hline $1(3)$ & $\mathrm{M} 1$ & 134,6 & 73,4 & 125,0 & 75,3 & 1890 & 620 & 2510 \\
$2(6)$ & $\mathrm{M} 2$ & 137,7 & 72,8 & 127,0 & 74,9 & 1910 & 620 & 2530 \\
$3(9)$ & $\mathrm{M} 3$ & 139,3 & 72,5 & 136,4 & 73,1 & 1880 & 650 & 2530 \\
$4(12)$ & $\mathrm{M} 4$ & 141,9 & 72,0 & 137,0 & 73,0 & 1860 & 620 & 2480 \\
$7(21)$ & $\mathrm{M} 5$ & 138,8 & 72,6 & 132,7 & 73,8 & 1860 & 670 & 2530 \\
$8(24)$ & $\mathrm{M} 6$ & 155,5 & 69,3 & 134,9 & 73,4 & 1820 & 740 & 2560 \\
$10(30)$ & $\mathrm{M} 7$ & 145,6 & 71,3 & 121,1 & 76,1 & 1800 & 680 & 2480 \\
$11(33)$ & $\mathrm{M} 8$ & 144,7 & 71,4 & 125,3 & 75,3 & 1800 & 700 & 2500 \\
$14(42)$ & $\mathrm{M} 9$ & 141,3 & 72,1 & 121,9 & 75,9 & 1780 & 710 & 2490 \\
$15(45)$ & $\mathrm{M} 10$ & 148,4 & 70,7 & 130,4 & 74,3 & 1780 & 740 & 2520 \\
$17(51)$ & $\mathrm{M} 11$ & 137,1 & 72,9 & 122,8 & 75,8 & 1740 & 810 & 2550 \\
$18(54)$ & $\mathrm{M} 12$ & 149,9 & 70,4 & 126,3 & 75,1 & 1720 & 740 & 2460 \\
$21(63)$ & $\mathrm{M} 13$ & 142,8 & 71,8 & 128,5 & 74,6 & 1700 & 760 & 2460 \\
$22(66)$ & $\mathrm{M} 14$ & 145,3 & 71,3 & 133,1 & 73,7 & 1710 & 740 & 2450 \\
$23(69)$ & $\mathrm{M} 15$ & 146,7 & 71,0 & 135,2 & 73,3 & 1700 & 720 & 2420 \\
$24(72)$ & $\mathrm{M} 16$ & 144,9 & 71,4 & 130,1 & 74,3 & 1690 & 740 & 2430 \\
$25(75)$ & $\mathrm{M} 17$ & 140,9 & 72,2 & 126,0 & 75,1 & 1680 & 740 & 2420 \\
\hline 125 & & & 1400
\end{tabular}

Nota: toP - tempo de operação, $\mathrm{C}_{\mathrm{OP}}$ - ciclo de operação, $M$ - identificação do meio. Unidades: $\left[\mathrm{t}_{\mathrm{OP}}\right]=\mathrm{d},\left[\mathrm{C}_{\mathrm{ST}}\right]=\left[\mathrm{C}_{\mathrm{SF}}\right]=\mathrm{mgDQO} / \mathrm{L},\left[\varepsilon_{\mathrm{T}}\right]=\left[\varepsilon_{\mathrm{F}}\right]=\%$, $\left[\mathrm{V}_{\mathrm{D}, \mathrm{RT}}\right]=\left[\mathrm{V}_{\mathrm{D}, \mathrm{RS}}\right]=\left[\mathrm{V}_{\mathrm{D}}\right]=\mathrm{L}$. Os dados referentes aos meios M1 e M2 não foram incluídos no cálculo dos valores médios de $\mathrm{C}_{\mathrm{ST}}, \mathrm{C}_{\mathrm{SF}}, \varepsilon_{\mathrm{T}}$ e $\varepsilon_{\mathrm{F}}$ da Condição 5. 
Tabela A.24 - Dados de pH, alcalinidade parcial (AP), intermediária (Al), total (AT) e a bicarbonato $(\mathrm{AB})$, razão Al/AP e concentração de ácidos voláteis totais (AVT), obtidos do monitoramento do efluente na Condição 5

\begin{tabular}{ccccccccc}
\hline tOP $\left._{\text {(COP }}\right)$ & $\mathrm{M}$ & $\mathrm{pH}$ & $\mathrm{AP}$ & $\mathrm{Al}$ & $\mathrm{Al} / \mathrm{AP}$ & $\mathrm{AT}$ & $\mathrm{AVT}$ & $\mathrm{AB}$ \\
\hline $3(9)$ & $\mathrm{M} 3$ & 7,39 & 207,5 & 49,0 & 0,24 & 256,5 & 22,3 & 240,7 \\
$4(12)$ & $\mathrm{M} 4$ & 7,39 & 207,8 & 54,4 & 0,26 & 262,2 & 25,3 & 244,2 \\
$10(30)$ & $\mathrm{M} 7$ & 7,53 & 205,9 & 51,6 & 0,25 & 257,5 & 22,3 & 241,6 \\
$15(45)$ & $\mathrm{M} 10$ & 7,49 & 206,9 & 49,2 & 0,24 & 256,1 & 21,7 & 240,7 \\
$17(51)$ & $\mathrm{M} 11$ & 7,56 & 208,9 & 48,6 & 0,23 & 257,5 & 23,5 & 240,8 \\
$18(54)$ & $\mathrm{M} 12$ & 7,54 & 210,2 & 50,2 & 0,24 & 260,4 & 23,1 & 244,1 \\
$22(66)$ & $\mathrm{M} 14$ & 7,64 & 209,2 & 48,9 & 0,23 & 258,1 & 22,6 & 242,1 \\
$24(72)$ & $\mathrm{M} 16$ & 7,62 & 211,2 & 44,6 & 0,21 & 255,8 & 21,2 & 240,7 \\
\hline
\end{tabular}

Nota: toP - tempo de operação, $\mathrm{C}_{\mathrm{OP}}$ - ciclo de operação, $M$ - identificação do meio. Unidades: $\left[\mathrm{t}_{\mathrm{OP}}\right]=\mathrm{d},[\mathrm{AP}]=[\mathrm{Al}]=[\mathrm{AT}]=[\mathrm{AB}]=\mathrm{mgCaCO}_{3} / \mathrm{L}$, $[\mathrm{AVT}]=\mathrm{mgHAc} / \mathrm{L}$.

Tabela A.25 - Dados de concentração de sólidos totais (ST), voláteis totais (SVT), em suspensão totais (SST) e em suspensão voláteis (SSV), obtidos do monitoramento do efluente na Condição 5

\begin{tabular}{cccccc}
\hline tOP $_{\text {(COP) }}$ & M & ST & SVT & SST & SSV \\
\hline $8(24)$ & M6 & 668 & 488 & 4 & 2 \\
$17(51)$ & M11 & 714 & 504 & 6 & 6 \\
\hline
\end{tabular}

Nota: top - tempo de operação, $\mathrm{C}_{\mathrm{OP}}$ - ciclo de operação, M - identificação do meio. Unidades: $\left[\mathrm{t}_{\mathrm{OP}}\right]=\mathrm{d},[\mathrm{ST}]=[\mathrm{SVT}]=[\mathrm{SST}]=[\mathrm{SSV}]=\mathrm{mg} / \mathrm{L}$. 
Tabela A.26 - Dados de concentração de matéria orgânica $\left(C_{A}\right), p H$, alcalinidade parcial (AP), intermediária (Al), total (AT) e a bicarbonato $(A B)$, razão $A l / A P$ e concentração de ácidos voláteis totais (AVT), obtidos do monitoramento do afluente na Condição 6

\begin{tabular}{cccccccccc}
\hline $\mathrm{t}_{\mathrm{OP}}(\mathrm{C} \mathrm{OP})$ & $\mathrm{M}$ & $\mathrm{C}_{\mathrm{A}}$ & $\mathrm{pH}$ & $\mathrm{AP}$ & $\mathrm{Al}$ & $\mathrm{Al} / \mathrm{AP}$ & $\mathrm{AT}$ & $\mathrm{AVT}$ & $\mathrm{AB}$ \\
\hline $\mathrm{0}(1)$ & $\mathrm{M} 1$ & 1395,5 & - & - & - & - & - & - & - \\
$1(4)$ & $\mathrm{M} 2$ & 1389,8 & - & - & - & - & - & - & - \\
$2(7)$ & $\mathrm{M} 3$ & 1394,8 & - & - & - & - & - & - & - \\
$3(10)$ & $\mathrm{M} 4$ & 1409,8 & 7,98 & 171,2 & 46,2 & 0,27 & 217,3 & 21,2 & 202,3 \\
$4(13)$ & $\mathrm{M} 5$ & 1261,9 & - & - & - & - & - & - & - \\
$7(22)$ & $\mathrm{M} 6$ & 1280,3 & - & - & - & - & - & - & - \\
$8(25)$ & $\mathrm{M} 7$ & 1272,0 & - & - & - & - & - & - & - \\
$10(31)$ & $\mathrm{M} 8$ & 1299,0 & 8,02 & 169,3 & 46,8 & 0,28 & 216,1 & 19,8 & 202,0 \\
$11(34)$ & $\mathrm{M} 9$ & 1186,7 & - & - & - & - & - & - & - \\
$14(43)$ & $\mathrm{M} 10$ & 1238,0 & 7,92 & 170,6 & 48,5 & 0,28 & 219,2 & 19,1 & 205,6 \\
$15(46)$ & $\mathrm{M} 11$ & 1228,0 & 7,95 & 167,5 & 48,8 & 0,29 & 216,4 & 18,4 & 203,3 \\
$17(52)$ & $\mathrm{M} 12$ & 1270,0 & 7,92 & 167,2 & 48,8 & 0,29 & 216,1 & 18,6 & 202,8 \\
$18(55)$ & $\mathrm{M} 13$ & 1308,0 & 7,96 & 169,7 & 42,3 & 0,25 & 212,0 & 19,2 & 198,4 \\
$21(64)$ & $\mathrm{M} 14$ & 1306,0 & 7,93 & 169,7 & 45,7 & 0,27 & 215,4 & 18,5 & 202,3 \\
$22(67)$ & $\mathrm{M} 15$ & 1300,0 & 7,96 & 164,8 & 48,2 & 0,29 & 213,0 & 18,4 & 199,9 \\
$23(70)$ & $\mathrm{M} 16$ & 1246,0 & - & - & - & - & - & - & - \\
$24(73)$ & $\mathrm{M} 17$ & 1284,0 & - & - & - & - & - & - & - \\
\hline
\end{tabular}

Nota: toP - tempo de operação, coP - ciclo de operação, $M$ - identificação do meio. Unidades: $\left[\mathrm{t}_{\mathrm{OP}}\right]=\mathrm{d},\left[\mathrm{C}_{\mathrm{A}}\right]=\mathrm{mgDQO} / \mathrm{L},[\mathrm{AP}]=[\mathrm{Al}]=[\mathrm{AT}]=[\mathrm{AB}]=\mathrm{mgCaCO}_{3} / \mathrm{L}$, $[\mathrm{AVT}]=\mathrm{mgHAc} / \mathrm{L}$.

Tabela A.27 - Dados de concentração de sólidos totais (ST), voláteis totais (SVT), em suspensão totais (SST) e em suspensão voláteis (SSV), obtidos do monitoramento do afluente na Condição 6

\begin{tabular}{cccccc}
\hline$t_{\mathrm{OP}}\left(\mathrm{C}_{\mathrm{OP}}\right)$ & $\mathrm{M}$ & $\mathrm{ST}$ & $\mathrm{SVT}$ & $\mathrm{SST}$ & $\mathrm{SSV}$ \\
\hline $8(25)$ & $\mathrm{M} 7$ & 1158 & 790 & 124 & 106 \\
$10(31)$ & $\mathrm{M} 8$ & 1110 & 784 & 130 & 100 \\
$17(52)$ & $\mathrm{M} 12$ & 1104 & 722 & 116 & 102 \\
\hline
\end{tabular}

Nota: toP - tempo de operação, cop - ciclo de operação, M - identificação do meio. Unidades: $\left[\mathrm{t}_{\mathrm{OP}}\right]=\mathrm{d},[\mathrm{ST}]=[\mathrm{SVT}]=[\mathrm{SST}]=[\mathrm{SSV}]=\mathrm{mg} / \mathrm{L}$. 
Tabela A.28 - Dados de concentração de matéria orgânica de amostras filtradas $\left(\mathrm{C}_{\mathrm{SF}}\right)$ e não filtradas $\left(\mathrm{C}_{\mathrm{ST}}\right)$, eficiência de remoção de matéria orgânica de amostras filtradas $\left(\varepsilon_{F}\right)$ e não filtradas $\left(\varepsilon_{T}\right)$ e volume descarregado do reator $\left(V_{D, R T}\right)$, do reservatório $\left(V_{D, R S}\right)$ e do sistema $\left(V_{D}\right)$, obtidos do monitoramento do efluente na Condição 6

\begin{tabular}{ccccccccc}
\hline$t_{\mathrm{OP}}\left(\mathrm{C}_{\mathrm{OP}}\right)$ & $\mathrm{M}$ & $\mathrm{C}_{\mathrm{ST}}$ & $\varepsilon_{\mathrm{T}}$ & $\mathrm{C}_{\mathrm{SF}}$ & $\varepsilon_{\mathrm{F}}$ & $\mathrm{V}_{\mathrm{D}, \mathrm{RT}}$ & $\mathrm{V}_{\mathrm{D}, \mathrm{RS}}$ & $\mathrm{V}_{\mathrm{D}}$ \\
\hline $1(3)$ & $\mathrm{M} 1$ & 270,5 & 79,2 & 221,4 & 82,9 & 1520 & 900 & 2420 \\
$2(6)$ & $\mathrm{M} 2$ & 271,2 & 79,1 & 244,7 & 81,2 & 1520 & 900 & 2420 \\
$3(9)$ & $\mathrm{M} 3$ & 284,2 & 78,1 & 235,5 & 81,9 & 1520 & 880 & 2400 \\
$4(12)$ & $\mathrm{M} 4$ & 331,2 & 74,5 & 252,6 & 80,5 & - & - & - \\
$7(21)$ & $\mathrm{M} 5$ & 312,0 & 76,0 & 243,6 & 81,2 & 1520 & 980 & 2500 \\
$8(24)$ & $\mathrm{M} 6$ & 292,6 & 77,5 & 229,4 & 82,3 & 1520 & 980 & 2500 \\
$10(30)$ & $\mathrm{M} 7$ & 306,8 & 76,4 & 244,7 & 81,2 & 1500 & 1000 & 2500 \\
$11(33)$ & $\mathrm{M} 8$ & 331,3 & 74,5 & 253,3 & 80,5 & 1500 & 1000 & 2500 \\
$14(42)$ & $\mathrm{M} 9$ & 301,0 & 76,8 & 282,0 & 78,3 & 1500 & 980 & 2480 \\
$15(45)$ & $\mathrm{M} 10$ & 278,0 & 78,6 & 228,0 & 82,4 & 1500 & 980 & 2480 \\
$17(51)$ & $\mathrm{M} 11$ & 302,0 & 76,7 & 244,0 & 81,2 & 1500 & 980 & 2480 \\
$18(54)$ & $\mathrm{M} 12$ & 316,0 & 75,7 & 260,0 & 80,0 & 1500 & 990 & 2490 \\
$21(63)$ & $\mathrm{M} 13$ & 309,0 & 76,2 & 253,0 & 80,5 & 1500 & 970 & 2470 \\
$22(66)$ & $\mathrm{M} 14$ & 297,0 & 77,1 & 253,0 & 80,5 & 1500 & 980 & 2480 \\
$23(69)$ & $\mathrm{M} 15$ & 321,0 & 75,3 & 295,0 & 77,3 & 1500 & 980 & 2480 \\
$24(72)$ & $\mathrm{M} 16$ & 330,0 & 74,6 & 289,0 & 77,7 & 1500 & 1000 & 2500 \\
$25(75)$ & $\mathrm{M} 17$ & 327,0 & 74,8 & 272,0 & 79,0 & 1500 & 980 & 2480 \\
\hline
\end{tabular}

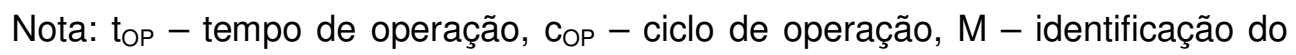
meio. Unidades: $\left[\mathrm{t}_{\mathrm{OP}}\right]=\mathrm{d},\left[\mathrm{C}_{\mathrm{ST}}\right]=\left[\mathrm{C}_{\mathrm{SF}}\right]=\mathrm{mgDQO} / \mathrm{L},\left[\varepsilon_{\mathrm{T}}\right]=\left[\varepsilon_{\mathrm{F}}\right]=\%$, $\left[\mathrm{V}_{\mathrm{D}, \mathrm{RT}}\right]=\left[\mathrm{V}_{\mathrm{D}, \mathrm{RS}}\right]=\left[\mathrm{V}_{\mathrm{D}}\right]=\mathrm{L}$. Os dados referentes aos meios M1 a M3 não foram incluídos no cálculo dos valores médios de $\mathrm{C}_{\mathrm{ST}}, \mathrm{C}_{\mathrm{SF}}, \varepsilon_{\mathrm{T}}$ e $\varepsilon_{\mathrm{F}}$ da Condição 6. 
Tabela A.29 - Dados de pH, alcalinidade parcial (AP), intermediária (Al), total (AT) e a bicarbonato $(\mathrm{AB})$, razão Al/AP e concentração de ácidos voláteis totais (AVT), obtidos do monitoramento do efluente na Condição 6

\begin{tabular}{ccccccccc}
\hline tOP $\left._{\text {(COP }}\right)$ & $\mathrm{M}$ & $\mathrm{pH}$ & $\mathrm{AP}$ & $\mathrm{Al}$ & $\mathrm{Al} / \mathrm{AP}$ & $\mathrm{AT}$ & $\mathrm{AVT}$ & $\mathrm{AB}$ \\
\hline $4(12)$ & $\mathrm{M} 4$ & 7,61 & 221,5 & 57,1 & 0,26 & 278,6 & 16,5 & 266,9 \\
$8(24)$ & $\mathrm{M} 6$ & 7,52 & 218,9 & 61,2 & 0,28 & 280,2 & 19,2 & 266,6 \\
$10(30)$ & $\mathrm{M} 7$ & 7,45 & 210,6 & 66,4 & 0,32 & 277,0 & 19,4 & 263,2 \\
$14(42)$ & $\mathrm{M} 9$ & 7,53 & 207,4 & 60,6 & 0,29 & 268,0 & 17,9 & 255,3 \\
$15(45)$ & $\mathrm{M} 10$ & 7,52 & 209,6 & 61,5 & 0,29 & 271,1 & 19,4 & 257,3 \\
$17(51)$ & $\mathrm{M} 11$ & 7,52 & 205,2 & 63,7 & 0,31 & 268,9 & 20,0 & 254,7 \\
$18(54)$ & $\mathrm{M} 12$ & 7,48 & 210,2 & 61,8 & 0,29 & 272,0 & 21,5 & 256,8 \\
$21(63)$ & $\mathrm{M} 13$ & 7,52 & 210,8 & 61,2 & 0,29 & 272,0 & 19,9 & 257,9 \\
\hline
\end{tabular}

Nota: toP - tempo de operação, $C_{O P}$ - ciclo de operação, $M$ - identificação do meio. Unidades: $\left[\mathrm{t}_{\mathrm{OP}}\right]=\mathrm{d},[\mathrm{AP}]=[\mathrm{Al}]=[\mathrm{AT}]=[\mathrm{AB}]=\mathrm{mgCaCO}_{3} / \mathrm{L}$, $[\mathrm{AVT}]=\mathrm{mgHAc} / \mathrm{L}$.

Tabela A.30 - Dados de concentração de sólidos totais (ST), voláteis totais (SVT), em suspensão totais (SST) e em suspensão voláteis (SSV), obtidos do monitoramento do efluente na Condição 6

\begin{tabular}{cccccc}
\hline toP $_{\text {(COP }}$ & M & ST & SVT & SST & SSV \\
\hline $10(30)$ & M7 & 882 & 622 & 42 & 24 \\
$15(45)$ & M10 & 924 & 592 & 36 & 36 \\
$17(51)$ & M11 & 880 & 556 & 20 & 16 \\
\hline
\end{tabular}

Nota: top - tempo de operação, $\mathrm{C}_{\mathrm{OP}}$ - ciclo de operação, M - identificação do meio. Unidades: $\left[\mathrm{t}_{\mathrm{OP}}\right]=\mathrm{d},[\mathrm{ST}]=[\mathrm{SVT}]=[\mathrm{SST}]=[\mathrm{SSV}]=\mathrm{mg} / \mathrm{L}$. 
Tabela $A .31$ - Dados de concentração de matéria orgânica $\left(C_{A}\right), p H$, alcalinidade parcial $(A P)$, intermediária $(A I)$, total $(A T)$ e a bicarbonato $(A B)$, razão $A \mathrm{l} / A P$ e concentração de ácidos voláteis totais (AVT), obtidos do monitoramento do afluente na Condição 7

\begin{tabular}{cccccccccc}
\hline $\mathrm{t}_{\mathrm{OP}}(\mathrm{COP})$ & $\mathrm{M}$ & $\mathrm{C}_{\mathrm{A}}$ & $\mathrm{pH}$ & $\mathrm{AP}$ & $\mathrm{Al}$ & $\mathrm{Al} / \mathrm{AP}$ & $\mathrm{AT}$ & $\mathrm{AVT}$ & $\mathrm{AB}$ \\
\hline $0(1)$ & $\mathrm{M} 1$ & 293,8 & - & - & - & - & - & - & - \\
$1(4)$ & $\mathrm{M} 2$ & 307,7 & - & - & - & - & - & - & - \\
$2(7)$ & $\mathrm{M} 3$ & 305,6 & 8,05 & 186,9 & 45,1 & 0,24 & 232,0 & 13,8 & 222,2 \\
$3(10)$ & $\mathrm{M} 4$ & 296,9 & - & - & - & - & - & - & - \\
$4(13)$ & $\mathrm{M} 5$ & 301,7 & - & - & - & - & - & - & - \\
$7(22)$ & $\mathrm{M} 6$ & 289,2 & - & - & - & - & - & - & - \\
$8(25)$ & $\mathrm{M} 7$ & 296,0 & - & - & - & - & - & - & - \\
$10(31)$ & $\mathrm{M} 8$ & 294,8 & 7,92 & 179,0 & 52,6 & 0,29 & 231,6 & 13,9 & 221,7 \\
$11(34)$ & $\mathrm{M} 9$ & 302,6 & 7,95 & 187,9 & 44,1 & 0,23 & 232,0 & 16,9 & 220,0 \\
$14(43)$ & $\mathrm{M} 10$ & 292,1 & - & - & - & - & - & - & - \\
$15(46)$ & $\mathrm{M} 11$ & 288,1 & 8,03 & 192,2 & 45,6 & 0,24 & 237,8 & 20,5 & 223,2 \\
$17(52)$ & $\mathrm{M} 12$ & 290,8 & 7,88 & 190,9 & 48,7 & 0,25 & 239,5 & 18,4 & 226,5 \\
$18(55)$ & $\mathrm{M} 13$ & 313,7 & 7,93 & 188,4 & 49,4 & 0,26 & 237,8 & 20,0 & 223,6 \\
$21(64)$ & $\mathrm{M} 14$ & 297,2 & - & - & - & - & - & - & - \\
$22(67)$ & $\mathrm{M} 15$ & 304,5 & 7,87 & 184,6 & 48,0 & 0,26 & 232,6 & 19,7 & 218,7 \\
$24(73)$ & $\mathrm{M} 16$ & 297,5 & 7,94 & 186,0 & 49,7 & 0,27 & 235,7 & 19,9 & 221,6 \\
\hline
\end{tabular}

Nota: toP - tempo de operação, cop - ciclo de operação, $M$ - identificação do meio. Unidades: $\left[\mathrm{t}_{\mathrm{OP}}\right]=\mathrm{d},\left[\mathrm{C}_{\mathrm{A}}\right]=\mathrm{mgDQO} / \mathrm{L},[\mathrm{AP}]=[\mathrm{Al}]=[\mathrm{AT}]=[\mathrm{AB}]=\mathrm{mgCaCO}_{3} / \mathrm{L}$, $[\mathrm{AVT}]=\mathrm{mgHAc} / \mathrm{L}$.

Tabela A.32 - Dados de concentração de sólidos totais (ST), voláteis totais (SVT), em suspensão totais (SST) e em suspensão voláteis (SSV), obtidos do monitoramento do afluente na Condição 7

\begin{tabular}{cccccc}
\hline$t_{\mathrm{OP}}\left(\mathrm{C}_{\mathrm{OP}}\right)$ & $\mathrm{M}$ & $\mathrm{ST}$ & $\mathrm{SVT}$ & $\mathrm{SST}$ & $\mathrm{SSV}$ \\
\hline $8(25)$ & $\mathrm{M} 7$ & 616 & 398 & 36 & 32 \\
$15(46)$ & $\mathrm{M} 11$ & 614 & 372 & 30 & 30 \\
$17(52)$ & $\mathrm{M} 12$ & 648 & 342 & 32 & 28 \\
\hline
\end{tabular}

Nota: top - tempo de operação, coP - ciclo de operação, $M$ - identificação do meio. Unidades: $\left[\mathrm{t}_{\mathrm{OP}}\right]=\mathrm{d},[\mathrm{ST}]=[\mathrm{SVT}]=[\mathrm{SST}]=[\mathrm{SSV}]=\mathrm{mg} / \mathrm{L}$. 
Tabela A.33 - Dados de concentração de matéria orgânica de amostras filtradas $\left(\mathrm{C}_{\mathrm{SF}}\right)$ e não filtradas $\left(\mathrm{C}_{\mathrm{ST}}\right)$, eficiência de remoção de matéria orgânica de amostras filtradas $\left(\varepsilon_{F}\right)$ e não filtradas $\left(\varepsilon_{T}\right)$ e volume descarregado do reator $\left(\mathrm{V}_{\mathrm{D}, \mathrm{RT}}\right)$, do reservatório $\left(\mathrm{V}_{\mathrm{D}, \mathrm{RS}}\right)$ e do sistema $\left(\mathrm{V}_{\mathrm{D}}\right)$, obtidos do monitoramento do efluente na Condição 7

\begin{tabular}{ccccccccc}
\hline $\mathrm{t}_{\mathrm{OP}}\left(\mathrm{C}_{\mathrm{OP}}\right)$ & $\mathrm{M}$ & $\mathrm{C}_{\mathrm{ST}}$ & $\varepsilon_{\mathrm{T}}$ & $\mathrm{C}_{\mathrm{SF}}$ & $\varepsilon_{\mathrm{F}}$ & $\mathrm{V}_{\mathrm{D}, \mathrm{RT}}$ & $\mathrm{V}_{\mathrm{D}, \mathrm{RS}}$ & $\mathrm{V}_{\mathrm{D}}$ \\
\hline $1(3)$ & $\mathrm{M} 1$ & 135,4 & 54,6 & 119,9 & 59,8 & - & - & - \\
$2(6)$ & $\mathrm{M} 2$ & 85,2 & 71,4 & 81,7 & 72,6 & - & - & - \\
$3(9)$ & $\mathrm{M} 3$ & 80,8 & 72,9 & 79,2 & 73,4 & - & - & - \\
$4(12)$ & $\mathrm{M} 4$ & 84,3 & 71,7 & 81,3 & 72,7 & 1940 & 600 & 2540 \\
$7(21)$ & $\mathrm{M} 5$ & 79,4 & 73,4 & 74,8 & 74,9 & 1900 & 600 & 2500 \\
$8(24)$ & $\mathrm{M} 6$ & 92,0 & 69,2 & 80,7 & 72,9 & 1900 & 590 & 2490 \\
$10(30)$ & $\mathrm{M} 7$ & 71,5 & 76,0 & 65,0 & 78,2 & 1880 & 640 & 2520 \\
$11(33)$ & $\mathrm{M} 8$ & 70,1 & 76,5 & 68,0 & 77,2 & 1880 & 580 & 2460 \\
$14(42)$ & $\mathrm{M} 9$ & 65,4 & 78,1 & 61,9 & 79,2 & 1870 & 620 & 2490 \\
$15(45)$ & $\mathrm{M} 10$ & 70,1 & 76,5 & 65,3 & 78,1 & 1860 & 620 & 2480 \\
$17(51)$ & $\mathrm{M} 11$ & 72,6 & 75,7 & 69,2 & 76,8 & 1860 & 660 & 2520 \\
$18(54)$ & $\mathrm{M} 12$ & 89,6 & 70,0 & 85,8 & 71,2 & 1840 & 700 & 2540 \\
$21(63)$ & $\mathrm{M} 13$ & 94,2 & 68,4 & 77,0 & 74,2 & 1820 & 670 & 2490 \\
$22(66)$ & $\mathrm{M} 14$ & 83,3 & 72,1 & 77,1 & 74,2 & - & - & - \\
$25(75)$ & $\mathrm{M} 16$ & 83,4 & 72,0 & 82,4 & 72,4 & 1820 & 680 & 2500 \\
\hline
\end{tabular}

Nota: $\mathrm{t}_{\mathrm{OP}}$ - tempo de operação, $\mathrm{c}_{\mathrm{OP}}$ - ciclo de operação, $\mathrm{M}$ - identificação do meio. Unidades: $\left[\mathrm{t}_{\mathrm{OP}}\right]=\mathrm{d},\left[\mathrm{C}_{\mathrm{ST}}\right]=\left[\mathrm{C}_{\mathrm{SF}}\right]=\mathrm{mgDQO} / \mathrm{L},\left[\varepsilon_{\mathrm{T}}\right]=\left[\varepsilon_{\mathrm{F}}\right]=\%$, $\left[\mathrm{V}_{\mathrm{D}, \mathrm{RT}}\right]=\left[\mathrm{V}_{\mathrm{D}, \mathrm{RS}}\right]=\left[\mathrm{V}_{\mathrm{D}}\right]=\mathrm{L}$. Os dados referentes ao meio M1 não foram incluídos no cálculo dos valores médios de $\mathrm{C}_{\mathrm{ST}}, \mathrm{C}_{\mathrm{SF}}, \varepsilon_{\mathrm{T}}$ e $\varepsilon_{\mathrm{F}}$ da Condição 7. 
Tabela A.34 - Dados de pH, alcalinidade parcial (AP), intermediária (Al), total (AT) e a bicarbonato $(\mathrm{AB})$, razão $\mathrm{Al} / \mathrm{AP}$ e concentração de ácidos voláteis totais (AVT), obtidos do monitoramento do efluente na Condição 7

\begin{tabular}{ccccccccc}
\hline $\mathrm{t}_{\mathrm{OP}}(\mathrm{COP})$ & $\mathrm{M}$ & $\mathrm{pH}$ & $\mathrm{AP}$ & $\mathrm{Al}$ & $\mathrm{Al} / \mathrm{AP}$ & $\mathrm{AT}$ & $\mathrm{AVT}$ & $\mathrm{AB}$ \\
\hline $2(6)$ & $\mathrm{M} 2$ & 7,76 & 224,1 & 56,7 & 0,25 & 280,8 & 14,9 & 270,2 \\
$11(33)$ & $\mathrm{M} 8$ & 7,68 & 214,2 & 48,9 & 0,23 & 263,1 & 15,1 & 252,4 \\
$15(45)$ & $\mathrm{M} 10$ & 7,56 & 212,9 & 53,8 & 0,25 & 266,8 & 17,7 & 254,2 \\
$17(51)$ & $\mathrm{M} 11$ & 7,63 & 213,3 & 55,6 & 0,26 & 268,8 & 17,7 & 256,3 \\
$18(54)$ & $\mathrm{M} 12$ & 7,51 & 210,5 & 56,9 & 0,27 & 267,5 & 22,5 & 251,5 \\
$22(66)$ & $\mathrm{M} 14$ & 7,47 & 210,2 & 56,9 & 0,27 & 267,1 & 18,5 & 254,0 \\
$25(75)$ & $\mathrm{M} 16$ & 7,46 & 206,4 & 61,1 & 0,30 & 267,5 & 18,6 & 254,3 \\
\hline
\end{tabular}

Nota: toP - tempo de operação, $\mathrm{C}_{\mathrm{OP}}$ - ciclo de operação, $M$ - identificação do meio. Unidades: $\left[\mathrm{t}_{\mathrm{OP}}\right]=\mathrm{d},[\mathrm{AP}]=[\mathrm{Al}]=[\mathrm{AT}]=[\mathrm{AB}]=\mathrm{mgCaCO}_{3} / \mathrm{L}$, $[\mathrm{AVT}]=\mathrm{mgHAc} / \mathrm{L}$.

Tabela A.35 - Dados de concentração de sólidos totais (ST), voláteis totais (SVT), em suspensão totais (SST) e em suspensão voláteis (SSV), obtidos do monitoramento do efluente na Condição 7

\begin{tabular}{|c|c|c|c|c|c|}
\hline toP (COP) & $M$ & ST & SVT & SST & SSV \\
\hline $8(24)$ & M6 & 678 & 496 & 6 & 6 \\
\hline $15(45)$ & M10 & 634 & 428 & 8 & 8 \\
\hline
\end{tabular}


Tabela $A .36$ - Dados de concentração de matéria orgânica $\left(C_{A}\right), p H$, alcalinidade parcial $(A P)$, intermediária $(A I)$, total $(A T)$ e a bicarbonato $(A B)$, razão $A \mathrm{l} / A P$ e concentração de ácidos voláteis totais (AVT), obtidos do monitoramento do afluente na Condição 8

\begin{tabular}{cccccccccc}
\hline toP $\left(\mathrm{COP}_{\mathrm{OP}}\right)$ & $\mathrm{M}$ & $\mathrm{C}_{\mathrm{A}}$ & $\mathrm{pH}$ & $\mathrm{AP}$ & $\mathrm{Al}$ & $\mathrm{Al} / \mathrm{AP}$ & $\mathrm{AT}$ & $\mathrm{AVT}$ & $\mathrm{AB}$ \\
\hline $0(1)$ & $\mathrm{M} 1$ & 1011,0 & - & - & - & - & - & - & - \\
$1(4)$ & $\mathrm{M} 2$ & 1014,0 & - & - & - & - & - & - & - \\
$3(10)$ & $\mathrm{M} 3$ & 983,1 & - & - & - & - & - & - & - \\
$4(13)$ & $\mathrm{M} 4$ & 992,5 & - & - & - & - & - & - & - \\
$7(22)$ & $\mathrm{M} 5$ & 998,5 & - & - & - & - & - & - & - \\
$8(25)$ & $\mathrm{M} 6$ & 979,5 & - & - & - & - & - & - & - \\
$10(31)$ & $\mathrm{M} 7$ & 962,6 & - & - & - & - & - & - & - \\
$11(34)$ & $\mathrm{M} 8$ & 974,5 & - & - & - & - & - & - & - \\
$14(43)$ & $\mathrm{M} 9$ & 825,7 & 8,16 & 180,3 & 41,3 & 0,23 & 221,6 & 15,4 & 210,7 \\
$15(46)$ & $\mathrm{M} 10$ & 859,6 & 8,07 & 177,9 & 43,3 & 0,24 & 221,2 & 16,6 & 209,5 \\
$17(52)$ & $\mathrm{M} 11$ & 866,9 & 8,13 & 182,3 & 41,7 & 0,23 & 223,9 & 15,2 & 213,1 \\
$18(55)$ & $\mathrm{M} 12$ & 868,0 & 8,16 & 182,9 & 39,3 & 0,21 & 222,2 & 15,9 & 211,0 \\
$21(64)$ & $\mathrm{M} 13$ & 864,5 & 8,15 & 179,6 & 42,7 & 0,24 & 222,2 & 16,0 & 210,9 \\
$22(67)$ & $\mathrm{M} 14$ & 846,4 & 8,09 & 171,6 & 49,0 & 0,29 & 220,6 & 14,9 & 210,0 \\
$23(70)$ & $\mathrm{M} 15$ & 870,4 & 8,06 & 176,6 & 46,6 & 0,26 & 223,2 & 14,6 & 212,9 \\
$24(73)$ & $\mathrm{M} 16$ & 824,9 & 8,07 & 174,9 & 47,0 & 0,27 & 221,9 & 14,4 & 211,7 \\
\hline
\end{tabular}

Nota: toP - tempo de operação, cop - ciclo de operação, $M$ - identificação do meio. Unidades: $\left[\mathrm{t}_{\mathrm{OP}}\right]=\mathrm{d},\left[\mathrm{C}_{\mathrm{A}}\right]=\mathrm{mgDQO} / \mathrm{L},[\mathrm{AP}]=[\mathrm{Al}]=[\mathrm{AT}]=[\mathrm{AB}]=\mathrm{mgCaCO}_{3} / \mathrm{L}$, $[\mathrm{AVT}]=\mathrm{mgHAc} / \mathrm{L}$.

Tabela A.37 - Dados de concentração de sólidos totais (ST), voláteis totais (SVT), em suspensão totais (SST) e em suspensão voláteis (SSV), obtidos do monitoramento do afluente na Condição 8

\begin{tabular}{cccccc}
\hline$t_{\mathrm{OP}}\left(\mathrm{C}_{\mathrm{OP}}\right)$ & $\mathrm{M}$ & $\mathrm{ST}$ & $\mathrm{SVT}$ & $\mathrm{SST}$ & $\mathrm{SSV}$ \\
\hline $8(25)$ & $\mathrm{M} 6$ & 948 & 658 & 100 & 92 \\
$10(31)$ & $\mathrm{M} 7$ & 970 & 668 & 98 & 82 \\
$24(73)$ & $\mathrm{M} 16$ & 944 & 580 & 88 & 82 \\
\hline
\end{tabular}

Nota: toP - tempo de operação, coP - ciclo de operação, M - identificação do meio. Unidades: $\left[\mathrm{t}_{\mathrm{OP}}\right]=\mathrm{d},[\mathrm{ST}]=[\mathrm{SVT}]=[\mathrm{SST}]=[\mathrm{SSV}]=\mathrm{mg} / \mathrm{L}$. 
Tabela A.38 - Dados de concentração de matéria orgânica de amostras filtradas $\left(\mathrm{C}_{\mathrm{SF}}\right)$ e não filtradas $\left(\mathrm{C}_{\mathrm{ST}}\right)$, eficiência de remoção de matéria orgânica de amostras filtradas $\left(\varepsilon_{F}\right)$ e não filtradas $\left(\varepsilon_{T}\right)$ e volume descarregado do reator $\left(\mathrm{V}_{\mathrm{D}, \mathrm{RT}}\right)$, do reservatório $\left(\mathrm{V}_{\mathrm{D}, \mathrm{RS}}\right)$ e do sistema $\left(\mathrm{V}_{\mathrm{D}}\right)$, obtidos do monitoramento do efluente na Condição 8

\begin{tabular}{ccccccccc}
\hline $\mathrm{t}_{\mathrm{OP}}\left(\mathrm{C}_{\mathrm{OP}}\right)$ & $\mathrm{M}$ & $\mathrm{C}_{\mathrm{ST}}$ & $\varepsilon_{\mathrm{T}}$ & $\mathrm{C}_{\mathrm{SF}}$ & $\varepsilon_{\mathrm{F}}$ & $\mathrm{V}_{\mathrm{D}, \mathrm{RT}}$ & $\mathrm{V}_{\mathrm{D}, \mathrm{RS}}$ & $\mathrm{V}_{\mathrm{D}}$ \\
\hline $1(3)$ & $\mathrm{M} 1$ & 155,3 & 83,1 & 152,7 & 83,4 & 1740 & 740 & 2480 \\
$3(9)$ & $\mathrm{M} 2$ & 164,4 & 82,2 & 162,9 & 82,3 & 1740 & 730 & 2470 \\
$4(12)$ & $\mathrm{M} 3$ & 184,3 & 80,0 & 158,3 & 82,8 & 1740 & 750 & 2490 \\
$7(21)$ & $\mathrm{M} 4$ & 203,9 & 77,9 & 178,8 & 80,6 & 1740 & 800 & 2540 \\
$8(24)$ & $\mathrm{M} 5$ & 206,6 & 77,6 & 170,0 & 81,5 & 1650 & 800 & 2450 \\
$10(30)$ & $\mathrm{M} 6$ & 177,9 & 80,7 & 146,0 & 84,2 & 1650 & 820 & 2470 \\
$11(33)$ & $\mathrm{M} 7$ & 160,3 & 82,6 & 149,7 & 83,8 & 1650 & 850 & 2500 \\
$14(42)$ & $\mathrm{M} 8$ & 175,1 & 81,0 & 137,8 & 85,0 & 1650 & 840 & 2490 \\
$15(45)$ & $\mathrm{M} 9$ & 162,4 & 82,4 & 143,9 & 84,4 & 1650 & 880 & 2530 \\
$17(51)$ & $\mathrm{M} 10$ & 157,5 & 82,9 & 132,6 & 85,6 & 1610 & 860 & 2470 \\
$18(54)$ & $\mathrm{M} 11$ & 167,9 & 81,8 & 138,2 & 85,0 & 1610 & 910 & 2520 \\
$21(63)$ & $\mathrm{M} 12$ & 168,7 & 81,7 & 134,6 & 85,4 & 1610 & 900 & 2510 \\
$22(66)$ & $\mathrm{M} 13$ & 180,7 & 80,4 & 137,0 & 85,1 & 1610 & 890 & 2500 \\
$23(69)$ & $\mathrm{M} 14$ & 159,0 & 82,7 & 120,5 & 86,9 & 1610 & 880 & 2490 \\
$24(72)$ & $\mathrm{M} 15$ & 154,7 & 83,2 & 132,8 & 85,6 & 1610 & 960 & 2570 \\
$25(75)$ & $\mathrm{M} 16$ & 131,4 & 85,7 & 103,1 & 88,8 & 1610 & 920 & 2530 \\
\hline
\end{tabular}

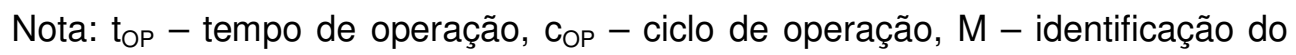
meio. Unidades: $\left[\mathrm{t}_{\mathrm{OP}}\right]=\mathrm{d},\left[\mathrm{C}_{\mathrm{ST}}\right]=\left[\mathrm{C}_{\mathrm{SF}}\right]=\mathrm{mgDQO} / \mathrm{L},\left[\varepsilon_{\mathrm{T}}\right]=\left[\varepsilon_{\mathrm{F}}\right]=\%$, $\left[\mathrm{V}_{\mathrm{D}, \mathrm{RT}}\right]=\left[\mathrm{V}_{\mathrm{D}, \mathrm{RS}}\right]=\left[\mathrm{V}_{\mathrm{D}}\right]=\mathrm{L}$. Os dados referentes aos meios M1 a M5 não foram incluídos no cálculo dos valores médios de $\mathrm{C}_{\mathrm{ST}}, \mathrm{C}_{\mathrm{SF}}, \varepsilon_{\mathrm{T}}$ e $\varepsilon_{\mathrm{F}}$ da Condição 8. 
Tabela A.39 - Dados de pH, alcalinidade parcial (AP), intermediária (Al), total (AT) e a bicarbonato (AB), razão Al/AP e concentração de ácidos voláteis totais (AVT), obtidos do monitoramento do efluente na Condição 8

\begin{tabular}{ccccccccc}
\hline tOP $\left._{\text {(COP }}\right)$ & $\mathrm{M}$ & $\mathrm{pH}$ & $\mathrm{AP}$ & $\mathrm{Al}$ & $\mathrm{Al} / \mathrm{AP}$ & $\mathrm{AT}$ & $\mathrm{AVT}$ & $\mathrm{AB}$ \\
\hline $14(42)$ & $\mathrm{M} 8$ & 7,64 & 234,2 & 55,6 & 0,24 & 289,9 & 14,5 & 279,6 \\
$15(45)$ & $\mathrm{M} 9$ & 7,62 & 230,9 & 54,0 & 0,23 & 284,9 & 14,2 & 274,8 \\
$17(51)$ & $\mathrm{M} 10$ & 7,59 & 230,9 & 53,6 & 0,23 & 284,6 & 13,7 & 274,8 \\
$18(54)$ & $\mathrm{M} 11$ & 7,67 & 227,9 & 50,0 & 0,22 & 277,9 & 13,1 & 268,6 \\
$21(63)$ & $\mathrm{M} 12$ & 7,66 & 230,2 & 48,0 & 0,21 & 278,2 & 12,9 & 269,0 \\
$22(66)$ & $\mathrm{M} 13$ & 7,57 & 218,6 & 61,3 & 0,28 & 279,9 & 15,3 & 269,0 \\
$23(69)$ & $\mathrm{M} 14$ & 7,64 & 213,9 & 62,0 & 0,29 & 275,9 & 13,3 & 266,4 \\
$24(72)$ & $\mathrm{M} 15$ & 7,73 & 220,9 & 58,6 & 0,27 & 279,6 & 12,9 & 270,4 \\
\hline
\end{tabular}

Nota: toP - tempo de operação, $\mathrm{C}_{\mathrm{OP}}$ - ciclo de operação, $M$ - identificação do meio. Unidades: $\left[\mathrm{t}_{\mathrm{OP}}\right]=\mathrm{d},[\mathrm{AP}]=[\mathrm{Al}]=[\mathrm{AT}]=[\mathrm{AB}]=\mathrm{mgCaCO}_{3} / \mathrm{L}$, $[\mathrm{AVT}]=\mathrm{mgHAc} / \mathrm{L}$.

Tabela A.40 - Dados de concentração de sólidos totais (ST), voláteis totais (SVT), em suspensão totais (SST) e em suspensão voláteis (SSV), obtidos do monitoramento do efluente na Condição 8

\begin{tabular}{cccccc}
\hline toP $_{\mathrm{O}}$ (COP) & M & ST & SVT & SST & SSV \\
\hline $10(30)$ & M6 & 754 & 504 & 58 & 46 \\
$17(51)$ & M10 & 714 & 440 & 56 & 56 \\
$24(72)$ & M15 & 746 & 506 & 58 & 58 \\
\hline
\end{tabular}

Nota: top - tempo de operação, $\mathrm{C}_{\mathrm{OP}}$ - ciclo de operação, M - identificação do meio. Unidades: $\left[\mathrm{t}_{\mathrm{OP}}\right]=\mathrm{d},[\mathrm{ST}]=[\mathrm{SVT}]=[\mathrm{SST}]=[\mathrm{SSV}]=\mathrm{mg} / \mathrm{L}$. 
Tabela $A .41$ - Dados de concentração de matéria orgânica $\left(C_{A}\right), p H$, alcalinidade parcial (AP), intermediária (Al), total (AT) e a bicarbonato $(A B)$, razão $A \mathrm{l} / \mathrm{AP}$ e concentração de ácidos voláteis totais (AVT), obtidos do monitoramento do afluente na Condição 9

\begin{tabular}{cccccccccc}
\hline$t_{\mathrm{OP}}\left(\mathrm{C}_{\mathrm{OP}}\right)$ & $\mathrm{M}$ & $\mathrm{C}_{\mathrm{A}}$ & $\mathrm{pH}$ & $\mathrm{AP}$ & $\mathrm{Al}$ & $\mathrm{Al} / \mathrm{AP}$ & $\mathrm{AT}$ & $\mathrm{AVT}$ & $\mathrm{AB}$ \\
\hline $0(1)$ & $\mathrm{M} 1$ & 505,5 & - & - & - & - & - & - & - \\
$1(4)$ & $\mathrm{M} 2$ & 504,9 & - & - & - & - & - & - & - \\
$2(7)$ & $\mathrm{M} 3$ & 514,2 & - & - & - & - & - & - & - \\
$5(16)$ & $\mathrm{M} 4$ & 504,6 & 7,83 & 155,5 & 49,6 & 0,32 & 205,1 & 14,4 & 194,9 \\
$6(19)$ & $\mathrm{M} 5$ & 507,1 & - & - & - & - & - & - & - \\
$9(28)$ & $\mathrm{M} 6$ & 506,1 & 8,04 & 173,2 & 42,2 & 0,24 & 215,3 & 15,0 & 204,7 \\
$12(37)$ & $\mathrm{M} 7$ & 518,3 & - & - & - & - & - & - & - \\
$14(43)$ & $\mathrm{M} 8$ & 510,2 & 7,66 & 154,3 & 59,1 & 0,38 & 213,4 & 12,0 & 204,8 \\
$16(49)$ & $\mathrm{M} 9$ & 507,8 & - & - & - & - & - & - & - \\
$19(58)$ & $\mathrm{M} 10$ & 502,6 & 8,04 & 166,8 & 45,7 & 0,27 & 212,6 & 17,0 & 200,5 \\
\hline
\end{tabular}

Nota: top - tempo de operação, cop - ciclo de operação, $M$ - identificação do meio. Unidades: $\left[\mathrm{t}_{\mathrm{OP}}\right]=\mathrm{d},\left[\mathrm{C}_{\mathrm{A}}\right]=\mathrm{mgDQO} / \mathrm{L},[\mathrm{AP}]=[\mathrm{Al}]=[\mathrm{AT}]=[\mathrm{AB}]=\mathrm{mgCaCO}_{3} / \mathrm{L}$, $[\mathrm{AVT}]=\mathrm{mgHAc} / \mathrm{L}$. 
Tabela A.42 - Dados de concentração de matéria orgânica de amostras filtradas $\left(\mathrm{C}_{\mathrm{SF}}\right)$ e não filtradas $\left(\mathrm{C}_{\mathrm{ST}}\right)$, eficiência de remoção de matéria orgânica de amostras filtradas $\left(\varepsilon_{F}\right)$ e não filtradas $\left(\varepsilon_{\mathrm{T}}\right)$ e volume descarregado do sistema $\left(\mathrm{V}_{\mathrm{D}}\right)$, obtidos do monitoramento do efluente na Condição 9

\begin{tabular}{|c|c|c|c|c|c|c|}
\hline$t_{O P}\left(C_{O P}\right)$ & M & $\mathrm{C}_{\mathrm{ST}}$ & $\varepsilon_{T}$ & $\mathrm{C}_{\mathrm{SF}}$ & $\varepsilon_{F}$ & $V_{D}$ \\
\hline $1(3)$ & M1 & 151,2 & 70,2 & 116,1 & 77,2 & 1010 \\
\hline $2(6)$ & M2 & 165,3 & 67,5 & 126,2 & 75,2 & 1010 \\
\hline $5(15)$ & M3 & 155,2 & 69,5 & 131,2 & 74,2 & 1010 \\
\hline $6(18)$ & M4 & 187,3 & 63,1 & 152,9 & 69,9 & 1020 \\
\hline $9(27)$ & M5 & 185,4 & 63,5 & 146,1 & 71,2 & 1020 \\
\hline $12(36)$ & M6 & 213,2 & 58,0 & 154,0 & 69,7 & 1020 \\
\hline $14(42)$ & M7 & 201,2 & 60,4 & 159,3 & 68,6 & 1020 \\
\hline $16(48)$ & M8 & 226,0 & 55,5 & 157,4 & 69,0 & 1020 \\
\hline $19(57)$ & M9 & 191,5 & 62,3 & 153,4 & 69,8 & 1020 \\
\hline $20(60)$ & M10 & 227,1 & 55,3 & 176,4 & 65,3 & 1010 \\
\hline \multicolumn{7}{|c|}{ 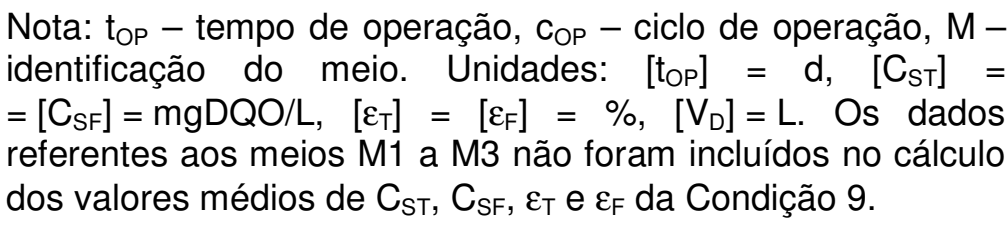 } \\
\hline
\end{tabular}

Tabela $\mathrm{A} .43$ - Dados de $\mathrm{pH}$, alcalinidade parcial (AP), intermediária (AI), total (AT) e a bicarbonato $(A B)$, razão Al/AP e concentração de ácidos voláteis totais (AVT), obtidos do monitoramento do efluente na Condição 9

\begin{tabular}{ccccccccc}
\hline$t_{\mathrm{OP}}(\mathrm{COP})$ & $\mathrm{M}$ & $\mathrm{pH}$ & $\mathrm{AP}$ & $\mathrm{Al}$ & $\mathrm{Al} / \mathrm{AP}$ & $\mathrm{AT}$ & $\mathrm{AVT}$ & $\mathrm{AB}$ \\
\hline $6(18)$ & $\mathrm{M} 4$ & 7,44 & 171,7 & 56,7 & 0,33 & 228,4 & 15,4 & 217,5 \\
$9(27)$ & $\mathrm{M} 5$ & 7,61 & 194,1 & 57,5 & 0,30 & 251,7 & 16,2 & 240,1 \\
$12(36)$ & $\mathrm{M} 6$ & 7,55 & 214,7 & 51,7 & 0,24 & 266,4 & 15,7 & 255,3 \\
$14(42)$ & $\mathrm{M} 7$ & 7,41 & 174,9 & 74,9 & 0,43 & 249,8 & 13,1 & 240,5 \\
\hline
\end{tabular}

Nota: $t_{O P}$ - tempo de operação, $c_{O P}$ - ciclo de operação, $M$ - identificação do meio. Unidades: $\left[\mathrm{t}_{\mathrm{OP}}\right]=\mathrm{d},[\mathrm{AP}]=[\mathrm{Al}]=[\mathrm{AT}]=[\mathrm{AB}]=\mathrm{mgCaCO}_{3} / \mathrm{L}$, $[\mathrm{AVT}]=\mathrm{mgHAc} / \mathrm{L}$. 
Tabela A.44 - Dados de concentração de matéria orgânica $\left(C_{A}\right), p H$, alcalinidade parcial $(A P)$, intermediária $(A I)$, total $(A T)$ e a bicarbonato $(A B)$, razão $A \mathrm{l} / A P$ e concentração de ácidos voláteis totais (AVT), obtidos do monitoramento do afluente na Condição 10

\begin{tabular}{cccccccccc}
\hline tOP (COP) & M & $\mathrm{C}_{\mathrm{A}}$ & $\mathrm{pH}$ & $\mathrm{AP}$ & $\mathrm{Al}$ & $\mathrm{Al} / \mathrm{AP}$ & $\mathrm{AT}$ & $\mathrm{AVT}$ & $\mathrm{AB}$ \\
\hline $0(1)$ & $\mathrm{M} 1$ & 752,1 & - & - & - & - & - & - & - \\
$1(3)$ & $\mathrm{M} 2$ & 757,7 & - & - & - & - & - & - & - \\
$2(5)$ & $\mathrm{M} 3$ & 760,9 & - & - & - & - & - & - & - \\
$4(9)$ & $\mathrm{M} 4$ & 758,5 & 7,98 & 195,5 & 51,5 & 0,26 & 247,0 & 22,3 & 231,2 \\
$5(11)$ & $\mathrm{M} 5$ & 758,6 & - & - & - & - & - & - & - \\
$6(13)$ & $\mathrm{M} 6$ & 755,4 & 8,02 & 176,9 & 47,9 & 0,27 & 224,8 & 21,4 & 209,6 \\
$7(15)$ & $\mathrm{M} 7$ & 759,8 & - & - & - & - & - & - & - \\
$8(17)$ & $\mathrm{M} 8$ & 746,7 & 7,91 & 188,2 & 54,8 & 0,29 & 243,0 & 20,6 & 228,4 \\
$11(23)$ & $\mathrm{M} 9$ & 751,7 & - & - & - & - & - & - & - \\
$12(25)$ & $\mathrm{M} 10$ & 748,4 & - & - & - & - & - & - & - \\
$13(27)$ & M11 & 772,1 & 7,91 & 170,3 & 58,8 & 0,35 & 229,1 & 21,5 & 213,8 \\
$14(29)$ & M12 & 758,4 & - & - & - & - & - & - & - \\
$15(31)$ & M13 & 749,2 & - & - & - & - & - & - & - \\
$18(37)$ & M14 & 746,4 & - & - & - & - & - & - & - \\
$19(39)$ & M15 & 759,4 & - & - & - & - & - & - & - \\
\hline
\end{tabular}

Nota: toP - tempo de operação, coP - ciclo de operação, $M$ - identificação do meio. Unidades: $\left[\mathrm{t}_{\mathrm{OP}}\right]=\mathrm{d},\left[\mathrm{C}_{\mathrm{A}}\right]=\mathrm{mgDQO} / \mathrm{L},[\mathrm{AP}]=[\mathrm{Al}]=[\mathrm{AT}]=[\mathrm{AB}]=\mathrm{mgCaCO}_{3} / \mathrm{L}$, $[\mathrm{AVT}]=\mathrm{mgHAc} / \mathrm{L}$.

Tabela A.45 - Dados de concentração de sólidos totais (ST), voláteis totais (SVT), em suspensão totais (SST) e em suspensão voláteis (SSV), obtidos do monitoramento do afluente na Condição 10

\begin{tabular}{cccccc}
\hline$t_{\mathrm{OP}}\left(\mathrm{C}_{\mathrm{OP}}\right)$ & $\mathrm{M}$ & $\mathrm{ST}$ & $\mathrm{SVT}$ & $\mathrm{SST}$ & $\mathrm{SSV}$ \\
\hline $12(25)$ & $\mathrm{M} 10$ & 714 & 390 & 48 & 28 \\
$19(39)$ & $\mathrm{M} 15$ & 692 & 430 & 24 & 24 \\
\hline
\end{tabular}

Nota: top - tempo de operação, cop - ciclo de operação, $M$ - identificação do meio. Unidades: $\left[\mathrm{t}_{\mathrm{OP}}\right]=\mathrm{d},[\mathrm{ST}]=[\mathrm{SVT}]=[\mathrm{SST}]=[\mathrm{SSV}]=\mathrm{mg} / \mathrm{L}$. 
Tabela A.46 - Dados de concentração de matéria orgânica de amostras filtradas $\left(\mathrm{C}_{\mathrm{SF}}\right)$ e não filtradas $\left(\mathrm{C}_{\mathrm{ST}}\right)$, eficiência de remoção de matéria orgânica de amostras filtradas $\left(\varepsilon_{F}\right)$ e não filtradas $\left(\varepsilon_{\mathrm{T}}\right)$ e volume descarregado do sistema $\left(\mathrm{V}_{\mathrm{D}}\right)$, obtidos do monitoramento do efluente na Condição 10

\begin{tabular}{|c|c|c|c|c|c|c|}
\hline$t_{\mathrm{OP}}\left(\mathrm{C}_{\mathrm{OP}}\right)$ & M & $\mathrm{C}_{\mathrm{ST}}$ & $\varepsilon_{\mathrm{T}}$ & $\mathrm{C}_{\mathrm{SF}}$ & $\varepsilon_{\mathrm{F}}$ & $V_{D}$ \\
\hline $1(2)$ & M1 & 246,7 & 67,4 & 189,4 & 74,9 & 1010 \\
\hline $2(4)$ & M2 & 252,7 & 66,6 & 192,9 & 74,5 & 1020 \\
\hline $4(8)$ & M3 & 375,4 & 50,3 & 237,1 & 68,6 & 1000 \\
\hline $5(10)$ & M4 & 294,4 & 61,0 & 218,2 & 71,1 & 1010 \\
\hline $6(12)$ & M5 & 279,4 & 63,0 & 217,6 & 71,2 & 1010 \\
\hline $7(14)$ & M6 & 297,9 & 60,6 & 228,8 & 69,7 & 1000 \\
\hline $8(16)$ & M7 & 306,0 & 59,5 & 230,7 & 69,5 & 1000 \\
\hline $11(22)$ & M8 & 316,0 & 58,2 & 232,9 & 69,2 & 1000 \\
\hline $12(24)$ & M9 & 318,8 & 57,8 & 228,9 & 69,7 & 1000 \\
\hline $13(26)$ & M10 & 338,3 & 55,2 & 244,1 & 67,7 & 1000 \\
\hline $14(28)$ & M11 & 327,9 & 56,6 & 246,2 & 67,4 & 1010 \\
\hline $15(30)$ & M12 & 327,4 & 56,7 & 240,6 & 68,2 & 980 \\
\hline $18(36)$ & M13 & 335,6 & 55,6 & 250,7 & 66,8 & 1000 \\
\hline $19(38)$ & M14 & 425,5 & 43,7 & 273,1 & 63,9 & 990 \\
\hline $20(40)$ & M15 & 451,4 & 40,3 & 264,2 & 65,0 & 1000 \\
\hline
\end{tabular}


Tabela A.47 - Dados de pH, alcalinidade parcial (AP), intermediária (Al), total (AT) e a bicarbonato (AB), razão Al/AP e concentração de ácidos voláteis totais (AVT), obtidos do monitoramento do efluente na Condição 10

\begin{tabular}{ccccccccc}
\hline$t_{\mathrm{OP}}(\mathrm{COP})$ & $\mathrm{M}$ & $\mathrm{pH}$ & $\mathrm{AP}$ & $\mathrm{Al}$ & $\mathrm{Al} / \mathrm{AP}$ & $\mathrm{AT}$ & $\mathrm{AVT}$ & $\mathrm{AB}$ \\
\hline $4(8)$ & $\mathrm{M} 3$ & 7,51 & 248,2 & 63,8 & 0,26 & 311,9 & 24,8 & 294,4 \\
$6(12)$ & $\mathrm{M} 5$ & 7,62 & 247,5 & 65,6 & 0,27 & 313,1 & 23,4 & 296,5 \\
$8(16)$ & $\mathrm{M} 7$ & 7,74 & 221,3 & 70,4 & 0,32 & 291,6 & 21,3 & 276,5 \\
$13(26)$ & $\mathrm{M} 10$ & 7,81 & 223,6 & 73,0 & 0,33 & 296,6 & 23,2 & 280,1 \\
\hline
\end{tabular}

Nota: toP - tempo de operação, $\mathrm{C}_{\mathrm{OP}}$ - ciclo de operação, $M$ - identificação do meio. Unidades: $\left[\mathrm{t}_{\mathrm{OP}}\right]=\mathrm{d},[\mathrm{AP}]=[\mathrm{Al}]=[\mathrm{AT}]=[\mathrm{AB}]=\mathrm{mgCaCO}_{3} / \mathrm{L}$, $[\mathrm{AVT}]=\mathrm{mgHAc} / \mathrm{L}$.

Tabela A.48 - Dados de concentração de sólidos totais (ST), voláteis totais (SVT), em suspensão totais (SST) e em suspensão voláteis (SSV), obtidos do monitoramento do efluente na Condição 10

\begin{tabular}{lccccc}
\hline tOP $_{\text {(COP) }}$ & M & ST & SVT & SST & SSV \\
\hline $12(24)$ & M9 & 572 & 276 & 66 & 52 \\
$14(28)$ & M11 & 526 & 268 & 84 & 74 \\
\hline Nota: top & - tempo de operação, cop - ciclo de \\
operação, & M - identificação do meio. Unidades: \\
[toP] = d, [ST] = [SVT] = [SST] = [SSV] = mg/L.
\end{tabular}


Tabela A.49 - Dados de concentração de matéria orgânica $\left(\mathrm{C}_{\mathrm{A}}\right), \mathrm{pH}$, alcalinidade parcial (AP), intermediária (Al), total (AT) e a bicarbonato (AB), razão Al/AP e concentração de ácidos voláteis totais (AVT), obtidos do monitoramento do afluente na Condição 11

\begin{tabular}{|c|c|c|c|c|c|c|c|c|c|}
\hline top (CoP) & $\mathrm{M}$ & $\mathrm{C}_{\mathrm{A}}$ & $\mathrm{pH}$ & AP & $\mathrm{Al}$ & $\mathrm{Al} / \mathrm{AP}$ & AT & AVT & $A B$ \\
\hline $0(1)$ & M1 & 1502,6 & - & - & - & - & - & - & - \\
\hline $1(2)$ & M2 & 1502,7 & - & - & - & - & - & - & - \\
\hline $5(6)$ & M3 & 1513,1 & - & - & - & - & - & - & - \\
\hline $6(7)$ & M4 & 1496,5 & - & - & - & - & - & - & - \\
\hline $7(8)$ & M5 & 1515,2 & - & - & - & - & - & - & - \\
\hline $8(9)$ & M6 & 1482,0 & - & - & - & - & - & - & - \\
\hline $9(10)$ & M7 & 1497,8 & - & - & - & - & - & - & - \\
\hline $12(13)$ & M8 & 1476,5 & 7,91 & 165,1 & 52,1 & 0,32 & 217,1 & 19,8 & 203,1 \\
\hline $14(15)$ & M9 & 1491,6 & 77,7 & 177,7 & 38,0 & 0,21 & 215,7 & 21,0 & 200,8 \\
\hline $16(17)$ & M10 & 1513,4 & 7,81 & 172,1 & 50,2 & 0,29 & 222,3 & 21,4 & 207,1 \\
\hline 17 (18) & M11 & 1487,9 & 7,85 & 173,7 & 50,4 & 0,29 & 224,2 & 22,5 & 208,2 \\
\hline $19(20)$ & M12 & 1501,8 & - & - & - & - & - & - & - \\
\hline
\end{tabular}

Tabela A.50 - Dados de concentração de sólidos totais (ST), voláteis totais (SVT), em suspensão totais (SST) e em suspensão voláteis (SSV), obtidos do monitoramento do afluente na Condição 11

\begin{tabular}{cccccc}
\hline tOP $_{\text {(COP) }}$ & M & ST & SVT & SST & SSV \\
\hline $12(13)$ & M8 & 1146 & 714 & 138 & 114 \\
$14(15)$ & M9 & 1074 & 696 & 134 & 120 \\
\hline
\end{tabular}

Nota: toP - tempo de operação, $c_{O P}$ - ciclo de operação, M - identificação do meio. Unidades: $\left[\mathrm{toP}_{\mathrm{OP}}=\mathrm{d},[\mathrm{ST}]=[\mathrm{SVT}]=[\mathrm{SST}]=[\mathrm{SSV}]=\mathrm{mg} / \mathrm{L}\right.$. 
Tabela A.51 - Dados de concentração de matéria orgânica de amostras filtradas $\left(\mathrm{C}_{\mathrm{SF}}\right)$ e não filtradas $\left(\mathrm{C}_{\mathrm{ST}}\right)$, eficiência de remoção de matéria orgânica de amostras filtradas $\left(\varepsilon_{F}\right)$ e não filtradas $\left(\varepsilon_{\mathrm{T}}\right)$ e volume descarregado do sistema $\left(\mathrm{V}_{\mathrm{D}}\right)$, obtidos do monitoramento do efluente na Condição 11

\begin{tabular}{|c|c|c|c|c|c|c|}
\hline top (COP) & M & $\mathrm{C}_{\mathrm{ST}}$ & $\varepsilon_{\mathrm{T}}$ & $\mathrm{C}_{\mathrm{SF}}$ & $\varepsilon_{\mathrm{F}}$ & $V_{D}$ \\
\hline $1(1)$ & M1 & 470,6 & 68,6 & 344,7 & 77,0 & 990 \\
\hline $2(2)$ & M2 & 523,8 & & 371,9 & 75,2 & 1000 \\
\hline $5(5)$ & M2 & 596,5 & & 400,3 & 73,3 & 1000 \\
\hline $6(6)$ & M3 & 618,6 & 58,7 & 427,7 & 71,5 & 1000 \\
\hline $7(7)$ & M4 & 649,0 & 56,7 & 465,0 & 69,0 & 1000 \\
\hline $8(8)$ & M5 & 644,6 & 57,0 & 481,7 & 67,9 & 990 \\
\hline $9(9)$ & M6 & 642,2 & 57,1 & 493,2 & 67,1 & 1000 \\
\hline $12(12)$ & M7 & 450,9 & 69,9 & 397,5 & 73,5 & 1000 \\
\hline $14(14)$ & M8 & 417,8 & 72,1 & 360,2 & 76,0 & 1000 \\
\hline $16(16)$ & M9 & 413,7 & 72,4 & 353,3 & 76,4 & 1000 \\
\hline 17 (17) & M10 & 397,1 & 73,5 & 348,6 & 76,7 & 1000 \\
\hline 19 (19) & M11 & 390,0 & 4,0 & 340,2 & 77,3 & - \\
\hline $20(20)$ & M12 & 403,4 & 73,1 & 336,6 & 77,5 & 1000 \\
\hline \multicolumn{7}{|c|}{$\begin{array}{l}\text { Nota: top - tempo de operação, } C_{\mathrm{OP}}-\text { ciclo de operação, } \mathrm{M}- \\
\text { identificação do meio. Unidades: }\left[\mathrm{t}_{\mathrm{OP}}\right]=\mathrm{d},\left[\mathrm{C}_{\mathrm{ST}}\right]= \\
=\left[\mathrm{C}_{\mathrm{SF}}\right]=\mathrm{mgDQO} / \mathrm{L},\left[\varepsilon_{\mathrm{T}}\right]=\left[\varepsilon_{\mathrm{F}}\right]=\%,\left[\mathrm{~V}_{\mathrm{D}}\right]=\mathrm{L} \text {. Os dados } \\
\text { referentes aos meios } \mathrm{M} 1 \text { a } \mathrm{M} 7 \text { não foram incluídos no cálculo } \\
\text { dos valores médios de } \mathrm{C}_{\mathrm{ST}}, \mathrm{C}_{\mathrm{SF}}, \varepsilon_{\mathrm{T}} \text { e } \varepsilon_{\mathrm{F}} \text { da Condição } 11 \text {. }\end{array}$} \\
\hline
\end{tabular}


Tabela A.52 - Dados de pH, alcalinidade parcial (AP), intermediária (Al), total (AT) e a bicarbonato (AB), razão Al/AP e concentração de ácidos voláteis totais (AVT), obtidos do monitoramento do efluente na Condição 11

\begin{tabular}{ccccccccc}
\hline $\mathrm{t}_{\mathrm{OP}}(\mathrm{COP})$ & $\mathrm{M}$ & $\mathrm{pH}$ & $\mathrm{AP}$ & $\mathrm{Al}$ & $\mathrm{Al} / \mathrm{AP}$ & $\mathrm{AT}$ & $\mathrm{AVT}$ & $\mathrm{AB}$ \\
\hline $14(14)$ & $\mathrm{M} 8$ & 7,60 & 194,0 & 66,8 & 0,34 & 260,8 & 20,2 & 246,5 \\
$16(16)$ & $\mathrm{M} 9$ & 7,54 & 200,3 & 62,6 & 0,31 & 262,9 & 21,1 & 247,9 \\
$17(17)$ & $\mathrm{M} 10$ & 7,65 & 200,8 & 56,1 & 0,28 & 256,8 & 22,7 & 240,7 \\
$19(19)$ & $\mathrm{M} 11$ & 7,66 & 201,7 & 59,0 & 0,29 & 260,7 & 21,7 & 245,3 \\
$20(20)$ & $\mathrm{M} 12$ & 7,43 & 171,6 & 55,3 & 0,32 & 227,0 & 20,4 & 212,5 \\
\hline
\end{tabular}

Nota: toP - tempo de operação, $\mathrm{C}_{O P}$ - ciclo de operação, $M$ - identificação do meio. Unidades: $\left[\mathrm{t}_{\mathrm{OP}}\right]=\mathrm{d},[\mathrm{AP}]=[\mathrm{Al}]=[\mathrm{AT}]=[\mathrm{AB}]=\mathrm{mgCaCO}_{3} / \mathrm{L}$, $[\mathrm{AVT}]=\mathrm{mgHAc} / \mathrm{L}$.

Tabela A.53 - Dados de concentração de sólidos totais (ST), voláteis totais (SVT), em suspensão totais (SST) e em suspensão voláteis (SSV), obtidos do monitoramento do efluente na Condição 11

\begin{tabular}{cccccc}
\hline tOP $_{\text {(COP) }}$ & M & ST & SVT & SST & SSV \\
\hline $13(13)$ & M8 & 898 & 478 & 156 & 138 \\
$15(15)$ & M9 & 840 & 512 & 140 & 120 \\
\hline
\end{tabular}

Nota: top - tempo de operação, $\mathrm{C}_{\mathrm{OP}}$ - ciclo de operação, M - identificação do meio. Unidades: $\left[\mathrm{t}_{\mathrm{OP}}\right]=\mathrm{d},[\mathrm{ST}]=[\mathrm{SVT}]=[\mathrm{SST}]=[\mathrm{SSV}]=\mathrm{mg} / \mathrm{L}$. 
Tabela A.54 - Dados de concentração de matéria orgânica $\left(C_{A}\right), p H$, alcalinidade parcial $(A P)$, intermediária $(A I)$, total $(A T)$ e a bicarbonato $(A B)$, razão $A \mathrm{l} / A P$ e concentração de ácidos voláteis totais (AVT), obtidos do monitoramento do afluente na Condição 12

\begin{tabular}{cccccccccc}
\hline$t_{O P}\left(\mathrm{C}_{\mathrm{OP}}\right)$ & $\mathrm{M}$ & $\mathrm{C}_{\mathrm{A}}$ & $\mathrm{pH}$ & $\mathrm{AP}$ & $\mathrm{Al}$ & $\mathrm{Al} / \mathrm{AP}$ & $\mathrm{AT}$ & $\mathrm{AVT}$ & $\mathrm{AB}$ \\
\hline $0(1)$ & $\mathrm{M} 1$ & 499,9 & - & - & - & - & - & - & - \\
$1(3)$ & $\mathrm{M} 2$ & 511,7 & - & - & - & - & - & - & - \\
$2(5)$ & $\mathrm{M} 3$ & 502,4 & - & - & - & - & - & - & - \\
$4(9)$ & $\mathrm{M} 4$ & 490,8 & - & - & - & - & - & - & - \\
$5(11)$ & $\mathrm{M} 5$ & 492,3 & - & - & - & - & - & - & - \\
$6(13)$ & $\mathrm{M} 6$ & 494,3 & 7,94 & 182,1 & 50,6 & 0,28 & 232,7 & 14,4 & 222,4 \\
$7(15)$ & $\mathrm{M} 7$ & 506,3 & - & - & - & - & - & - & - \\
$8(17)$ & $\mathrm{M} 8$ & 488,8 & 7,93 & 191,3 & 42,0 & 0,22 & 233,3 & 17,5 & 220,9 \\
$11(23)$ & $\mathrm{M} 9$ & 498,1 & 7,91 & 192,6 & 46,2 & 0,24 & 238,8 & 19,6 & 224,9 \\
$12(25)$ & $\mathrm{M} 10$ & 492,8 & - & - & - & - & - & - & - \\
$13(27)$ & $\mathrm{M} 11$ & 506,8 & 7,90 & 194,0 & 47,6 & 0,25 & 241,6 & 21,1 & 226,6 \\
$14(29)$ & $\mathrm{M} 12$ & 512,0 & - & - & - & - & - & - & - \\
$15(31)$ & $\mathrm{M} 13$ & 497,1 & 7,96 & 187,1 & 47,3 & 0,25 & 234,3 & 21,0 & 219,4 \\
$18(37)$ & $\mathrm{M} 14$ & 495,6 & 7,93 & 184,6 & 48,7 & 0,26 & 233,3 & 20,9 & 218,4 \\
$19(39)$ & $\mathrm{M} 15$ & 508,6 & 7,90 & 185,3 & 50,4 & 0,27 & 235,7 & 20,5 & 221,2 \\
\hline
\end{tabular}

Nota: toP - tempo de operação, coP - ciclo de operação, $M$ - identificação do meio. Unidades: $\left[\mathrm{t}_{\mathrm{OP}}\right]=\mathrm{d},\left[\mathrm{C}_{\mathrm{A}}\right]=\mathrm{mgDQO} / \mathrm{L},[\mathrm{AP}]=[\mathrm{Al}]=[\mathrm{AT}]=[\mathrm{AB}]=\mathrm{mgCaCO}_{3} / \mathrm{L}$, $[\mathrm{AVT}]=\mathrm{mgHAc} / \mathrm{L}$.

Tabela A.55 - Dados de concentração de sólidos totais (ST), voláteis totais (SVT), em suspensão totais (SST) e em suspensão voláteis (SSV), obtidos do monitoramento do afluente na Condição 12

\begin{tabular}{cccccc}
\hline$t_{\text {OP }}$ (COP) & M & ST & SVT & SST & SSV \\
\hline $5(11)$ & M5 & 682 & 424 & 48 & 44 \\
$12(25)$ & M10 & 672 & 402 & 46 & 46 \\
$14(29)$ & M12 & 710 & 362 & 48 & 46 \\
\hline
\end{tabular}

Nota: toP - tempo de operação, coP - ciclo de operação, $M$ - identificação do meio. Unidades: $\left[\mathrm{t}_{\mathrm{OP}}\right]=\mathrm{d},[\mathrm{ST}]=[\mathrm{SVT}]=[\mathrm{SST}]=[\mathrm{SSV}]=\mathrm{mg} / \mathrm{L}$. 
Tabela A.56 - Dados de concentração de matéria orgânica de amostras filtradas $\left(\mathrm{C}_{\mathrm{SF}}\right)$ e não filtradas $\left(\mathrm{C}_{\mathrm{ST}}\right)$, eficiência de remoção de matéria orgânica de amostras filtradas $\left(\varepsilon_{F}\right)$ e não filtradas $\left(\varepsilon_{\mathrm{T}}\right)$ e volume descarregado do sistema $\left(\mathrm{V}_{\mathrm{D}}\right)$, obtidos do monitoramento do efluente na Condição 12

\begin{tabular}{|c|c|c|c|c|c|c|}
\hline$t_{\mathrm{OP}}\left(\mathrm{C}_{\mathrm{OP}}\right)$ & M & $\mathrm{C}_{\mathrm{ST}}$ & $\varepsilon_{\mathrm{T}}$ & $\mathrm{C}_{\mathrm{SF}}$ & $\varepsilon_{\mathrm{F}}$ & $V_{D}$ \\
\hline $1(2)$ & M1 & 314,7 & 37,0 & 244,1 & 51,2 & 1040 \\
\hline $2(4)$ & M2 & 288,8 & 42,2 & 216,7 & 56,6 & 1040 \\
\hline $4(8)$ & M3 & 283,5 & 43,3 & 200,5 & 59,9 & 1040 \\
\hline $5(10)$ & M4 & 274,0 & 45,2 & 202,6 & 59,5 & 1030 \\
\hline $6(12)$ & M5 & 270,3 & 45,9 & 199,4 & 60,1 & 970 \\
\hline $7(14)$ & M6 & 288,9 & 42,2 & 197,9 & 60,4 & 990 \\
\hline $8(16)$ & M7 & 249,3 & 50,1 & 196,7 & 60,6 & 980 \\
\hline $11(22)$ & M8 & 250,1 & 50,0 & 186,1 & 62,8 & 1010 \\
\hline $12(24)$ & M9 & 247,2 & 50,5 & 175,9 & 64,8 & 990 \\
\hline $13(26)$ & M10 & 265,0 & 47,0 & 196,8 & 60,6 & 1000 \\
\hline $14(28)$ & M11 & 263,6 & 47,3 & 187,2 & 62,5 & 1000 \\
\hline $15(30)$ & M12 & 267,9 & 46,4 & 192,5 & 61,5 & 1000 \\
\hline $18(36)$ & M13 & 246,5 & 50,7 & 203,3 & 59,3 & 1000 \\
\hline $19(38)$ & M14 & 318,3 & 36,3 & 204,3 & 59,1 & 1000 \\
\hline $20(40)$ & M15 & 310,6 & 37,9 & 201,0 & 59,8 & 1030 \\
\hline
\end{tabular}


Tabela A.57 - Dados de pH, alcalinidade parcial (AP), intermediária (Al), total (AT) e a bicarbonato (AB), razão Al/AP e concentração de ácidos voláteis totais (AVT), obtidos do monitoramento do efluente na Condição 12

\begin{tabular}{ccccccccc}
\hline $\mathrm{t}_{\mathrm{OP}}(\mathrm{COP})$ & $\mathrm{M}$ & $\mathrm{pH}$ & $\mathrm{AP}$ & $\mathrm{Al}$ & $\mathrm{Al} / \mathrm{AP}$ & $\mathrm{AT}$ & $\mathrm{AVT}$ & $\mathrm{AB}$ \\
\hline $6(12)$ & $\mathrm{M} 5$ & 7,71 & 203,6 & 60,5 & 0,30 & 264,1 & 15,5 & 253,1 \\
$8(16)$ & $\mathrm{M} 7$ & 7,73 & 211,8 & 56,0 & 0,26 & 267,8 & 17,5 & 255,4 \\
$11(22)$ & $\mathrm{M} 8$ & 7,70 & 216,0 & 55,2 & 0,26 & 271,3 & 20,1 & 257,0 \\
$13(26)$ & $\mathrm{M} 10$ & 7,63 & 211,9 & 58,7 & 0,28 & 270,6 & 21,5 & 255,3 \\
$15(30)$ & $\mathrm{M} 12$ & 7,62 & 209,8 & 49,7 & 0,24 & 259,5 & 21,3 & 244,4 \\
$18(36)$ & $\mathrm{M} 13$ & 7,63 & 205,0 & 57,3 & 0,28 & 262,3 & 21,4 & 247,1 \\
$19(38)$ & $\mathrm{M} 14$ & 7,64 & 204,3 & 55,9 & 0,27 & 260,2 & 20,6 & 245,6 \\
\hline
\end{tabular}

Nota: toP - tempo de operação, $\mathrm{C}_{\mathrm{OP}}$ - ciclo de operação, $M$ - identificação do meio. Unidades: $\left[\mathrm{t}_{\mathrm{OP}}\right]=\mathrm{d},[\mathrm{AP}]=[\mathrm{Al}]=[\mathrm{AT}]=[\mathrm{AB}]=\mathrm{mgCaCO}_{3} / \mathrm{L}$, $[\mathrm{AVT}]=\mathrm{mgHAc} / \mathrm{L}$.

Tabela A.58 - Dados de concentração de sólidos totais (ST), voláteis totais (SVT), em suspensão totais (SST) e em suspensão voláteis (SSV), obtidos do monitoramento do efluente na Condição 12

\begin{tabular}{cccccc}
\hline tOP $\left._{\text {(COP }}\right)$ & M & ST & SVT & SST & SSV \\
\hline $5(10)$ & M4 & 692 & 426 & 80 & 80 \\
$12(24)$ & M9 & 676 & 428 & 72 & 72 \\
$14(28)$ & M11 & 734 & 402 & 72 & 68 \\
\hline
\end{tabular}

Nota: top - tempo de operação, $\mathrm{C}_{\mathrm{OP}}$ - ciclo de operação, M - identificação do meio. Unidades: $\left[\mathrm{t}_{\mathrm{OP}}\right]=\mathrm{d},[\mathrm{ST}]=[\mathrm{SVT}]=[\mathrm{SST}]=[\mathrm{SSV}]=\mathrm{mg} / \mathrm{L}$. 
Tabela A.59 - Dados de concentração de matéria orgânica $\left(\mathrm{C}_{\mathrm{A}}\right), \mathrm{pH}$, alcalinidade parcial $(A P)$, intermediária $(A I)$, total $(A T)$ e a bicarbonato $(A B)$, razão $A \mathrm{l} / A P$ e concentração de ácidos voláteis totais (AVT), obtidos do monitoramento do afluente na Condição 13

\begin{tabular}{cccccccccc}
\hline $\mathrm{tOP}_{\mathrm{OP}}(\mathrm{C} \mathrm{OP})$ & $\mathrm{M}$ & $\mathrm{C}_{\mathrm{A}}$ & $\mathrm{pH}$ & $\mathrm{AP}$ & $\mathrm{Al}$ & $\mathrm{Al} / \mathrm{AP}$ & $\mathrm{AT}$ & $\mathrm{AVT}$ & $\mathrm{AB}$ \\
\hline $0(1)$ & $\mathrm{M} 1$ & 512,8 & - & - & - & - & - & - & - \\
$1(2)$ & $\mathrm{M} 2$ & 491,7 & - & - & - & - & - & - & - \\
$2(3)$ & $\mathrm{M} 3$ & 507,3 & - & - & - & - & - & - & - \\
$3(4)$ & $\mathrm{M} 4$ & 494,9 & - & - & - & - & - & - & - \\
$6(7)$ & $\mathrm{M} 5$ & 498,7 & 7,92 & 198,1 & 51,0 & 0,26 & 249,1 & 17,4 & 236,7 \\
$7(8)$ & $\mathrm{M} 6$ & 506,4 & - & - & - & - & - & - & - \\
$8(9)$ & $\mathrm{M} 7$ & 506,6 & 7,86 & 193,5 & 51,9 & 0,27 & 245,4 & 17,0 & 233,3 \\
$9(10)$ & $\mathrm{M} 8$ & 490,9 & 7,94 & 195,3 & 53,7 & 0,28 & 249,1 & 17,3 & 236,8 \\
$10(11)$ & $\mathrm{M} 9$ & 503,4 & 7,96 & 200,2 & 47,0 & 0,23 & 247,2 & 18,7 & 233,9 \\
$13(14)$ & $\mathrm{M} 10$ & 511,9 & 7,94 & 197,8 & 51,6 & 0,26 & 249,4 & 19,6 & 235,5 \\
$14(15)$ & $\mathrm{M} 11$ & 516,0 & - & - & - & - & - & - & - \\
$16(17)$ & $\mathrm{M} 12$ & 510,4 & 8,05 & 201,7 & 46,7 & 0,23 & 248,4 & 17,4 & 236,1 \\
$17(18)$ & $\mathrm{M} 13$ & 516,6 & 7,88 & 198,7 & 49,1 & 0,25 & 247,8 & 16,5 & 236,1 \\
\hline
\end{tabular}

Nota: toP - tempo de operação, $C_{O P}$ - ciclo de operação, $M$ - identificação do meio. Unidades: $\left[\mathrm{t}_{\mathrm{OP}}\right]=\mathrm{d},\left[\mathrm{C}_{\mathrm{A}}\right]=\mathrm{mgDQO} / \mathrm{L},[\mathrm{AP}]=[\mathrm{Al}]=[\mathrm{AT}]=[\mathrm{AB}]=\mathrm{mgCaCO}_{3} / \mathrm{L}$, $[\mathrm{AVT}]=\mathrm{mgHAc} / \mathrm{L}$.

Tabela A.60 - Dados de concentração de sólidos totais (ST), voláteis totais (SVT), em suspensão totais (SST) e em suspensão voláteis (SSV), obtidos do monitoramento do afluente na Condição 13

\begin{tabular}{cccccc}
\hline$t_{\mathrm{OP}}\left(\mathrm{C}_{\mathrm{OP}}\right)$ & $\mathrm{M}$ & $\mathrm{ST}$ & $\mathrm{SVT}$ & $\mathrm{SST}$ & $\mathrm{SSV}$ \\
\hline $7(8)$ & $\mathrm{M} 6$ & 610 & 342 & 44 & 42 \\
$14(15)$ & $\mathrm{M} 11$ & 606 & 336 & 42 & 36 \\
\hline
\end{tabular}

Nota: toP - tempo de operação, $C_{O P}$ - ciclo de operação, M - identificação do meio. Unidades: $\left[\mathrm{t}_{\mathrm{OP}}\right]=\mathrm{d},[\mathrm{ST}]=[\mathrm{SVT}]=[\mathrm{SST}]=[\mathrm{SSV}]=\mathrm{mg} / \mathrm{L}$. 
Tabela A.61 - Dados de concentração de matéria orgânica de amostras filtradas $\left(\mathrm{C}_{\mathrm{SF}}\right)$ e não filtradas $\left(\mathrm{C}_{\mathrm{ST}}\right)$, eficiência de remoção de matéria orgânica de amostras filtradas $\left(\varepsilon_{F}\right)$ e não filtradas $\left(\varepsilon_{\mathrm{T}}\right)$ e volume descarregado do sistema $\left(\mathrm{V}_{\mathrm{D}}\right)$, obtidos do monitoramento do efluente na Condição 13

\begin{tabular}{|c|c|c|c|c|c|c|}
\hline $\mathrm{t}_{\mathrm{OP}}\left(\mathrm{C}_{\mathrm{OP}}\right)$ & $M$ & $\mathrm{C}_{\mathrm{ST}}$ & $\varepsilon_{T}$ & $\mathrm{C}_{\mathrm{SF}}$ & $\varepsilon_{\mathrm{F}}$ & $V_{D}$ \\
\hline $1(1)$ & M1 & 454,1 & 10,1 & 379,7 & 24,8 & 1000 \\
\hline 2 (2) & M2 & 429,2 & 15,0 & 350,2 & 30,7 & 1000 \\
\hline $3(3)$ & M3 & 376,3 & 25,5 & 296,9 & 41,2 & 1000 \\
\hline $4(4)$ & M4 & 341,7 & 32,4 & 268,2 & 46,9 & 1000 \\
\hline $6(6)$ & M4 & 345,2 & 31,7 & 263,1 & 47,9 & - \\
\hline 7 (7) & M5 & 323,2 & 36,0 & 260,5 & 48,4 & 1000 \\
\hline $8(8)$ & M6 & 317,4 & 37,2 & 254,8 & 49,6 & 1000 \\
\hline 9 (9) & M7 & 293,0 & 42,0 & 225,3 & 55,4 & 980 \\
\hline $10(10)$ & M8 & 308,2 & 39,0 & 223,1 & 55,8 & 1030 \\
\hline $13(13)$ & M9 & 308,1 & 39,0 & 227,4 & 55,0 & 1000 \\
\hline $14(14)$ & M10 & 332,6 & 34,2 & 249,6 & 50,6 & 1000 \\
\hline $16(16)$ & M11 & 312,4 & 38,2 & 239,4 & 52,6 & 1020 \\
\hline $17(17)$ & M12 & 316,7 & 37,3 & 220,4 & 56,4 & 1000 \\
\hline $20(20)$ & M13 & 335,1 & 33,7 & 256,8 & 49,2 & 1020 \\
\hline
\end{tabular}


Tabela A.62 - Dados de pH, alcalinidade parcial (AP), intermediária (Al), total (AT) e a bicarbonato $(\mathrm{AB})$, razão Al/AP e concentração de ácidos voláteis totais (AVT), obtidos do monitoramento do efluente na Condição 13

\begin{tabular}{ccccccccc}
\hline $\mathrm{t}_{\mathrm{OP}}(\mathrm{COP})$ & $\mathrm{M}$ & $\mathrm{pH}$ & $\mathrm{AP}$ & $\mathrm{Al}$ & $\mathrm{Al} / \mathrm{AP}$ & $\mathrm{AT}$ & $\mathrm{AVT}$ & $\mathrm{AB}$ \\
\hline $8(8)$ & $\mathrm{M} 6$ & 7,81 & 223,4 & 62,3 & 0,28 & 285,7 & 21,1 & 270,7 \\
$9(9)$ & $\mathrm{M} 7$ & 7,75 & 224,0 & 63,5 & 0,28 & 287,5 & 19,4 & 273,7 \\
$10(10)$ & $\mathrm{M} 8$ & 7,80 & 224,9 & 59,2 & 0,26 & 284,2 & 23,4 & 267,5 \\
$13(13)$ & $\mathrm{M} 9$ & 7,76 & 213,7 & 58,3 & 0,27 & 271,9 & 22,8 & 255,8 \\
$14(14)$ & $\mathrm{M} 10$ & 7,81 & 206,9 & 46,7 & 0,23 & 253,6 & 26,3 & 234,9 \\
$16(16)$ & $\mathrm{M} 11$ & 7,66 & 193,5 & 45,5 & 0,24 & 239,0 & 20,0 & 224,8 \\
$17(17)$ & $\mathrm{M} 12$ & 7,94 & 232,3 & 60,7 & 0,26 & 293,0 & 22,4 & 277,1 \\
\hline
\end{tabular}

Nota: toP - tempo de operação, $C_{O P}$ - ciclo de operação, $M$ - identificação do meio. Unidades: $\left[\mathrm{t}_{\mathrm{OP}}\right]=\mathrm{d},[\mathrm{AP}]=[\mathrm{Al}]=[\mathrm{AT}]=[\mathrm{AB}]=\mathrm{mgCaCO}_{3} / \mathrm{L}$, $[\mathrm{AVT}]=\mathrm{mgHAc} / \mathrm{L}$.

Tabela A.63 - Dados de concentração de sólidos totais (ST), voláteis totais (SVT), em suspensão totais (SST) e em suspensão voláteis (SSV), obtidos do monitoramento do efluente na Condição 13

\begin{tabular}{cccccc}
\hline tOP $\left._{\text {(COP }}\right)$ & M & ST & SVT & SST & SSV \\
\hline $7(7)$ & M5 & 638 & 400 & 70 & 58 \\
$9(9)$ & M7 & 704 & 394 & 72 & 62 \\
\hline
\end{tabular}

Nota: toP - tempo de operação, $\mathrm{C}_{\mathrm{OP}}$ - ciclo de operação, M - identificação do meio. Unidades: $\left[\mathrm{t}_{\mathrm{OP}}\right]=\mathrm{d},[\mathrm{ST}]=[\mathrm{SVT}]=[\mathrm{SST}]=[\mathrm{SSV}]=\mathrm{mg} / \mathrm{L}$. 
Tabela A.64 - Dados de concentração de matéria orgânica $\left(C_{A}\right), p H$, alcalinidade parcial $(A P)$, intermediária $(A I)$, total $(A T)$ e a bicarbonato $(A B)$, razão $A \mathrm{l} / A P$ e concentração de ácidos voláteis totais (AVT), obtidos do monitoramento do afluente na Condição 14

\begin{tabular}{cccccccccc}
\hline $\mathrm{t}_{\mathrm{OP}}(\mathrm{COP})$ & $\mathrm{M}$ & $\mathrm{C}_{\mathrm{A}}$ & $\mathrm{pH}$ & $\mathrm{AP}$ & $\mathrm{Al}$ & $\mathrm{Al} / \mathrm{AP}$ & $\mathrm{AT}$ & $\mathrm{AVT}$ & $\mathrm{AB}$ \\
\hline $0(1)$ & $\mathrm{M} 1$ & 506,4 & - & - & - & - & - & - & - \\
$1(4)$ & $\mathrm{M} 2$ & 514,2 & - & - & - & - & - & - & - \\
$2(7)$ & $\mathrm{M} 3$ & 496,5 & - & - & - & - & - & - & - \\
$4(13)$ & $\mathrm{M} 4$ & 483,4 & 8,11 & 180,5 & 40,4 & 0,22 & 220,8 & 28,0 & 200,9 \\
$5(16)$ & $\mathrm{M} 5$ & 504,6 & - & - & - & - & - & - & - \\
$6(19)$ & $\mathrm{M} 6$ & 505,7 & 8,04 & 180,8 & 46,0 & 0,25 & 226,8 & 29,8 & 205,7 \\
$7(22)$ & $\mathrm{M} 7$ & 501,9 & - & - & - & - & - & - & - \\
$8(25)$ & $\mathrm{M} 8$ & 486,3 & 8,07 & 180,1 & 44,7 & 0,25 & 224,8 & 28,7 & 204,4 \\
$11(34)$ & $\mathrm{M} 9$ & 509,7 & - & - & - & - & - & - & - \\
$12(37)$ & $\mathrm{M} 10$ & 520,1 & 8,12 & 175,8 & 42,6 & 0,24 & 218,5 & 28,7 & 198,1 \\
$13(40)$ & $\mathrm{M} 11$ & 523,9 & 8,11 & 177,8 & 44,3 & 0,25 & 222,1 & 28,5 & 201,8 \\
$14(43)$ & $\mathrm{M} 12$ & 496,7 & 8,07 & 173,8 & 45,3 & 0,26 & 219,1 & 29,1 & 198,5 \\
$15(46)$ & $\mathrm{M} 13$ & 497,1 & 8,10 & 177,1 & 45,9 & 0,26 & 223,1 & 27,9 & 203,3 \\
$18(55)$ & M14 & 499,3 & - & - & - & - & - & - & - \\
$19(58)$ & M15 & 511,5 & - & - & - & - & - & - & - \\
\hline
\end{tabular}

Nota: toP - tempo de operação, coP - ciclo de operação, $M$ - identificação do meio. Unidades: $\left[\mathrm{t}_{\mathrm{OP}}\right]=\mathrm{d},\left[\mathrm{C}_{\mathrm{A}}\right]=\mathrm{mgDQO} / \mathrm{L},[\mathrm{AP}]=[\mathrm{Al}]=[\mathrm{AT}]=[\mathrm{AB}]=\mathrm{mgCaCO}_{3} / \mathrm{L}$, $[\mathrm{AVT}]=\mathrm{mgHAc} / \mathrm{L}$.

Tabela A.65 - Dados de concentração de sólidos totais (ST), voláteis totais (SVT), em suspensão totais (SST) e em suspensão voláteis (SSV), obtidos do monitoramento do afluente na Condição 14

\begin{tabular}{cccccc}
\hline$t_{\text {OP }}\left(\mathrm{C}_{\mathrm{OP}}\right)$ & $\mathrm{M}$ & $\mathrm{ST}$ & $\mathrm{SVT}$ & $\mathrm{SST}$ & $\mathrm{SSV}$ \\
\hline $12(37)$ & $\mathrm{M} 10$ & 790 & 510 & 52 & 50 \\
$14(43)$ & $\mathrm{M} 12$ & 820 & 508 & 46 & 46 \\
\hline
\end{tabular}

Nota: toP - tempo de operação, $\mathrm{c}_{\mathrm{OP}}$ - ciclo de operação, $M$ - identificação do meio. Unidades: $\left[\mathrm{t}_{\mathrm{OP}}\right]=\mathrm{d},[\mathrm{ST}]=[\mathrm{SVT}]=[\mathrm{SST}]=[\mathrm{SSV}]=\mathrm{mg} / \mathrm{L}$. 
Tabela A.66 - Dados de concentração de matéria orgânica de amostras filtradas $\left(\mathrm{C}_{\mathrm{SF}}\right)$ e não filtradas $\left(\mathrm{C}_{\mathrm{ST}}\right)$, eficiência de remoção de matéria orgânica de amostras filtradas $\left(\varepsilon_{F}\right)$ e não filtradas $\left(\varepsilon_{\mathrm{T}}\right)$ e volume descarregado do sistema $\left(\mathrm{V}_{\mathrm{D}}\right)$, obtidos do monitoramento do efluente na Condição 14

\begin{tabular}{|c|c|c|c|c|c|c|}
\hline $\mathrm{t}_{\mathrm{OP}}\left(\mathrm{C}_{\mathrm{OP}}\right)$ & $M$ & $\mathrm{C}_{\mathrm{ST}}$ & $\varepsilon_{\mathrm{T}}$ & $\mathrm{C}_{\mathrm{SF}}$ & $\varepsilon_{\mathrm{F}}$ & $V_{D}$ \\
\hline $1(3)$ & M1 & 267,6 & 46,9 & 214,7 & 57,4 & 1020 \\
\hline $2(6)$ & M2 & 270,3 & 46,3 & 206,0 & 59,1 & 1030 \\
\hline $4(12)$ & M3 & 274,4 & 45,5 & 214,4 & 57,4 & 1010 \\
\hline $5(15)$ & M4 & 270,3 & 46,3 & 212,8 & 57,8 & 1020 \\
\hline $6(18)$ & M5 & 273,1 & 45,8 & 201,2 & 60,1 & 1010 \\
\hline $7(21)$ & M6 & 264,4 & 47,5 & 193,8 & 61,5 & 1000 \\
\hline $8(24)$ & M7 & 270,1 & 46,4 & 196,9 & 60,9 & 1000 \\
\hline $11(33)$ & M8 & 262,1 & 48,0 & 216,5 & 57,0 & 1010 \\
\hline $12(36)$ & M9 & 270,8 & 46,3 & 185,4 & 63,2 & 1000 \\
\hline $13(39)$ & M10 & 277,4 & 44,9 & 189,8 & 62,3 & 1010 \\
\hline $14(42)$ & M11 & 268,5 & 46,7 & 204,3 & 59,4 & 1000 \\
\hline $15(45)$ & M12 & 275,9 & 45,2 & 190,8 & 62,1 & 1020 \\
\hline $18(54)$ & M13 & 270,0 & 46,4 & 190,5 & 62,2 & 1000 \\
\hline $19(57)$ & M14 & 283,8 & 43,7 & 194,0 & 61,5 & 1020 \\
\hline $20(60)$ & M15 & 282,2 & 44,0 & 191,4 & 62,0 & 1020 \\
\hline
\end{tabular}


Tabela A.67 - Dados de pH, alcalinidade parcial (AP), intermediária (Al), total (AT) e a bicarbonato (AB), razão Al/AP e concentração de ácidos voláteis totais (AVT), obtidos do monitoramento do efluente na Condição 14

\begin{tabular}{ccccccccc}
\hline $\mathrm{t}_{\mathrm{OP}}(\mathrm{COP})$ & $\mathrm{M}$ & $\mathrm{pH}$ & $\mathrm{AP}$ & $\mathrm{Al}$ & $\mathrm{Al} / \mathrm{AP}$ & $\mathrm{AT}$ & $\mathrm{AVT}$ & $\mathrm{AB}$ \\
\hline $4(12)$ & $\mathrm{M} 3$ & 7,66 & 204,5 & 60,7 & 0,30 & 265,2 & 34,0 & 241,1 \\
$6(18)$ & $\mathrm{M} 5$ & 7,76 & 210,8 & 55,0 & 0,26 & 265,9 & 32,2 & 243,0 \\
$8(24)$ & $\mathrm{M} 7$ & 7,68 & 210,5 & 59,4 & 0,28 & 269,9 & 33,9 & 245,8 \\
$12(36)$ & $\mathrm{M} 9$ & 7,73 & 215,2 & 56,2 & 0,26 & 271,3 & 32,3 & 248,4 \\
$13(39)$ & $\mathrm{M} 10$ & 7,76 & 211,2 & 55,9 & 0,26 & 267,0 & 29,4 & 246,1 \\
$14(42)$ & $\mathrm{M} 11$ & 7,74 & 209,5 & 55,5 & 0,26 & 265,1 & 28,5 & 244,8 \\
$15(45)$ & $\mathrm{M} 12$ & 7,69 & 215,5 & 53,5 & 0,25 & 269,0 & 28,7 & 248,7 \\
\hline
\end{tabular}

Nota: toP - tempo de operação, $\mathrm{C}_{\mathrm{OP}}$ - ciclo de operação, $M$ - identificação do meio. Unidades: $\left[\mathrm{t}_{\mathrm{OP}}\right]=\mathrm{d},[\mathrm{AP}]=[\mathrm{Al}]=[\mathrm{AT}]=[\mathrm{AB}]=\mathrm{mgCaCO}_{3} / \mathrm{L}$, $[\mathrm{AVT}]=\mathrm{mgHAc} / \mathrm{L}$.

Tabela A.68 - Dados de concentração de sólidos totais (ST), voláteis totais (SVT), em suspensão totais (SST) e em suspensão voláteis (SSV), obtidos do monitoramento do efluente na Condição 14

\begin{tabular}{cccccc}
\hline tOP $_{\text {(COP) }}$ & M & ST & SVT & SST & SSV \\
\hline $12(36)$ & M9 & 782 & 508 & 88 & 88 \\
$14(42)$ & M11 & 804 & 510 & 84 & 82 \\
\hline
\end{tabular}

Nota: toP - tempo de operação, $\mathrm{C}_{\mathrm{OP}}$ - ciclo de operação, M - identificação do meio. Unidades: $\left[\mathrm{t}_{\mathrm{OP}}\right]=\mathrm{d},[\mathrm{ST}]=[\mathrm{SVT}]=[\mathrm{SST}]=[\mathrm{SSV}]=\mathrm{mg} / \mathrm{L}$. 


\section{APÊNDICE B - TABELAS DOS PERFIS}

Tabela B.1 - Dados dos perfis de concentração de matéria orgânica $\left(C_{S}\right), p H$, concentração de ácidos voláteis totais (AVT), alcalinidade a bicarbonato (AB), concentração de metano $\left(\mathrm{C}_{\mathrm{CH} 4}\right)$ e de gás carbônico $\left(\mathrm{C}_{\mathrm{CO} 2}\right)$, fração molar de metano $\left(\mathrm{Y}_{\mathrm{CH} 4}\right)$ e de gás carbônico $\left(\mathrm{Y}_{\mathrm{CO}_{2}}\right)$ e volume de metano $\left(\mathrm{V}_{\mathrm{CH} 4}\right)$, obtidos na Condição 1

\begin{tabular}{cccccccccc}
\hline Tempo & $\mathrm{C}_{\mathrm{S}}$ & $\mathrm{pH}$ & $\mathrm{AVT}$ & $\mathrm{AB}$ & $\mathrm{C}_{\mathrm{CH} 4}$ & $\mathrm{C}_{\mathrm{CO} 2}$ & $\mathrm{Y}_{\mathrm{CH} 4}$ & $\mathrm{Y}_{\mathrm{CO} 2}$ & $\mathrm{~V}_{\mathrm{CH} 4}$ \\
\hline 0 & 355,4 & 7,74 & 15,9 & 189,7 & $0,00 \mathrm{E}+0$ & $1,06 \mathrm{E}-2$ & 0,0 & 100,0 & 0,00 \\
0,5 & 285,2 & 7,55 & 13,8 & 192,5 & $9,70 \mathrm{E}-3$ & $2,59 \mathrm{E}-1$ & 3,6 & 96,4 & 0,53 \\
1,0 & 252,9 & 7,47 & 18,6 & 188,3 & $2,36 \mathrm{E}-2$ & $4,11 \mathrm{E}-1$ & 5,4 & 94,6 & 1,01 \\
1,5 & 246,7 & 7,40 & 16,5 & 189,8 & $3,83 \mathrm{E}-2$ & $5,08 \mathrm{E}-1$ & 7,0 & 93,0 & 1,99 \\
2,0 & 239,8 & 7,39 & 15,4 & 190,8 & $5,53 \mathrm{E}-2$ & $5,89 \mathrm{E}-1$ & 8,6 & 91,4 & 2,96 \\
2,5 & 235,1 & 7,38 & 15,0 & 189,5 & $7,06 \mathrm{E}-2$ & $6,20 \mathrm{E}-1$ & 10,2 & 89,8 & 3,89 \\
3,0 & 220,1 & 7,37 & 15,0 & 188,3 & $8,90 \mathrm{E}-2$ & $6,55 \mathrm{E}-1$ & 12,0 & 88,0 & 4,66 \\
4,0 & 216,9 & 7,33 & 15,9 & 182,0 & $1,27 \mathrm{E}-1$ & $7,17 \mathrm{E}-1$ & 15,1 & 84,9 & 5,63 \\
5,5 & 214,8 & 7,27 & 14,8 & 187,1 & $1,86 \mathrm{E}-1$ & $7,92 \mathrm{E}-1$ & 19,0 & 81,0 & 6,73 \\
7,5 & 208,1 & 7,30 & 16,3 & 187,0 & $2,60 \mathrm{E}-1$ & $8,42 \mathrm{E}-1$ & 23,6 & 76,4 & 7,58 \\
\hline
\end{tabular}

Unidades: $\left[\right.$ Tempo] $=\mathrm{h},\left[\mathrm{C}_{\mathrm{S}}\right]=\mathrm{mgDQO} / \mathrm{L},[\mathrm{AVT}]=\mathrm{mgHAc} / \mathrm{L},[\mathrm{AB}]=\mathrm{mgCaCO}_{3} / \mathrm{L}$, $\left[\mathrm{C}_{\mathrm{CH} 4}\right]=\left[\mathrm{C}_{\mathrm{CO} 2}\right]=\mathrm{mmol} / \mathrm{L},\left[\mathrm{Y}_{\mathrm{CH} 4}\right]=\left[\mathrm{Y}_{\mathrm{CO} 2}\right]=\%,\left[\mathrm{~V}_{\mathrm{CH} 4}\right]=\mathrm{mL}^{\left({ }^{(\mathrm{NTP})}\right)}$.

Tabela B.2 - Dados dos perfis de concentração de matéria orgânica $\left(C_{S}\right), p H$, concentração de ácidos voláteis totais (AVT), alcalinidade a bicarbonato (AB), concentração de metano $\left(\mathrm{C}_{\mathrm{CH} 4}\right)$ e de gás carbônico $\left(\mathrm{C}_{\mathrm{CO} 2}\right)$, fração molar de metano $\left(\mathrm{Y}_{\mathrm{CH} 4}\right)$ e de gás carbônico $\left(\mathrm{Y}_{\mathrm{CO} 2}\right)$ e volume de metano $\left(\mathrm{V}_{\mathrm{CH} 4}\right)$, obtidos na Condição 2

\begin{tabular}{cccccccccc}
\hline Tempo & $\mathrm{C}_{\mathrm{S}}$ & $\mathrm{pH}$ & $\mathrm{AVT}$ & $\mathrm{AB}$ & $\mathrm{C}_{\mathrm{CH} 4}$ & $\mathrm{C}_{\mathrm{CO} 2}$ & $\mathrm{Y}_{\mathrm{CH} 4}$ & $\mathrm{Y}_{\mathrm{CO} 2}$ & $\mathrm{~V}_{\mathrm{CH} 4}$ \\
\hline 0 & 783,4 & 7,58 & 19,6 & 197,5 & $0,00 \mathrm{E}+0$ & $6,67 \mathrm{E}-3$ & 0,0 & 100,0 & 0,00 \\
0,5 & 689,4 & 7,57 & 19,8 & 204,3 & $2,37 \mathrm{E}-2$ & $1,79 \mathrm{E}-1$ & 11,7 & 88,3 & 1,15 \\
1,0 & 660,6 & 7,58 & 21,0 & 204,3 & $5,34 \mathrm{E}-2$ & $3,06 \mathrm{E}-1$ & 14,8 & 85,2 & 1,77 \\
1,5 & 653,5 & 7,59 & 20,3 & 206,1 & $8,54 \mathrm{E}-2$ & $3,91 \mathrm{E}-1$ & 17,9 & 82,1 & 2,34 \\
2,0 & 649,2 & 7,58 & 18,6 & 206,3 & $1,15 \mathrm{E}-1$ & $4,55 \mathrm{E}-1$ & 20,1 & 79,9 & 2,78 \\
2,5 & 647,6 & 7,58 & 17,2 & 205,6 & $1,41 \mathrm{E}-1$ & $4,94 \mathrm{E}-1$ & 22,2 & 77,8 & 3,14 \\
3,0 & 634,0 & 7,58 & 18,8 & 206,7 & $1,70 \mathrm{E}-1$ & $5,31 \mathrm{E}-1$ & 24,3 & 75,7 & 3,58 \\
4,0 & 642,8 & 7,55 & 18,7 & 205,6 & $2,24 \mathrm{E}-1$ & $5,96 \mathrm{E}-1$ & 27,4 & 72,6 & 4,05 \\
5,5 & 630,7 & 7,53 & 17,0 & 207,1 & $3,04 \mathrm{E}-1$ & $6,64 \mathrm{E}-1$ & 31,4 & 68,6 & 4,52 \\
7,5 & 646,0 & 7,55 & 15,5 & 209,3 & $4,08 \mathrm{E}-1$ & $7,56 \mathrm{E}-1$ & 35,1 & 64,9 & 4,92 \\
\hline
\end{tabular}

Unidades: $[$ Tempo $]=\mathrm{h},\left[\mathrm{C}_{\mathrm{S}}\right]=\mathrm{mgDQO} / \mathrm{L},[\mathrm{AVT}]=\mathrm{mgHAc} / \mathrm{L},[\mathrm{AB}]=\mathrm{mgCaCO}_{3} / \mathrm{L}$, $\left[\mathrm{C}_{\mathrm{CH} 4}\right]=\left[\mathrm{C}_{\mathrm{CO} 2}\right]=\mathrm{mmol} / \mathrm{L},\left[\mathrm{Y}_{\mathrm{CH} 4}\right]=\left[\mathrm{Y}_{\mathrm{CO} 2}\right]=\%,\left[\mathrm{~V}_{\mathrm{CH} 4}\right]=\mathrm{mL}^{(\mathrm{CNTP})}$. 
Tabela B.3 - Dados dos perfis de concentração de matéria orgânica $\left(C_{S}\right), p H$, concentração de ácidos voláteis totais (AVT), alcalinidade a bicarbonato (AB), concentração de metano $\left(\mathrm{C}_{\mathrm{CH} 4}\right)$ e de gás carbônico $\left(\mathrm{C}_{\mathrm{CO} 2}\right)$, fração molar de metano $\left(\mathrm{Y}_{\mathrm{CH}_{4}}\right)$ e de gás carbônico $\left(\mathrm{Y}_{\mathrm{CO} 2}\right)$ e volume de metano $\left(\mathrm{V}_{\mathrm{CH} 4}\right)$, obtidos na Condição 3

\begin{tabular}{cccccccccc}
\hline Tempo & $\mathrm{C}_{\mathrm{S}}$ & $\mathrm{pH}$ & $\mathrm{AVT}$ & $\mathrm{AB}$ & $\mathrm{C}_{\mathrm{CH} 4}$ & $\mathrm{C}_{\mathrm{CO} 2}$ & $\mathrm{Y}_{\mathrm{CH} 4}$ & $\mathrm{Y}_{\mathrm{CO} 2}$ & $\mathrm{~V}_{\mathrm{CH} 4}$ \\
\hline 0 & 146,1 & 7,69 & 15,4 & 216,2 & $0,00 \mathrm{E}+0$ & $7,35 \mathrm{E}-3$ & 0,0 & 100,0 & 0,00 \\
0,5 & 108,6 & 7,53 & 15,6 & 220,4 & $0,00 \mathrm{E}+0$ & $1,72 \mathrm{E}-1$ & 0,0 & 100,0 & 2,12 \\
1,0 & 106,1 & 7,55 & 16,8 & 220,1 & $1,68 \mathrm{E}-2$ & $3,24 \mathrm{E}-1$ & 4,9 & 95,1 & 3,58 \\
1,5 & 100,6 & 7,57 & 14,8 & 227,8 & $2,73 \mathrm{E}-2$ & $4,32 \mathrm{E}-1$ & 5,9 & 94,1 & 4,37 \\
2,0 & 91,3 & 7,59 & 14,1 & 227,4 & $3,77 \mathrm{E}-2$ & $5,06 \mathrm{E}-1$ & 6,9 & 93,1 & 4,60 \\
2,5 & 102,4 & 7,64 & 13,1 & 233,0 & $5,20 \mathrm{E}-2$ & $5,70 \mathrm{E}-1$ & 8,4 & 91,6 & 4,73 \\
3,0 & 96,5 & 7,65 & 14,4 & 234,7 & $6,85 \mathrm{E}-2$ & $6,18 \mathrm{E}-1$ & 10,0 & 90,0 & 5,30 \\
4,0 & 99,4 & 7,65 & 14,4 & 239,3 & $1,08 \mathrm{E}-1$ & $6,94 \mathrm{E}-1$ & 13,5 & 86,5 & 5,73 \\
5,5 & 96,3 & 7,65 & 12,1 & 241,3 & $1,54 \mathrm{E}-1$ & $7,80 \mathrm{E}-1$ & 16,5 & 83,5 & 5,90 \\
7,5 & 87,2 & 7,58 & 12,0 & 243,6 & $2,15 \mathrm{E}-1$ & $8,53 \mathrm{E}-1$ & 20,1 & 79,9 & 5,94 \\
\hline
\end{tabular}

Unidades: $[$ Tempo $]=\mathrm{h},\left[\mathrm{C}_{\mathrm{S}}\right]=\mathrm{mgDQO} / \mathrm{L},[\mathrm{AVT}]=\mathrm{mgHAc} / \mathrm{L},[\mathrm{AB}]=\mathrm{mgCaCO}_{3} / \mathrm{L}$, $\left[\mathrm{C}_{\mathrm{CH} 4}\right]=\left[\mathrm{C}_{\mathrm{CO} 2}\right]=\mathrm{mmol} / \mathrm{L},\left[\mathrm{Y}_{\mathrm{CH} 4}\right]=\left[\mathrm{Y}_{\mathrm{CO} 2}\right]=\%,\left[\mathrm{~V}_{\mathrm{CH} 4}\right]=\mathrm{mL}^{(\mathrm{CNTP})}$.

Tabela B.4 - Dados dos perfis de concentração de matéria orgânica $\left(\mathrm{C}_{\mathrm{S}}\right)$, $\mathrm{pH}$, concentração de ácidos voláteis totais (AVT), alcalinidade a bicarbonato (AB), concentração de metano $\left(\mathrm{C}_{\mathrm{CH} 4}\right)$ e de gás carbônico $\left(\mathrm{C}_{\mathrm{CO} 2}\right)$, fração molar de metano $\left(\mathrm{Y}_{\mathrm{CH}_{4}}\right)$ e de gás carbônico $\left(\mathrm{Y}_{\mathrm{CO} 2}\right)$ e volume de metano $\left(\mathrm{V}_{\mathrm{CH} 4}\right)$, obtidos na Condição 4

\begin{tabular}{cccccccccc}
\hline Tempo & $\mathrm{C}_{\mathrm{S}}$ & $\mathrm{pH}$ & $\mathrm{AVT}$ & $\mathrm{AB}$ & $\mathrm{C}_{\mathrm{CH} 4}$ & $\mathrm{C}_{\mathrm{CO} 2}$ & $\mathrm{Y}_{\mathrm{CH} 4}$ & $\mathrm{Y}_{\mathrm{CO} 2}$ & $\mathrm{~V}_{\mathrm{CH} 4}$ \\
\hline 0 & 374,0 & 7,72 & 21,2 & 209,8 & $0,00 \mathrm{E}+0$ & $7,50 \mathrm{E}-3$ & 0,0 & 100,0 & 0,00 \\
0,5 & 323,6 & 7,68 & 21,4 & 219,9 & $0,00 \mathrm{E}+0$ & $1,40 \mathrm{E}-1$ & 0,0 & 100,0 & 1,95 \\
1,0 & 304,8 & 7,68 & 21,6 & 223,1 & $3,32 \mathrm{E}-2$ & $2,52 \mathrm{E}-1$ & 11,6 & 88,4 & 2,97 \\
1,5 & 294,1 & 7,64 & 21,4 & 222,8 & $5,31 \mathrm{E}-2$ & $3,30 \mathrm{E}-1$ & 13,9 & 86,1 & 3,89 \\
2,0 & 293,3 & 7,64 & 21,2 & 228,3 & $7,29 \mathrm{E}-2$ & $3,89 \mathrm{E}-1$ & 15,8 & 84,2 & 4,60 \\
2,5 & 292,1 & 7,62 & 20,3 & 229,6 & $9,15 \mathrm{E}-2$ & $4,37 \mathrm{E}-1$ & 17,3 & 82,7 & 5,22 \\
3,0 & 295,6 & 7,60 & 21,1 & 231,7 & $1,10 \mathrm{E}-1$ & $4,74 \mathrm{E}-1$ & 18,9 & 81,1 & 5,48 \\
4,0 & 290,1 & 7,58 & 21,5 & 232,1 & $1,44 \mathrm{E}-1$ & $5,34 \mathrm{E}-1$ & 21,3 & 78,7 & 5,61 \\
5,5 & 286,5 & 7,60 & 19,6 & 233,7 & $1,99 \mathrm{E}-1$ & $6,15 \mathrm{E}-1$ & 24,5 & 75,5 & 5,61 \\
7,5 & 281,9 & 7,59 & 18,5 & 234,5 & $2,64 \mathrm{E}-1$ & $6,83 \mathrm{E}-1$ & 27,8 & 72,2 & 5,61 \\
\hline
\end{tabular}

Unidades: $[$ Tempo $]=\mathrm{h},\left[\mathrm{C}_{\mathrm{S}}\right]=\mathrm{mgDQO} / \mathrm{L},[\mathrm{AVT}]=\mathrm{mgHAc} / \mathrm{L},[\mathrm{AB}]=\mathrm{mgCaCO}_{3} / \mathrm{L}$, $\left[\mathrm{C}_{\mathrm{CH} 4}\right]=\left[\mathrm{C}_{\mathrm{CO} 2}\right]=\mathrm{mmol} / \mathrm{L},\left[\mathrm{Y}_{\mathrm{CH} 4}\right]=\left[\mathrm{Y}_{\mathrm{CO} 2}\right]=\%,\left[\mathrm{~V}_{\mathrm{CH} 4}\right]=\mathrm{mL}^{(\mathrm{CNTP})}$. 
Tabela B.5 - Dados dos perfis de concentração de matéria orgânica $\left(\mathrm{C}_{\mathrm{S}}\right), \mathrm{pH}$, concentração de ácidos voláteis totais (AVT), alcalinidade a bicarbonato $(A B)$, concentração de metano $\left(\mathrm{C}_{\mathrm{CH}}\right)$ e de gás carbônico $\left(\mathrm{C}_{\mathrm{CO}_{2}}\right)$ e fração molar de metano $\left(\mathrm{Y}_{\mathrm{CH} 4}\right)$ e de gás carbônico $\left(\mathrm{Y}_{\mathrm{CO} 2}\right)$, obtidos na Condição 5

\begin{tabular}{ccccccccc}
\hline Tempo & $\mathrm{C}_{\mathrm{S}}$ & $\mathrm{pH}$ & $\mathrm{AVT}$ & $\mathrm{AB}$ & $\mathrm{C}_{\mathrm{CH} 4}$ & $\mathrm{C}_{\mathrm{CO} 2}$ & $\mathrm{Y}_{\mathrm{CH} 4}$ & $\mathrm{Y}_{\mathrm{CO} 2}$ \\
\hline 0 & 313,3 & 7,81 & 12,8 & 232,9 & $0,00 \mathrm{E}+0$ & $9,41 \mathrm{E}-3$ & 0,0 & 100,0 \\
0,5 & 207,4 & 7,66 & 12,2 & 238,1 & $1,80 \mathrm{E}-2$ & $1,58 \mathrm{E}-1$ & 10,2 & 89,8 \\
1,0 & 174,0 & 7,62 & 12,1 & 242,3 & $3,74 \mathrm{E}-2$ & $2,45 \mathrm{E}-1$ & 13,3 & 86,7 \\
1,5 & 162,5 & 7,60 & 12,1 & 246,0 & $6,33 \mathrm{E}-2$ & $3,22 \mathrm{E}-1$ & 16,4 & 83,6 \\
2,0 & 156,2 & 7,62 & 12,2 & 246,3 & $8,87 \mathrm{E}-2$ & $3,78 \mathrm{E}-1$ & 19,0 & 81,0 \\
2,5 & 148,6 & 7,61 & 12,6 & 251,2 & $1,14 \mathrm{E}-1$ & $4,25 \mathrm{E}-1$ & 21,2 & 78,8 \\
3,0 & 145,3 & 7,64 & 11,9 & 254,7 & $1,44 \mathrm{E}-1$ & $4,68 \mathrm{E}-1$ & 23,6 & 76,4 \\
4,0 & 147,1 & 7,66 & 12,3 & 260,3 & $2,12 \mathrm{E}-1$ & $5,44 \mathrm{E}-1$ & 28,0 & 72,0 \\
5,5 & 134,6 & 7,66 & 12,9 & 266,9 & $3,05 \mathrm{E}-1$ & $6,09 \mathrm{E}-1$ & 33,4 & 66,6 \\
7,5 & 135,6 & 7,72 & 13,2 & 270,7 & $4,73 \mathrm{E}-1$ & $7,36 \mathrm{E}-1$ & 39,1 & 60,9 \\
\hline
\end{tabular}

Unidades: $[$ Tempo $]=\mathrm{h},\left[\mathrm{C}_{\mathrm{S}}\right]=\mathrm{mgDQO} / \mathrm{L},[\mathrm{AVT}]=\mathrm{mgHAc} / \mathrm{L},[\mathrm{AB}]=\mathrm{mgCaCO}_{3} / \mathrm{L}$, $\left[\mathrm{C}_{\mathrm{CH} 4}\right]=\left[\mathrm{C}_{\mathrm{CO} 2}\right]=\mathrm{mmol} / \mathrm{L},\left[\mathrm{Y}_{\mathrm{CH} 4}\right]=\left[\mathrm{Y}_{\mathrm{CO} 2}\right]=\%$.

Tabela B.6 - Dados dos perfis de concentração de matéria orgânica $\left(\mathrm{C}_{\mathrm{S}}\right), \mathrm{pH}$, concentração de ácidos voláteis totais (AVT), alcalinidade a bicarbonato (AB), concentração de metano $\left(\mathrm{C}_{\mathrm{CH} 4}\right)$ e de gás carbônico $\left(\mathrm{C}_{\mathrm{CO} 2}\right)$ e fração molar de metano $\left(\mathrm{Y}_{\mathrm{CH} 4}\right)$ e de gás carbônico $\left(\mathrm{Y}_{\mathrm{CO} 2}\right)$, obtidos na Condição 6

\begin{tabular}{ccccccccc}
\hline Tempo & $\mathrm{C}_{\mathrm{S}}$ & $\mathrm{pH}$ & $\mathrm{AVT}$ & $\mathrm{AB}$ & $\mathrm{C}_{\mathrm{CH} 4}$ & $\mathrm{C}_{\mathrm{CO} 2}$ & $\mathrm{Y}_{\mathrm{CH} 4}$ & $\mathrm{Y}_{\mathrm{CO} 2}$ \\
\hline 0 & 290,0 & 7,59 & 19,4 & 267,4 & $0,00 \mathrm{E}+0$ & $4,22 \mathrm{E}-2$ & 0,0 & 100,0 \\
0,5 & 312,0 & 7,62 & 20,7 & 263,0 & $1,51 \mathrm{E}-1$ & $4,44 \mathrm{E}-1$ & 25,4 & 74,6 \\
1,0 & 316,0 & 7,61 & 22,4 & 258,6 & $2,66 \mathrm{E}-1$ & $6,27 \mathrm{E}-1$ & 29,8 & 70,2 \\
1,5 & 328,0 & 7,65 & 19,9 & 257,6 & $3,75 \mathrm{E}-1$ & $8,20 \mathrm{E}-1$ & 31,4 & 68,6 \\
2,0 & 332,0 & 7,63 & 18,9 & 258,7 & $4,84 \mathrm{E}-1$ & $9,44 \mathrm{E}-1$ & 33,9 & 66,1 \\
2,5 & 334,0 & 7,62 & 18,4 & 259,4 & $6,16 \mathrm{E}-1$ & $1,02 \mathrm{E}+0$ & 37,8 & 62,2 \\
3,0 & 345,0 & 7,61 & 19,2 & 259,1 & $7,90 \mathrm{E}-1$ & $1,08 \mathrm{E}+0$ & 42,2 & 57,8 \\
4,0 & 350,0 & 7,60 & 19,9 & 258,7 & $9,91 \mathrm{E}-1$ & $1,13 \mathrm{E}+0$ & 46,7 & 53,3 \\
5,5 & 313,0 & 7,59 & 20,1 & 262,4 & $1,15 \mathrm{E}+0$ & $1,22 \mathrm{E}+0$ & 48,6 & 51,4 \\
7,5 & 264,0 & 7,56 & 20,1 & 264,1 & $1,56 \mathrm{E}+0$ & $1,36 \mathrm{E}+0$ & 53,4 & 46,6 \\
\hline
\end{tabular}

Unidades: $[$ Tempo $]=\mathrm{h},\left[\mathrm{C}_{\mathrm{S}}\right]=\mathrm{mgDQO} / \mathrm{L},[\mathrm{AVT}]=\mathrm{mgHAc} / \mathrm{L},[\mathrm{AB}]=\mathrm{mgCaCO}_{3} / \mathrm{L}$, $\left[\mathrm{C}_{\mathrm{CH} 4}\right]=\left[\mathrm{C}_{\mathrm{CO} 2}\right]=\mathrm{mmol} / \mathrm{L},\left[\mathrm{Y}_{\mathrm{CH} 4}\right]=\left[\mathrm{Y}_{\mathrm{CO} 2}\right]=\%$. 
Tabela B.7 - Dados dos perfis de concentração de matéria orgânica $\left(\mathrm{C}_{\mathrm{S}}\right), \mathrm{pH}$, concentração de ácidos voláteis totais (AVT), alcalinidade a bicarbonato (AB), concentração de metano $\left(\mathrm{C}_{\mathrm{CH} 4}\right)$ e de gás carbônico $\left(\mathrm{C}_{\mathrm{CO} 2}\right)$ e fração molar de metano $\left(\mathrm{Y}_{\mathrm{CH} 4}\right)$ e de gás carbônico $\left(\mathrm{Y}_{\mathrm{CO} 2}\right)$, obtidos na Condição 7

\begin{tabular}{ccccccccc}
\hline Tempo & $\mathrm{C}_{\mathrm{S}}$ & $\mathrm{pH}$ & $\mathrm{AVT}$ & $\mathrm{AB}$ & $\mathrm{C}_{\mathrm{CH} 4}$ & $\mathrm{C}_{\mathrm{CO} 2}$ & $\mathrm{Y}_{\mathrm{CH} 4}$ & $\mathrm{Y}_{\mathrm{CO} 2}$ \\
\hline 0 & 143,5 & 7,62 & 20,5 & 230,2 & $0,00 \mathrm{E}+0$ & $1,62 \mathrm{E}-2$ & 0,0 & 100,0 \\
0,5 & 100,3 & 7,44 & 19,7 & 231,9 & $0,00 \mathrm{E}+0$ & $2,20 \mathrm{E}-1$ & 0,0 & 100,0 \\
1,0 & 92,9 & 7,43 & 22,4 & 227,8 & $0,00 \mathrm{E}+0$ & $3,56 \mathrm{E}-1$ & 0,0 & 100,0 \\
1,5 & 89,4 & 7,46 & 20,4 & 227,4 & $0,00 \mathrm{E}+0$ & $4,72 \mathrm{E}-1$ & 0,0 & 100,0 \\
2,0 & 86,8 & 7,46 & 20,9 & 228,5 & $9,61 \mathrm{E}-3$ & $5,48 \mathrm{E}-1$ & 1,7 & 98,3 \\
2,5 & 83,0 & 7,50 & 20,2 & 229,7 & $1,41 \mathrm{E}-2$ & $5,98 \mathrm{E}-1$ & 2,3 & 97,7 \\
3,0 & 88,5 & 7,51 & 21,4 & 228,5 & $1,82 \mathrm{E}-2$ & $6,39 \mathrm{E}-1$ & 2,8 & 97,2 \\
4,0 & 80,8 & 7,54 & 21,8 & 230,4 & $2,85 \mathrm{E}-2$ & $6,82 \mathrm{E}-1$ & 4,0 & 96,0 \\
5,5 & 81,0 & 7,59 & 20,1 & 235,9 & $6,47 \mathrm{E}-2$ & $7,25 \mathrm{E}-1$ & 8,2 & 91,8 \\
7,5 & 82,0 & 7,60 & 20,9 & 240,8 & $1,34 \mathrm{E}-1$ & $8,21 \mathrm{E}-1$ & 14,0 & 86,0 \\
\hline
\end{tabular}

Unidades: $\left[\right.$ Tempo] $=\mathrm{h},\left[\mathrm{C}_{\mathrm{S}}\right]=\mathrm{mgDQO} / \mathrm{L},[\mathrm{AVT}]=\mathrm{mgHAc} / \mathrm{L},[\mathrm{AB}]=\mathrm{mgCaCO}_{3} / \mathrm{L}$, $\left[\mathrm{C}_{\mathrm{CH} 4}\right]=\left[\mathrm{C}_{\mathrm{CO} 2}\right]=\mathrm{mmol} / \mathrm{L},\left[\mathrm{Y}_{\mathrm{CH} 4}\right]=\left[\mathrm{Y}_{\mathrm{CO} 2}\right]=\%$

Tabela B.8 - Dados dos perfis de concentração de matéria orgânica $\left(\mathrm{C}_{\mathrm{S}}\right), \mathrm{pH}$, concentração de ácidos voláteis totais (AVT), alcalinidade a bicarbonato (AB), concentração de metano $\left(\mathrm{C}_{\mathrm{CH} 4}\right)$ e de gás carbônico $\left(\mathrm{C}_{\mathrm{CO} 2}\right)$ e fração molar de metano $\left(\mathrm{Y}_{\mathrm{CH} 4}\right)$ e de gás carbônico $\left(\mathrm{Y}_{\mathrm{CO} 2}\right)$, obtidos na Condição 8

\begin{tabular}{ccccccccc}
\hline Tempo & $\mathrm{C}_{\mathrm{S}}$ & $\mathrm{pH}$ & $\mathrm{AVT}$ & $\mathrm{AB}$ & $\mathrm{C}_{\mathrm{CH} 4}$ & $\mathrm{C}_{\mathrm{CO} 2}$ & $\mathrm{Y}_{\mathrm{CH} 4}$ & $\mathrm{Y}_{\mathrm{CO} 2}$ \\
\hline 0 & 137,6 & 7,39 & 17,6 & 256,9 & $0,00 \mathrm{E}+0$ & $1,47 \mathrm{E}-2$ & 0,0 & 100,0 \\
0,5 & 144,0 & 7,42 & 17,1 & 253,6 & $8,48 \mathrm{E}-2$ & $2,51 \mathrm{E}-1$ & 25,3 & 74,7 \\
1,0 & 146,9 & 7,46 & 18,7 & 251,8 & $1,54 \mathrm{E}-1$ & $3,71 \mathrm{E}-1$ & 29,3 & 70,7 \\
1,5 & 151,8 & 7,50 & 16,2 & 250,5 & $2,12 \mathrm{E}-1$ & $4,52 \mathrm{E}-1$ & 31,9 & 68,1 \\
2,0 & 155,7 & 7,51 & 16,6 & 248,2 & $2,74 \mathrm{E}-1$ & $5,26 \mathrm{E}-1$ & 34,3 & 65,7 \\
2,5 & 164,8 & 7,52 & 15,8 & 249,5 & $3,24 \mathrm{E}-1$ & $5,86 \mathrm{E}-1$ & 35,6 & 64,4 \\
3,0 & 162,0 & 7,53 & 16,7 & 248,9 & $4,14 \mathrm{E}-1$ & $6,36 \mathrm{E}-1$ & 39,4 & 60,6 \\
4,0 & 157,7 & 7,54 & 16,7 & 245,5 & $5,38 \mathrm{E}-1$ & $7,00 \mathrm{E}-1$ & 43,5 & 56,5 \\
5,5 & 149,3 & 7,58 & 15,4 & 249,8 & $7,36 \mathrm{E}-1$ & $8,17 \mathrm{E}-1$ & 47,4 & 52,6 \\
7,5 & 130,2 & 7,59 & 14,9 & 251,8 & $9,71 \mathrm{E}-1$ & $9,26 \mathrm{E}-1$ & 51,2 & 48,8 \\
\hline
\end{tabular}

Unidades: $[$ Tempo $]=\mathrm{h},\left[\mathrm{C}_{\mathrm{S}}\right]=\mathrm{mgDQO} / \mathrm{L},[\mathrm{AVT}]=\mathrm{mgHAc} / \mathrm{L},[\mathrm{AB}]=\mathrm{mgCaCO}_{3} / \mathrm{L}$, $\left[\mathrm{C}_{\mathrm{CH} 4}\right]=\left[\mathrm{C}_{\mathrm{CO} 2}\right]=\mathrm{mmol} / \mathrm{L},\left[\mathrm{Y}_{\mathrm{CH} 4}\right]=\left[\mathrm{Y}_{\mathrm{CO} 2}\right]=\%$. 
Tabela B.9 - Dados dos perfis de concentração de matéria orgânica $\left(\mathrm{C}_{\mathrm{S}}\right), \mathrm{pH}$, concentração de ácidos voláteis totais (AVT), alcalinidade a bicarbonato (AB), concentração de metano $\left(\mathrm{C}_{\mathrm{CH}}\right)$ e de gás carbônico $\left(\mathrm{C}_{\mathrm{CO}_{2}}\right)$ e fração molar de metano $\left(\mathrm{Y}_{\mathrm{CH} 4}\right)$ e de gás carbônico $\left(\mathrm{Y}_{\mathrm{CO} 2}\right)$, obtidos na Condição 9

\begin{tabular}{ccccccccc}
\hline Tempo & $\mathrm{C}_{\mathrm{S}}$ & $\mathrm{pH}$ & $\mathrm{AVT}$ & $\mathrm{AB}$ & $\mathrm{C}_{\mathrm{CH} 4}$ & $\mathrm{C}_{\mathrm{CO} 2}$ & $\mathrm{Y}_{\mathrm{CH} 4}$ & $\mathrm{Y}_{\mathrm{CO} 2}$ \\
\hline 0 & 245,7 & 7,47 & 19,0 & 227,3 & $0,00 \mathrm{E}+0$ & $9,61 \mathrm{E}-3$ & 0,0 & 100,0 \\
0,5 & 202,4 & 7,43 & 18,0 & 230,6 & $3,91 \mathrm{E}-2$ & $1,01 \mathrm{E}-1$ & 28,0 & 72,0 \\
1,0 & 194,3 & 7,43 & 23,1 & 226,7 & $8,63 \mathrm{E}-2$ & $1,83 \mathrm{E}-1$ & 32,1 & 67,9 \\
1,5 & 188,1 & 7,44 & 21,1 & 232,1 & $1,35 \mathrm{E}-1$ & $2,43 \mathrm{E}-1$ & 35,6 & 64,4 \\
2,0 & 183,6 & 7,42 & 21,4 & 232,8 & $1,85 \mathrm{E}-1$ & $2,88 \mathrm{E}-1$ & 39,2 & 60,8 \\
2,5 & 183,5 & 7,42 & 20,8 & 237,3 & $2,33 \mathrm{E}-1$ & $3,20 \mathrm{E}-1$ & 42,1 & 57,9 \\
3,0 & 183,4 & 7,42 & 22,0 & 232,0 & $2,81 \mathrm{E}-1$ & $3,48 \mathrm{E} 1$ & 44,7 & 55,3 \\
4,0 & 181,7 & 7,44 & 21,5 & 239,7 & $3,81 \mathrm{E}-1$ & $4,01 \mathrm{E} 1$ & 48,7 & 51,3 \\
5,5 & 187,2 & 7,44 & 20,2 & 232,0 & $5,05 \mathrm{E}-1$ & $4,73 \mathrm{E}-1$ & 51,6 & 48,4 \\
7,5 & 180,2 & 7,43 & 21,4 & 238,1 & $6,53 \mathrm{E}-1$ & $5,72 \mathrm{E}-1$ & 53,3 & 46,7 \\
\hline
\end{tabular}

Unidades: $\left[\right.$ Tempo] $=\mathrm{h},\left[\mathrm{C}_{\mathrm{S}}\right]=\mathrm{mgDQO} / \mathrm{L},[\mathrm{AVT}]=\mathrm{mgHAc} / \mathrm{L},[\mathrm{AB}]=\mathrm{mgCaCO}_{3} / \mathrm{L}$, $\left[\mathrm{C}_{\mathrm{CH} 4}\right]=\left[\mathrm{C}_{\mathrm{CO} 2}\right]=\mathrm{mmol} / \mathrm{L},\left[\mathrm{Y}_{\mathrm{CH} 4}\right]=\left[\mathrm{Y}_{\mathrm{CO} 2}\right]=\%$.

Tabela B.10 - Dados dos perfis de concentração de matéria orgânica $\left(\mathrm{C}_{\mathrm{S}}\right), \mathrm{pH}$, concentração de ácidos voláteis totais (AVT), alcalinidade a bicarbonato (AB), concentração de metano $\left(\mathrm{C}_{\mathrm{CH} 4}\right)$ e de gás carbônico $\left(\mathrm{C}_{\mathrm{CO} 2}\right)$ e fração molar de metano $\left(\mathrm{Y}_{\mathrm{CH} 4}\right)$ e de gás carbônico $\left(\mathrm{Y}_{\mathrm{CO} 2}\right)$, obtidos na Condição 10

\begin{tabular}{ccccccccc}
\hline Tempo & $\mathrm{C}_{\mathrm{S}}$ & $\mathrm{pH}$ & $\mathrm{AVT}$ & $\mathrm{AB}$ & $\mathrm{C}_{\mathrm{CH} 4}$ & $\mathrm{C}_{\mathrm{CO} 2}$ & $\mathrm{Y}_{\mathrm{CH} 4}$ & $\mathrm{Y}_{\mathrm{CO} 2}$ \\
\hline 0 & 380,8 & 7,77 & 26,1 & 209,3 & $0,00 \mathrm{E}+0$ & $4,54 \mathrm{E}-3$ & 0,0 & 100,0 \\
0,5 & 344,6 & 7,68 & 23,9 & 210,6 & $0,00 \mathrm{E}+0$ & $5,57 \mathrm{E}-2$ & 0,0 & 100,0 \\
1,0 & 310,7 & 7,61 & 24,1 & 214,2 & $0,00 \mathrm{E}+0$ & $1,07 \mathrm{E}-1$ & 0,0 & 100,0 \\
1,5 & 299,6 & 7,60 & 25,2 & 214,5 & $3,09 \mathrm{E}-2$ & $1,52 \mathrm{E}-1$ & 17,0 & 83,0 \\
2,0 & 293,8 & 7,57 & 25,5 & 219,5 & $3,99 \mathrm{E}-2$ & $1,82 \mathrm{E}-1$ & 18,0 & 82,0 \\
2,5 & 301,0 & 7,61 & 28,0 & 221,7 & $5,26 \mathrm{E}-2$ & $2,10 \mathrm{E}-1$ & 20,0 & 80,0 \\
3,0 & 269,1 & 7,63 & 31,9 & 221,3 & $6,24 \mathrm{E}-2$ & $2,27 \mathrm{E}-1$ & 21,6 & 78,4 \\
4,0 & 273,4 & 7,66 & 30,4 & 224,8 & $8,04 \mathrm{E}-2$ & $2,54 \mathrm{E}-1$ & 24,0 & 76,0 \\
5,5 & 263,7 & 7,67 & 29,7 & 222,1 & $1,17 \mathrm{E}-1$ & $3,01 \mathrm{E}-1$ & 28,0 & 72,0 \\
7,5 & 285,4 & 7,68 & 29,4 & 226,1 & $1,72 \mathrm{E}-1$ & $3,57 \mathrm{E}-1$ & 32,5 & 67,5 \\
9,5 & 273,7 & 7,74 & 27,9 & 232,3 & $2,38 \mathrm{E}-1$ & $4,12 \mathrm{E}-1$ & 36,7 & 63,3 \\
11,5 & 273,1 & 7,77 & 25,4 & 222,7 & $2,81 \mathrm{E}-1$ & $4,33 \mathrm{E}-1$ & 39,4 & 60,6 \\
\hline
\end{tabular}

Unidades: $[$ Tempo $]=\mathrm{h},\left[\mathrm{C}_{\mathrm{S}}\right]=\mathrm{mgDQO} / \mathrm{L},[\mathrm{AVT}]=\mathrm{mgHAc} / \mathrm{L},[\mathrm{AB}]=\mathrm{mgCaCO}_{3} / \mathrm{L}$, $\left[\mathrm{C}_{\mathrm{CH} 4}\right]=\left[\mathrm{C}_{\mathrm{CO} 2}\right]=\mathrm{mmol} / \mathrm{L},\left[\mathrm{Y}_{\mathrm{CH} 4}\right]=\left[\mathrm{Y}_{\mathrm{CO} 2}\right]=\%$. 
Tabela B.11 - Dados dos perfis de concentração de matéria orgânica $\left(\mathrm{C}_{S}\right), \mathrm{pH}$, concentração de ácidos voláteis totais (AVT), alcalinidade a bicarbonato ( $A B)$, concentração de metano $\left(\mathrm{C}_{\mathrm{CH}}\right)$ e de gás carbônico $\left(\mathrm{C}_{\mathrm{CO}_{2}}\right)$ e fração molar de metano $\left(\mathrm{Y}_{\mathrm{CH} 4}\right)$ e de gás carbônico $\left(\mathrm{Y}_{\mathrm{CO} 2}\right)$, obtidos na Condição 11

\begin{tabular}{ccccccccc}
\hline Tempo & $\mathrm{C}_{\mathrm{S}}$ & $\mathrm{pH}$ & $\mathrm{AVT}$ & $\mathrm{AB}$ & $\mathrm{C}_{\mathrm{CH} 4}$ & $\mathrm{C}_{\mathrm{CO} 2}$ & $\mathrm{Y}_{\mathrm{CH} 4}$ & $\mathrm{Y}_{\mathrm{CO} 2}$ \\
\hline 0 & 655,5 & 7,57 & 19,9 & 203,5 & $0,00 \mathrm{E}+0$ & $3,01 \mathrm{E}-3$ & 0,0 & 100,0 \\
0,5 & 501,7 & 7,55 & 20,5 & 210,2 & $2,66 \mathrm{E}-2$ & $5,01 \mathrm{E}-2$ & 34,7 & 65,3 \\
1,0 & 466,1 & 7,55 & 22,3 & 209,2 & $5,90 \mathrm{E}-2$ & $9,83 \mathrm{E}-2$ & 37,5 & 62,5 \\
2,0 & 463,8 & 7,54 & 26,7 & 217,0 & $1,24 \mathrm{E}-1$ & $1,73 \mathrm{E}-1$ & 41,8 & 58,2 \\
3,0 & 392,2 & 7,50 & 17,9 & 213,6 & $1,80 \mathrm{E}-1$ & $2,34 \mathrm{E}-1$ & 43,4 & 56,6 \\
5,0 & 383,3 & 7,55 & 18,1 & 215,0 & $2,76 \mathrm{E}-1$ & $3,22 \mathrm{E}-1$ & 46,2 & 53,8 \\
7,0 & 371,8 & 7,49 & 17,3 & 219,9 & $3,79 \mathrm{E}-1$ & $3,84 \mathrm{E}-1$ & 49,7 & 50,3 \\
10,0 & 415,1 & 7,51 & 21,1 & 218,2 & $4,99 \mathrm{E}-1$ & $4,78 \mathrm{E}-1$ & 51,1 & 48,9 \\
13,0 & 358,2 & 7,53 & 23,2 & 234,7 & $6,24 \mathrm{E}-1$ & $5,47 \mathrm{E}-1$ & 53,3 & 46,7 \\
16,0 & 402,3 & 7,67 & 24,6 & 242,4 & $7,49 \mathrm{E}-1$ & $6,14 \mathrm{E}-1$ & 55,0 & 45,0 \\
19,5 & 397,2 & 7,67 & 28,0 & 227,9 & $8,60 \mathrm{E}-1$ & $6,80 \mathrm{E}-1$ & 55,8 & 44,2 \\
23,5 & 379,3 & 7,90 & 25,7 & 227,7 & $1,01 \mathrm{E}+0$ & $7,53 \mathrm{E}-1$ & 57,4 & 42,6 \\
\hline
\end{tabular}

Unidades: $[$ Tempo $]=\mathrm{h},\left[\mathrm{C}_{\mathrm{S}}\right]=\mathrm{mgDQO} / \mathrm{L},[\mathrm{AVT}]=\mathrm{mgHAc} / \mathrm{L},[\mathrm{AB}]=\mathrm{mgCaCO}_{3} / \mathrm{L}$, $\left[\mathrm{C}_{\mathrm{CH} 4}\right]=\left[\mathrm{C}_{\mathrm{CO} 2}\right]=\mathrm{mmol} / \mathrm{L},\left[\mathrm{Y}_{\mathrm{CH} 4}\right]=\left[\mathrm{Y}_{\mathrm{CO} 2}\right]=\%$.

Tabela B.12 - Dados dos perfis de concentração de matéria orgânica $\left(\mathrm{C}_{\mathrm{S}}\right), \mathrm{pH}$, concentração de ácidos voláteis totais (AVT), alcalinidade a bicarbonato (AB), concentração de metano $\left(\mathrm{C}_{\mathrm{CH} 4}\right)$ e de gás carbônico $\left(\mathrm{C}_{\mathrm{CO} 2}\right)$ e fração molar de metano $\left(\mathrm{Y}_{\mathrm{CH} 4}\right)$ e de gás carbônico $\left(\mathrm{Y}_{\mathrm{CO}}\right)$, obtidos na Condição 12

\begin{tabular}{ccccccccc}
\hline Tempo & $\mathrm{C}_{\mathrm{S}}$ & $\mathrm{pH}$ & $\mathrm{AVT}$ & $\mathrm{AB}$ & $\mathrm{C}_{\mathrm{CH} 4}$ & $\mathrm{C}_{\mathrm{CO} 2}$ & $\mathrm{Y}_{\mathrm{CH} 4}$ & $\mathrm{Y}_{\mathrm{CO} 2}$ \\
\hline 0 & 271,3 & 7,50 & 33,2 & 247,5 & $0,00 \mathrm{E}+0$ & $5,04 \mathrm{E}-3$ & 0,0 & 100,0 \\
0,5 & 246,7 & 7,48 & 30,2 & 250,0 & $0,00 \mathrm{E}+0$ & $6,41 \mathrm{E}-2$ & 0,0 & 100,0 \\
1,0 & 224,1 & 7,51 & 31,7 & 252,6 & $2,18 \mathrm{E}-2$ & $1,26 \mathrm{E}-1$ & 14,7 & 85,3 \\
1,5 & 220,4 & 7,59 & 30,0 & 253,8 & $3,42 \mathrm{E}-2$ & $1,76 \mathrm{E}-1$ & 16,3 & 83,7 \\
2,0 & 210,4 & 7,61 & 27,3 & 254,2 & $4,33 \mathrm{E}-2$ & $2,02 \mathrm{E}-1$ & 17,7 & 82,3 \\
2,5 & 215,5 & 7,68 & 24,1 & 251,9 & $5,15 \mathrm{E}-2$ & $2,33 \mathrm{E}-1$ & 18,1 & 81,9 \\
3,0 & 211,9 & 7,66 & 26,7 & 248,9 & $5,95 \mathrm{E}-2$ & $2,55 \mathrm{E}-1$ & 18,9 & 81,1 \\
4,0 & 204,9 & 7,72 & 27,5 & 244,7 & $6,72 \mathrm{E}-2$ & $2,72 \mathrm{E}-1$ & 19,8 & 80,2 \\
5,5 & 230,7 & 7,75 & 26,7 & 243,9 & $9,24 \mathrm{E}-2$ & $3,42 \mathrm{E}-1$ & 21,3 & 78,7 \\
7,5 & 212,7 & 7,81 & 26,7 & 245,3 & $1,15 \mathrm{E}-1$ & $4,00 \mathrm{E}-1$ & 22,4 & 77,6 \\
9,5 & 215,0 & 7,81 & 28,3 & 245,3 & $1,39 \mathrm{E}-1$ & $4,43 \mathrm{E}-1$ & 23,8 & 76,2 \\
11,5 & 222,0 & 7,80 & 25,4 & 243,0 & $1,60 \mathrm{E}-1$ & $4,76 \mathrm{E}-1$ & 25,2 & 74,8 \\
\hline
\end{tabular}

Unidades: $[$ Tempo $]=\mathrm{h},\left[\mathrm{C}_{\mathrm{S}}\right]=\mathrm{mgDQO} / \mathrm{L},[\mathrm{AVT}]=\mathrm{mgHAc} / \mathrm{L},[\mathrm{AB}]=\mathrm{mgCaCO}_{3} / \mathrm{L}$, $\left[\mathrm{C}_{\mathrm{CH} 4}\right]=\left[\mathrm{C}_{\mathrm{CO} 2}\right]=\mathrm{mmol} / \mathrm{L},\left[\mathrm{Y}_{\mathrm{CH} 4}\right]=\left[\mathrm{Y}_{\mathrm{CO} 2}\right]=\%$. 
Tabela B.13 - Dados dos perfis de concentração de matéria orgânica $\left(\mathrm{C}_{S}\right), \mathrm{pH}$, concentração de ácidos voláteis totais (AVT), alcalinidade a bicarbonato ( $A B)$, concentração de metano $\left(\mathrm{C}_{\mathrm{CH} 4}\right)$ e de gás carbônico $\left(\mathrm{C}_{\mathrm{CO} 2}\right)$ e fração molar de metano $\left(\mathrm{Y}_{\mathrm{CH} 4}\right)$ e de gás carbônico $\left(\mathrm{Y}_{\mathrm{CO} 2}\right)$, obtidos na Condição 13

\begin{tabular}{ccccccccc}
\hline Tempo & $\mathrm{C}_{\mathrm{S}}$ & $\mathrm{pH}$ & $\mathrm{AVT}$ & $\mathrm{AB}$ & $\mathrm{C}_{\mathrm{CH} 4}$ & $\mathrm{C}_{\mathrm{CO} 2}$ & $\mathrm{Y}_{\mathrm{CH} 4}$ & $\mathrm{Y}_{\mathrm{CO} 2}$ \\
\hline 0 & 291,9 & 7,67 & 20,7 & 215,4 & $0,00 \mathrm{E}+0$ & $2,81 \mathrm{E}-3$ & 0,0 & 100,0 \\
0,5 & 253,9 & 7,65 & 20,9 & 219,2 & $0,00 \mathrm{E}+0$ & $4,18 \mathrm{E}-2$ & 0,0 & 100,0 \\
1,0 & 235,7 & 7,63 & 19,1 & 217,9 & $0,00 \mathrm{E}+0$ & $8,29 \mathrm{E}-2$ & 0,0 & 100,0 \\
2,0 & 223,5 & 7,58 & 20,1 & 220,1 & $0,00 \mathrm{E}+0$ & $1,35 \mathrm{E}-1$ & 0,0 & 100,0 \\
3,0 & 226,9 & 7,57 & 18,4 & 221,0 & $0,00 \mathrm{E}+0$ & $1,79 \mathrm{E}-1$ & 0,0 & 100,0 \\
5,0 & 232,2 & 7,60 & 19,1 & 225,1 & $1,84 \mathrm{E}-2$ & $2,41 \mathrm{E}-1$ & 7,1 & 92,9 \\
7,0 & 231,3 & 7,72 & 19,7 & 223,1 & $2,82 \mathrm{E}-2$ & $2,80 \mathrm{E}-1$ & 9,1 & 90,9 \\
10,0 & 244,1 & 7,95 & 22,9 & 225,7 & $4,24 \mathrm{E}-2$ & $3,33 \mathrm{E}-1$ & 11,3 & 88,7 \\
13,0 & 222,5 & 7,52 & 23,0 & 227,6 & $6,22 \mathrm{E}-2$ & $3,67 \mathrm{E}-1$ & 14,5 & 85,5 \\
16,0 & 220,1 & 7,56 & 20,3 & 224,6 & $8,55 \mathrm{E}-2$ & $4,09 \mathrm{E}-1$ & 17,3 & 82,7 \\
19,5 & 223,9 & 7,66 & 22,9 & 220,8 & $1,22 \mathrm{E}-1$ & $4,80 \mathrm{E}-1$ & 20,2 & 79,8 \\
23,5 & 217,9 & 7,71 & 20,4 & 213,0 & $1,50 \mathrm{E}-1$ & $5,29 \mathrm{E}-1$ & 22,1 & 77,9 \\
\hline
\end{tabular}

Unidades: $[$ Tempo $]=\mathrm{h},\left[\mathrm{C}_{\mathrm{S}}\right]=\mathrm{mgDQO} / \mathrm{L},[\mathrm{AVT}]=\mathrm{mgHAc} / \mathrm{L},[\mathrm{AB}]=\mathrm{mgCaCO}_{3} / \mathrm{L}$, $\left[\mathrm{C}_{\mathrm{CH} 4}\right]=\left[\mathrm{C}_{\mathrm{CO} 2}\right]=\mathrm{mmol} / \mathrm{L},\left[\mathrm{Y}_{\mathrm{CH} 4}\right]=\left[\mathrm{Y}_{\mathrm{CO} 2}\right]=\%$.

Tabela B.14 - Dados dos perfis de concentração de matéria orgânica $\left(\mathrm{C}_{S}\right), \mathrm{pH}$, concentração de ácidos voláteis totais (AVT), alcalinidade a bicarbonato ( $A B)$, concentração de metano $\left(\mathrm{C}_{\mathrm{CH} 4}\right)$ e de gás carbônico $\left(\mathrm{C}_{\mathrm{CO} 2}\right)$ e fração molar de metano $\left(\mathrm{Y}_{\mathrm{CH} 4}\right)$ e de gás carbônico $\left(\mathrm{Y}_{\mathrm{CO} 2}\right)$, obtidos na Condição 14

\begin{tabular}{ccccccccc}
\hline Tempo & $\mathrm{C}_{\mathrm{S}}$ & $\mathrm{pH}$ & $\mathrm{AVT}$ & $\mathrm{AB}$ & $\mathrm{C}_{\mathrm{CH} 4}$ & $\mathrm{C}_{\mathrm{CO} 2}$ & $\mathrm{Y}_{\mathrm{CH} 4}$ & $\mathrm{Y}_{\mathrm{CO} 2}$ \\
\hline 0 & 278,9 & 7,61 & 24,6 & 252,3 & $0,00 \mathrm{E}+0$ & $6,03 \mathrm{E}-3$ & 0,0 & 100,0 \\
0,5 & 228,6 & 7,61 & 20,6 & 262,9 & $1,08 \mathrm{E}-2$ & $9,16 \mathrm{E}-2$ & 10,5 & 89,5 \\
1,0 & 216,1 & 7,63 & 24,8 & 262,2 & $2,41 \mathrm{E}-2$ & $1,64 \mathrm{E}-1$ & 12,8 & 87,2 \\
1,5 & 214,7 & 7,64 & 22,6 & 267,0 & $3,89 \mathrm{E}-2$ & $2,17 \mathrm{E}-1$ & 15,2 & 84,8 \\
2,0 & 211,1 & 7,65 & 21,9 & 268,3 & $5,36 \mathrm{E}-2$ & $2,60 \mathrm{E}-1$ & 17,1 & 82,9 \\
2,5 & 206,8 & 7,65 & 23,7 & 270,3 & $6,61 \mathrm{E}-2$ & $2,87 \mathrm{E}-1$ & 18,7 & 81,3 \\
3,0 & 202,8 & 7,68 & 21,9 & 273,5 & $7,67 \mathrm{E}-2$ & $3,10 \mathrm{E}-1$ & 19,8 & 80,2 \\
4,0 & 196,9 & 7,78 & 18,1 & 274,3 & $1,07 \mathrm{E}-1$ & $3,52 \mathrm{E}-1$ & 23,2 & 76,8 \\
5,5 & 197,2 & 7,75 & 17,8 & 275,2 & $1,48 \mathrm{E}-1$ & $4,03 \mathrm{E}-1$ & 26,8 & 73,2 \\
7,5 & 186,2 & 7,73 & 17,0 & 275,4 & $1,94 \mathrm{E}-1$ & $4,38 \mathrm{E}-1$ & 30,7 & 69,3 \\
\hline
\end{tabular}

Unidades: $[$ Tempo $]=\mathrm{h},\left[\mathrm{C}_{\mathrm{S}}\right]=\mathrm{mgDQO} / \mathrm{L},[\mathrm{AVT}]=\mathrm{mgHAc} / \mathrm{L},[\mathrm{AB}]=\mathrm{mgCaCO}_{3} / \mathrm{L}$, $\left[\mathrm{C}_{\mathrm{CH} 4}\right]=\left[\mathrm{C}_{\mathrm{CO} 2}\right]=\mathrm{mmol} / \mathrm{L},\left[\mathrm{Y}_{\mathrm{CH} 4}\right]=\left[\mathrm{Y}_{\mathrm{CO} 2}\right]=\%$. 


\section{APÊNDICE C - CARACTERIZAÇÃO DO AFLUENTE}

Tabela C.1 - Dados de concentração de matéria orgânica de amostras filtradas $\left(C_{A F}\right)$ e não filtradas $\left(C_{A T}\right)$, as diferenças destes valores $\left(C_{A T}-C_{A F}\right)$ e as porcentagens destas diferenças em relação aos valores de concentração de amostras não filtradas $\left(\left(\mathrm{C}_{\mathrm{AT}}-\mathrm{C}_{\mathrm{AF}}\right) / \mathrm{C}_{\mathrm{AT}}\right)$, obtidos do monitoramento do afluente nas Condição 1 a 8

\begin{tabular}{ccccccc}
\hline toP (COP) & Condição & $\mathrm{M}$ & $\mathrm{C}_{\mathrm{AF}}$ & $\mathrm{C}_{\mathrm{AT}}$ & $\mathrm{C}_{\mathrm{AT}}-\mathrm{C}_{\mathrm{AF}}$ & $\frac{\mathrm{C}_{\mathrm{AT}}-\mathrm{C}_{\mathrm{AF}}}{\mathrm{C}_{\mathrm{AT}}}$ \\
\hline $14(43)$ & 1 & $\mathrm{M} 12$ & 414,5 & 515,4 & 100,9 & 19,6 \\
$21(64)$ & 1 & $\mathrm{M} 17$ & 400,5 & 515,1 & 114,6 & 22,2 \\
$21(64)$ & 2 & $\mathrm{M} 15$ & 1101,6 & 1385,3 & 283,7 & 20,5 \\
$23(70)$ & 2 & $\mathrm{M} 17$ & 1103,6 & 1377,7 & 274,1 & 19,9 \\
$4(13)$ & 3 & $\mathrm{M} 5$ & 234,0 & 298,7 & 64,7 & 21,7 \\
$7(22)$ & 3 & $\mathrm{M} 6$ & 236,3 & 286,9 & 50,6 & 17,6 \\
$10(31)$ & 4 & $\mathrm{M} 7$ & 689,6 & 874,2 & 184,6 & 21,1 \\
$11(34)$ & 4 & $\mathrm{M} 8$ & 681,2 & 877,1 & 195,9 & 22,3 \\
$2(7)$ & 5 & $\mathrm{M} 3$ & 402,9 & 500,1 & 97,2 & 19,4 \\
$3(10)$ & 5 & $\mathrm{M} 4$ & 404,6 & 501,7 & 97,1 & 19,4 \\
$3(10)$ & 6 & $\mathrm{M} 4$ & 1118,2 & 1409,8 & 291,6 & 20,7 \\
$7(22)$ & 6 & $\mathrm{M} 6$ & 1041,3 & 1280,3 & 239,0 & 18,7 \\
$1(4)$ & 7 & $\mathrm{M} 2$ & 241,1 & 307,7 & 66,6 & 21,6 \\
$2(7)$ & 7 & $\mathrm{M} 3$ & 250,0 & 305,6 & 55,6 & 18,2 \\
$3(10)$ & 8 & $\mathrm{M} 3$ & 786,9 & 983,1 & 196,2 & 20,0 \\
$4(13)$ & 8 & $\mathrm{M} 4$ & 801,4 & 992,5 & 191,1 & 19,3 \\
\hline
\end{tabular}

Nota: toP - tempo de operação, $C_{O P}$ - ciclo de operação, $M$ - identificação do meio. Unidades: $\left[\mathrm{C}_{A F}\right]=\left[\mathrm{C}_{A T}\right]=\left[\mathrm{C}_{A T}-\mathrm{C}_{A F}\right]=\mathrm{mgDQO} / \mathrm{L} ;\left[\left(\mathrm{C}_{\mathrm{AT}}-\mathrm{C}_{\mathrm{AF}}\right) / \mathrm{C}_{\mathrm{AT}}\right]=\%$. 
Tabela C.2 - Dados de concentração de matéria orgânica de amostras filtradas $\left(\mathrm{C}_{\mathrm{AF}}\right)$ e não filtradas $\left(\mathrm{C}_{\mathrm{AT}}\right)$, as diferenças destes valores $\left(\mathrm{C}_{A T}-\mathrm{C}_{\mathrm{AF}}\right)$ e as porcentagens destas diferenças em relação aos valores de concentração de amostras não filtradas $\left(\left(\mathrm{C}_{\mathrm{AT}}-\mathrm{C}_{\mathrm{AF}}\right) / \mathrm{C}_{\mathrm{AT}}\right)$, obtidos do monitoramento do afluente nas Condição 9 a 14

\begin{tabular}{ccccccc}
\hline toP (COP) & Condição & $M$ & $C_{A F}$ & $C_{A T}$ & $C_{A T}-C_{A F}$ & $\frac{C_{A T}-C_{A F}}{C_{A T}}$ \\
\hline $9(28)$ & 9 & $M 6$ & 394,7 & 506,1 & 111,4 & 22,0 \\
$12(37)$ & 9 & $M 7$ & 418,3 & 518,3 & 100,0 & 19,3 \\
$2(5)$ & 10 & $M 3$ & 599,5 & 760,9 & 161,4 & 21,2 \\
$8(17)$ & 10 & $M 8$ & 588,5 & 746,7 & 158,2 & 21,2 \\
$9(10)$ & 11 & $M 7$ & 1198,7 & 1497,8 & 299,1 & 20,0 \\
$12(13)$ & 11 & $M 8$ & 1205,8 & 1476,5 & 270,7 & 18,3 \\
$1(3)$ & 12 & $M 2$ & 403,4 & 511,7 & 108,3 & 21,2 \\
$2(5)$ & 12 & $M 3$ & 401,6 & 502,4 & 100,8 & 20,1 \\
$6(7)$ & 13 & $M 5$ & 395,6 & 498,7 & 103,1 & 20,7 \\
$7(8)$ & 13 & $M 6$ & 399,3 & 506,4 & 107,1 & 21,1 \\
$5(16)$ & 14 & $M 5$ & 412,4 & 504,6 & 92,2 & 18,3 \\
$6(19)$ & 14 & $M 6$ & 418,4 & 505,7 & 87,3 & 17,3 \\
\hline
\end{tabular}

Nota: toP $_{\mathrm{O}}$ - tempo de operação, $\mathrm{C}_{\mathrm{OP}}$ - ciclo de operação, $\mathrm{M}$ - identificação do meio. Unidades: $\left[\mathrm{C}_{\mathrm{AF}}\right]=\left[\mathrm{C}_{\mathrm{AT}}\right]=\left[\mathrm{C}_{\mathrm{AT}^{-}} \mathrm{C}_{\mathrm{AF}}\right]=\mathrm{mgDQO} / \mathrm{L} ;\left[\left(\mathrm{C}_{\mathrm{AT}} \mathrm{C}_{\mathrm{AF}}\right) / \mathrm{C}_{\mathrm{AT}}\right]=\%$. 